\title{
Laboratory Studies of Gas Genera- tion and Potential for Tank Wall \\ Corrosion During Blending of High-Level Wastes at the West Valley Demonstration Project
}

W.J. Gray

R.E. Westerman

May 1995

Prepared for the U.S. Department of Energy under Contract DE-AC06-76RLO 1830

Pacific Northwest Laboratory Richland, Washington 99352 


\title{
DISCLAIMER
}

This report was prepared as an account of work sponsored by an agency of the United States Government. Neither the United States Government nor any agency thereof, nor Battelle Memorial institute, nor any of their employees, makes any warranty, expressed or implied, or assumes any legal liability or responsibility for the accuracy, completeness, or usefulness of any information, apparatus, product, or process disclosed, or represents that its use would not infringe privately owned rights. Reference herein to any specific commercial product, process, or service by trade name, trademark, manufacturer, or otherwise does not necéssarily constitute or imply its endorsement, recommendation, or favoring by the United States Government or any agency thereof, or Battelle Memorial institute. The views and opinions of authors expressed herein do not necessarily state or reflect those of the United States Government or any agency thereof.

\section{PACIFIC NORTHWEST LABORATORY, operated by \\ BATTELLE MEMORIAL INSTITUTE for the \\ UNITED STATES DEPARTMENT OF ENERGY under Contract DE-AC06-76RLO 1830}

\author{
Printed in the United States of America
}

Available to DOE and DOE contractors from the

Office of Scientific and Technical Information, P.O. Box 62, Oak Ridge, TN37831; prices available from (615) 5,76-8401. FTS 626-8401.

Avallable to the public from the National Technical Information Service, U.S. Department of Commerce, 5285 Port Royal Rd,; Springfield, VA 22161. 
PNL-10511

$\mathrm{UC}-100$

2030

Laboratory Studies of Gas Generation and Potential for Tank Wall Corrosion During Blending of High-Level Wastes at the West Valley Demonstration Project

W.J. Gray

R.E. Westerman

May 1995

Prepared for

the U.S. Department of Energy

under Contract DE-AC06-76RLO 1830

Pacific Northwest Laboratory

Richland, Washington 99352

DISTRIBUTION OF THIS DOCUMENT IS UNLIMITED

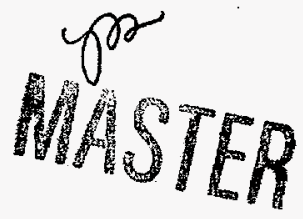





\section{DISCLAIMER}

Portions of this document may be illegible in electronic image products. Images are produced from the best available original document. 


\begin{abstract}
Laboratory experiments were conducted to simulate the transfer of acidic THOREX waste from Tank 8D-4 into the alkaline PUREX waste in Tank 8D-2 at West Valley. The purpose of the experiments was to explore means of minimizing the production of nitric oxide (NO) gas during mixing of the two wastes and to assess the potential for the gas to further react in the vapor space possibly leading to enhanced corrosion of the tank walls. Forty one THOREX/PUREX mixing tests were conducted to explore the effects of stirring rate, $\mathrm{pH}$, THOREX addition rate, THOREX or PUREX dilution, and temperature. The two most important criteria for minimizing NO production were to maintain some degree of agitation and the keep the $\mathrm{pH}$ in the PUREX high, preferably $>12$.

Steel corrosion tests were performed in the presence of low partial pressures of $\mathrm{NO}_{2}$ and liquid water or water vapor. The $\mathrm{NO}_{2}$ (from oxidation of $\mathrm{NO}$ in the vapor space) concentrations were representative of those derived from the THOREX/PUREX mixing tests. It was concluded that no significant corrosion of the tank walls would be expected under the anticipated THOREX/PUREX mixing conditions if the exposure was short ( $<100$ days).
\end{abstract}




\section{Summary}

Radioạctive wastes from reprocessing of spent nuclear fuel are stored at West Valley, New York in large underground tanks. Most of the spent fuel was treated with the PUREX process, neutralized, and stored in the steel 8D-2 waste tank. A single core of mixed thorium and uranium fuel was also processed, and the waste (called THOREX) was stored as a nitric acid solution in Tank 8D-4. Before the wastes are vitrified, there are plans to transfer acidic THOREX waste from Tank 8D-4 into the alkaline PUREX waste in Tank 8D-2. During mixing, there may be some reaction between acid in the THOREX and $\mathrm{NO}_{2}^{-}$in the PUREX that can result in the generation of nitric oxide (NO) gas. Once NO forms and escapes to the vapor space in Tank $8 \mathrm{D}-2$, it will be quickly oxidized by air ${ }^{(\mathrm{a})}$ to $\mathrm{NO}_{2}$, which can react with the water film that coats the tank walls above the PUREX slurry and form a dilute $\mathrm{HNO}_{3}$ solution. If the $\mathrm{pH}$ in the water film drops to low enough values, increased corrosion of the carbon steel tank walls could occur. To assess the magnitude of this potential problem and explore means of minimizing the production of NO gas, the Pacific Northwest Laboratory was commissioned to conduct relevant laboratory experiments.

THOREX/PUREX mixing experiments were conducted in two phases. Most of the testing was done during FY 1993 and 1994, but a few supplementary tests were conducted during FY 1995. All of the corrosion-related work was done during FY 1993 and 1994.

During the early THOREX/PUREX mixing experiments, small amounts of $\mathrm{NO}$ gas (plus $\mathrm{CO}_{2}$ gas from reaction of the acidic THOREX with carbonate in the PUREX) were measured during laboratory scale tests in which simulated THOREX was added to simulated PUREX. The scale of most of the tests was $1.5 \mathrm{~L}$ of PUREX to which 15 to $30 \mathrm{~mL}$ of THOREX (same approximate ratio as the wastes in the two tanks) were typically added. A few tests were conducted with simulated waste volumes that were 10 times larger.

Because the $\mathrm{CO}_{2}$ was of no consequence, only the generation rate and total amount of $\mathrm{NO}$ gas were measured during all but the first few tests. Various test parameters were changed during 41 tests to explore prospects for minimizing the amount of NO production. Test parameters that received primary emphasis included stirring rate, THOREX addition rate, incremental addition of THOREX and $\mathrm{NaOH}$ to maintain a high $\mathrm{pH}$, effect of THOREX or PUREX dilution, and temperature. As a result of the testing, it was found that the two most important criteria for minimizing NO production were to maintain some degree of agitation and to keep the $\mathrm{pH}$ in the PUREX as high as possible (preferably $>12$ ) through either periodic or simultaneous addition of $\mathrm{NaOH}$. These and other conclusions based on the early THOREX/PUREX mixing tests described in Section 2.0 are further described below:

- Different stirring rates had little effect on the total amount of NO that was generated, but when the stirring was stopped, the amount of NO increased by a factor of 20 to 50 .

(a) The oxidation of $\mathrm{NO}$ to $\mathrm{NO}_{2}$ could be practically eliminated if air were removed from Tank 8D-2 by purging with $\mathrm{N}_{2}$ gas during the THOREX/PUREX mixing. However, this option was not explored during the course of this work. 
- The nature of the testing did not allow a simple correlation to be made between the $\mathrm{pH}$ of the PUREX and the generation rate of NO although, in general, less NO was produced when high $\mathrm{pH}$ was maintained during mixing. For example, in one test where the $\mathrm{pH}$ was maintained at 13.3 by simultaneous addition of $\mathrm{NaOH}$, the amount of $\mathrm{NO}$ that was generated was four times less than in other tests where the pH decreased to 10 or 11 during the THOREX addition, with all other parameters for the two test conditions being the same.

- The total amount of NO that was generated was approximately proportional to the $\mathrm{NO}_{2}^{-}$concentration in the PUREX; $\sim 0.1 \%$ of the $\mathrm{NO}_{2}^{-}$was converted to $\mathrm{NO}$ in tests at $45^{\circ} \mathrm{C}$ where stirring was maintained. Thus, reducing the $\mathrm{NO}_{2}^{-}$concentration in the PUREX by additional washing would reduce the amount of NO produced by a corresponding proportion.

- The activation energy for NO production between $22^{\circ} \mathrm{C}$ and $45^{\circ} \mathrm{C}$ was determined to be $12.1 \mathrm{kcal} / \mathrm{mol}$; between $45^{\circ} \mathrm{C}$ and $65^{\circ} \mathrm{C}$ it was $5.4 \mathrm{kcal} / \mathrm{mol}$. The nonlinearity indicates that two or more processes with different temperature dependencies were involved.

- In tests where THOREX was added to a PUREX recirculation loop, the amount of NO that was produced was very dependent on the relative flow rate in the loop compared with the THOREX addition rate. With a high ratio of loop-flow-rate to THOREX-addition rate, the amount of NO was nearly 5 times smaller than when THOREX was added directly to the reaction vessel. But with a low ratio of loop-flow-rate to THOREX-addition rate, the amount of NO was 5 times larger than when THOREX was added directly to the reaction vessel. These results are consistent with the observation that less NO was generated when the $\mathrm{pH}$ was kept high, i.e., a high ratio of loop-flow-rate to THOREX-addition rate kept the $\mathrm{pH}$ high in the mixing region of the loop.

- In the event of an accidental reversal of flow where PUREX would flow out of Tank 8D-2 into the THOREX in Tank 8D-4, tests conducted here indicated that the generation rate and total amount of NO could be much higher (perhaps a factor of 10 although a direct comparison cannot be made) than in the normal flow direction, THOREX into Tank 8D-2.

- In tests where THOREX was added directly to the PUREX and stirring was maintained, the total amount of NO that was generated was nearly independent of THOREX addition rate.

- When the acidity of the THOREX was increased $\sim 5$ times, the amount of NO increased $\sim 50 \%$. However, no effect on the amount of NO was observed when all constituents of the THOREX, including acidity, were diluted to $50 \%$ of their original concentrations.

- Tests conducted with 10-times larger waste volumes produced 6 to 12 times more NO gas. Thus, over this very limited volume range, these data indicate that the amount of NO that is generated may scale in direct proportion to the volume of waste involved in the mixing. It is not known whether this scaling factor can be extrapolated to the size of the actual tanks (one million times larger than the laboratory test volumes) at West Valley.

Supplemental THOREX/PUREX mixing tests described in Section 3.0 were designed to measure the effect on $\mathrm{NO}$ gas production caused by increasing the $\mathrm{NO}_{2}^{-}$concentrations in the PUREX for the purpose of maintaining pitting corrosion control in Tank 8D-2. Sodium hydroxide was also added to the PUREX during these tests to keep the $\mathrm{pH}$ high during the initial THOREX addition. Because the 
$\mathrm{pH}$ was kept higher than in most of the earlier testing described in Section 2.0, the increased $\mathrm{NO}_{2}^{-}$ concentrations in the present tests resulted in only modest increases in the amounts of NO gas that were observed.

In addition to the THOREX/PUREX mixing experiments, laboratory experiments were also conducted to measure the $\mathrm{pH}$ of water exposed to the low concentrations of $\mathrm{NO}_{2}$ that were estimated for the Tank 8D-2 vapor space based on results from the THOREX/PUREX mixing tests. In addition, actual steel corrosion tests were performed in the presence of low partial pressures of $\mathrm{NO}_{2}$ and liquid water or water vapor. Based on the results of these tests, it was concluded that no significant corrosion of the tank walls would be expected under the anticipated THOREX/PUREX mixing conditions if the exposure was short ( $<100$ days), but the steady state $\mathrm{pH}$ values could potentially be low enough to cause concern over long exposure periods.

An alternative to direct addition of THOREX to Tank 8D-2 would be to first neutralize the THOREX with $\mathrm{NaOH}$ before transferring it to Tank 8D-2. A few simple tests indicated that this could be done with no measurable gas generated during neutralization of the THOREX and subsequent mixing with the PUREX. Under these conditions, the possibility of enhanced corrosion of the tank walls would be moot. Possible engineering problems that could be encountered with this scenario were not addressed. 



\section{Acknowledgments}

The authors acknowledge the many technical discussions with S.M. Barnes and M.A. Schiffhauer of West Valley Nuclear Services plus the following Pacific Northwest Laboratory personnel for setting up and running the test apparatus, for supplying some of the laboratory equipment, and for providing some analysis of the corrosion data: R.D. Bell, M.R. Elmore, S.M. Faber, W.M. Gerry, E.V. Morrey, M.R. Powell, G.L. Whiting, and R.E. Williford. 



\section{Contents}

Abstract $\ldots \ldots \ldots \ldots \ldots \ldots \ldots \ldots \ldots \ldots \ldots \ldots \ldots \ldots \ldots \ldots \ldots \ldots$ iii

Summary $\ldots \ldots \ldots \ldots \ldots \ldots \ldots \ldots \ldots \ldots \ldots \ldots \ldots \ldots \ldots \ldots \ldots$

Acknowledgments $\ldots \ldots \ldots \ldots \ldots \ldots \ldots \ldots \ldots \ldots \ldots \ldots \ldots \ldots \ldots \ldots$

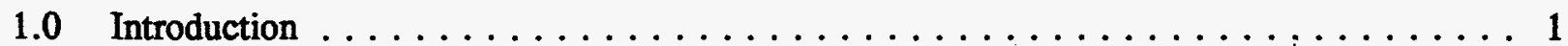

2.0 Early THOREX/PUREX Mixing Tests $\ldots \ldots \ldots \ldots \ldots \ldots \ldots \ldots \ldots$

2.1. Experimental Description $\ldots \ldots \ldots \ldots \ldots \ldots \ldots \ldots \ldots \ldots \ldots \ldots \ldots \ldots \ldots \ldots \ldots$

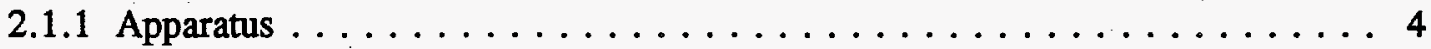

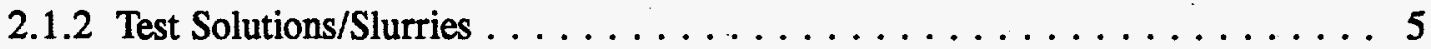

2.1.3 Calibrations and Performance Checks $\ldots \ldots \ldots \ldots \ldots \ldots$

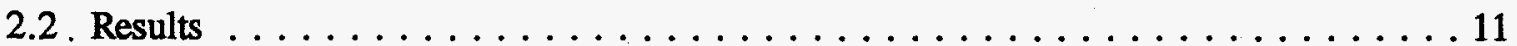

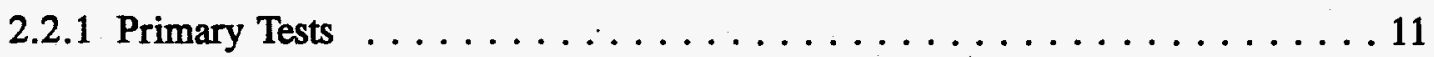

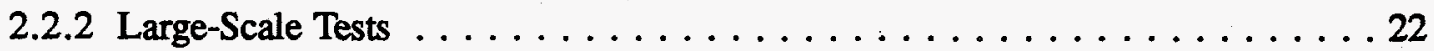

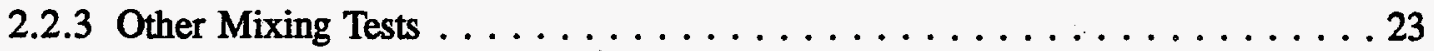

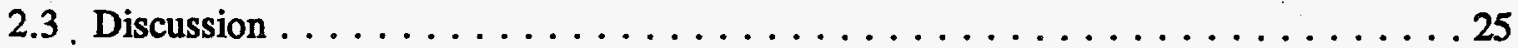

3.0 Supplemental THOREX/PUREX Mixing Tests $\ldots \ldots \ldots \ldots \ldots \ldots \ldots \ldots \ldots \ldots$

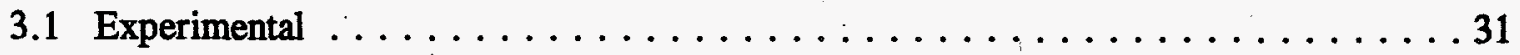

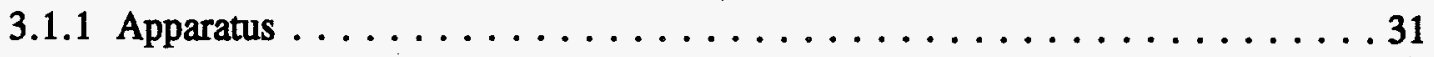

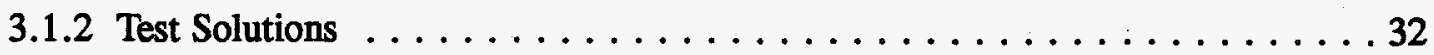

3.1.3 Calibrations and Performance Checks $\ldots \ldots \ldots \ldots \ldots \ldots$

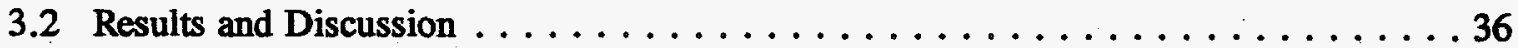




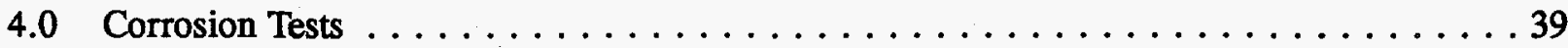

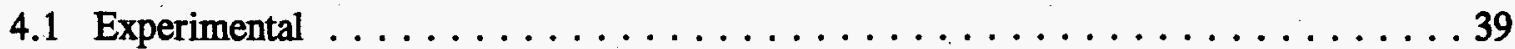

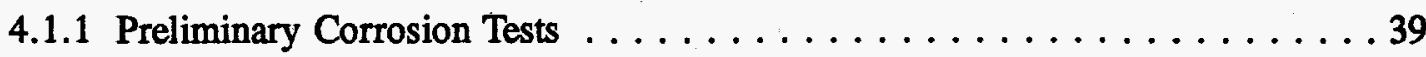

4.1.2 Determination of $\mathrm{pH}$ as a Function of $\mathrm{NO}_{2}$ Partial Pressure $\ldots \ldots \ldots \ldots 39$

4.1.3 Determination of Corrosiveness of $\mathrm{NO}_{2}$-Equilibrated Solutions $\ldots \ldots \ldots \ldots 41$

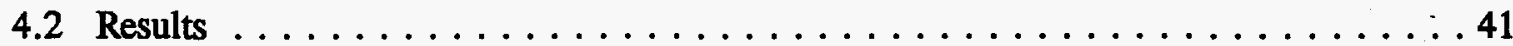

4.2.1 Preliminary Corrosion Tests $\ldots \ldots \ldots \ldots \ldots \ldots \ldots \ldots \ldots \ldots \ldots 1$

4.2.2 Determination of $\mathrm{pH}$ as a Function of $\mathrm{NO}_{2}$ Partial Pressure $\ldots \ldots \ldots \ldots 4$

4.2.3 Determination of Corrosiveness of $\mathrm{NO}_{2}$-Equilibrated Solution $\ldots \ldots \ldots 43$

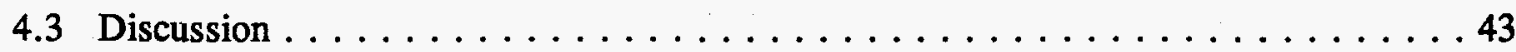

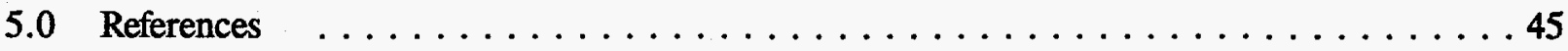

Appendix A - Rheological and Flow Properties of NT-1 and NT-5 Samples . . . . . . . A.1

Appendix B - Particle-Size Distribution Results . . . . . . . . . . . . . B.1

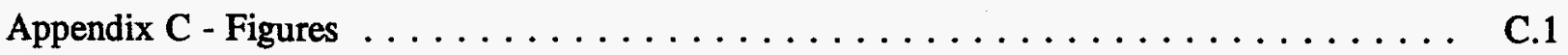




\section{Tables}

2.1 Detection Limits for Gas Chromatograph $\ldots \ldots \ldots \ldots \ldots \ldots$

2.2 THOREX Composition (First Batch) $\ldots \ldots \ldots \ldots \ldots \ldots$

2.3 THOREX Composition (Second Batch) $\ldots \ldots \ldots \ldots \ldots \ldots \ldots$

2.4 PUREX Sludge/Supernate Composition $(\mathrm{g} / \mathrm{L}) \ldots \ldots \ldots \ldots \ldots \ldots$

2.5 Description of Column Headings in Tables 2.6 to $2.10 \ldots \ldots \ldots \ldots \ldots \ldots$

2.6 Comparison of Direct THOREX Addition to PUREX Versus THOREX Recirculation Loop $\ldots \ldots \ldots \ldots \ldots \ldots \ldots \ldots$

2.7 Back-Flow Tests of PUREX Added to THOREX $\ldots \ldots \ldots \ldots \ldots \ldots \ldots$

2.8 Laboratory-Scale Tests of THOREX Added to Either

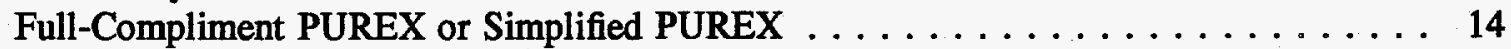

2.9 Laboratory-Scale Tests of THOREX Added to Either Full-Compliment PUREX or Simplified PUREX

2.10 Large-Scale Tests of THOREX Added to Either

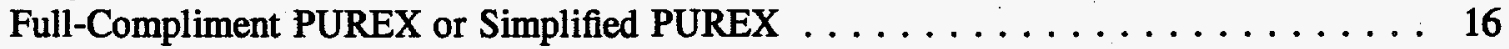

2.11 Mean Particle Diameters Based on Number or Volume of Particles . . . . . . . . . 25

3.1 Test Conditions Requested by WVNS for Supplemental Runs $\ldots \ldots \ldots \ldots \ldots$

3.2 Nominal THOREX Composition for Supplemental Mixing Test $\ldots \ldots \ldots \ldots$

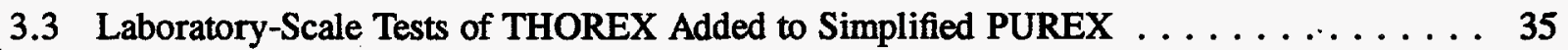

3.4 Composition of $\mathrm{Th}$ Solutions $(\mathrm{mol} / \mathrm{L}) \ldots \ldots \ldots \ldots \ldots$

3.5 Supplementary Tests of THOREX Added to Simplified PUREX $\ldots \ldots \ldots \ldots \ldots$

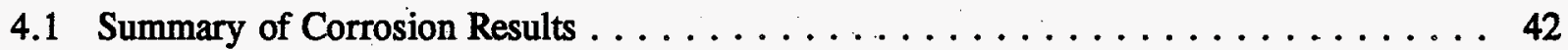

4.2 Corrosion Rates and Pit Depths for $\mathrm{NO}_{2}$ Corrosion Tests $\ldots \ldots \ldots \ldots \ldots \ldots$ 


\subsection{Introduction}

The Western New York Nuclear Service Center at West Valley, New York was operated by Nuclear Fuel Services, Inc. from 1968 through 1972 to recover fissionable isotopes from spent nuclear reactor fuel. The waste materials from these operations were stored on the site in large underground tanks. Nearly all of the spent fuel was treated with the PUREX process, neutralized, and stored in the steel 8D-2 waste tank. A single core of mixed thorium and uranium fuel was also processed, and the waste (called THOREX) was stored as a nitric acid solution in Tank 8D-4.

Before the stored radioactive wastes are vitrified, plans are being made to transfer acidic THOREX waste $(\sim 45,000 \mathrm{~L})$ from Tank $8 \mathrm{D}-4$ into the alkaline PUREX waste $(\sim 2,100,000 \mathrm{~L})$ in Tank 8D-2. Some options for the THOREX neutralization and transfer process were initially explored by Bray and Wise (1986). The work described in this report was performed to further explore some of those options.

Because the PUREX contains nitrite, the option of direct THOREX addition to Tank 8D-2 includes the potential for nitric oxide (NO) gas to be formed and released into the vapor space during THOREX addition. NO can be oxidized by air in the tank vapor space to form $\mathrm{NO}_{2}$, which can diffuse into and react with the water film that coats the tank walls above the slurry. This process will ultimately lead to the formation of a dilute solution of $\mathrm{HNO}_{3}$ in the water film, possibly leading to corrosion of the carbon steel.

West Valley Nuclear Services (WVNS) has been developing and gathering data to determine whether the THOREX addition procedure would result in significant corrosion of Tank 8D-2. The Pacific Northwest Laboratory (PNL) is supporting this effort by performing laboratory studies through the West Valley Support Program (WVSP). The PNL support activities were directed to two areas:

- Perform laboratory- and bench-scale experiments to quantify the $\mathrm{NO}_{\mathrm{X}}$ gas release under a variety of test conditions that included variations in stirring rate, THOREX addition rate, incremental addition of THOREX and $\mathrm{NaOH}$ to maintain a high $\mathrm{pH}$, effect of THOREX or PUREX dilution, and temperature.

- Perform laboratory experiments to determine the buildup of $\mathrm{H}^{+}$(decrease in $\mathrm{pH}$ ) in water exposed to different concentrations of $\mathrm{NO}$ gas mixed with air and to measure the corrosion rate of carbon steel coupons suspended in the water or vapor.

Most of the THOREX/PUREX mixing tests were conducted during FY 1993 and FY 1994 as described in Section 2.0. Supplemental THOREX/PUREX mixing tests were conducted during FY 1995 as described in Section 3.0. The corrosion work, which was conducted during FY 1994, is reported in Section 4.0.

Application of the results described in this report to the actual full-scale case of transferring the THOREX from Tank 8D-4 into the PUREX in Tank 8D-2 would entail important uncertainties. Probably the greatest uncertainty is in extrapolation of the laboratory- and bench-scale results to the full scale tanks where the waste volumes are one million times larger than in the laboratory-scale tests. 
A possible scaling factor is suggested as part of this report, but much larger-scale tests would be required to determine the validity of such a large extrapolation.

Another uncertainty involves the use of simulated wastes in the laboratory tests. Although the simulants were based on analyses of the actual wastes, a few mixing tests with the actual THOREX and PUREX wastes should be considered to verify the test results reported here.

This work was performed to quality assurance impact level three requirements as defined in PNL's quality assurance manual. This level ensures that the traceability, quality, and reproducibility of the results can be verified. However, if this work is the primary basis for making major project decisions, this work should be upgraded to impact level two standards. This upgrade may require additional documentation and laboratory tests. 


\subsection{Early THOREX/PUREX Mixing Tests}

The mechanism for $\mathrm{HNO}_{3}$ production in the condensed film on the tank wall is described by Equations.(2.1) to (2.4).

$$
\begin{aligned}
\mathrm{H}^{+}(\mathrm{THOREX})+\mathrm{NO}_{3}^{-}+2 \mathrm{NO}(\mathrm{g}) & \rightleftarrows \mathrm{HNO}_{2} \\
3 \mathrm{HNO}_{2}(\mathrm{aq}) & \rightleftarrows \mathrm{H}^{+}+\mathrm{NO}_{2}^{-}+2 \mathrm{NO}(\mathrm{g})+\mathrm{H}_{2} \mathrm{O} \\
2 \mathrm{NO}(\mathrm{g})+\mathrm{O}_{2} \text { (air) } & \rightleftarrows 2 \mathrm{NO}_{2}(\mathrm{~g}) \\
3 \mathrm{NO}_{2}(\mathrm{~g})+\mathrm{H}_{2} \mathrm{O} & \rightleftarrows 2 \mathrm{HNO}_{3}(\mathrm{aq})+\mathrm{NO}(\mathrm{g})
\end{aligned}
$$

At the point where the THOREX enters the PUREX in Tank 8D-2, the local pH is low enough to allow Equation (2.1) to proceed to the right even though in a hypothetical, instantly homogenized system, the high $\mathrm{pH}$ would force Equation (2.1) to the left via acid/base neutralization. Nitrous acid $\left(\mathrm{HNO}_{2}\right)$ formed by Equation (2.1) is a weak acid (dissociation constant $6.0 \times 10^{-4}$ at $30^{\circ} \mathrm{C}$ ) that rather slowly (seconds to minutes) decomposes according to Equation (2.2) (Yost and Russell 1944). Equation (2.2) must also take place in the region of localized low $\mathrm{pH}$ because, otherwise, the reverse of Equation (2.1) would again prevail. Once NO gas is formed and enters the vapor space, it can be oxidized by air and combine with moisture to form $\mathrm{HNO}_{3}$ according to Equations (2.3) and (2.4).

This section describes laboratory studies performed to measure the amount of NO gas formed during THOREX neutralization and mixing with PUREX, and to investigate methods for minimizing the amount of NO.

\subsection{Experimental Description}

Most of the THOREX/PUREX mixing experiments were conducted with equipment similar to that shown schematically in Appendix C, Figure C.1 and described in Section 2.1.1. Simulated THOREX and PUREX wastes were prepared for these tests as described in Section 2.1.2. The simulated wastes were completely nonradioactive except for the natural ${ }^{232}$ Th used in making the THOREX. System calibrations and performance checks are described in Section 2.1.3.

A few other simple laboratory mixing experiments were conducted that did not involve qualitative gas analysis equipment. The nature of these experiments are described along with the results in Section 2.2.3: 


\subsubsection{Apparatus}

Temperature of the 2-L glass reaction vessel (Appendix C, Figure C.1) was controlled by a heating mantle and automatic temperature controller, which used a thermocouple immersed in the liquid in the vessel as a temperature sensor. In all tests unless otherwise noted, 1.5 L of PUREX was placed in the vessel to start the test.

All tests were conducted as follows. After calibration of the gas chromatograph (GC) and $\mathrm{NO}_{\mathbf{X}}$ analyzer (see Section 2.1.3), the Ar carrier gas flow was established through the system at a rate measured by the calibrated mass flow controller (MFC). Argon was used as a carrier gas rather than air, which would simulate the conditions in Tank 8D-2, because it was desired to discover the gases formed by the reaction of THOREX with PUREX prior to oxidation by air. After allowing a few minutes to ensure that the initial concentrations of $\mathrm{NO}, \mathrm{CO}_{2}$, etc. in the Ar carrier gas were at or near zero, the THOREX pump was turned on and allowed to run until a predetermined amount of THOREX ${ }^{(\mathrm{a})}$ had been added to the reaction vessel. Data collection normally continued until the concentrations of NO and $\mathrm{CO}_{2}$, the only gases detected, returned to near zero. At the end of each test, the gas concentrations recorded during the test were multiplied by the Ar carrier gas flow rate to yield the generation rates of $\mathrm{NO}$ and $\mathrm{CO}_{2}$. Integration of the generation rates over time gave the total amounts generated during the tests.

The system operated at a very slightly elevated pressure $(<1 \mathrm{psi}$ above atmospheric). The metal bellows pump was used to raise the pressure in the off-gas line to the 5 psig required by the $\mathrm{NO}_{\mathrm{X}}$ analyzer.

Separate computers served as both controllers and data loggers for the $\mathrm{GC}$ and $\mathrm{NO}_{\mathrm{X}}$ analyzer, respectively. The computer used to control the $\mathrm{GC}$ also recorded $\mathrm{pH}$ and temperature. Gases analyzed by the GC, and their respective detection limits, are listed in Table 2.1. The $\mathrm{NO}_{\mathrm{X}}$ analyzer was capable of detecting both $\mathrm{NO}$ and $\mathrm{NO}_{2}$ at concentrations as low as $\sim 1$ part per million (ppm). Temperature, $\mathrm{pH}$, and $\mathrm{GC}$ data were recorded approximately once every $1.5 \mathrm{~min}$. Data from the $\mathrm{NO}_{\mathrm{X}}$ analyzer were recorded once per minute; total $\mathrm{NO}_{X}$ concentrations were recorded $9 \mathrm{~min}$. out of 10 and NO concentrations were recorded every 10 th $\mathrm{min}$. Interpretation of the $\mathrm{NO}_{\mathbf{X}}$ data are described below.

The $\mathrm{NO}_{X}$ analyzer operates either in the NO-analysis mode or the $\mathrm{NO}_{X}$ mode, but not simultaneously. It measures $\mathrm{NO}$ concentrations directly, but when switched to the $\mathrm{NO}_{\mathrm{x}}$ analysis mode, the $\mathrm{NO}_{\mathrm{X}}$ analyzer first oxidizes all of the incoming $\mathrm{NO}_{\mathrm{X}}$ to $\mathrm{NO}_{2}$. Therefore, the difference between $\mathrm{NO}$ and $\mathrm{NO}_{\mathrm{X}}$ represents the concentration of $\mathrm{NO}_{2}$ originally present in the incoming gas. If the measured $\mathrm{NO}$ and $\mathrm{NO}_{\mathrm{X}}$ concentrations are the same, then no $\mathrm{NO}_{2}$ is present in the incoming gas; $100 \%$ of the incoming $\mathrm{NO}_{X}$ is NO. The clearest example of this is shown in Figure $\mathrm{C} .10$ (Appendix C). The $\mathrm{NO}_{\mathrm{X}}$ curve in that figure increases nearly uniformly up to a maximum and then decreases slowly. The NO curve increases, and then decreases, in a step-wise fashion because the NO data were recorded only once every $10 \mathrm{~min}$.. However, each time the NO data were recorded, a match with the $\mathrm{NO}_{\mathrm{X}}$ data was observed. This means that $100 \%$ of the incoming $\mathrm{NO}_{\mathrm{X}}$ gas was NO. Similar results were observed

(a) The THOREX supply reservoir rested on a balance, and the amount added to the reaction vessel was determined by weight change. 
Table 2.1. Detection Limits for Gas Chromatograph(a)

\begin{tabular}{|c|c|}
\hline Gas & Detection Limit (ppm) \\
\hline $\mathrm{CO}_{2}$ & 5 \\
\hline $\mathrm{CO}$ & 200 \\
\hline $\mathrm{N}_{2} \mathrm{O}$ & 5 \\
\hline $\mathrm{H}_{2}$ & 10 \\
\hline $\mathrm{N}_{2}$ & 100 \\
\hline $\mathrm{O}_{2}$ & 100 \\
\hline
\end{tabular}

(a) Calibrations were performed only for the first four gases listed. Even though no calibrations were performed for $\mathrm{N}_{2}$ and $\mathrm{O}_{2}$, the listed detection limits are expected to be approximately correct.

for all of the tests conducted in this study. Other examples are shown in Figures C.6 and C.8 (Appendix C), but they are less clear because of the erratic nature of the gas evolution in those tests. Therefore, the $\mathrm{NO}_{\mathrm{X}}$ curves in all of the tests can be labelled "NO," and that was done in all cases except the illustrations in Figures C.6, C.8, and C.10 (Appendix C).

After the first five runs (Figures C.6 to C.10 in Appendix C and Tables 2.6 and 2.7 in Section 2.2.1), use of the $\mathrm{GC}$ and associated computer was discontinued because only $\mathrm{NO}$ and $\mathrm{CO}_{2}$ gases were detected, and the latter was of little interest. As a result, the remaining tests did not have continuous recordings of $\mathrm{pH}$ and temperature. Rather, the temperature was recorded in a laboratory record book (LRB) at the beginning and two or three times during each test. The $\mathrm{pH}$ was measured for samples of solution (or slurry) from the reaction vessel before and after each test. In addition; a different $\mathrm{NO}_{\mathrm{X}}$ analyzer was used that recorded data every 15 seconds instead of at one-minute intervals.

Besides the lab-scale tests conducted in the 2-L glass vessel, three large-scale tests were performed at room temperature using a 17-L polyethylene vessel. Otherwise, the setup for the large-scale tests was the same as shown schematically in Figure C.1 (Appendix C) minus the GC and the heating mantle for the reaction vessel.

\subsubsection{Test Solutions/Slurries}

Different batches of both THOREX and PUREX were used during the course of this work. Preparation methods and compositions are given here. In Section 2.2, the particular batches used in each test are identified along with any additional details that may be pertinent. 


\section{THOREX}

The method used to prepare the THOREX was described by Bray and Wise (Appendix B, 1986). This recipe assumed the volume of THOREX in Tank 8D-4 was 45,000 L. To ensure that all components remained dissolved in solution at $25^{\circ} \mathrm{C}$, Bray and Wise determined that this THOREX should be diluted to a volume representative of $59,000 \mathrm{~L}$. Therefore, most of the early tests were conducted with the "diluted" THOREX.

The first batch of THOREX had been prepared for use in a related project more than a year earlier. Its composition was assumed to be represented by the nominal values listed in Table 2.2, and it was put into use at the same time that a representative sample was being analyzed. The results of the analyses given in Table 2.2 show that the actual concentrations of the more prominent components (e.g., Th and $\mathrm{NO}_{3}$ ) were only about $60 \%$ of the nominal values.

Table 2.2. THOREX Composition (First Batch)

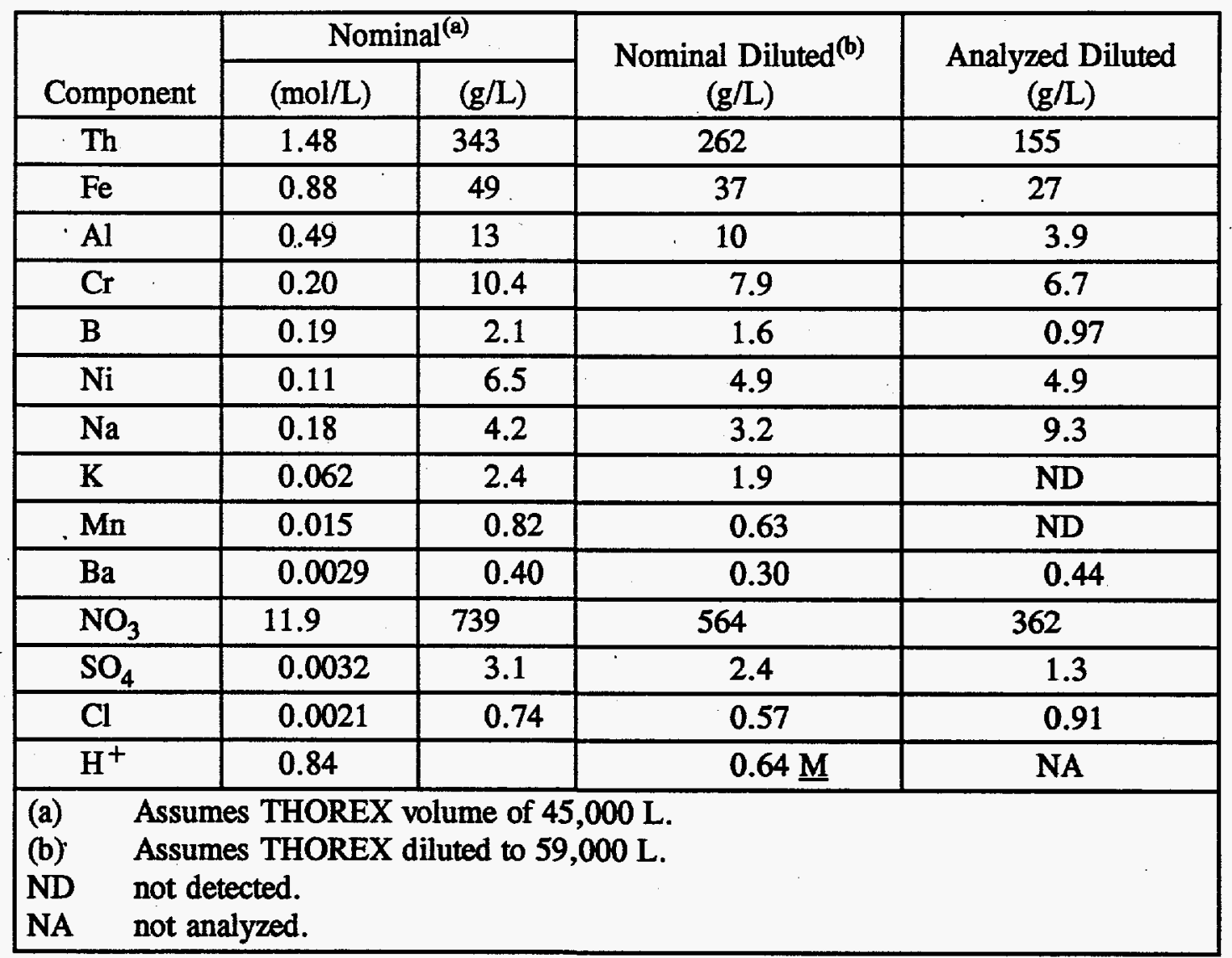


Table 2.3 shows that the analyzed concentrations of the major constituents in the second batch of THOREX were within the normally expected precision and bias $( \pm 15 \%)$ of the nominal values.

Therefore, the nominal values were used to calculate the amounts of THOREX to add to the PUREX in each test. The third batch of THOREX was prepared in the same manner as the second batch and was assumed to contain the nominal concentrations listed in Table 2.3, but it was not analyzed.

\section{PUREX}

At the time these tests were conducted, it was assumed that the PUREX sludge in Tank 8D-2 would be washed three times to remove sodium, cesium, nitrite, and other soluble constituents before adding the THOREX. To mimic this process, the simulated PUREX prepared for this study was also washed. The nominal composition of the original, unwashed PUREX, which was prepared according to a recipe provided by Bray and Wise (Appendix C, 1986), is listed in Table 2.4. Most of the Fe, Cr, and several other constituents precipitate as hydroxides in the high $\mathrm{pH}$ solution. Therefore, the PUREX was washed by allowing the solids in the original slurry to settle for a few days, which resulted in a settled solids volume equal to about one third of the total volume. Then the supernate was decanted and an equal volume of deionized water was returned. After thorough stirring, the solids were allowed to settle a second time followed by decanting the supernate and returning an equal volume of deionized water. At this point, the PUREX slurry was split into two portions. Each portion of the second-wash PUREX was washed a third time in the same manner described for the first and second washes. The total volume of the third-wash PUREX batches (solids plus supernate) was the same as the original volume of the unwashed PUREX simulant.

Table 2.3. THOREX Composition (Second Batch)

\begin{tabular}{|c|c|c|c|}
\hline \multirow[b]{2}{*}{ Component } & \multicolumn{2}{|c|}{ Nominal $^{(\mathrm{a})}$} & \multirow{2}{*}{$\begin{array}{c}\text { Analyzed } \\
(\mathrm{g} / \mathrm{L})\end{array}$} \\
\hline & $(\mathrm{mol} / \mathrm{L})$ & $(g / L)$ & \\
\hline Th & 1.48 & 343 & 303 \\
\hline$\overline{\mathrm{Fe}}$ & 0.88 & 49 & 55 \\
\hline$\overline{\mathrm{Al}}$ & 0.49 & 13 & 12 \\
\hline$\overline{\mathrm{Cr}}$ & 0.20 & 10.4 & 11.2 \\
\hline$\overline{\mathbf{B}}$ & 0.19 & 2.1 & 2.2 \\
\hline$\overline{\mathrm{Ni}}$ & 0.11 & 6.5 & 7.2 \\
\hline $\mathrm{Na}$ & 0.18 & 4.2 & 6.4 \\
\hline$\overline{\mathbf{K}}$ & 0.062 & 2.4 & 3.4 \\
\hline$\overline{\mathbf{M n}}$ & 0.015 & 0.82 & 1.5 \\
\hline $\mathbf{B a}$ & 0.0029 & 0.40 & $\overline{0.52}$ \\
\hline $\mathrm{NO}_{3}$ & 11.9 & 739 & 695 \\
\hline $\mathrm{SO}_{4}$ & 0.0032 & 3.1 & \\
\hline $\mathrm{Cl}$ & 0.0021 & 0.74 & \\
\hline $\mathrm{H}^{+}$ & 0.84 & $\overline{\mathbf{N A}}$ & $\overline{\mathbf{N A}}$ \\
\hline \multicolumn{4}{|c|}{$\begin{array}{l}\text { Assumes THOREX volume of } 45,000 \mathrm{~L} \text {. } \\
\text { not detected. } \\
\text { not analyzed. }\end{array}$} \\
\hline
\end{tabular}


Table 2.4. PUREX Sludge/Supernate Composition $(g / L)^{(a)}$

\begin{tabular}{|c|c|c|c|c|}
\hline Component & $\begin{array}{c}\text { Nominall }^{(b)} \\
\text { Original }\end{array}$ & $\begin{array}{c}\text { Analyzed }^{(0)} \\
\text { R3A }\end{array}$ & $\begin{array}{c}\text { Analyzed } \\
\text { R3B }\end{array}$ & $\begin{array}{c}\text { Analyzed }^{(e)} \\
\text { R4 }\end{array}$ \\
\hline $\mathrm{Na}$ & $\overline{152}$ & $27.5^{(\mathrm{t})}$ & 21.3 & 10.2 \\
\hline $\mathrm{Fe}$ & 17.1 & & & \\
\hline K & 7.41 & 0.81 & 0.79 & 0.39 \\
\hline $\bar{P}$ & 3.1 & 0.173 & & 0.071 \\
\hline $\mathrm{Cr}$ & 1.40 & & & \\
\hline $\mathrm{Sm}$ & 1.2 & & & \\
\hline $\mathbf{M n}$ & 0.66 & & & \\
\hline $\mathrm{Ni}$ & 0.65 & & & \\
\hline $\mathrm{Al}$ & 0.46 & 0.092 & 0.012 & 0.006 \\
\hline$\overline{\mathrm{Zr}}$ & 0.21 & & & \\
\hline Cs & 0.18 & & & \\
\hline Mo & 0.14 & & & \\
\hline $\mathbf{R u}^{(\mathrm{g})}$ & 0.14 & & & \\
\hline $\mathrm{Ba}$ & 0.082 & & & \\
\hline Sr & 0.049 & & & \\
\hline $\mathbf{R b}$ & 0.032 & & & \\
\hline $\mathrm{Rh}^{(\mathbf{g})}$ & 0.024 & & & \\
\hline $\mathrm{Pd}^{(\mathrm{g})}$ & 0.014 & & & \\
\hline$\widehat{A g(g)}$ & 0.00031 & & & \\
\hline $\mathrm{NO}_{3}$ & 214 & 33.1 & 25.6 & 12.4 \\
\hline $\mathrm{NO}_{2}$ & 96 & 10.7 & 10.4 & 5.0 \\
\hline $\mathrm{SO}_{4}$ & 24 & 3.0 & 2.7 & 1.3 \\
\hline $\mathrm{CO}_{3}$ & 21 & $3.5^{(\mathrm{h})}$ & $\overline{\mathbf{N A}}$ & NA \\
\hline $\mathrm{Cl}$ & 1.4 & & 0.24 & 0.14 \\
\hline $\mathbf{F}$ & 0.025 & & & \\
\hline$\overline{\mathrm{OH}}$ & & NA & $0.11 \underline{\mathrm{M}}$ & NA \\
\hline \multicolumn{5}{|c|}{$\begin{array}{l}\text { Blanks represent components not detected in the supernate analyses because they } \\
\text { had precipitated as hydroxides or were present in very low concentrations initially. } \\
\text { As prepared slurry, before any washing. } \\
\text { First batch of third-wash supernate from original batch of second-wash slurry. } \\
\text { Second batch of third-wash supernate from original batch of second-wash slurry. } \\
\text { First batch of fourth wash supernate from second batch of third-wash slurry. } \\
\text { Includes } 7.9 \mathrm{~g} / \mathrm{L} \text { added as } \mathrm{NaOH} \text { after third wash. } \\
\text { Added after third wash. } \\
\text { Based on inorganic carbon analysis. } \\
\text { not analyzed. }\end{array}$} \\
\hline
\end{tabular}


To the first batch of third-wash PUREX (designated R3A) was added $18 \mathrm{~mL}$ of $19 \mathrm{M} \mathrm{NaOH}$ to neutralize the acid and to precipitate, as hydroxides, the metal nitrates in the THOREX, which was to be added later as part of this testing program. In addition, the quantities of noble metals $(\mathbf{R u}, \mathbf{R h}, \mathbf{P d}$, and $\mathrm{Ag}$ ) listed in Table 2.4 were added to the PUREX after the third washing. Although the noble metals were not expected to affect the mixing results, the desire was to make the simulated PUREX as representative of the waste in Tank 8D-2 as possible. After stirring and allowing the solids to settle, a sample of the supernate was analyzed and the results are listed under the column heading R3A in Table 2.4 .

After preparation of the second batch of third-wash PUREX (designated R3B), the same quantities of noble metals listed in Table 2.4 were added, but no $\mathrm{NaOH}$ was added at this time. A supernate sample from this batch of PUREX was analyzed, and the results, including hydroxide, are listed under the column heading R3B in Table 2.4. For each mixing test that used a 1.5-L portion of PUREX batch $\mathrm{R} 3 \mathrm{~B}$, an amount of $\mathrm{NaOH}$ was added that was calculated to increase the $\mathrm{OH}^{-}$concentration to $0.2 \underline{\mathrm{M}}$. Although the $\mathrm{OH}^{-}$concentrations after the addition of $\mathrm{NaOH}$ were thought to be close to $0.2 \mathrm{M}$, the measured $\mathrm{pH}$ values listed for Tests 6 and 8 to 11 in Table 2.8 (Section 2.2.1) were always a little less than the expected value of 13.3. The discrepancies between expected $\mathrm{OH}^{-}$concentrations and measured $\mathrm{pH}$ values were apparently due to consumption of $\mathrm{OH}^{-}$by complex interactions with other components in the PUREX.

To determine whether there would be any potential benefit, from a NO generation standpoint, of additional washing of the PUREX, a fourth-wash PUREX was prepared from the second batch of thirdwash PUREX, R3B. After decanting the supernate from R3B PUREX and adding deionized water to restore the slurry to its original volume, stirring, and allowing the solids to settle, an analysis of the supernate yielded the results listed under column R4 in Table 2.4. In the one test where this batch of PUREX was used, Test 13 (Table 2.8), an amount of $\mathrm{NaOH}$ was added that was calculated to increase the $\mathrm{OH}^{-}$concentration to $0.2 \underline{\mathrm{M}}$.

In addition to the "full compliment" batches of simulated PUREX described above, many of the mixing tests were performed using "simplified" PUREX. These were prepared using only $\mathrm{NaOH}$, $\mathrm{NaNO}_{2}$, and $\mathrm{Na}_{2} \mathrm{CO}_{3}$, which were the only components in the PUREX that were expected to react with the THOREX. The concentrations of these were chosen to provide $0.2 \mathrm{M} \mathrm{OH}^{-}$plus the analyzed concentrations of $\mathrm{NO}_{2}^{-}$and $\mathrm{CO}_{3}^{2-}$ listed under column R3A in Table 2.4. Thus, solutions were prepared that contained $0.20 \underline{\mathrm{M} \mathrm{NaOH}}, 0.23 \underline{\mathrm{M} \mathrm{NaNO}}{ }_{2}$, and $0.058 \underline{\mathrm{M} \mathrm{Na}} \mathrm{CO}_{3}$. These solutions are represented as "S3" in Tables 2.8 and 2.9 (Sections 2.2.1 and 2.2.2).

A "simplified" PUREX representative of the fourth-wash PUREX was also prepared by assuming that the $\mathrm{NO}_{2}^{-}$and $\mathrm{CO}_{3}^{2-}$ concentrations should be equal to one-third the values used for the S3 PUREX given above. In addition, the intent was to maintain the $0.2 \mathrm{M} \mathrm{NaOH}$ concentration. Therefore, PUREX batches represented as "S4" in Tables 2.8 to 2.10 (Sections 2.2.1 and 2.2.2) were prepared that contained $0.20 \underline{\mathrm{M} \mathrm{NaOH}}, 0.077 \underline{\mathrm{M} \mathrm{NaNO}}{ }_{2}$, and $0.019 \underline{\mathrm{M} \mathrm{Na}} \mathrm{CO}_{3}$.

\subsubsection{Calibrations and Performance Checks}

The gas chromatograph and $\mathrm{NO}_{\mathrm{x}}$ analyzer were calibrated periodically, as required by the operating procedures, using gas mixtures with known concentrations of the appropriate gases. In addition, system performance checks were conducted from time to time using known concentrations of NO gas. 
This was done to ensure that nothing in the gas train of the system (condenser, drierite column, and Tygon tubing) affected the measured $\mathrm{NO}_{\mathrm{X}}$ concentrations. In some cases, the NO-containing gas was bubbled through the PUREX in the reaction vessel to determine the response time of NO showing up at the $\mathrm{NO}_{\mathrm{X}}$ analyzer as well as the response time for return of the NO concentration to zero.

Initially there was some concern that NO gas could diffuse from the Tygon tubing used between the reaction vessel and $\mathrm{NO}_{\mathrm{X}}$ analyzer, or that $\mathrm{O}_{2}$ could diffuse into the tubing from the room atmosphere and oxidize some of the $\mathrm{NO}$ to $\mathrm{NO}_{2}$. To evaluate this possibility, the $\mathrm{NO}_{\mathrm{X}}$ analyzer settings for both $\mathrm{NO}$ and $\mathrm{NO}_{2}$ were set to $94 \mathrm{ppm}$ using a calibration gas containing $94 \mathrm{ppm} \mathrm{NO}$ in $\mathrm{Ar}$, i.e., normal calibration procedure. Then the same calibration gas was passed through $\sim 6 \mathrm{ft}$. of $1 / 4 \mathrm{in}$. inside diameter (ID) Tygon tubing at $\sim 650 \mathrm{~mL} / \mathrm{min}$ into the $\mathrm{NO}_{\mathrm{X}}$ analyzer. The tubing dimensions and gas flow rates. were both representative of that used in the system gas train. Readings of $98 \mathrm{ppm}$ NO and $92 \mathrm{ppm} \mathrm{NO} \mathrm{N}_{2}$ were obtained, which is within the expected reproducibility range of the analyzer. Thus, the Tygon tubing had no measurable effect. Figure C.2 (Appendix C) shows the results obtained when this same calibration gas was next injected below the surface of R3B PUREX in the reaction vessel. After a 1-minute delay, the measured NO concentration began to increase rapidly. Within $10 \mathrm{~min}$., the measured concentration of NO approached the expected value of $94 \mathrm{ppm}$ indicating that nothing within the system acted to reduce the NO concentration. Another 1-minute delay was observed after the NO was shut off. Then, the concentration fell rapidly to near zero in about $5 \mathrm{~min}$. with a very small tail extending for another $5 \mathrm{~min}$. or so.

Figure C.3 (Appendix C) shows results from a second performance check that was conducted somewhat differently from the first in three ways. First, simplified PUREX, rather than fullcompliment PUREX was used. Thus, there were no solids in the vessel. Second, two gas streams were used because it was thought that, during the first performance check, the continued sparging of Ar through the PUREX may have contributed to the rapid decrease in NO concentration after the flow of NO was stopped. Thus, a calibration gas containing $1100 \mathrm{ppm}$ NO in Ar was injected below the surface of the S4 PUREX at $410 \mathrm{~mL} / \mathrm{min}$, and a second stream of Ar entered the vessel above the surface at $1090 \mathrm{~mL} / \mathrm{min}$ giving a final $\mathrm{NO}$ concentration of $301 \mathrm{ppm}$. Third, the temperature was $45^{\circ} \mathrm{C}$, rather than $25^{\circ} \mathrm{C}$ as it was in the first performance check.

Figure C.3 (Appendix C) shows that the measured NO concentration stabilized at $295 \mathrm{ppm}$ after about $15 \mathrm{~min}$. When the Ar/NO gas was shut off, the Ar flow through the vessel was maintained at $1090 \mathrm{~mL} / \mathrm{min}$, but there was no gas bubbling through the PUREX. Again, the NO concentration returned rapidly to zero, at least as rapidly as in the first performance check, even without continued sparging of the PUREX.

Figures C.4 and C.5 (Appendix C) show results from two performance checks conducted with the large-scale system. In both cases, Ar gas containing $301 \mathrm{ppm}$ NO was injected below the surface of the S4 PUREX and, after the NO was turned off, Ar continued to sparge the PUREX at $1090 \mathrm{~mL} / \mathrm{min}$. In the first test (Appendix C, Figure C.4), fresh S4 PUREX was used, so there were no solids present. The second test (Appendix C, Figure C.5) was conducted following Test 23B (Table 2.10), so solids resulting from that test were present. Steady-state concentrations of NO reached $286 \mathrm{ppm}$ and $292 \mathrm{ppm}$, respectively, in the two performance checks (i.e., 5\% and 3\% below the expected values). The first concentration, in particular, is a little outside the range of expected reproducibility of the $\mathrm{NO}_{\mathrm{X}}$ analyzer, which may indicate some loss of NO in the system. 
However, for the purpose of this work, the observed NO concentrations were considered acceptable. Clearly, the approach to steady-state NO concentrations and the return to zero following shut-off of the NO was about the same as in the earlier tests with the 2-L vessel.

\subsection{Results}

This section is divided into three subsections, Primary Tests, Large-Scale Tests, and Other Mixing Tests. Primary Tests included all of the THOREX/PUREX mixing tests conducted in the 2-L test vessel using a set-up similar to that shown schematically in Figure C.1. (Appendix C). ${ }^{\text {(a) }}$ Large-Scale Tests were conducted in a 17-L vessel and also used a set-up similar to that shown schematically in Figure C.1. (Appendix C). ${ }^{\text {(a) }}$ Other Mixing Tests involved, primarily, some THOREX/NaOH mixing experiments conducted without qualitative gas analyses.

\subsubsection{Primary Tests}

Results from all of the primary THOREX/PUREX mixing tests are summarized in Tables 2.6 to 2.9 and Figures C. 6 to C.39 (Appendix C). Explanations for some of the column headings in Tables 2.6 to 2.10 are given in Table 2.5, below. Other information given in the tables includes 1) corresponding figure number, 2) $\mathrm{pH}$ at the start and end of each test, 3) test temperature, and 4) amount of NO gas that was generated. The tests were grouped within the tables so that tests with similar parameters, or with the objective of determining the effect of changing a particular parameter, occur together. Tests in Tables 2.8 to 2.10 with nominally identical parameters were given the same number followed by a letter.

Table 2.5. Description of Column Headings in Tables 2.6 to 2.10

\begin{tabular}{|l|l|}
\hline Ar gas carrier flow rate & $\begin{array}{l}\text { Flow rate (mL/min at STP) of the Ar carrier gas sweeping through the } \\
\text { reaction vessel, as measured by the calibrated mass flow controller (MFC). } \\
\text { Gas generation rates were calculated from the measured concentrations } \\
\text { multiplied by these flow rates. }\end{array}$ \\
\hline Stir rate & $\begin{array}{l}\text { Rotational speed, rpm, of the stirrer. In the early tests, a careful record of } \\
\text { the exact stirrer speed setting was not made. Therefore, the rate is simply } \\
\text { listed as medium, "med," and was probably between } 300 \text { and } 400 \mathrm{rpm} .\end{array}$ \\
\hline THOREX batch & Compositions listed in Tables 2.2 and 2.3. \\
\hline PUREX batch & Compositions listed in Table 2.4 or described in Section 2.1.2. \\
\hline
\end{tabular}

(a) Only the first 5 tests (Tables 2.6 and 2.7) used both the GC and NOx analyzer. The remaining primary tests and all the large-scale tests used only the NOx analyzer. 
Table 2.6. Comparison of Direct THOREX Addition to PUREX Versus THOREX Addition to PUREX Recirculation Loop ${ }^{(a)}$

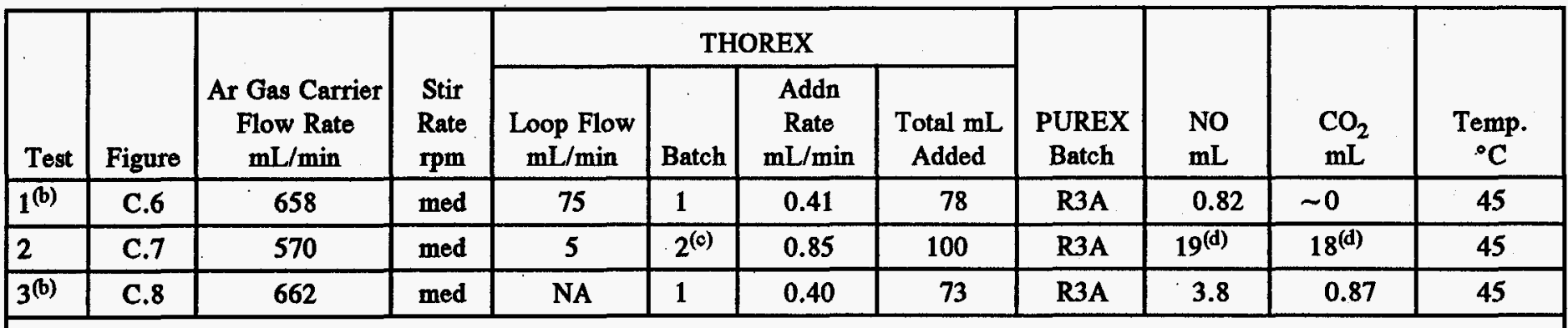

(a) See Table 2.5 for descriptions of some of the column headings.

(b) Included corrosion coupons. See schematic diagram in Figure 2.1 and Section 3.4 for results.

(c) THOREX composition listed in Table 2.3 except diluted by $59 / 45$ with deionized water.

(d) Values could be 10 to $30 \%$ low due to loss of gas through $\mathrm{pH}$ holder in loop. See description in text. 
Table 2.7. Back-Flow Tests of PUREX Added to THOREX(a)

\begin{tabular}{|c|c|c|c|c|c|c|c|c|c|}
\hline \multirow[b]{2}{*}{ Test } & \multirow[b]{2}{*}{ Figures } & \multirow{2}{*}{$\begin{array}{c}\text { Ar gas Carrier } \\
\text { Flow Rate } \\
\text { mL/min }\end{array}$} & \multirow{2}{*}{$\begin{array}{l}\text { Stir } \\
\text { Rate } \\
\text { rpm } \\
\end{array}$} & \multicolumn{2}{|c|}{ PUREX } & \multirow[b]{2}{*}{$\begin{array}{l}\text { THOREX } \\
\text { Batch }\end{array}$} & \multirow[b]{2}{*}{$\begin{array}{l}\text { NO } \\
\text { mL }\end{array}$} & \multirow[b]{2}{*}{$\begin{array}{l}\mathrm{CO}_{2} \\
\mathrm{~mL}\end{array}$} & \multirow[b]{2}{*}{$\begin{array}{c}\text { Temp. } \\
{ }^{\circ} \mathrm{C}\end{array}$} \\
\hline & & & & Batch & $\begin{array}{c}\text { Addn Rate } \\
\mathrm{mL} / \mathrm{min}\end{array}$ & & & & \\
\hline 4 & C.9 & 578 & med & R3A & 1.24 & 2 & 61 & 39 & 45 \\
\hline 5 & C. 10 & 568 & med & R3A & 1.27 & $2^{(b)}$ & 66 & 37 & 25 \\
\hline
\end{tabular}

(a) See Table 2.5 for descriptions of some of the column headings.

(b) THOREX composition listed in Table 2.3 except diluted by 59/45 with deionized water.

The in-vessel and in-loop pH probes, which were used only in Tests 1 to 3 , did not accurately read $\mathrm{pH}$ values-above about 10 . Indeed, the readings were found to be one-half to one unit low at $\mathrm{pH} 13$ as determined by a secondary $\mathrm{pH}$ probe that responded properly to the high $\mathrm{pH}$ values. The secondary $\mathrm{pH}$ probe was calibrated at $\mathrm{pH} 13.3$ using a $0.2 \mathrm{M} \mathrm{NaOH}$ solution. Approximate corrections were applied to the recorded $\mathrm{pH}$ values obtained from the in-vessel and in-loop probes. The applied corrections were varied in a linear fashion from the measured error (one-half to one $\mathrm{pH}$ unit) at the beginning of the test $(\mathrm{pH} \sim 13)$ to zero correction at $\mathrm{pH} 10$. The corrected values are the ones that are plotted in Figures C.6 to C.8 (Appendix C).

\section{Test 1.}

A major objective of Tests 1 to 3 [Table 2.6, Figures C.6 to C.8 (Appendix C)] was to compare the amount of NO that was generated when THOREX was added directly to the reaction vessel with the amount that was generated when the PUREX was pumped through a recirculation loop and THOREX was added to the loop. The recirculation loop feature of the apparatus is not shown in the schematic representation in Figure C.1 (Appendix C). In the loop tests, a peristaltic pump was used to circulate PUREX through a 2- to 3-ft-long loop of approximately 1/8-in. ID Tygon tubing, and THOREX was pumped into a "T" in the loop. Agitation by the stirrer kept the PUREX solids in suspension in the reaction vessel, and PUREX passed through the loop as a slurry of suspended solids.

Three important points should be noted about the results from Test 1, which are shown in Figure C.6 (Appendix C) and Table 2.6. First, the spikes in the $\mathrm{NO} / \mathrm{NO}_{\mathrm{X}}$ data are thought to have been caused by NO bubble generation in the recirculation loop. Bubbles were not actually observed; they were merely surmised. Small bubbles are thought to have accumulated within the loop where they agglomerated into much larger bubbles, which were expelled into the reaction vessel at irregular intervals. Only after the bubbles entered the reaction vessel would they be swept away by the carrier gas into the $\mathrm{NO}_{\mathrm{x}}$ analyzer. Thus, the spikes are thought to have been caused by irregular bursts of NO bubbles into the reaction vessel. Note the absence of large spikes when THOREX was added directly to the reaction vessel (Figure C. 8 in Appendix C). 
Table 2.8. Laboratory-Scale Tests of THOREX Added to Either Full-Compliment PUREX or Simplified PUREX ${ }^{(\mathfrak{a})}$

\begin{tabular}{|c|c|c|c|c|c|c|c|c|c|c|c|c|}
\hline \multirow[b]{2}{*}{ Test } & \multirow[b]{2}{*}{ Figure } & \multirow{2}{*}{$\begin{array}{c}\text { Ar Gas Carrier } \\
\text { Flow Rate } \\
\text { mL/min }\end{array}$} & \multirow[b]{2}{*}{$\begin{array}{c}\text { Stir Rate } \\
\mathbf{r p m}\end{array}$} & \multicolumn{3}{|c|}{ THOREX $^{(\mathbf{b})}$} & \multirow[b]{2}{*}{$\begin{array}{c}\text { PUREX } \\
\text { Batch (1.5 L) }\end{array}$} & \multicolumn{2}{|c|}{ NO Gas } & \multicolumn{2}{|c|}{$\mathrm{pH}$} & \multirow[b]{2}{*}{$\begin{array}{c}\text { Temp } \\
{ }^{\circ} \mathrm{C}\end{array}$} \\
\hline & & & & Batch & $\begin{array}{c}\text { Addn Rate } \\
\mathrm{mL} / \mathrm{min}\end{array}$ & $\begin{array}{c}\text { Total } \mathrm{mL} \\
\text { Added }\end{array}$ & & Total $\mathrm{mL}$ & $\begin{array}{c}\text { Peak Rate } \\
\mu \mathrm{L} / \mathrm{min}\end{array}$ & Start & End & \\
\hline 6 & \begin{tabular}{l|} 
C.11 \\
\end{tabular} & 566 & med & 3 & 1.84 & 30 & $\mathrm{R}^{3} \mathrm{~B}^{(\mathrm{c})}$ & 5.5 & 290 & 13.1 & 11.3 & 45 \\
\hline $7 \mathrm{~A}$ & C.12 & 827 & 350 & 3 & 1.85 & 30 & S3 & 7.6 & 390 & 13.2 & 10.8 & 45 \\
\hline $7 \mathrm{~B}$ & C.13 & 827 & 350 & 3 & 1.77 & 30 & s3 & 6.4 & 380 & 13.2 & 10.8 & 45 \\
\hline 8 & C.14 & 566 & med & 3 & 0.22 & 30 & $\mathrm{R} \mathrm{B}^{(\mathrm{d})}$ & 5.5 & 50 & 13.0 & 10.8 & 45 \\
\hline 9 & C.15 & 566 & med & $3^{(e)}$ & 1.84 & 30 & R3B $^{(\mathrm{f})}$ & 8.4 & 425 & 13.0 & 11.7 & 45 \\
\hline 10 & C.16 & 662 & med & $3^{(8)}$ & 1.94 & 60 & $\mathrm{R}^{3} \mathrm{~B}^{(\mathfrak{c})}$ & 5.8 & 140 & 13.1 & 12.1 & 45 \\
\hline 11 & C.17 & 827 & 0 & 3 & 1.76 & 30 & ${\mathrm{R} 3 \mathrm{~B}^{(\mathrm{c})}}$ & 130 & 5200 & 13.1 & 11.6 & 45 \\
\hline 12 & C.18 & 827 & 0 & 3 & 1.79 & 30 & S3 & 320 & 4900 & 13.2 & 11.6 & 45 \\
\hline 13 & C.19 & 662 & med & 3 & 2.04 & 30 & $R 4^{(\mathrm{h})}$ & 1.6 & 88 & 13.2 & 12.2 & 45 \\
\hline $14 \mathrm{~A}$ & C.20 & 827 & 350 & 3 & 1.88 & 30 & $\$ 4$ & 3.8 & 170 & 13.3 & 10.4 & 45 \\
\hline 14B & C.21 & 827 & 350 & 3 & 1.84 & 30 & 54 & 3.0 & 190 & 13.3 & 10.0 & 45 \\
\hline $14 \mathrm{C}$ & C.22 & 827 & 350 & 3 & 1.73 & 30 & S4 & 3.1 & 140 & 13.3 & 11.0 & 45 \\
\hline 14D & C.23 & 827 & 350 & 3 & 1.73 & 30 & S4 & 3.2 & 170 & 13.3 & 10.7 & 45 \\
\hline
\end{tabular}

(a) See Table 2.5 for descriptions of some of the column headings.

(b) $30 \mathrm{~mL}$ of THOREX per $1.5 \mathrm{~L}$ of PUREX is approximately the same ratio as 45,000 L THOREX per 2,100,000 L PUREX.

(c) $7.12 \mathrm{~mL} 19 \mathrm{M} \mathrm{NaOH}$ added.

(d) $16 \mathrm{~mL} 19 \mathrm{M} \mathrm{NaOH}$ added to vessel following Test 6.

(e) $23.8 \mathrm{~mL}$ conc. $\mathrm{HNO}_{3}$ added to $68.8 \mathrm{~mL}$ THOREX raising $\mathrm{H}^{+}$to $\sim 4 \underline{\mathrm{M}}$ and diluting other constituents.

(f) $27 \mathrm{~mL} 19 \mathrm{M} \mathrm{NaOH}$ added to vessel following Test 8 .

(g) THOREX diluted with deionized water to $50 \%$ of is original concentration.

(h) $12 \mathrm{~g} \mathrm{NaOH}$ pellets added. 
Table 2.9. Laboratory-Scale Tests of THOREX Added to Either Full-Compliment PUREX or Simplified PUREX ${ }^{(a)}$

\begin{tabular}{|c|c|c|c|c|c|c|c|c|c|c|c|c|}
\hline \multirow[b]{2}{*}{ Test } & \multirow[b]{2}{*}{ Figure } & \multirow{2}{*}{$\begin{array}{c}\text { Ar Gas Carrier } \\
\text { Flow Rate } \\
\text { mL/min }\end{array}$} & \multirow{2}{*}{$\begin{array}{l}\text { Stir } \\
\text { Rate } \\
\text { rpm }\end{array}$} & \multicolumn{3}{|c|}{ THOREX $^{(\mathbf{b})}$} & \multirow{2}{*}{$\begin{array}{l}\text { PUREX } \\
\text { Batch } \\
(1.5 \mathrm{~L}) \\
\end{array}$} & \multicolumn{2}{|c|}{ NO Gas } & \multicolumn{2}{|c|}{ pH } & \multirow[b]{2}{*}{$\begin{array}{l}\text { Temp } \\
{ }^{\circ} \mathrm{C}\end{array}$} \\
\hline & & & & Batch & $\begin{array}{c}\text { Addn Rate } \\
\mathrm{mL} / \mathrm{min}\end{array}$ & $\begin{array}{c}\text { Total } \mathrm{mL} \\
\text { Added }\end{array}$ & & $\begin{array}{c}\text { Total } \\
\text { mL }\end{array}$ & $\begin{array}{c}\text { Peak Rate } \\
\mu \mathrm{L} / \mathrm{min}\end{array}$ & Start & End & \\
\hline 15 & C.24 & 827 & 50 & 3 & 1.75 & 30 & s3 & 13 & 120 & 13.2 & 10.8 & 45 \\
\hline 16 & C.25 & 827 & 600 & 3 & 1.83 & 30 & $\mathrm{S3}^{(\mathrm{e})}$ & 5.6 & 400 & 13.3 & 12.3 & 45 \\
\hline $17 \mathrm{~A}$ & \begin{tabular}{l|} 
C.26 \\
\end{tabular} & 827 & 350 & 3 & 1.87 & 15 & S4 & 1.4 & 110 & 13.3 & 12.9 & 45 \\
\hline $17 \mathrm{~B}$ & C.27 & 827 & 350 & 3 & 1.96 & 15 & S4 & 0.80 & 60 & 13.3 & 12.9 & 45 \\
\hline $17 \mathrm{C}$ & C.28 & 827 & 350 & 3 & 1.83 & 15 & 54 & 0.77 & 60 & 13.3 & 12.9 & 45 \\
\hline 18 & $\begin{array}{ll}\text { C.29 } \\
\end{array}$ & 827 & 50 & 3 & 1.80 & 15 & $S 4^{(d)}$ & 1.9 & 40 & 13.3 & 12.9 & 45 \\
\hline 19 & C.30 & 827 & 350 & 3 & 1.89 & 30 & $S 4^{(\mathrm{e})}$ & 2.0 & 95 & 13.3 & 11.3 & 45 \\
\hline $20 \mathrm{~A}$ & \begin{tabular}{l|} 
C.31 \\
\end{tabular} & 827 & 350 & 3 & 1.74 & 30 & S4 & 0.63 & 30 & 13.3 & 11.1 & 22 \\
\hline $20 \mathrm{~B}$ & $\begin{array}{ll}\mathbf{C} .32 \\
\end{array}$ & 827 & 350 & 3 & 1.81 & 30 & S4 & 0.84 & 34 & 13.3 & 11.1 & 22 \\
\hline $21 \mathrm{~A}$ & $\begin{array}{ll}\text { C.33 } \\
\end{array}$ & 827 & 350 & 3 & 1.56 & 30 & S4 & 5.1 & 280 & 13.3 & 11.1 & 65 \\
\hline $21 B$ & \begin{tabular}{l|l|} 
C.34 \\
\end{tabular} & 827 & 350 & 3 & 1.71 & 30 & S4 & 5.8 & 320 & 13.3 & 11.0 & 65 \\
\hline 22 & $\begin{array}{ll}\text { C.36 } \\
\end{array}$ & 827 & 350 & 3 & 1.76 & 30 & $S 4^{(\mathrm{f})}$ & 0.85 & 43 & 13.26 & 13.25 & 45 \\
\hline
\end{tabular}

(a) See Table 2.5 for descriptions of some of the column headings.

(b) $30 \mathrm{~mL}$ of THOREX per 1.5 L of PUREX is approximately the same ratio as 45,000 L THOREX per 2,100,000 L PUREX.

(c) $7 \mathrm{~g} \mathrm{NaOH}$ pellets added to vessel following Test $7 \mathrm{~B}$.

(d) $8.6 \mathrm{~g} \mathrm{NaOH}$ pellets added to vessel following Test $17 \mathrm{~A}$.

(e) $0.19 \mathrm{M} \mathrm{Na} \mathrm{CO}_{3}$.

(f) $\mathrm{NaOH}$ was added to the reaction vessel in a separate line to keep the $\mathrm{pH}$ constant at the same time as the THOREX was added. 
Table 2.10. Large-Scale Tests of THOREX Added to Either Full-Compliment PUREX or Simplified PUREX(a)

\begin{tabular}{|c|c|c|c|c|c|c|c|c|c|c|c|c|}
\hline \multirow[b]{2}{*}{ Test } & \multirow[b]{2}{*}{ Figure } & \multirow{2}{*}{$\begin{array}{c}\text { Ar Gas Carrier } \\
\text { Flow Rate } \\
\mathrm{mL} / \mathrm{min}\end{array}$} & \multirow{2}{*}{$\begin{array}{l}\text { Stir } \\
\text { Rate } \\
\text { rpm } \\
\end{array}$} & \multicolumn{3}{|c|}{ THOREX $^{(b)}$} & \multirow[b]{2}{*}{$\begin{array}{c}\text { PUREX } \\
\text { Batch }(1.5 \mathrm{~L})\end{array}$} & \multicolumn{2}{|c|}{ NO Gas } & \multicolumn{2}{|c|}{ pH } & \multirow[b]{2}{*}{$\begin{array}{c}\text { Temp } \\
{ }^{\circ} \mathrm{C}\end{array}$} \\
\hline & & & & Batch & $\begin{array}{c}\text { Addn Rate } \\
\mathrm{mL} / \mathrm{min}\end{array}$ & $\begin{array}{c}\text { Total mL } \\
\text { Added }\end{array}$ & & $\begin{array}{c}\text { Total } \\
\text { mL }\end{array}$ & $\begin{array}{c}\text { Peak Rate } \\
\mu \mathrm{L} / \mathrm{min}\end{array}$ & Start & End & \\
\hline $23 \mathrm{~A}$ & C.40 & 827 & 350 & 3 & 1.86 & $321^{(c)}$ & 54 & 4.3 & 25 & 13.3 & 9.3 & 22 \\
\hline $23 B$ & C.41 & 827 & 350 & 3 & 1.86 & $292^{(d)}$ & S4 & 9.2 & 34 & 13.3 & 10.9 & 22 \\
\hline 24 & C.42 & 827 & 600 & $3^{(e)}$ & 1.86 & $290^{(f)}$ & $S 4^{(g)}$ & 5.1 & 58 & 13.2 & 10.7 & 23 \\
\hline
\end{tabular}

(a) See Table 2.5 for descriptions of some of the column headings.

(b) $300 \mathrm{~mL}$ of THOREX per $15 \mathrm{~L}$ of PUREX is approximately the same ratio as $45,000 \mathrm{~L}$ THOREX per 2,100,000 L PUREX.

(c) The intended amount of THOREX (300 mL) was inadvertently exceeded.

(d) The intended amount of THOREX (300 mL) was stopped slightly short due to a clogged line caused by solids that crystallized from solution.

(e) THOREX was diluted about $10 \%$ with deionized water to prevent solids from crystallizing from solution.

(f) The amount of "full strength" THOREX is somewhat uncertain because of the dilution noted in (e).

(g) $120 \mathrm{~g}$ of $\mathrm{NaOH}$ pellets were added to vessel following Test $23 \mathrm{~B}$. 
Secondly, the curve labelled "NO${ }_{X}$ " in Figure C.6 (Appendix C) actually represents the NO gas. Both curves, $\mathrm{NO}$ and $\mathrm{NO}_{\mathrm{X}}$, were included in this figure for illustrative purposes as described in Section 2.1.1.

The third point about the data in Figure C.6 (Appendix C) is that, at the time this test was run, it was assumed that the THOREX composition corresponded to the "Nominal Diluted" values listed in the fourth column of Table 2.2. This would correspond to a THOREX/PUREX ratio of $42 \mathrm{~mL}$ THOREX per $1.5 \mathrm{~L}$ PUREX. Had that been true, the amount of THOREX added in this test $(78 \mathrm{~mL})$ would have nearly doubled the representative amount. However, the as-analyzed concentrations of the major constituents in this batch of THOREX simulant were only about $60 \%$ of the expected values (Table 2.2). Therefore, $70 \mathrm{~mL}$ of this THOREX simulant was required to add the appropriate amounts of Th, $\mathrm{HNO}_{3}$, and other constituents. At the point where $70 \mathrm{~mL}$ of THOREX had been added in this test, the amount of NO generated was $0.82 \mathrm{~mL}$. This point is shown by Figure C.6 (Appendix C) to have occurred $175 \mathrm{~min}$. into the test.

There are a few other points to be made about the results from this first test: 1) Figure C.6 (Appendix C) shows no obvious effect of increasing the stir speed at $180 \mathrm{~min}$.; 2) the $\mathrm{NO} / \mathrm{NO}_{\mathrm{X}}$ concentrations returned to zero about an hour after the THOREX addition was stopped at $195 \mathrm{~min}$.. This slow return to zero was common to all the tests (much slower in some cases than others) and is discussed in detail in Section $2.3 ; 3$ ) Table 2.6 indicates that little $\mathrm{CO}_{2}$ was generated during this test. An error in setting up the computer for this run resulted in loss of the chromatograms containing the $\mathrm{CO}_{2}$ data. However, personal observations of the GC data "on-the-fly" indicated the presence of only a very little $\mathrm{CO}_{2}$ in this test; and 4) corrosion coupons were placed in the reaction vessel during this test as described in Section 3.1.1.

\section{Test 2}

Figure C.7 (Appendix C) and Table 2.6 show results from the second recirculation loop test, which used a lower ratio of loop-flow-rate to THOREX-addition-rate than Test 1. The main purpose of this test was to reduce that ratio to one that was more representative of anticipated full-scale conditions. Also in this test, a device for holding a pH probe was placed within the PUREX recirculation loop downstream from the " $T$ " where THOREX was introduced into the loop.

The most notable results from this second loop test were the rapid drop in $\mathrm{pH}$ within the recirculation loop and the observation of large volumes of bubbles within the loop. Some of the bubbles lodged within the $\mathrm{pH}$ probe holder and displaced the PUREX/THOREX slurry enough to uncover the sensing portion of the probe. To resubmerge the probe within the slurry, the gas bubbles had to be released from the holder every $5 \mathrm{~min}$. or so. This unexpected problem with the bubbles is thought not to have had more than a transient effect on the in-loop pH measurements. However, gas released from the $\mathrm{pH}$ probe holder obviously did not get swept into the gas analyzers and, therefore, was not included in the rates and amounts shown in Figure C.7 (Appendix C) and Table 2.6. The fraction of the gas that was lost through the $\mathrm{pH}$ probe holder is hard to judge, but may have been 10 to $30 \%$ of the total gas volume.

The volume of bubbles within the recirculation loop was much greater in Test 2 than in Test 1 , apparently because of the much lower ratio of loop-flow-rate to THOREX-addition-rate. This probably allowed more bubbles to accumulate because they were not being carried away by the loop flow as rapidly. A more important cause of the greater bubble volume in the second loop test was probably 
that the $\mathrm{pH}$ within the loop dropped to lower values. Although in-loop $\mathrm{pH}$ measurements were not made in the first test, the $\mathrm{pH}$ was unlikely to have dropped so low as that shown for Test 2 in Figure C.7 (Appendix C). Lower in-loop pH values in the second test are an expected result of the lower ratio of loop-flow-rate to THOREX-addition-rate simply because of the greater proportion of the acidic THOREX within the loop.

Four other features of the second loop test deserve mention. First, the second batch of THOREX was used, and the measured concentrations were close to the expected values (see Table 2.3). Second, the test was continued until more than double the full-scale ratio of $28 \mathrm{~mL}$ THOREX per L of PUREX (42 mL THOREX per 1.5 L PUREX) was added. At the point where $42 \mathrm{~mL}$ of THOREX had been added, $19 \mathrm{~mL}$ of $\mathrm{NO}$ and $18 \mathrm{~mL}$ of $\mathrm{CO}_{2}$ had been generated. Third, as more THOREX beyond $42 \mathrm{~mL}$ was added, the $\mathrm{pH}$ within the reaction vessel eventually dropped sharply to about 5 , which is far below the value that would be allowed in the full-scale case. The sharp rise in $\mathrm{NO}$ and $\mathrm{CO}_{2}$ generation rates about $100 \mathrm{~min}$. into the test may be associated with the $\mathrm{pH}$ drop, but the abrupt nature of the rise suggests that the irregular passage of gas bubbles from the loop into the vessel may also have been involved. Fourth, after the in-flow of THOREX was stopped, the NO concentration returned to near zero within about $30 \mathrm{~min}$., but the $\mathrm{CO}_{2}$ concentration remained high. Perhaps $\mathrm{CO}_{2}$ gas continued to slowly evolve from solution due to the low $\mathrm{pH}$.

\section{Fest 3}

Results from the first test where THOREX was added directly to PUREX are shown in Figure C.8 (Appendix C) and Table 2.6. The first batch of THOREX, which had only about $60 \%$ of the expected concentrations of $\mathrm{Th}, \mathrm{HNO}_{3}$, etc., was used. By the time $70 \mathrm{~mL}$ of this THOREX had been added, which is representative of the full-scale case, $3.8 \mathrm{~mL} \mathrm{NO}$ and $0.87 \mathrm{~mL} \mathrm{CO}$ had been generated. Again, as was described for Test 1 , the $\mathrm{NO}_{\mathrm{X}}$ curve is actually representative of the NO data. After the THOREX addition was stopped, the $\mathrm{CO}_{2}$ curve dropped rapidly to zero while the $\mathrm{NO}$ and $\mathrm{NO}_{\mathrm{X}}$ curves tailed off rather slowly. This is the reverse of what happened in Test 2 and probably reflects the very different final $\mathrm{pH}$ values in the two tests $(\sim 5$ in Test 2 and $\sim 11.6$ in Test 3 ).

\section{Test 4}

This test was run to evaluate the consequences of an accidental backflow of PUREX from Tank 8D-2 into the THOREX in Tank 8D-4. The potential for this to happen might exist if THOREX were pumped into a PUREX recirculation loop, such as was evaluated in Tests 1 and 2 . The potential might also exist if THOREX were pumped directly into Tank 8D-2 and if the end of the inlet pipe were below the surface of the slurry in the tank. If the inlet pipe were above the slurry surface, accidental backflow would suck only air, not PUREX slurry.

The test was run by placing one liter of undiluted THOREX (Table 2.3) in the reaction vessel and pumping PUREX into the vessel. The total amount of PUREX added was purely arbitrary since there was no specified amount of accidental backflow. Because of the high acidity of the THOREX (initially $0.8 \mathrm{M} \mathrm{HNO} 3$ ), large amounts of $\mathrm{NO}$ and $\mathrm{CO}_{2}$ were generated in this test as shown in Figure $\mathrm{C.9}$ (Appendix C) and Table 2.7. After stopping the PUREX addition, the generation rates of $\mathrm{NO}$ and $\mathrm{CO}_{2}$ dropped rapidly at first but thereafter tailed off extremely slowly. 


\section{Test 5}

This test [Table 2.7, Figure C.10 (Appendix C)] was a repeat of Test 4 except that it used diluted THOREX and was run at $25^{\circ} \mathrm{C}$ rather than $45^{\circ} \mathrm{C}$. The results from these two backflow tests were similar. Because of the method of data recording, as was described in the Section 2.1.1, the NO and $\mathrm{NO}_{\mathrm{X}}$ curves show that there was no $\mathrm{NO}_{2}$ present. Therefore, the generation rate of $\mathrm{NO}$ is actually represented by the $\mathrm{NO}_{\mathrm{X}}$ curve. Both curves are shown here, as they were in Figures C.6 and C.8 (Appendix C), for illustrative purposes.

Tests 6, 7A, and $7 B$

Results from these tests, which were run under similar conditions, are presented in Table 2.8 and Figures C.11 to C.13 (Appendix C). Test 6 used PUREX containing the full complement of constituents whereas Tests 7A and 7B used simplified PUREX. Slightly higher peak generation rates of NO, as well as higher total NO, were observed with the simplified PUREX (Tests 7A and 7B), but otherwise the results from all three tests were quite similar.

\section{Test 8}

The THOREX addition rate in this test (Figure C.14 in Appendix C) was nearly 10 times slower than in Tests 6; 7A and 7B, but the total amount of THOREX was the same. About the same amount of NO was generated as in Tests $6,7 \mathrm{~A}$, and $7 \mathrm{~B}$, but the peak generation rate was six to eight times lower in Test 8 because of the lower THOREX addition rate.

\section{Test 9}

The acidity of the THOREX used in this test was raised to $\sim 4 \underline{\mathrm{M}}$ by adding concentrated $\mathrm{HNO}_{3}$. This resulted in dilution of the other constituents to about two-thirds of their normal concentrations. However, the total $\mathrm{OH}^{-}$equivalent of this THOREX (i.e., the amount of $\mathrm{OH}^{-}$in the PUREX required to neutralize the acid in the THOREX and also to precipitate the Th, Fe, and other components in the THOREX as hydroxides) changed very little from the normal THOREX. The results in Table 2.8 and Figure C. 15 (Appendix C) show that the total NO increased by about 50\% compared to Tests 6 and 8 . Clearly, the higher acidity of Test 9 , compared to Tests 6 and 8, resulted in the production and decomposition of more $\mathrm{HNO}_{2}$.

\section{Test 10}

Rather than increasing the acidity of the THOREX as in Test 9, this test explored decreased acidity by using THOREX that had been diluted by deionized water to $50 \%$ of its nominal concentration. To compensate for the reduced concentrations, double the volume $(60 \mathrm{~mL})$ of THOREX was added so that the same total amount of active ingredients were involved. Table 2.8 and Figure C.16 (Appendix C) show that about the same total amount of NO was generated as in Tests 6 and 8 . The peak generation rate in Test 10 was about half that in Test 6 . Thus, diluting the THOREX in Test 10 had an effect similar to reducing the THOREX addition rate as in Test 8. 


\section{Tests 11 and 12}

These tests, one with full-compliment PUREX and one with simplified PUREX, were conducted with no stirring. Table 2.8 and Figures C.17 and C.18 (Appendix C) show that the total amount of NO increased by a factor of 24 to 46 compared with Tests 6 to 8 , which had medium stirring rates. Not only were the peak rates high in Tests 11 and 12 , but the return to zero was very slow. Turning on the stirrer after a time resulted in another peak in the NO generation rate and, thereafter, a more rapid return to zero, particularly in Figure C.18 (Appendix C). Test 12, with simplified PUREX, generated more NO than Test 11, which used full-compliment PUREX. The larger amount of NO with simplified PUREX, compared to full-compliment PUREX, is similar to the difference observed between Test 6 and Tests 7A and 7B.

\section{Test 13}

Table 2.8 and Figure C.19 (Appendix C) show the results of this test, which was the only test run with fourth-wash PUREX that contained the full compliment of components. Less than one-third as much NO was generated in Test 13 as in Tests 6 and 8, which used third-wash PUREX, even though Table 2.4 shows that the difference in $\mathrm{NO}_{2}^{-}$concentrations between third- and fourth-wash PUREX was a factor of only about two. Note, however, that the $\mathrm{pH}$ drop in Test 13 was less than in Tests 6 and 8 and also less than in Tests 14A to 14D, which used simplified PUREX.

\section{Tests 14A to 14D}

These four tests [Table 2.8, Figures C.20 to C.23 (Appendix C)] with simplified PUREX generated about twice as much $\mathrm{NO}$ as did Test 13 with full-compliment PUREX. The difference between Test 13 and Tests 14A to 14D may be related to the $\mathrm{pH}$ difference noted above. Perhaps the additional components, primarily solids, present in the full-compliment PUREX (Test 13) reacted with acid from the THOREX to prevent such a large change in $\mathrm{pH}$.

\section{Tests 15 and 16}

Results from these two tests, which were performed to investigate the effect of stirring rate, are shown in Table 2.9 and Figures C.24 and C.25 (Appendix C). The effect of stirring rate on total NO was small but the shapes of the curves were quite different. With slow stirring (Test 15), the total amount of NO was roughly double that generated with medium stirring (Tests 7A and 7B) but not nearly so much as with no stirring (Test 12). However, the peak rate in Test 15 was over three times lower (until the stirrer speed was increased) than in Tests 7A and 7B, and the return to zero was very slow. Increasing the stirrer speed (Figure C.24, Appendix C) after nearly $4 \mathrm{~h}$ caused a large immediate increase in the NO generation rate followed by a more normal rate of return to zero. The peak rate and total amount of NO generated during fast stirring [Test 16, Figure C.25 (Appendix C)] were about the same as with medium stirring (Tests 7A and 7B). However, the return to zero was faster in Test 16. Table 2.9 also shows that the final $\mathrm{pH}$ was higher with fast stirring (Test 16) than with slow or medium stirring (Tests 7A, 7B, or 15). This $\mathrm{pH}$ difference was unexpected and, without repeating the fast-stir test, it is hard to judge how much faith to place in this single pH measurement. 


\section{Tests 17A to 17C}

These tests [Table 2.9, Figures C.26 to C.28 (Appendix C)] were conducted to determine the effect of adding only half as much THOREX, which was intended to lower the $\mathrm{OH}^{-}$concentration only to $0.1 \mathrm{M}$ (pH 13.0). Clearly, halving the amount of THOREX reduced the amount of NO by more than a factor of two (compare Tests $17 \mathrm{~A}$ to $17 \mathrm{C}$ with Tests $7 \mathrm{~A}$ and $7 \mathrm{~B}$ ).

The difference in peak rate and total NO between Test 17A and Tests 17B and 17C apparently can be attributed to random differences. Examination of other replicate test results (7A and 7B, 14A to $14 \mathrm{D}, 20 \mathrm{~A}$ and $20 \mathrm{~B}$, and $21 \mathrm{~A}$ and $21 \mathrm{~B}$ ) indicates that the overall reproducibility between tests was approximately $\pm 0.5 \mathrm{~mL}$, almost independent of the total amount of $\mathrm{NO}$ generated.

\section{Test 18}

Table 2.9 and Figure C.29 (Appendix C) show that the effect of slow stirring on fourth-wash PUREX was about the same as on third-wash PUREX (Test 15). That is, there was a small increase in the amount of NO compared to similar tests with medium stirring (Tests $17 \mathrm{~A}$ to $17 \mathrm{C}$ ), and the return to zero was very slow.

\section{Test 19}

This test [Table 2.9, Figure C.30 (Appendix C)] was conducted to investigate the effect of a tenfold increase in $\mathrm{Na}_{2} \mathrm{CO}_{3}$ concentration. Compared to Tests $14 \mathrm{~A}$ to $14 \mathrm{D}$, the peak rate and total NO were somewhat smaller here. This result makes sense because some of the acid from the THOREX will have reacted with the increased $\mathrm{Na}_{2} \mathrm{CO}_{3}$ in Test 19 (see Equation 2.11 in Section 2.3), resulting in the formation of less $\mathrm{HNO}_{2}$ and its $\mathrm{NO}$ decomposition product.

Tests 20A to 21B

These tests [Table 2.9, Figures C.31 to C.34 (Appendix C)] were conducted, along with Tests 14A to 14D [Table 2.8, Figures C.20 to C.23 (Appendix C)], to investigate the temperature dependence of NO production during THOREX/PUREX mixing. An Arrhenius plot of all eight test results is shown in Figure C.35 (Appendix C). Calculated activation energies were $12.1 \mathrm{kcal} / \mathrm{mol} \mathrm{between} 22^{\circ} \mathrm{C}$ and $45^{\circ} \mathrm{C}$ and $5.4 \mathrm{kcal} / \mathrm{mol}$ between $45^{\circ} \mathrm{C}$ and $65^{\circ} \mathrm{C}$. The nonlinearity indicates that two or more processes with different temperature dependencies are involved.

\section{Test 22}

Table 2.9 and Figure C.36 (Appendix C) show results from simultaneous addition of THOREX and $5.4 \mathrm{M} \mathrm{NaOH}$ in separate lines to S4 PUREX. The relative addition rates of THOREX and NaOH were selected with the objective of maintaining a nearly constant $\mathrm{pH}$ in the reaction vessel. The start and end $\mathrm{pH}$ values cited in the figure indicate that this objective was accomplished. However, it is suspected that the $\mathrm{NaOH}$ got slightly ahead of the THOREX, despite the pH measurements to the contrary, because the NO generation rate started to decrease slightly just before the THOREX and NaOH pumps were turned off. This decrease in NO generation rate may indicate that the effective $\mathrm{pH}$ of the slurry was actually beginning to increase. The total amount of NO was only about one fourth the amount generated under conditions (Tests 14A to 14D) that were similar except for the simultaneous addition of $\mathrm{NaOH}$. 


\section{Other Laboratory-Scale Mixing Tests}

In an effort to understand the reason(s) for the rather slow tail-off in NO generation rates observed in many of the tests described above, two tests were conducted using pure $\mathrm{HNO}_{3}$ so that no solids would be generated. Figure C.37 (Appendix $\mathrm{C}$ ) shows results from adding pure $\mathrm{HNO}_{3}$ to pure $\mathrm{NaNO}_{2}$. No $\mathrm{pH}$ measurements were made. The starting $\mathrm{NaNO}_{2}$ solution would have had a nearneutral $\mathrm{pH}$, and addition of the $\mathrm{HNO}_{3}$ would have lowered the $\mathrm{pH}$ somewhat. However, most of the added $\mathrm{HNO}_{3}\left(0.0052\right.$ moles) would have reacted with a portion of the 0.12 moles of $\mathrm{NO}_{2}^{-}$, which was originally present, to form $\mathrm{HNO}_{2}$. Seventy milliliters ( 0.0031 moles) of $\mathrm{NO}$ gas was generated from decomposition of the $\mathrm{HNO}_{2}$. Thus, about $60 \%$ of the added $\mathrm{HNO}_{3}$ reacted to form $\mathrm{HNO}_{2}$ with subsequent decomposition to generate NO. This is a far higher percentage of $\mathrm{HNO}_{3}$ reacting with the $\mathrm{NO}_{2}^{-}$ than in the THOREX/PUREX mixing tests. In those tests, almost all of the $\mathrm{HNO}_{3}$ from the THOREX reacted with $\mathrm{OH}^{-}$from the PUREX and only a small percentage reacted with $\mathrm{NO}_{2}^{-}$from the PUREX. For example, $1.2 \%$ of the $\mathrm{HNO}_{3}$ in Tests 7A and $7 \mathrm{~B}$ reacted to form $\mathrm{NO}$ gas.

Figure C.38 (Appendix C) shows results from adding pure $\mathrm{HNO}_{3}$ to $\mathrm{S} 4 \mathrm{PUREX}$ in step-wise fashion and measuring the $\mathrm{pH}$ after each step. The first three steps were conducted one day and the last two steps the next day. With the exception of the first run on the second day, the total amount of NO in each step increased as the $\mathrm{pH}$ decreased. Figure C.39 (Appendix C) is an expansion of the data from Figure C.38 (Appendix C) between 240 and 330 min.; the small offset from zero near 300 min. in Figure C.38 (Appendix C) was subtracted from the data to produce Figure C.39 (Appendix C). This zero-correction allowed for better comparison of the NO tail-off with tests where THOREX was added to S4 PUREX (Figures C.31 to C.34 in Appendix C). Although the NO tail-off shown in Figure C.39 (Appendix C) was somewhat faster in this test where no solids were generated, it was still not as fast as in the performance checks (Figures C.2 to C.5 in Appendix C where NO gas was simply bubbled through the PUREX).

\subsubsection{Large-Scale Tests}

Large-scale tests were conducted with THOREX and PUREX volumes 10 times larger than in the Primary Tests described above, i.e., $300 \mathrm{~mL}$ of THOREX and $15 \mathrm{~L}$ of simplified fourth-wash PUREX $\left(0.20 \underline{\mathrm{M} \mathrm{NaOH}}, 0.077 \underline{\mathrm{M} \mathrm{NaNO}}{ }_{2}\right.$, and $\left.0.019 \underline{\mathrm{M} \mathrm{Na}} \mathrm{CO}_{3}\right)$. The reaction vessel was made of polyethylene and was $\sim 17 \mathrm{~L}$ in size, the same stirrer that was used in the Primary Tests was also used here, and the tests were conducted at ambient temperature. The test setup was the same as shown in Figure C.1 (Appendix C) minus the $\mathrm{GC}$, temperature controller, and $\mathrm{pH}$ probe inside the reaction vessel, i.e., the same setup as in Tests 6 to 21B except for size. The purpose of these tests was to help determine the scaling factor that should be used to extrapolate the results described in this report to the actual addition of THOREX from Tank 8D-4 into the PUREX in Tank 8D-2. Results from these large-scale tests are summarized in Table 2.10 and Figures C. 40 to C.42 (Appendix C). Descriptions of some of the column headings in Table 2.10 are listed in Table 2.5 (Section 2.2.1).

Test 23A

Table 2.10 and Figure C.40 (Appendix C) show results from the first large-scale test. The stir rate, which was the same as in most of the Primary Tests, was enough to create a slight vortex in the reaction vessel. Slightly more than the intended amount of THOREX was inadvertently added, which apparently caused the $\mathrm{pH}$ to drop more than was desired. 
The most notable feature of the data in Figure C. 40 (Appendix C), however, was the very slow return of the NO generation rate toward zero. The total amount of NO generated by the time the test was terminated was $\sim 6$ times the amount generated in Tests $20 \mathrm{~A}$ and $20 \mathrm{~B}$, which were conducted under similar conditions but employed 10 times less THOREX and PUREX.

\section{Test 23B}

This test [Table 2.10, Figure C.41 (Appendix C)] was essentially a repeat of Test 23A. However, it was allowed to continue longer; after the test was terminated, the zero setting on the $\mathrm{NO}_{\mathrm{X}}$ analyzer was checked to ensure that part of the reason for the persistent tail in the NO data was not caused by a zero shift of the analyzer. More than double the amount of NO was generated, compared to Test 23A, despite the slightly higher final $\mathrm{pH}$, which was due to the slightly smaller quantity of THOREX that was added. Only a small part of the additional NO can be attributed to the longer duration of the test that allowed more of the NO in the tail to be measured and included in the total. Apparently the different amounts of NO simply represent random variations between tests. The average amount of NO generated in Tests $23 \mathrm{~A}$ and $23 \mathrm{~B}(6.8 \mathrm{~mL})$ was $\sim 9$ times the average amount generated in Tests $20 \mathrm{~A}$ and $20 \mathrm{~B}(0.74 \mathrm{~mL})$, a difference approximately equal to the ten-fold difference in solution volumes.

\section{Test 24}

The conditions for this test were the same as for Tests 23A and 23B except that the stirring rate was faster, which resulted in a large vortex. Also, the end of the THOREX addition line was moved closed to the center of the reaction vessel such that it was in, or near, the vortex created by the fast stirring. Table 2.10 and Figure C.42 (Appendix C) show that the peak NO generation rate was higher and the NO tail-off was much faster, but the total amount of NO was in the range of Tests 23A and 23B. The dip in the curve happened when the THOREX was inadvertently drawn down below the level of the pump intake line in the supply reservoir. This appears not to have had much effect on the test results, particularly not in the rate of NO tail-off. Clearly, the faster tail-off rate was caused by the faster stirring rate.

\subsubsection{Other Mixing Tests}

A possible alternative to direct addition of THOREX from Tank 8D-4 to the PUREX in Tank 8D-2 would be to neutralize the THOREX prior to transferring it into Tank 8D-2. Bray and Wise (1986) recommended against this alternative because a sticky, viscous precipitate formed when $19 \mathrm{M} \mathrm{NaOH}$ was added to THOREX. They believed that this precipitate could not be easily broken up to the point where it would form a pumpable slurry. To explore the prior neutralization alternative further, it was decided to perform a few simple THOREX/NaOH mixing experiments using a variety of $\mathrm{NaOH}$ concentrations. These experiments were performed using "dilute" THOREX equivalent to $59,000 \mathrm{~L}$ in Tank 8D-4 (second THOREX batch; see Table 2.3 for undiluted composition).

Several simple mixing experiments were performed where $\mathrm{NaOH}$ was mixed in a beaker with the dilute THOREX in the ratio of 8.9 moles of $\mathrm{NaOH}$ per liter of THOREX. This is the approximate amount of $\mathrm{NaOH}$ needed to neutralize the $\mathrm{HNO}_{3}$, precipitate the $\mathrm{Th}, \mathrm{Fe}$, and $\mathrm{Cr}$ as hydroxides, and complex with the Al. The $\mathrm{NaOH}$ concentrations varied from one to 19 moles/liter. Sometimes the THOREX was added to the $\mathrm{NaOH}$ solution, but more often $\mathrm{NaOH}$ was added to the THOREX. The mixing order seemed not to make much difference. 
With $\mathrm{NaOH}$ concentrations of 1 to $5 \underline{\mathrm{M}}$, readily pumpable slurries were formed. Rheology and particle-size-distribution measurements were performed on two of these slurries; the results are summarized in the two following subsections.

The highest $\mathrm{NaOH}$ concentration tried was $19 \underline{\mathrm{M}}$. When this was combined with THOREX with no stirring, a viscous precipitate formed that tended to stick to the container surfaces, in agreement with the observations of Bray and Wise (1986). However, it was possible to use vigorous prodding and stirring to break up this sticky precipitate to the point where it appeared to be a pumpable slurry, albeit a stiff one because of the high solids/liquid ratio. When the $19 \mathrm{M} \mathrm{NaOH}$ and THOREX were combined and stirred vigorously at the same time, a seemingly pumpable slurry was produced to begin with.

No matter what $\mathrm{NaOH}$ concentration was used, combining and simultaneous vigorous stirring, as opposed to combining first and then stirring, gave better results in terms of producing a readily pumpable slurry. Combining with no stirring produced a gelatinous precipitate that took considerable effort to break up into a pumpable form. The more concentrated the $\mathrm{NaOH}$, the more important it became to combine and stir at the same time.

In another experiment shown schematically in Figure C.43 (Appendix C), $1 \underline{\mathrm{M}} \mathrm{NaOH}$ was pumped at $6.5 \mathrm{~mL} / \mathrm{min}$ through $1 / 16 \mathrm{in}$. ID Tygon tubing while diluted THOREX was pumped at $0.7 \mathrm{~mL} / \mathrm{min}$ into a "T" in the line. This ratio of THOREX to $\mathrm{NaOH}$ was about the same as in the THOREX/NaOH mixing tests described above. The Tygon tubing downstream from the " $T$ " extended into an inverted graduated cylinder that was nearly full of water. Any gas bubbles coming through the Tygon tubing would have escaped to the vapor space in the graduated cylinder and allowed the volume of gas generated by the mixing to be measured to within approximately $\pm 0.1 \mathrm{~mL}$. The precipitate, which formed immediately inside the " $T$," could be seen passing readily through the Tygon tubing downstream from the " $T$ " with no tendency to stick to the tubing. After exiting the Tygon tubing, the precipitate piled up in the bottom of the beaker and could be readily broken up by gentle stirring. This experiment was continued for about an hour during which time $\sim 45 \mathrm{~mL}$ of THOREX was combined with $\sim 400 \mathrm{~mL}$

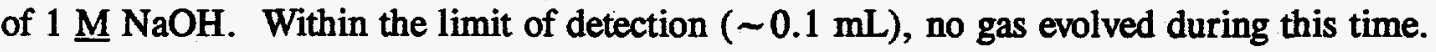

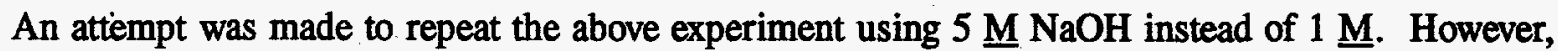
the precipitate that formed in the " $T$ " could not be pumped. Either the Tygon tubing came loose from the stainless steel "T," or the peristaltic pumps stalled.

In one last experiment, a previously-prepared mixture of diluted THOREX plus $1 \mathrm{M} \mathrm{NaOH}$ (same ratio as above) was pumped at $1.3 \mathrm{~mL} / \mathrm{min}$ into a beaker containing an inverted graduated cylinder filled with second-wash PUREX, (a) using an arrangement similar to that shown in Figure C.43 (Appendix C). The experiment was continued for $20 \mathrm{~min}$. during which time no gas collected in the inverted cylinder. Again, the minimum detectable amount of gas was $\sim 0.1 \mathrm{~mL}$.

(a) This PUREX had been washed only twice. Therefore, its $\mathrm{NO}_{2}^{-}$concentration was expected to be about three times higher than that listed for the 3rd-wash supernate in Table 2.4 . 


\section{Rheology Results}

Measurements were made on two slurries produced by mixing dilute THOREX with $1 \underline{\mathrm{M}} \mathrm{NaOH}$ (designated NT-1) and with $5 \underline{\mathrm{M} ~ N a O H}$ (designated NT-5). Both slurries were determined to be readily pumpable through 2 - or 3-in.-diameter pipes. Critical flow velocities necessary to ensure the particles remained in suspension were calculated to be $2.3 \mathrm{ft} / \mathrm{s}$ or less for NT-5 at $25^{\circ}$ to $65^{\circ} \mathrm{C}$. Even lower critical flow velocities would apply to the NT-1 slurry. Details of the rheology measurements are described in Appendix A.

\section{Particle-Size Distribution}

Measurements were made on the same two slurries used for the rheology measurements, NT-1 and NT-5. The Brinkman particle-size analyzer used for these measurements was set to cover the size range 0.5 to $150 \mu \mathrm{m}$.

Particle-size distribution results can be represented either on the basis of the total number of particles or on the basis of the total volume of particles. The mean particle diameters listed in Table 2.11 show that there is a big difference between the particle number and particle volume basis of representation. This difference occurs because most distributions, including the two shown here, include a very large number of very small particles that brings the average size down when particle numbers are used as the basis for averaging. However, the total volume of these small particles is insignificant when compared to the total volume of all the particles. Therefore, the particle-size distributions based on volume are probably most useful.

There is some evidence that many of the particles smaller than $\sim 3 \mu \mathrm{m}$ detected by the Brinkman instrument are erroneous. However, even if this were true, it has almost no effect on the total volume of particles or on the mean diameter based on the volume of particles. This is another reason for putting more faith in the volume-based distribution. Details of the particle-size distribution measurements are described in Appendix B.

\subsection{Discussion}

The major results of the THOREX/PUREX mixing studies can be summarized as follows:

1. Small amounts of $\mathrm{CO}_{2}$ and $\mathrm{NO}$ gases were generated; no other gases were detected. Because the amounts of $\mathrm{CO}_{2}$ were small and inconsequential to the process, analysis of $\mathrm{CO}_{2}$ was discontinued after the first five tests.

Table 2.11. Mean Particle Diameters Based on Number or Volume of Particles

\begin{tabular}{|c|c|c|}
\hline Test & Mean Diameter, Number $(\mu \mathrm{m})$ & Mean Diameter, Volume $(\mu \mathrm{m})$ \\
\hline NT-1 & 2.3 & 77 \\
\hline NT-5 & 2.0 & 95 \\
\hline
\end{tabular}


2. During initial testing, a comparison was made between the amount of NO that was generated when THOREX was added directly to the reaction vessel with the amount that was generated when the PUREX was pumped through a recirculation loop and THOREX was added to the loop. Results from the two loop tests varied considerably. With a high ratio of loop-flow-rate to THOREXaddition rate, the amount of NO was nearly 5 times smaller than when THOREX was added directly to the reaction vessel. With a low ratio of loop-flow-rate to THOREX-addition rate, the amount of NO was 5 times larger than when THOREX was added directly to the reaction vessel.

3. Only a small fraction of the $\mathrm{NO}_{2}^{-}$in the PUREX was converted to NO gas during THOREX addition. For example, the amounts of NO generated in Tests 6 and 8 represent the conversion of $0.072 \%$ of the $\mathrm{NO}_{2}^{-}$in the full-compliment, third-wash, PUREX to NO gas. In Test 13, $0.066 \%$ of the $\mathrm{NO}_{2}^{-}$in the full-compliment, fourth-wash, PUREX was converted to NO gas. Thus, about the same fraction of $\mathrm{NO}_{2}^{-}$was converted to $\mathrm{NO}$ gas with both third-wash and fourth-wash PUREX batches despite the different initial concentrations of $\mathrm{NO}_{2}^{-}$.

4. Somewhat more NO gas was generated in tests using simplified PUREX compared to those using full-compliment PUREX. Thus, the average of Tests 7A and 7B represent the conversion of $0.091 \%$ of the $\mathrm{NO}_{2}^{-}$in the simplified, third-wash, PUREX to NO gas. In Tests 14A to 14D, an average of $0.13 \%$ of the $\mathrm{NO}_{2}^{-}$in the simplified, fourth-wash, PUREX was converted to NO gas.

5. The activation energy for NO production between $22^{\circ} \mathrm{C}$ and $45^{\circ} \mathrm{C}$ was determined to be $12.1 \mathrm{kcal} / \mathrm{mol}$; between $45^{\circ} \mathrm{C}$ and $65^{\circ} \mathrm{C}$ it was $5.4 \mathrm{kcal} / \mathrm{mol}$. The nonlinearity indicates that two or more processes with different temperature dependencies were involved.

6. Different stirring rates had little effect on the total amounts of NO generated, but the NO generation tail-off was very dependent on stirring rate (much slower at slow stirring rates). However, when the stirring was stopped, the amount of NO generated was very much greater. Thus, $1.7 \%$ of the $\mathrm{NO}_{2}^{-}$in the full-compliment, third-wash, PUREX (Test 11) was converted to NO gas and $4.2 \%$ of the $\mathrm{NO}_{2}^{-}$in the simplified, third-wash, PUREX (Test 12) was converted to NO gas.

7. The total amount of NO that was generated was nearly independent of THOREX addition rate.

8. When the acidity of the THOREX was increased $\sim 5$ times, the amount of NO increased $\sim 50 \%$. However, no effect on the amount of NO was observed when all constituents of the THOREX, including acidity, were diluted to $50 \%$ of their original concentrations.

9. In the event of an accidental reversal of flow where PUREX would fiow out of Tank 8D-2 into the THOREX in Tank 8D-4, tests conducted here indicated that the generation rate and total amount of NO could be much higher (perhaps a factor of 10 although a direct comparison cannot be made) than in the normal flow direction, THOREX into Tank 8D-2.

10. Tests conducted with 10-times larger waste volumes produced 6 to 12 times more NO gas. Thus, over this very limited volume range, these data indicate that the amount of NO that is generated may scale in direct proportion to the volume of waste involved in the mixing. It is not known whether this scaling factor can be extrapolated to the size of the actual tanks at West Valley. 
11. In all cases, it took anywhere from several minutes to a few hours after the THOREX addition was stopped for the NO gas generation rate to tail off to zero. Testing performed to date has not been able to identify a specific reason for this result.

Some of these observations are readily explained while, in other cases, the chemistry and kinetics are imperfectly understood, as indicated by the following discussion.

The major chemical reactions involved with mixing the acidic THOREX with the alkaline PUREX are summarized by Equations (2.5) to (2.12).

$$
\begin{aligned}
& \mathrm{HNO}_{3}(\mathrm{aq})+\mathrm{NaOH}(\mathrm{aq}) \rightarrow \mathrm{NaNO}_{3}(\mathrm{aq})+\mathrm{H}_{2} \mathrm{O} \\
& \mathrm{Th}\left(\mathrm{NO}_{3}\right)_{4}(\mathrm{aq})+4 \mathrm{NaOH}(\mathrm{aq}) \rightarrow \mathrm{Th}(\mathrm{OH})_{4}(\mathrm{~s})+3 \mathrm{NaNO}_{3}(\mathrm{aq}) \\
& \mathrm{Fe}\left(\mathrm{NO}_{3}\right)_{3}(\mathrm{aq})+3 \mathrm{NaOH}(\mathrm{aq}) \rightarrow \mathrm{Fe}(\mathrm{OH})_{3}(\mathrm{~s})+3 \mathrm{NaNO}_{3}(\mathrm{aq}) \\
& \mathrm{Cr}\left(\mathrm{NO}_{3}\right)_{3}(\mathrm{aq})+3 \mathrm{NaOH}(\mathrm{aq}) \rightarrow \mathrm{Cr}(\mathrm{OH})_{3}(\mathrm{~s})+3 \mathrm{NaNO}_{3}(\mathrm{aq}) \\
& \mathrm{Ni}\left(\mathrm{NO}_{3}\right)_{2}(\mathrm{aq})+2 \mathrm{NaOH}(\mathrm{aq}) \rightarrow \mathrm{Ni}(\mathrm{OH})_{2}(\mathrm{~s})+2 \mathrm{NaNO}_{3}(\mathrm{aq}) \\
& \mathrm{Al}\left(\mathrm{NO}_{3}\right)_{3}(\mathrm{aq})+4 \mathrm{NaOH}(\mathrm{aq}) \rightarrow \mathrm{NaAl}(\mathrm{OH})_{4}(\mathrm{aq})+3 \mathrm{NaNO}_{3}(\mathrm{aq}) \\
& 2 \mathrm{HNO}_{3}(\mathrm{aq})+\mathrm{Na}_{2} \mathrm{CO}_{3}(\mathrm{aq}) \rightarrow \mathrm{CO}_{2}(\mathrm{~g})+2 \mathrm{NaNO}_{3}(\mathrm{aq})+\mathrm{H}_{2} \mathrm{O} \\
& \mathrm{HNO}_{3}(\mathrm{aq})+\mathrm{NaNO}_{2}(\mathrm{aq}) \rightarrow \mathrm{NaNO}_{3}(\mathrm{aq})+\mathrm{HNO}_{2}(\mathrm{aq})
\end{aligned}
$$

In all cases where the component is listed as (aq), the aqueous species are actually ionic with the exception of $\mathrm{HNO}_{2}$, which is one of the products in Equation (2.12). $\mathrm{HNO}_{2}$ is a weak acid with an ionization coefficient of $6.0 \times 10^{-4}$ at $30^{\circ} \mathrm{C}$ (Yost and Russell 1944).

In the mixing tests, the relative amounts of THOREX and PUREX were such that the final pH of the mixture was generally 10 or higher. Under these alkaline conditions, the acidic THOREX is neutralized [Equation (2.5)] and most of the constituents are precipitated from solution as hydroxides [Equations (2.6 to 2.9)], forming a slurry. At these high $\mathrm{pH}$ values, the aluminum probably remains in solution as a hydroxide complex as indicated by Equation (2.10). As indicated by Result 1 above, the production of $\mathrm{CO}_{2}$ gas, which is represented by Equation (2.11), is of little consequence. 
Equation (2.12) shows $\mathrm{HNO}_{2}$ as a reaction product. Under well stirred equilibrium conditions, molecular $\mathrm{HNO}_{2}$ would not exist because it would be neutralized by the excess hydroxide. However, it obviously does form because $\mathrm{HNO}_{2}$ is the source of $\mathrm{NO}$ gas observed in these mixing tests. Apparently, localized acidic conditions exist at the point where THOREX enters the PUREX thereby allowing $\mathrm{HNO}_{2}$ to form according to Equation (2.12) and decompose according to Equation (2.13).

$$
3 \mathrm{HNO}_{2}(\mathrm{aq}) \rightleftarrows \mathrm{H}^{+}+\mathrm{NO}_{3}^{-}+2 \mathrm{NO}(\mathrm{g})+\mathrm{H}_{2} \mathrm{O}
$$

When THOREX is added to PUREX, there is competition for reaction with the $\mathrm{HNO}_{3}$ between Equations (2.5), (2.11), and (2.12). It is clear that Equation (2.5) is favored because so little NO (from the decomposition of $\mathrm{HNO}_{2}$ ) and $\mathrm{CO}_{2}$ gases are formed.

The kinetics and equilibrium constant for Equation (2.13) are given by Equations (2.14) and (2.15), respectively (Yost and Russell 1944), where the concentrations are expressed in moles/L, the pressure, $\mathbf{P}_{\text {NO }}$, in atmospheres, and the time in minutes. Values for the rate and equilibrium constants as functions of temperature are plotted in Figures C.44 and C.45 (Appendix C).

$$
\begin{aligned}
& \frac{-\mathrm{d}\left(\mathrm{HNO}_{2}\right)}{\mathrm{dt}}=\frac{\mathrm{k}\left(\mathrm{HNO}_{2}\right)^{4}}{\left(\mathrm{P}_{\mathrm{NO}}\right)^{2}} \\
& K=\frac{\left(\mathrm{H}^{+}\right)\left(\mathrm{NO}_{3}^{-}\right)\left(\mathrm{P}_{\mathrm{NO}}\right)^{2}}{\left(\mathrm{HNO}_{2}\right)^{3}}
\end{aligned}
$$

It would be possible to calculate the generation rate of NO gas during and after THOREX/PUREX mixing if the process were controlled entirely by the partitioning between Equations (2.5), (2.11), and (2.12) together with the decomposition of $\mathrm{HNO}_{2}$ according to Equations (2.13), (2.14), and (2.15). In fact, the calculation would be simple if the partition coefficients for Equations (2.5), (2.11), and (2.12) were known. However, the situation is complicated by two things. First, and most important, the concentration of $\mathrm{HNO}_{2}$ in the alkaline THOREX/PUREX mixture should be extremely small. That is, there should be essentially no $\mathrm{HNO}_{2}$ left to decompose into $\mathrm{NO}$ gas once a homogeneous mixture has been achieved, a process that should require no more than a minute or two under the stirring conditions used in these tests. Second, the proton that is generated as part of Equation (2.13) has the potential to react with excess $\mathrm{NO}_{2}^{-}$to generate more $\mathrm{HNO}_{2}$ which, in turn, can decompose to produce more NO gas. This second mechanism has the potential to contribute to the tail-off in NO generation rates that was a common feature of the experimental mixing results. 
An approximate decomposition rate of $\mathrm{HNO}_{2}$ in the absence of these two complicating factors can be obtained from a very simple calculation. The instantaneous rate of decomposition of $\mathrm{HNO}_{2}$ in the THOREX/PUREX mixtures can be approximated by substituting appropriate values into Equation (2.14) based on experimentally observed parameters.

- The concentration of $\mathrm{NO}_{2}^{-}$in third-wash PUREX is $\sim 0.23 \underline{\mathrm{M}}$. Less than $0.1 \%$ of that is converted to $\mathrm{NO}$ gas (Item 3 above). A reasonable maximum concentration to assume for $\mathrm{HNO}_{2}$, therefore, might be $2 \times 10^{-4} \underline{\mathrm{M}}$.

- Concentrations of NO gas in the vapor space of the reaction vessel were commonly on the order of $100 \mathrm{ppm}$. Therefore, assume a pressure of $10^{-4} \mathrm{~atm}$.

- The rate constant at $45^{\circ} \mathrm{C}$ is about $1000 \mathrm{~L}^{3} \cdot \mathrm{atm}^{2} /\left(\right.$ moles $\left.{ }^{3} \cdot \mathrm{min}\right)$.

- Using these values in Equation (2.14) gives an instantaneous decomposition rate of $1.6 \times 10^{-4} \mathrm{~mol} /(\mathrm{L} \cdot \mathrm{min})$.

At this rate of reaction, it would take just over one minute for all of the $\mathrm{HNO}_{2}$ to decompose. However, by the time the $\mathrm{HNO}_{2}$ concentration is halved, the decomposition rate would be cut by a factor of 16, assuming no change in NO partial pressure. Thus, it is easy to visualize a tail-off in NO generation rate that extends over $30 \mathrm{~min}$., which is the approximate time period observed in many of the tests. However, for this mechanism to operate requires the persistence of molecular $\mathrm{HNO}_{2}$ in a high $\mathrm{pH}$ solution, which is an unreasonable supposition.

As was noted in Section 2.2.1, a few tests were performed with the objective of explaining the cause for the slow tail-off in NO generation rates. The relevant observations are reiterated here.

1. The tail-off was very strongly influenced by stirring rate. Slow stirring, or no stirring, resulted in a slow tail-off (Figures C.17, C.18, C.24 and C.29 in Appendix C).

2. When pure $\mathrm{HNO}_{3}$ was added to pure $\mathrm{NaNO}_{2}$ (Figure C.37 in Appendix C), there was a very slow tail-off. In this test, the $\mathrm{pH}$ remained low because there was no hydroxide present. Therefore, molecular $\mathrm{HNO}_{2}$ would be expected to persist and decompose according to Equations (2.13) to (2.15). This is in contrast to the THOREX/PUREX mixing tests where the pH remained high and molecular $\mathrm{HNO}_{2}$ would not be expected to persist.

3. In the high $\mathrm{pH}$ THOREX/PUREX mixtures where $\mathrm{HNO}_{2}$ would not persist, it would be only in the localizied low pH region near the THOREX entry point where $\mathrm{HNO}_{2}$ would exist and could decompose according to Equation (2.13). It was thought that the NO gas generated by this localized decomposition of $\mathrm{HNO}_{2}$ might dissolve in the mixture and then slowly evolve from solution into the vapor space. To evaluate this possibility, low concentrations of NO gas were bubbled through both full-compliment and simplified PUREX. However, Figures C.2 to C.5 (Appendix C) show that the NO tail-off was fast after NO was eliminated from the incoming gas stream. Thus, NO dissolution followed by slow evolution did not appear to offer the sought-for explanation for the 
slow NO tail-off. However, in retrospect, the gas bubbles in these tests were large, and NO was only a small percentage of the gas in the bubbles. As a result, the mixtures may never have become truly saturated with dissolved NO gas. Therefore, the possibility that the slow NO tail-off might be caused by the slow evolution of dissolved NO gas from solution has not been entirely discounted.

4. It was felt that the solids present in the THOREX/PUREX mixtures might play a role in the slow NO tail-off. For example, very small bubbles of NO gas might adhere to solid particles in the slurry where they would be slow to dislodge and escape into the vapor space. This mechanism could also explain the dependence of the NO tail-off on stirring rate (faster stirring would dislodge the bubbles from the solids faster). To assess the effect of solids, a test (Figures C.38 and C.39 in Appendix C) was run in which pure $\mathrm{HNO}_{3}$ was added to S4 PUREX so that no solids were generated. Figures C.38 and C.39 (Appendix C) show that the NO tail-off was somewhat faster than in tests that included solids, but not nearly so fast as when NO gas was simply bubbled through either full-compliment or simplified PUREX (Figures C.2 to C.5 in Appendix C). Therefore, the results presented in Figures C.38 and C.39 (Appendix C) show that the presence of solids is also not the complete explanation for the slow tail-off in the NO gas generation rates.

In summary, the slow tail-off in NO generation rates after the THOREX addition was stopped has at least four possible contributing mechanisms: 1) the slow decomposition of $\mathrm{HNO}_{2}$ given by kinetic Equation $(2.14)$; 2) the reaction of the proton from Equation $(2.13)$ to produce more $\mathrm{HNO}_{2}$; 3) attachment of small bubbles of NO gas to solids and their subsequent slow release; and 4) slow evolution of dissolved NO gas from solution. All four mechanisms may operate, thus making the phenomenon very difficult to model with any confidence. Because of the strong dependence of the NO tail-off on stirring rate, it seems clear that there must be more involved than the strictly chemical mechanisms given in 1 and 2 , above. The stirring rate effect strongly suggests that there is some dependence on physical mechanisms such as 3 and 4 , above.

Although the slow tail-off in NO generation rates is of academic interest, it may be relatively unimportant from an operations standpoint. Even though the tail-off was strongly dependent on stirring rate, the total amount of NO that was generated in the tests described here was nearly independent of stirring rate as long as the stirring was not stopped entirely. Thus, the total amount of NO that was generated in these tests, which seems to be the more important parameter, appears not to be very dependent on the tail-off. 


\subsection{Supplemental THOREX/PUREX Mixing Tests}

Following completion of the mixing tests described in Section 2.0, WVNS requested additional tests, which are described in Table 3.1. The motivations for the additional tests were:

- Recent analyses of the wastes in Tanks 8D-4 and 8D-2 indicated that the acidity of the THOREX was less than suggested by historical records, as was the nitrite concentration of the PUREX.

- To maintain pitting corrosion control during THOREX addition, the $\mathrm{NO}_{2}^{-} / \mathrm{NO}_{3}^{-}$ratio in Tank 8D-2 must be kept above a minimum value. Compensation for the addition of $\mathrm{NO}_{\mathbf{3}}^{-}$, which is a major component of the THOREX, requires the simultaneous or periodic addition of $\mathrm{NaNO}_{2}$ during THOREX addition.

- There were also some minor adjustments to the relative volumes of Tanks 8D-4 and 8D-2. compared to the values assumed for the testing described in Section 2.0.

The test conditions listed in Table 3.1 were designed to explore the effect that these differences would have on the amount of NO gas produced during the transfer of THOREX into Tank 8D-2.

\subsection{Experimental}

\subsubsection{Apparatus}

In the period between the testing described in Section 2.0 and before the supplemental testing described in this section, all the equipment had been dispersed to other projects or confined by temporary closure of the building for safety and operational upgrading. Therefore, the entire experimental setup had to be reassembled using mostly different equipment that was acquired by purchasing, borrowing, or fabrication.

The new equipment setup was the same as shown schematically in Figure C.1 (Appendix C) with the following exceptions:

- There was no gas chromatograph and associated computer; the reaction vessel contained no corrosion coupons, $\mathrm{pH}$ probe, or thermocouple; i.e., the configuration was the same as it was following the first five runs as described in Section 2.1.1.

- A second peristaltic pump was used to allow the simultaneous addition of $\mathrm{NaOH}$ during Batch \#1 as described in Table 3.1.

- Because the earlier tests showed that NO was the only gas produced, aside from a little $\mathrm{CO}_{2}$, the $\mathrm{NO}_{\mathrm{X}}$ analyzer was set up to analyze only $\mathrm{NO}$, rather than both $\mathrm{NO}$ and $\mathrm{NO}_{2}$, and it was programmed to analyze the NO concentration at 10 second intervals. 
Table 3.1. Test Conditions Requested by WVNS for Supplemental Runs (a,b)

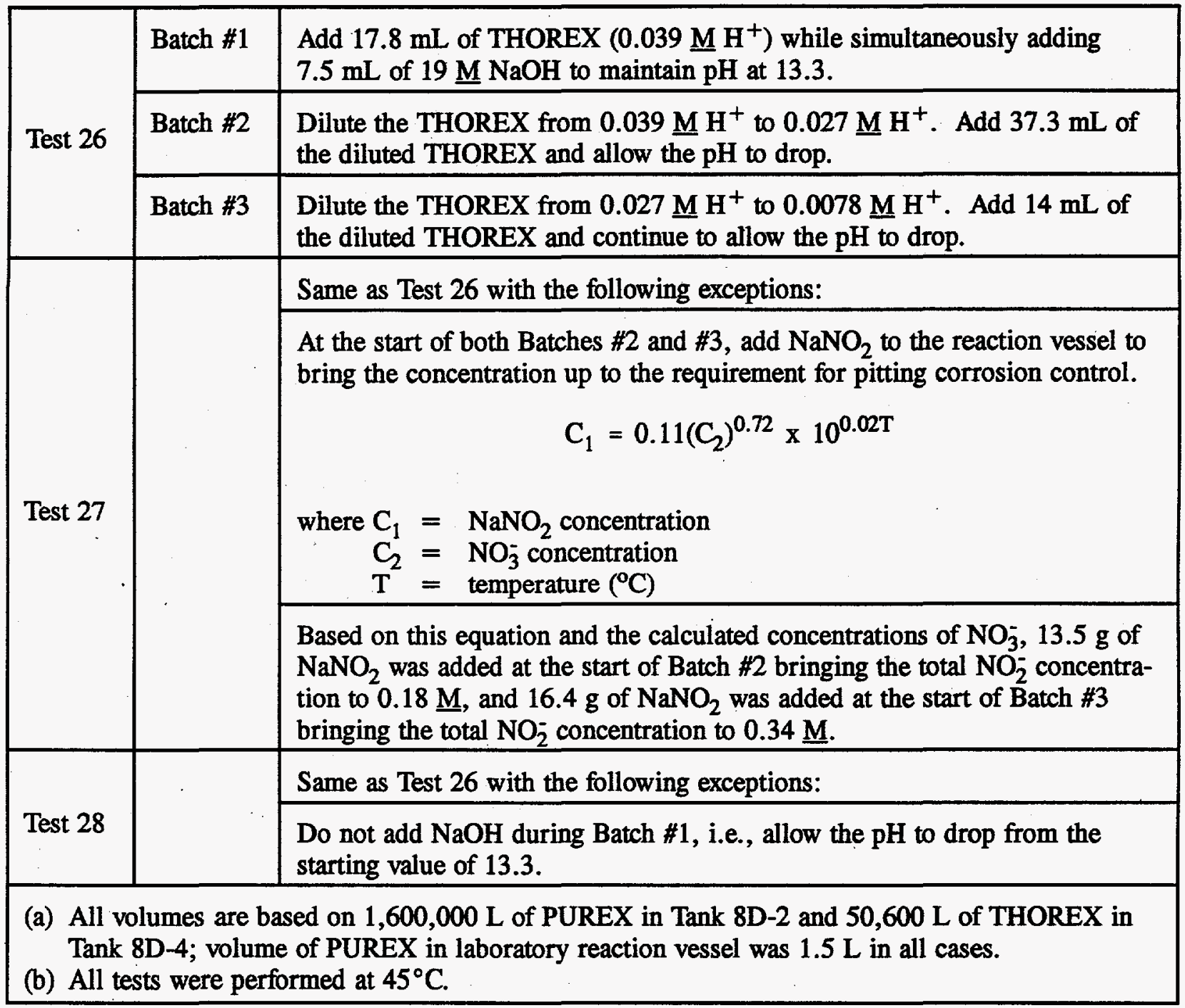

\subsubsection{Test Solutions}

\section{THOREX}

The THOREX used in these tests had the same nominal composition listed in Table 2.1 except that it was diluted with deionized water by a factor of $11.1 / 9.1$ so that the total $\mathrm{NO}_{3}^{-}$concentration was reduced from $11.1 \underline{\mathrm{M}}$ to $9.1 \underline{\mathrm{M}}$, and the final $\mathrm{H}^{+}$concentration was reduced to $0.039 \underline{\mathrm{M}}$ (see Table 3.2). 
Table 3.2. Nominal THOREX Composition for Supplemental Mixing Tests

\begin{tabular}{|c|c|}
\hline Component & $\begin{array}{c}\text { Concentration } \\
(\mathrm{mol} / \mathrm{L})\end{array}$ \\
\hline $\mathrm{Th}$ & 1.21 \\
\hline $\mathrm{Fe}$ & 0.72 \\
\hline Al & 0.40 \\
\hline $\mathrm{Cr}$ & 0.16 \\
\hline B & 0.16 \\
\hline $\mathrm{Ni}$ & 0.090 \\
\hline $\mathrm{Na}$ & 0.15 \\
\hline K & 0.051 \\
\hline $\mathrm{Mn}$ & 0.012 \\
\hline $\mathrm{Ba}$ & 0.0024 \\
\hline $\mathrm{NO}_{3}$ & 9.1 \\
\hline $\mathrm{SO}_{4}$ & 0.0026 \\
\hline $\mathrm{Cl}$ & 0.0017 \\
\hline $\mathrm{H}^{+}$ & 0.039 \\
\hline
\end{tabular}

\section{PUREX}

The nominal PUREX composition used in these tests was similar to the simplified batch "S4" described in Section 2.1.2 except that the $\mathrm{NaNO}_{2}$ and $\mathrm{Na}_{2} \mathrm{CO}_{3}$ concentrations were reduced somewhat. Thus, the simplified PUREX composition used in these supplemental tests was $0.20 \mathrm{M} \mathrm{NaOH}$, $0.049 \underline{\mathrm{M}} \mathrm{NaNO}_{2}$, and $0.005 \underline{\mathrm{M} \mathrm{Na}} \mathrm{CO}_{3}$.

\subsubsection{Calibrations and Performance Checks}

The $\mathrm{NO}_{\mathrm{X}}$ analyzer was calibrated according to instructions in the equipment manual before testing began. Calibration involved establishing gas flow conditions approximately equal to those to be used during testing. Then, with pure Ar gas flowing through the instrument, the "zero" knob was adjusted to give a null reading on the computer that served both to control the $\mathrm{NO}_{\mathbf{X}}$ analyzer and as the data acquisition system. Next, a certified calibration gas consisting of Ar containing $274 \mathrm{ppm}$ NO was passed through the instrument, and the "span" was adjusted to give a reading of $274 \mathrm{ppm}$ on the computer. Thereafter, readings within $\pm 5 \%$ of the actual value were expected for NO concentrations 
ranging from zero to a few thousand $\mathrm{ppm}$. When a second calibration gas consisting of Ar containing $1040 \mathrm{ppm}$ NO was passed through the instrument, a reading of $1020 \mathrm{ppm}$ was observed. This was considered to be an acceptable demonstration of the linearity of the instrument.

To check the entire gas-train system (see Figure C.1, Appendix C), the $274 \mathrm{ppm}$ NO in Ar calibration gas was connected to the mass flow controller (MFC) so that it passed through the reaction vessel before entering the $\mathrm{NO}_{\mathrm{X}}$ analyzer. Again, a reading of $274 \mathrm{ppm}$ was registered on the computer thereby confirming the integrity of the system.

Six weeks after the initial calibration described above and immediately before the last two runs, the instrument calibration was rechecked. Pure Ar gave a reading of $0.10 \mathrm{ppm}$ and the $274 \mathrm{ppm}$ NO in Ar calibration gas gave a reading of $273 \mathrm{ppm}$. Both were considered acceptable and no calibration readjustment was made.

Because the entire experimental setup had to be reestablished as described in Section 3.1.1, a determination was made to try to reproduce the results obtained with Tests 7A and 7B (Table 2.8). This would provide a measure of any differences caused by uncontrolled experimental variables and allow them to be factored into comparisons between the supplemental test results and results from the earlier tests.

To reproduce the Test 7A/7B conditions, a new batch of THOREX was prepared with the same nominal composition listed in Table 2.3, and a new batch of simplified PUREX containing $0.20 \mathrm{M} \mathrm{NaOH}, 0.077 \underline{\mathrm{M} \mathrm{NaNO}}$, and $0.019 \underline{\mathrm{M} \mathrm{Na}} \mathrm{CO}_{3}$ (the same composition as in Tests 7A/7B) was made. Two different runs were conducted (Tests $25 \mathrm{~A}$ and $25 \mathrm{~B}$ ), and the results are given in Table 3.3 and Figures C.46 and C.47 (Appendix C).

The amounts of NO generated by Tests $25 \mathrm{~A}$ and $25 \mathrm{~B}(9.8$ and $9.3 \mathrm{~mL}$, see Table 3.3) were somewhat higher than for Tests $7 \mathrm{~A}$ and $7 \mathrm{~B}\left(7.6\right.$ and $6.4 \mathrm{~mL}$, see Table 2.8). Since the source of $\mathrm{Th}\left(\mathrm{NO}_{3}\right)_{4}$ was different from that used in the earlier tests, a chemical analysis of the THOREX seemed in order to determine whether more or less than the nominal hydration water might be associated with the $\mathrm{Th}\left(\mathrm{NO}_{3}\right)_{4} \cdot 4 \mathrm{H}_{2} \mathrm{O}$ that was used. In addition, a dilute solution of the $\mathrm{Th}\left(\mathrm{NO}_{3}\right)_{4} \bullet 4 \mathrm{H}_{2} \mathrm{O}$, by itself, was prepared and analyzed. The results of both analyses are listed in Table 3.4. Except for the Al, the analyzed values are within the uncertainty of the analyses $( \pm 10 \%$ for $\mathrm{Al}$ and $\mathrm{Cr}, \pm 15 \%$ for $\mathrm{Th}, \mathrm{Fe}$, and $\mathrm{Ni}$ ). Thus, the difference between the results for Tests $25 \mathrm{~A} / 25 \mathrm{~B}$ and Tests $7 \mathrm{~A} / 7 \mathrm{~B}$ does not appear to be attributable to an error in the makeup of the THOREX.

Two other possible reasons for the slightly different results of Test 25A/25B and Tests 7A/7B were considered. One potential reason is the slightly lower final $\mathrm{pH}$ values listed for Tests $25 \mathrm{~A} / 25 \mathrm{~B}$. If this difference were real, it might explain a slight excess of NO generation in Tests 25A/25B because, typically, more NO is generated as the $\mathrm{pH}$ decreases. However, the $\mathrm{pH}$ difference cannot be ensured. All $\mathrm{pH}$ measurements in the current set of tests were performed at a controlled temperature of $25 \pm 1{ }^{\circ} \mathrm{C}$ whereas those in the previous test series were done at room temperature, which may have differed from $25^{\circ} \mathrm{C}$ by \pm 3 to $4^{\circ} \mathrm{C}$. Such temperature differences could account for the observed $\mathrm{pH}$ differences, which were not temperature-corrected. 
Table 3.3. Laboratory-Scale Test of THOREX Added to Simplified PUREX ${ }^{(a)}$

\begin{tabular}{|c|c|c|c|c|c|c|c|c|c|c|}
\hline \multirow[b]{2}{*}{ Test } & \multirow[b]{2}{*}{ Figure } & \multirow[b]{2}{*}{$\begin{array}{c}\text { Ar Gas Carrier } \\
\text { Flow Rate } \\
\text { mL/min }\end{array}$} & \multirow[b]{2}{*}{$\begin{array}{c}\text { Stir Rate } \\
\text { rpm }\end{array}$} & \multicolumn{2}{|c|}{ THOREX } & \multicolumn{2}{|c|}{ NO Gas } & \multicolumn{2}{|c|}{$\mathrm{pH}$} & \multirow[b]{2}{*}{ Temp. ${ }^{\circ} \mathrm{C}$} \\
\hline & & & & $\begin{array}{l}\text { Addn Rate } \\
\mathrm{mL} / \mathrm{min}\end{array}$ & $\begin{array}{l}\text { Total } \mathrm{mL} \\
\text { Added }\end{array}$ & Total $\mathrm{mL}$ & $\begin{array}{c}\text { Peak Rate } \\
\mu \mathrm{L} / \mathrm{min}\end{array}$ & Start & End & \\
\hline $25 \mathrm{~A}$ & C. 46 & 700 & 350 & 1.6 & 36 & 9.8 & 290 & 13.2 & 10.6 & 45 \\
\hline $25 B$ & C. 47 & 700 & 350 & 1.4 & 36 & 9.3 & 270 & 13.3 & 10.3 & 45 \\
\hline
\end{tabular}


Table 3.4. Composition of Th Solutions (mol/L)

\begin{tabular}{|c|c|c|c|c|}
\hline \multirow{2}{*}{ Element } & \multicolumn{2}{|c|}{ THOREX } & \multicolumn{2}{c|}{ Th Solution } \\
\cline { 2 - 5 } & Nominal & Measured & Nominal & Measured \\
\hline $\mathrm{Th}$ & 1.48 & 1.33 & $1.48 \times 10^{-5}$ & $1.44 \times 10^{-5}$ \\
\hline $\mathrm{Fe}$ & 0.88 & 0.90 & & \\
\hline $\mathrm{Al}$ & 0.49 & 0.39 & & \\
\hline $\mathrm{Cr}$ & 0.20 & 0.18 & & \\
\hline $\mathrm{Ni}$ & 0.11 & 0.095 & & \\
\hline
\end{tabular}

The second potential reason considered for the noted differences in NO generation was the stirring conditions. A precise record of the configuration of the propellers attached to the stirrer shaft during the earlier testing was not made. Therefore, it is known only that the configuration was similar during the current tests, but it may not have been exact. Also, a new stir motor (same brand and model) was used, but its rotational speed was not measured as it was in the earlier tests. Earlier, a speed of $350 \mathrm{rpm}$ was measured for a motor setting of " 3 ," the setting used for most tests. Literature that accompanied the new stir motor indicated a speed of $350 \mathrm{rpm}$ at a motor setting of "3," which was also used for the recent tests. However, it cannot be guaranteed that the rotational speeds were indeed the same for the two sets of tests.

The fact that the "tail-off" in the NO generation curves (Figures C.46 and C.47 in Appendix C) had a slightly longer duration than was observed earlier (Figures C.12 and C.13 in Appendix C) suggests that the stirring in the current test series may have been slightly less vigorous than it was in the earlier tests. It was found in the earlier testing that slower stirring led not only to a longer NO tail-off but also to slightly more total NO generation. All of this suggests that the slightly longer tail-off and the slightly larger amounts of NO in the current tests might have been caused by somewhat less vigorous stirring.

Although the difference in results between Tests $25 \mathrm{~A} / 25 \mathrm{~B}$ and Tests $7 \mathrm{~A} / 7 \mathrm{~B}$ was reproducible, it was decided that the magnitude of the difference did not warrant further investigation. Rather, the reader should simply be cognizant of this small difference when comparing the results from the current test series with those from the earlier testing.

\subsection{Results and Discussion}

Initial results for Tests 26, 27, and 28 are shown in Table 3.5 and Figures C.48 to C.51 (Appendix C). Figures C.50 and C.51 (Appendix C) are two different plots of the same data for Test 28. The pH dropped dramatically in Test 28 because all of the available hydroxide precipitated, primarily as $\mathrm{Th}(\mathrm{OH})_{4}$ and $\mathrm{Fe}(\mathrm{OH})_{3}$, upon addition of the THOREX, and no $\mathrm{NaOH}$ was added during Batch \#1 to compensate as was done in Tests 26 and 27. A large volume of NO was generated during 
Table 3.5. Supplementary Tests of THOREX Added to Simplified PUREX ${ }^{(a, b)}$

\begin{tabular}{|c|c|c|c|c|c|c|c|c|c|c|c|c|}
\hline \multirow[b]{2}{*}{ Test } & \multirow[b]{2}{*}{ Figure } & \multirow[b]{2}{*}{$\begin{array}{l}\text { THOREX } \\
\text { Addn Rate } \\
\text { mL/min (c) }\end{array}$} & \multirow{2}{*}{ 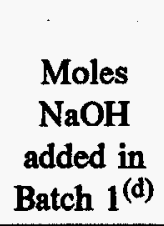 } & \multirow{2}{*}{$\begin{array}{c}\mathrm{NaNO}_{2} \\
\text { Added at } \\
\text { start of } \\
\text { Batches } 2 \\
\text { and } 3\end{array}$} & \multicolumn{2}{|c|}{ Batch \#1 ${ }^{(e)}$} & \multicolumn{2}{|c|}{ Batch $\# 2^{(e)}$} & \multicolumn{2}{|c|}{ Batch $\# 3^{(e)}$} & \multirow[b]{2}{*}{$\begin{array}{l}\text { Total } \\
\text { NO } \\
\text { mL }\end{array}$} & \multirow[b]{2}{*}{$\begin{array}{c}\text { Temp. } \\
{ }^{\circ} \mathrm{C}\end{array}$} \\
\hline & & & & & $\begin{array}{l}\text { Total } \\
\text { NO } \\
\text { mL }\end{array}$ & $\begin{array}{l}\text { End } \\
\mathrm{pH}\end{array}$ & $\begin{array}{l}\text { Total } \\
\text { NO } \\
\mathrm{mL}\end{array}$ & $\begin{array}{l}\text { End } \\
\text { pH }\end{array}$ & $\begin{array}{l}\text { Total } \\
\text { NO } \\
\mathrm{mL}\end{array}$ & $\begin{array}{l}\text { End } \\
\text { pH }\end{array}$ & & \\
\hline 26 & C.48 & 1.6 & 0.145 & No & 0.16 & 13.23 & 1.2 & 12.41 & 0.22 & 12.06 & 1.6 & 45 \\
\hline 27 & C.49 & 1.6 & 0.139 & Yes & 0.32 & 13.18 & 5.4 & 11.21 & 2.0 & 9.03 & 7.7 & 45 \\
\hline 28 & C.50, C.51 & 1.6 & none & Yes & 0.10 & 12.92 & 690 & 4.3 & -- & - & 690 & 45 \\
\hline $26^{1 / 2}$ & C.52 & 1.6 & 0.146 & $\overline{Y e s}^{(t)}$ & 0.26 & 13.26 & 1.5 & 12.34 & 0.88 & 11.85 & 2.6 & $\overline{45}$ \\
\hline $27 A$ & C.53 & 1.5 & 0.143 & Yes & 0.47 & 13.26 & 3.0 & 12.36 & 1.4 & 11.93 & 4.9 & 45 \\
\hline 29 & C.54 & 1.4 & 0.148 & No & 0.53 & 13.26 & 1.3 & 12.37 & 0.25 & 11.94 & 2.1 & 45 \\
\hline
\end{tabular}

(a) Ar carrier gas flow rate was the same for all tests, $700 \mathrm{~mL} / \mathrm{min}$

(b) The stir rate was the same for all tésts, $350 \mathrm{rpm}$

(c) These addition rates are slightly less than for most of the tests listed in Tables 2.6 to 2.10. However, results from the earlier tests showed that THOREX addition rate, by itself, was not an important parameter.

(d) Measured by before-and-after weighing of the supply container

(e) See Table 2.12 for description of batch numbers

(f) Only half as much $\mathrm{NaNO}_{2}$ added as in Tests $27,27 \mathrm{~A}$, and 28 
Batch \#2 of Test 28 because of the large $\mathrm{pH}$ decrease. Because the $\mathrm{pH}$ dropped so low during Test 28 , those test conditions clearly do not represent viable conditions for the addition of Tank 8D-4 waste to Tank 8D-2 waste. Therefore, Batch \#3 was not run for Test 28 and no further consideration was given to Test 28.

There was a marked difference between Tests 26 and 27 with respect to the ending $\mathrm{pH}$ values observed at the ends of Batches \#2 and \#3 [Table 3.5, Figures C.48 and C.49 (Appendix C)]. This difference seemed questionable because the addition of $\mathrm{NaNO}_{2}$ in Test 27 at the beginnings of Batches \#2 and \#3 was not expected to have a significant effect on the pH of this slurry at such a high initial pH. Therefore, to explore further any possible effect of $\mathrm{NaNO}_{2}$ on the $\mathrm{pH}$, Test $261 / 2$ was conducted with only half as much $\mathrm{NaNO}_{2}$ added at the beginnings of Batches \#2 and \#3 (Figure C.52 in Appendix C). In addition, Test 27 was repeated as Test 27A (Figure C.53 in Appendix C).

Test 27A generated a little less NO than Test 27, but more importantly, the pH dropped only about as much as in Tests 26 and $26 \%$. The difference appears to be related to the amounts of $\mathrm{NaOH}$ added during Batch \#1 of the various tests (see Table 3.5).

The amount of $\mathrm{NaOH}$ added during Test 27 was slightly less, and the $\mathrm{pH}$ at the end of Test 27 , Batch \#1 was only slightly lower than during the other tests. However, by the end of Test 27 , Batches \#2 and \#3, the slight deficiency in $\mathrm{NaOH}$ resulted in significantly lower $\mathrm{pH}$ values. Therefore, it appears that adding $\mathrm{NaNO}_{2}$ at the beginning of Batches \#2 and \#3 increased the amount of NO that was generated by modest amounts (compared to not adding $\mathrm{NaNO}_{2}$ as was done in Test 26), but it did not have a significant effect on the final $\mathrm{pH}$ values as was first indicated.

One final run, Test 29 , was requested by WVNS in which the starting $\mathrm{NaNO}_{2}$ concentration was increased slightly to $0.056 \underline{\mathrm{M}}$ and no $\mathrm{NaNO}_{2}$ was added at the beginnings of Batches \#2 and \#3. Table 3.5 and Figure C.54 (Appendix C) show that the amounts of NO that were generated were about the same as in Test 26 , which was expected since the only difference was an increase in the starting $\mathrm{NaNO}_{2}$ concentration from $0.049 \underline{\mathrm{M}}$ to $0.056 \underline{\mathrm{M}}$.

Comparing the data from these supplementary tests with that from the tests described in Section 2.0 is not straightforward because the test parameters were different. One useful comparison is the fraction of $\mathrm{NO}_{2}^{-}$converted to $\mathrm{NO}$ gas. For example, the $3 \mathrm{~mL}$ of $\mathrm{NO}$ produced during Batch $\# 2$ of Test $27 \mathrm{~A}$ represents, $0.05 \%$ of the $\mathrm{NO}_{2}^{-}$present at the start of that batch. This is only about half the fraction converted during Tests 7A/7B and 14A to 14D (see Item \#4 in Section 2.3). There are two reasons for the smaller conversion to NO in Test 27A. One reason is that a somewhat smaller amount of THOREX was added during Batch $\# 2$ of Test $27 \mathrm{~A}$ compared to the other tests. The second reason is the addition of $\mathrm{NaOH}$ during Batch \#1 of Test 27A such that the $\mathrm{pH}$ remained higher than in Tests 7A/7B and 14A. to $14 \mathrm{D}$. 


\subsection{Corrosion Tests}

Three separate corrosion investigations were performed in the course of this work. The first tests, called "preliminary corrosion tests," were conducted as adjuncts to the first THOREX/PUREX mixing tests to determine if any severe corrosion problems existed that would show up in short time periods. The second tests were conducted to determine the $\mathrm{pH}$ that might be expected in water equilibrated with $\mathrm{NO}_{\mathrm{X}}$ evolved during THOREX/PUREX mixing. The third tests were actual corrosion tests conducted using test environments of water equilibrated with a low partial pressure of $\mathrm{NO}_{2}$. The three tests are discussed below.

\subsection{Experimental}

Completely different experimental approaches were used in each of the corrosion tests. The different approaches are described in this section.

\subsubsection{Preliminary Corrosion Tests}

In the preliminary corrosion tests, corrosion coupons made of A516 grade 55 carbon steel (a steel similar to WVNS Tank 8D-2 material) were exposed to the environment resulting after simulated THOREX waste was added to simulated PUREX waste under laboratory test conditions. The specific tests containing the corrosion test coupons were Tests 1 and 3 (see Table 2.6). The coupons were 3/4-in. wide $\times 1-1 / 2$-in. high $\times 1 / 8$-in thick, and were cleaned, measured, and weighed before each test. Duplicate coupons were located at each of the three positions shown schematically in Figure C.55 in Appendix C (vapor space, liquid/vapor interface, and submerged). The tests had a duration of approximately $6 \mathrm{~h}$. Corrosion rates in $\mathrm{mpy}^{(\mathrm{a})}$ were based on weight loss and were calculated by assuming uniform weight loss over the entire surface of each coupon. This assumption is acceptable for these tests since no severe localized corrosion, such as pitting or liquid/vapor interfacial corrosion, was observed.

\subsubsection{Determination of $\mathrm{pH}$ as a Function of $\mathrm{NO}_{2}$ Partial Pressure}

A series of investigations was undertaken to determine the potential seriousness of the attack of $\mathrm{NO}_{\mathrm{X}}$ on the walls of Tank 8D-2. Before the investigations could progress to the experimental stage, it was necessary to develop a logical, conservative scenario for acid generation that would be amenable to laboratory simulation and investigation. The scenario that was developed was based on the following assumptions:

1. The amount of gas generated would be based on the experimental THOREX/PUREX mixing runs;

(a) $\mathrm{mil} / \mathrm{year}$, where $1 \mathrm{mil}=0.001 \mathrm{in}$. 
2. The $\mathrm{NO}$ generated would react with air to form $\mathrm{NO}_{2}$ at a certain partial pressure estimated from the generation rate and tank vapor-space volume;

3. The $\mathrm{NO}_{2}$ would equilibrate with the film of water condensate assumed to be present on the steel in the tank's vapor space to form a film of continually replenished dilute acid.

The foregoing assumptions, considered strongly conservative, were reflected in the experimental approach, in which gas of a given $\mathrm{NO}$ or $\mathrm{NO}_{2}$ partial pressure was allowed to equilibrate for times up to $45 \mathrm{~h}$ with a relatively large volume of water to determine the resulting $\mathrm{pH}$ as a function of the partial pressure of $\mathrm{NO}_{2}$.

An order-of-magnitude estimate of the approximate $\mathrm{NO}_{\mathrm{X}}$ partial pressure expected in the plenum of Tank 8D-2 during THOREX neutralization was made by using the procedure described below. It is based on the amount of NO produced in Test 2 (Table 2.6 in Section 2.2.1), which was the maximum amount of NO produced in the first three THOREX/PUREX mixing tests.

If it is assumed 1) that the amount of $\mathrm{NO}_{2}$ generated is equal to the amount of NO that was produced in the Test 2 mixing run (equivalent to $13 \mathrm{~mL} / \mathrm{L}$ of PUREX solution, or $27,000 \mathrm{~L}$ for the $2.1 \times 10^{6} \mathrm{~L}$ of PUREX solution in Tank 8D-2); 2) that the total amount of $\mathrm{NO}_{2}$ generated is independent of the THOREX addition rate; 3) that the total volume of THOREX from Tank 8D-4 is added to Tank 8D-2 over a period of 10 days; 4) that the plenum space in the tank is $1,600,000 \mathrm{~L}$; and (5) that the tank is vented at $100 \mathrm{ft}^{3} / \mathrm{min}(2,800 \mathrm{~L} / \mathrm{min})$; then

$$
\begin{gathered}
\text { Total air vol. }=1.6 \times 10^{6}+(2800 \mathrm{~L} / \mathrm{min})(1440 \mathrm{~min} / \mathrm{day})(10 \mathrm{days})=4.2 \times 10^{7} \mathrm{~L} \\
\text { and }
\end{gathered}
$$

$$
\mathrm{NO}_{2} \text { concentration }=2.7 \times 10^{4} / 4.2 \times 10^{7}=6.4 \times 10^{-4} \mathrm{~atm} \text {, or } 0.064 \text { mole } \% \mathrm{NO}_{2} \text {. }
$$

This was considered to be a conservative upper limit on the $\mathrm{NO}_{2}$ concentration expected in a stirred system. (a) Later it was determined that the total NO amounts were likely to be much less than the maximum found and referred to in the first three mixing tests. Therefore, the partial pressure of $\mathrm{NO}_{2}$ in the third $\mathrm{pH}$ run in this test series was reduced by a factor of $\sim 13$ to $<0.005$ mole \%, which corresponds approximately to the amounts of NO found in Tests 17A to 17C (Table 2.9 in Section 2.2.1), for example.

An experimental apparatus was set up wherein cylinders containing nitrogen oxide (either NO or $\left.\mathrm{NO}_{2}\right), \mathrm{O}_{2}$, and $\mathrm{N}_{2}$ were connected to a common manifold. The gases, blended to form the desired $\mathrm{NO}_{2}$ /simulated air mixture, were conducted through a length $\left(-10^{\prime}\right)$ of Tygon tubing, a gas sample bulb, and a gas dispenser into a sealed resin kettle containing $2.7 \mathrm{~L}$ of stirred distilled water. The $\mathrm{pH}$ in the distilled water was monitored continuously by a temperature-compensated $\mathrm{pH}$ meter. Tests were conducted at temperatures ranging from $20^{\circ}$ to $40^{\circ} \mathrm{C}$.

(a) Tests 11 and 12 (Table 2.8 in Section 2.2.1) show that the amount of NO can be much higher in an unstirred system. 


\subsubsection{Determination of Corrosiveness of $\mathrm{NO}_{2}$-Equilibrated Solutions}

The $\mathrm{pH}$ values attained in the tests described above were low enough to justify performance of actual steel corrosion tests. The tests were conducted in wet and humid environments at temperatures of $40^{\circ} \mathrm{C}$ and $50^{\circ} \mathrm{C}$. The steel coupons were ASTM A516 grade 55 carbon steel, similar in composition and microstructure to the material of construction for Tank 8D-2. The $\mathrm{NO}_{2}$ gas was continually supplied to the system from a gas bottle and diluted by a carrier gas of $\sim 80 \% \mathrm{~N}_{2}$ and $-20 \% \mathrm{O}_{2}$. The target concentration for the $\mathrm{NO}_{2}$ was $\sim 100 \mathrm{ppm}$, and the total gas flow through the system was $\sim 20 \mathrm{~L} / \mathrm{h}$. Figure C.55 (Appendix C) is a schematic representation of the test system.

Four vessels were used for the tests (Figure C.55 in Appendix C). Before coupons were added to the vessels, the gas was purged through the system to equilibrate the water with the $\mathrm{NO}_{2}$ resulting in a $\mathrm{pH}$ of 4.0 in vessels 1 and 2; the pH in vessels 3 and 4 was 4.3 and 5.0, respectively. In two vessels (one at $40^{\circ} \mathrm{C}$ and one at $50^{\circ} \mathrm{C}$ ) the gas was bubbled into the water through a gas sparging tube. Six coupons were suspended in each of these vessels: two in the vapor space, two at the air/water interface, and two totally submerged in the water. In the other two vessels (one at $40^{\circ} \mathrm{C}$ and one at $50^{\circ} \mathrm{C}$ ) the gas flow passed into and out of the plenum region of the vessels and was not bubbled into the water. In these vessels, one coupon was suspended in each vessel so that water just covered the coupon surface.

\subsection{Results}

All of the corrosion test results are presented in this section of the report.

\subsubsection{Preliminary Corrosion Tests}

The results of the preliminary corrosion tests are presented in Table 4.1. Tests 1 and 3 in that table are the same as Tests 1 and 3 in Table 2.6 (Section 2.2.1). There was no appreciable difference in corrosion rates between submerged, interface, and vapor-space coupons. The $6 \mathrm{~h}$ test time was apparently not long enough to initiate and grow pits, which have always occurred on vapor space coupons (and some submerged specimens) in sludge-wash tests.

The major conclusion that was drawn from these brief corrosion tests is that no severe steel degradation was observed, such as pitting or knife-line interfacial attack. Some localized etching of some coupons was observed where they touched the supports. This observation suggests that pitting and crevice corrosion might eventually occur in these locations.

\subsubsection{Determination of $\mathrm{pH}$ as a Function of $\mathrm{NO}_{2}$ Partial Pressure}

Figure C.56 (Appendix C) shows results from a total of three runs that were made. In Run No. 1, the nitrogen oxide gas was NO. In this run, the total gas flow rate was approximately $12 \mathrm{~L} / \mathrm{h}$. The gas analysis from the sample bulb showed the gas mixture to consist of $0.03 \% \mathrm{NO}_{\mathrm{X}}, 86 \% \mathrm{~N}_{2}$, and 
Table 4.1. Summary of Corrosion Results

\begin{tabular}{|c|c|c|}
\hline Test No. & Coupon Position & Corrosion Rate (mpy) \\
\hline \multirow{4}{*}{1} & Vapor & 12.7 \\
\cline { 2 - 3 } & Vapor & 6.5 \\
\cline { 2 - 3 } & Interface & 5.0 \\
\cline { 2 - 3 } & Interface & 5.6 \\
\cline { 2 - 3 } & Submerged & 7.1 \\
\cline { 2 - 3 } & Submerged & 7.1 \\
\hline \multirow{4}{*}{3} & Vapor & 4.0 \\
\cline { 2 - 3 } & Vapor & 8.5 \\
\cline { 2 - 3 } & Interface & 7.9 \\
\cline { 2 - 3 } & Interface & 9.7 \\
\cline { 2 - 3 } & Submerged & 10.1 \\
\cline { 2 - 3 } & Submerged & 7.3 \\
\hline
\end{tabular}

$14 \% \mathrm{O}_{2} \cdot{ }^{(a)}$ (The mass spectrometer cannot differentiate between $\mathrm{NO}$ and $\mathrm{NO}_{2}$. However, because NO is known to oxidize to $\mathrm{NO}_{2}$ in the presence of $\mathrm{O}_{2}$, the " $\mathrm{NO}_{2}$ " in the analysis was assumed to be $\mathrm{NO}_{2}$.) The temperature was maintained at $21 \pm 1^{\circ} \mathrm{C}$ for the duration of the run, until a reasonably stable (very slowly decreasing) $\mathrm{pH}$ of 3.3 was observed at $\sim 23 \mathrm{~h}$. The temperature of the system was then increased to $39^{\circ} \mathrm{C}$, and a reasonably stable (very slowly decreasing) $\mathrm{pH}$ of 3.1 resulted. The $\mathrm{pH}$ values reported are temperature-corrected.

The second run, Run No. 2, was performed in essentially the same way as the first, except that nitrogen dioxide $\left(\mathrm{NO}_{2}\right)$ was substituted for the $\mathrm{NO}$ of the previous run, and the flow rate of the diluent gas, $\mathrm{N}_{2}$, was increased. The total flow rate in the second run was approximately $40 \mathrm{~L} / \mathrm{h}$. The gas in the second run consisted of $0.06 \% \mathrm{NO}_{2}, 76.4 \% \mathrm{~N}_{2}$, and $23.4 \% \mathrm{O}_{2}$. After $25 \mathrm{~h}$, the $\mathrm{pH}$ of the water was a reasonably stable (very slowly decreasing) value of 3.0. The temperature of the system was then increased to $39^{\circ} \mathrm{C}$, and a (very slowly decreasing) $\mathrm{pH}$ of 2.9 was observed after $\sim 3 \mathrm{~h}$.

The third run, Run No. 3, was an attempt to obtain an $\mathrm{NO}_{2}$ concentration in the gas stream of $\sim 0.009 \%$. The gas analysis mass spectrometer was not successful in sensing the $\mathrm{NO}_{2}$ concentration in this run. The limit of detection of the mass spectrometer for $\mathrm{NO}_{2}$ is estimated to be $\sim 0.005$ mole $\%$ under the circumstances of the analysis; this value is probably as valid an estimate for the $\mathrm{NO}_{2}$ concentration as can be achieved for this test. When the solution temperature was increased to $40^{\circ} \mathrm{C}$ at $48 \mathrm{~h}$ total test time, the $\mathrm{pH}$ decreased from 3.96 to 3.89 . The test was then terminated.

(a) All gas compositions are given in mole \%. 
The $\mathrm{pH}$ values attained over periods of 20 to $40 \mathrm{~h}$ were low enough $(<4)$ to be considered potentially important in assessing the corrosive effects of such gas-water-equilibrated solutions on carbon steel (Whitman, Russell and Altieri 1924). A corrosion test was therefore conducted to obtain actual corrosion data.

\subsubsection{Determination of Corrosiveness of $\mathrm{NO}_{2}$-Equilibrated Solution}

The corrosion tests were conducted for 20 days. Only a limited supply of $\mathrm{NO}_{2}$ gas was available at the beginning of the test, and a second bottle was ordered on an emergency basis before testing began. When it had not been received about halfway through the test, the $\mathrm{NO}_{2}$ flow was reduced to about half the initial flow, thus reducing its concentration in the test vessels to $\sim 50 \mathrm{ppm}$. The bottle was still not delivered by the end of the test; before the planned test end, the $\mathrm{NO}_{2}$ was exhausted. During the last four days only $\mathrm{N}_{2}$ and $\mathrm{O}_{2}$ passed through the system. The $\mathrm{pH}$ of the water in the vessels was monitored during the test, and remained fairly constant between about 3.5 and 4.5 with the $\mathrm{NO}_{2}$ flowing (even at the lower concentration). The $\mathrm{pH}$ did start to increase once the $\mathrm{NO}_{2}$ ran out and increased to 5.5 in vessel 1 and about 8.0 in the other three vessels at the conclusion of the test.

After 20 days exposure, the coupons were removed and cleaned in an inhibited acid solution to remove corrosion products. The coupons were then weighed and examined. The uniform corrosion rates calculated from weight loss measurements are shown in Table 4.2. Pits were observed on all specimens. Pit depths were measured with an optical micrometer. The depths of the deepest pits observed on each specimen are shown in Table 4.2. Pitting was markedly more severe on wetted coupons. Those coupons suspended in the vapor spaces of the first two vessels described above were nearly free of pits.

The test temperature, over the narrow range employed, appeared to have some effect on corrosion, with the highest corrosion rates observed at the lower temperature. The statistical significance of this observation is not clear, given the limited number of specimens and the limited test duration.

Neither the uniform corrosion of the test specimens nor the nonuniform (pitting) corrosion would appear to present any potential hazard to Tank 8D-2 if the laboratory simulation described herein represents a reasonably close approximation to the conditions existing within the tank during the actual THOREX neutralization process.

\subsection{Discussion}

Passage of simulated air containing low concentrations of $\mathrm{NO}_{2}$ into a fixed volume of $\mathrm{H}_{2} \mathrm{O}$ has been shown to be capable of reducing the $\mathrm{pH}$ of the gas-equilibrated $\mathrm{H}_{2} \mathrm{O}$ to values $<4$, even at concentrations of $\mathrm{NO}_{2}$ as low as 0.005 mole \%. The potential for high corrosion rates therefore exists, if $\mathrm{NO}_{2}$-equilibrated $\mathrm{H}_{2} \mathrm{O}$ were to contact carbon steel for protracted periods of time, and if the $\mathrm{NO}_{2}$ were continually replenished to maintain such a low $\mathrm{pH}$ level at the steel surface. Actual steel corrosion tests performed in the presence of low partial pressures of $\mathrm{NO}_{2}$ and either liquid water or water vapor showed that for "short" time periods, e.g., time periods of $<100$ days, there would be no significant degradation of a tank wall if it were contacted by $\mathrm{NO}_{2}^{-}$equilibrated $\mathrm{H}_{2} \mathrm{O}$ at $\mathrm{NO}_{2}$ concentrations of 0.01 to 0.005 mole \% in air. 
Table 4.2. Corrosion Rates and Pit Depths for $\mathbf{N O}_{2}$ Corrosion Tests

\begin{tabular}{|c|c|c|c|c|}
\hline $\begin{array}{l}\text { Vessel ID/ } \\
\text { Temperature }\end{array}$ & $\begin{array}{l}\text { Coupon } \\
\text { Position }\end{array}$ & $\begin{array}{c}\text { Uniform } \\
\text { Corrosion } \\
\text { Rate (mils/year) }\end{array}$ & $\begin{array}{c}\text { Deepest } \\
\text { Pits (mils) }\end{array}$ & $\begin{array}{c}\text { Coupon } \\
\text { ID\# }\end{array}$ \\
\hline \multirow[b]{2}{*}{ Vessel \#1 } & \multirow{2}{*}{ Vapor } & 1.05 & 5 & 421 \\
\hline & & 1.02 & 6 & 422 \\
\hline \multirow{4}{*}{$40^{\circ} \mathrm{C}$} & \multirow{2}{*}{ Interface } & 14.87 & 10 & 423 \\
\hline & & 15.31 & 14 & 424 \\
\hline & \multirow{2}{*}{ Submerged } & 21.12 & 7 & 425 \\
\hline & & 22.75 & 8 & 426 \\
\hline \multirow{3}{*}{ Vessel \#2 } & \multirow{2}{*}{ Vapor } & 0.58 & 5 & 427 \\
\hline & & 0.43 & 4 & 428 \\
\hline & \multirow{2}{*}{ Interface } & 15.21 & 11 & 429 \\
\hline \multirow[t]{3}{*}{$50^{\circ} \mathrm{C}$} & & 13.76 & 10 & 430 \\
\hline & \multirow{2}{*}{ Submerged } & 12.82 & 11 & 431 \\
\hline & & 12.96 & 11 & 432 \\
\hline Vessel \#3/40 ${ }^{\circ} \mathrm{C}$ & Wetted & 5.51 & 6 & 433 \\
\hline 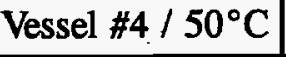 & Wetted & 4.78 & 5 & 434 \\
\hline
\end{tabular}




\subsection{References}

Bray, L.A., and B.M. Wise. 1986. Chemistry Required for Tank 8D-4 Thoria Waste Removal, WVST 86/59 JRC. Pacific Northwest Laboratory, Richland, Washington.

Whitman, W., R. Russell, and V. Altieri. 1924. Industrial Engineering Chemistry, Vol. 16, p. 665.

Yost, D.U., and H.R. Russell, Jr. 1944. Systematic Chemistry of the 5th and 6th Group Nonmetallic Elements, Prentice Hall. 
Appendix A

Rheological and Flow Properties of NT-1 and NT-5 Samples 


\section{Appendix A}

\section{Rheological and Flow Properties of NT-1 and NT-5 Samples}

The rheological properties of two THOREX was samples were measured using the Bohlin CS viscometer modified for glovebox operations. The measuring geometry used for these samples consisted of concentric cylinders with a $25 \mathrm{~mm}$ diameter inner cylinder and a $2.5 \mathrm{~mm}$ gap between the cylinders (Bohlin C25 measuring sensor). These properties were obtained by measuring the shear rate required to obtain a specified shear stress. The specified shear stresses were ramped to provide a shear rate.range from 0 to approximately $500 \mathrm{~s}^{-1}$. Duplicate runs were performed on each sample at two temperatures $\left(25\right.$ and $65^{\circ} \mathrm{C}$ ). Plots of the shear stress and viscosity as a function of shear rate are attached.

Both samples exhibited some dilatant behavior over the measuring range $\left(0\right.$ to $\left.500 \mathrm{~s}^{-1}\right)$, but this effect is minimal. Dilatancy generally occurs in concentrated suspensions which tend to gel upon mixing. The viscosity of dilatant liquids increases with increasing shear rate. For the NT-1 samples the viscosity of this sample at $25^{\circ} \mathrm{C}$ ranges from 6 to $3 \mathrm{cP}$ (mPa-s) over most of the shear rate range. At $65^{\circ} \mathrm{C}$ the viscosity is somewhat lower than at $25^{\circ} \mathrm{C}$. The viscosity of this sample at $65^{\circ} \mathrm{C}$ ranges between 4 and $2 \mathrm{cP}$.

The NT-5 sample has a significant yield stress, and the data was fit to a power law equation (see Equation A.1). The yield stress and power law curve fit parameters for the duplicate runs at 25 and $65^{\circ} \mathrm{C}$ are reported in Table A.1. The data was fit to a power law fit to obtain the necessary parameters to model the flow properties of these samples. The flow properties of these samples were determined using the method of Hanks to calculate Hedstrom Numbers, values of friction factor as a function of Reynolds number, and pressure drop as a function of velocity for turbulent, nonNewtonian fluid flow. The data obtained from this analysis are given in Table A.2 and on the attached computer printouts.

$$
\mathbf{T}=\mathbf{T}_{\mathbf{S}}+\mathbf{K} \boldsymbol{\gamma}^{\mathbf{n}}
$$

where $T$ is the shear stress of the sample,

$T_{S}$ is the yield stress of the sample,

$\mathrm{K}$ is the consistency parameter,

$\gamma$ is the shear rate, and

$\mathrm{n}$ is the flow behavior index. 
Table A.1. Power Law Curve Fit Parameters for Sample NT-5

\begin{tabular}{|c|c|c|c|c|}
\hline $\begin{array}{c}\text { Temperature } \\
\left({ }^{\circ} \mathrm{C}\right)\end{array}$ & Run & $\begin{array}{c}\text { Yield } \\
\text { Stress }(\mathrm{Pa}) \\
\end{array}$ & $\begin{array}{c}\text { Consistency } \\
\text { Parameter }(\mathrm{Pa} \bullet \mathrm{s})\end{array}$ & $\begin{array}{c}\text { Flow Behavior } \\
\text { Index }\end{array}$ \\
\hline \multirow[t]{2}{*}{25} & 1 & 0.71 & $2.37 \times 10^{-2}$ & 0.86 \\
\hline & 2 & 0.73 & $8.87 \times 10^{-3}$ & 1.00 \\
\hline \multirow[t]{2}{*}{65} & 3 & 0.53 & $3.83 \times 10^{-3}$ & 1.09 \\
\hline & 4 & 0.63 & $3.63 \times 10^{-4}$ & 1.43 \\
\hline
\end{tabular}

Table A.2. Flow Behavior Properties for NT-5 Sample

\begin{tabular}{|c|c|c|c|c|c|c|}
\hline \multirow[b]{2}{*}{$\begin{array}{c}\text { Pipe } \\
\text { Diameter (in.) }\end{array}$} & \multirow[b]{2}{*}{$\begin{array}{c}\text { Temp. } \\
\left({ }^{\circ} \mathrm{C}\right)\end{array}$} & \multirow[b]{2}{*}{ Run } & \multirow[b]{2}{*}{$\begin{array}{c}\text { Hedstrom } \\
\text { Number }\end{array}$} & \multicolumn{3}{|c|}{ Values for Critical } \\
\hline & & & & $\begin{array}{l}\text { Reynolds } \\
\text { Number }\end{array}$ & $\begin{array}{c}\text { Velocity } \\
\text { (ft/s) }\end{array}$ & $\begin{array}{c}\text { Flow Rate } \\
\text { (GPM) }\end{array}$ \\
\hline \multirow[t]{4}{*}{2} & 25 & 1 & 13,900 & 3,800 & 2.3 & 24 \\
\hline & & 2 & 32,700 & 4,700 & 2.0 & 21 \\
\hline & 65 & 3 & 56,500 & 5,800 & 1.6 & 16 \\
\hline & & 4 & 205,000 & 14,300 & 1.3 & 13 \\
\hline \multirow[t]{4}{*}{3} & 25 & 1 & 30,600 & 4,600 & 2.0 & 47 \\
\hline & & 2 & 72,100 & 6,100 & 1.8 & 41 \\
\hline & 65 & 3 & 124,000 & 7,900 & 1.4 & 31 \\
\hline & & 4 & 422,000 & 22,600 & 1.1 & 25 \\
\hline
\end{tabular}


BOHLIN CS AHEOMETEA

Stress viscometry test

1993-08-19 09: 26: $13 * 1$

** Viscosity

o- Shear stress

w

cot $20=$ It 60 s

in of $n 1$

nis 5

T $24.9-25.16$

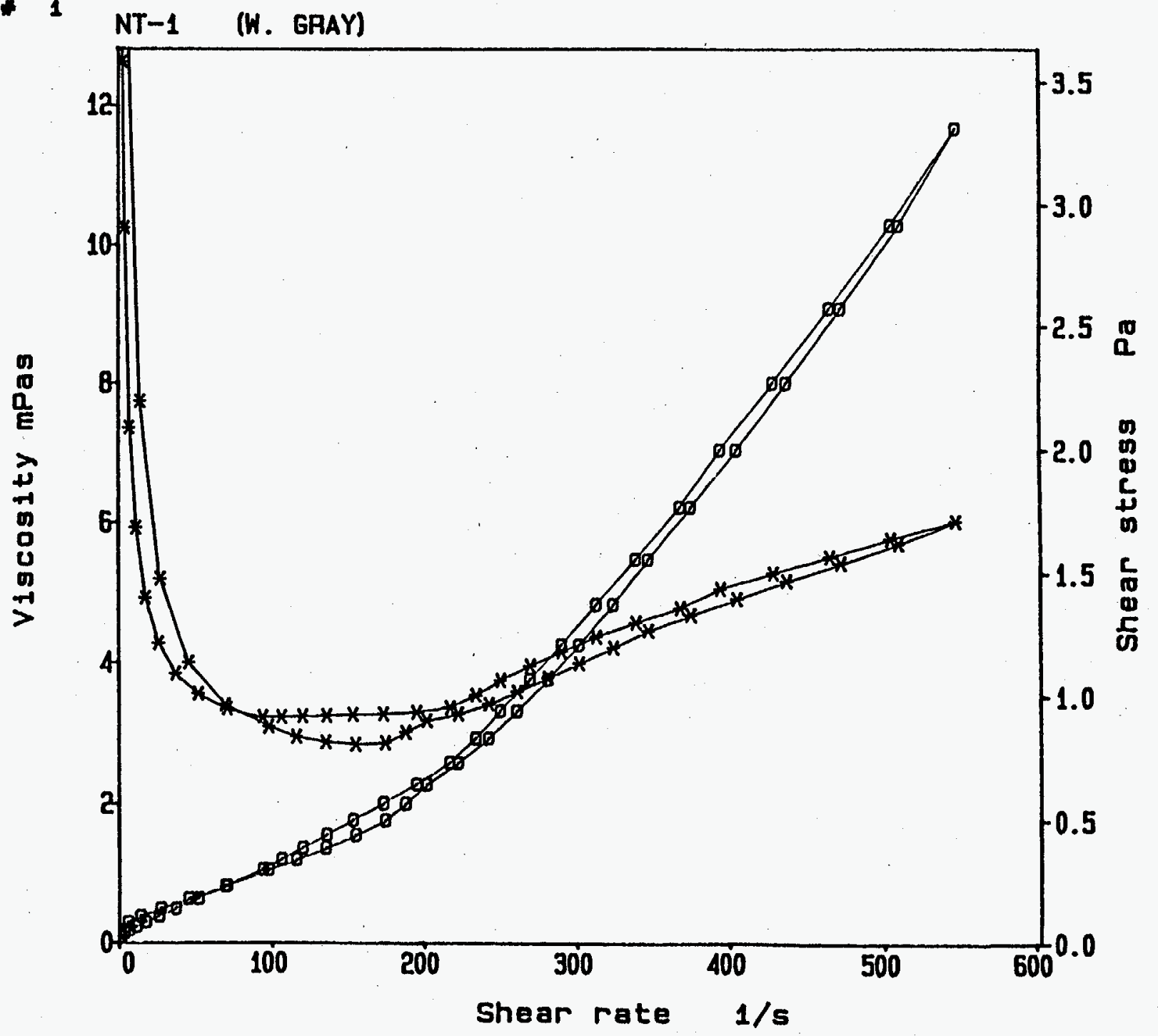


BOHLIN CS RHEOMETER

Stress viscometry test

1993-08-19 10: 44: $19 * 1$

cot $10=$ It 60 to of $n 1$ ur 5

T $24.9-20.1 \mathrm{C}$

** Viscosity

G Shour stress

C 25

$?$

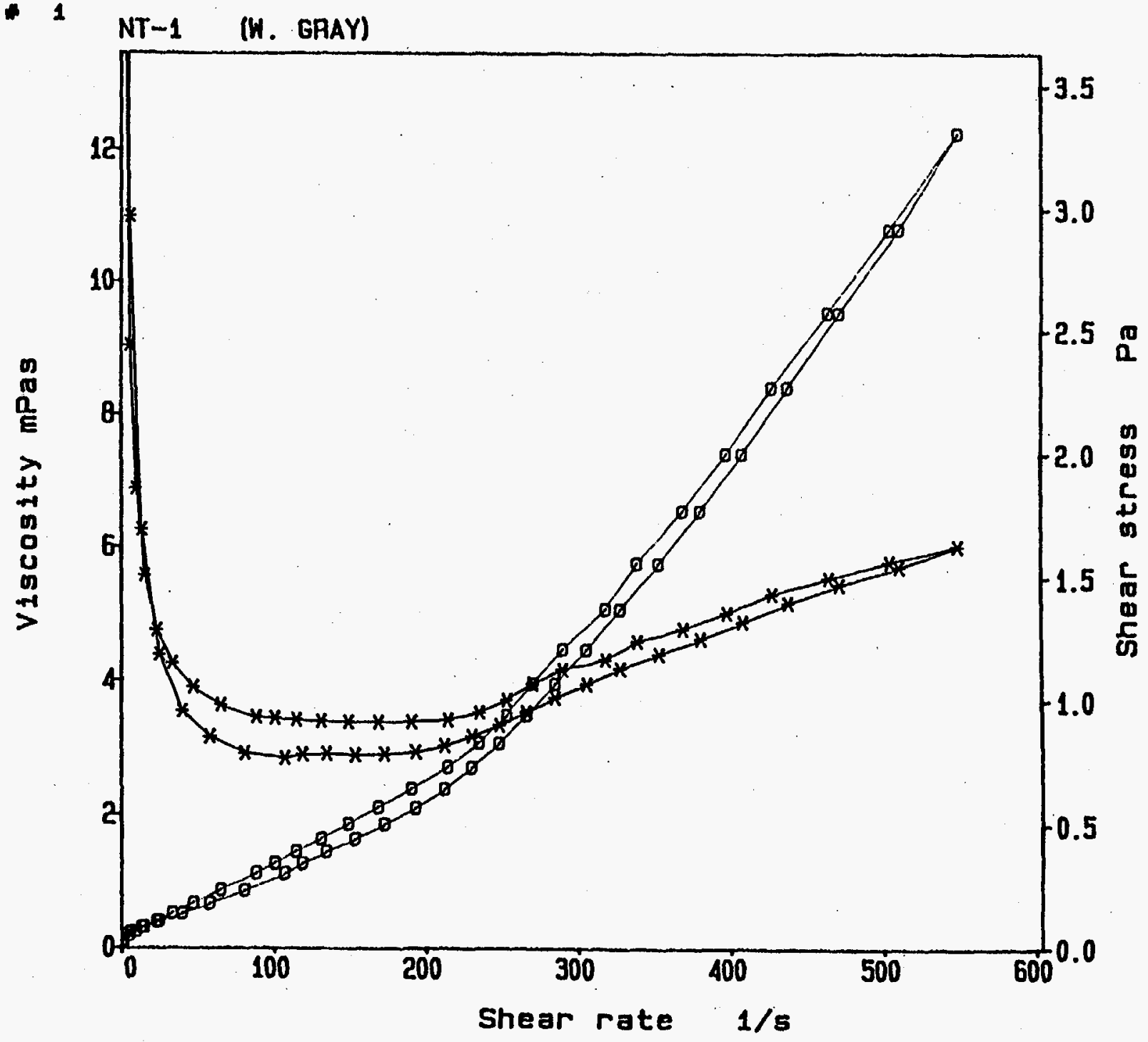




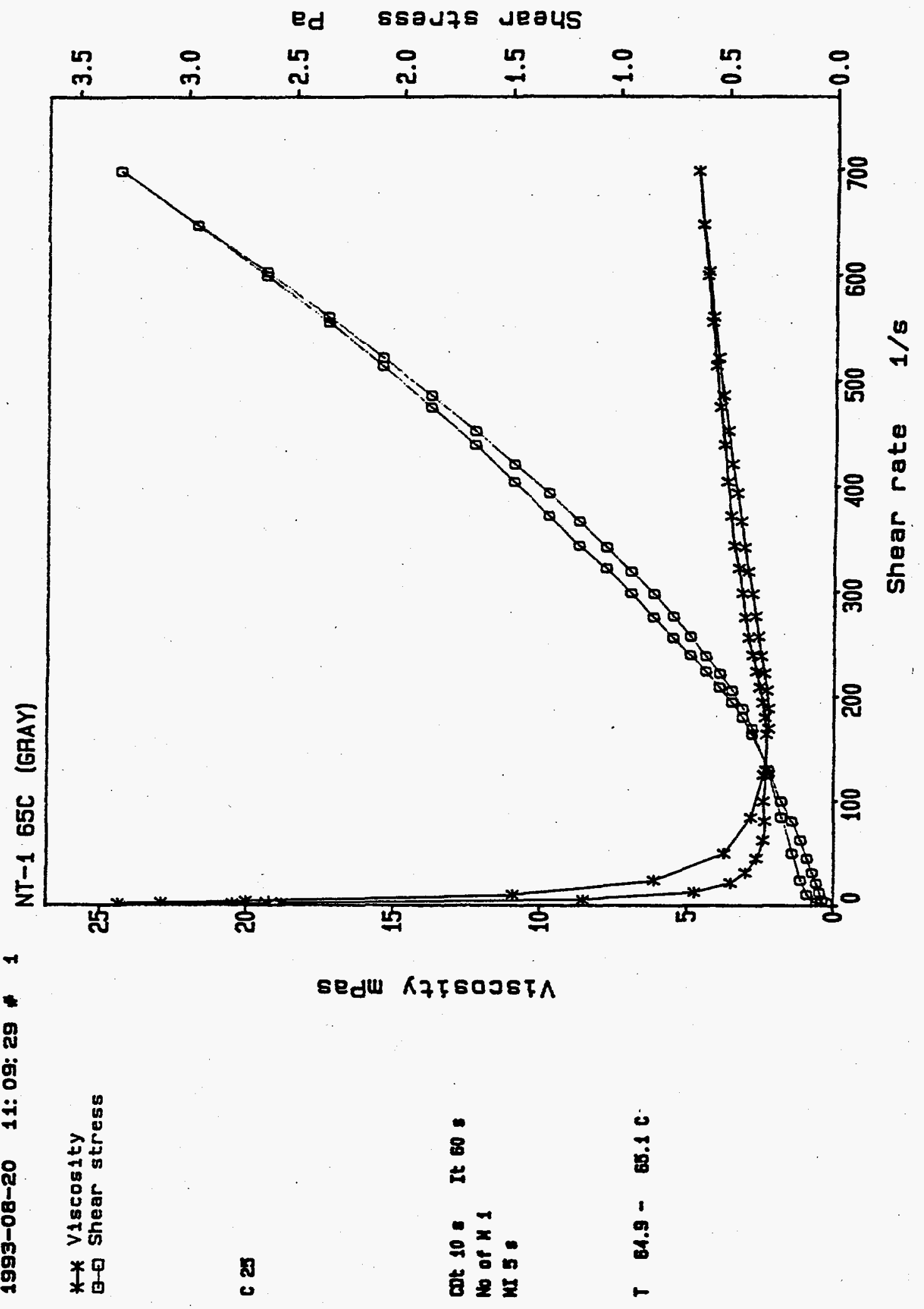

A.5 


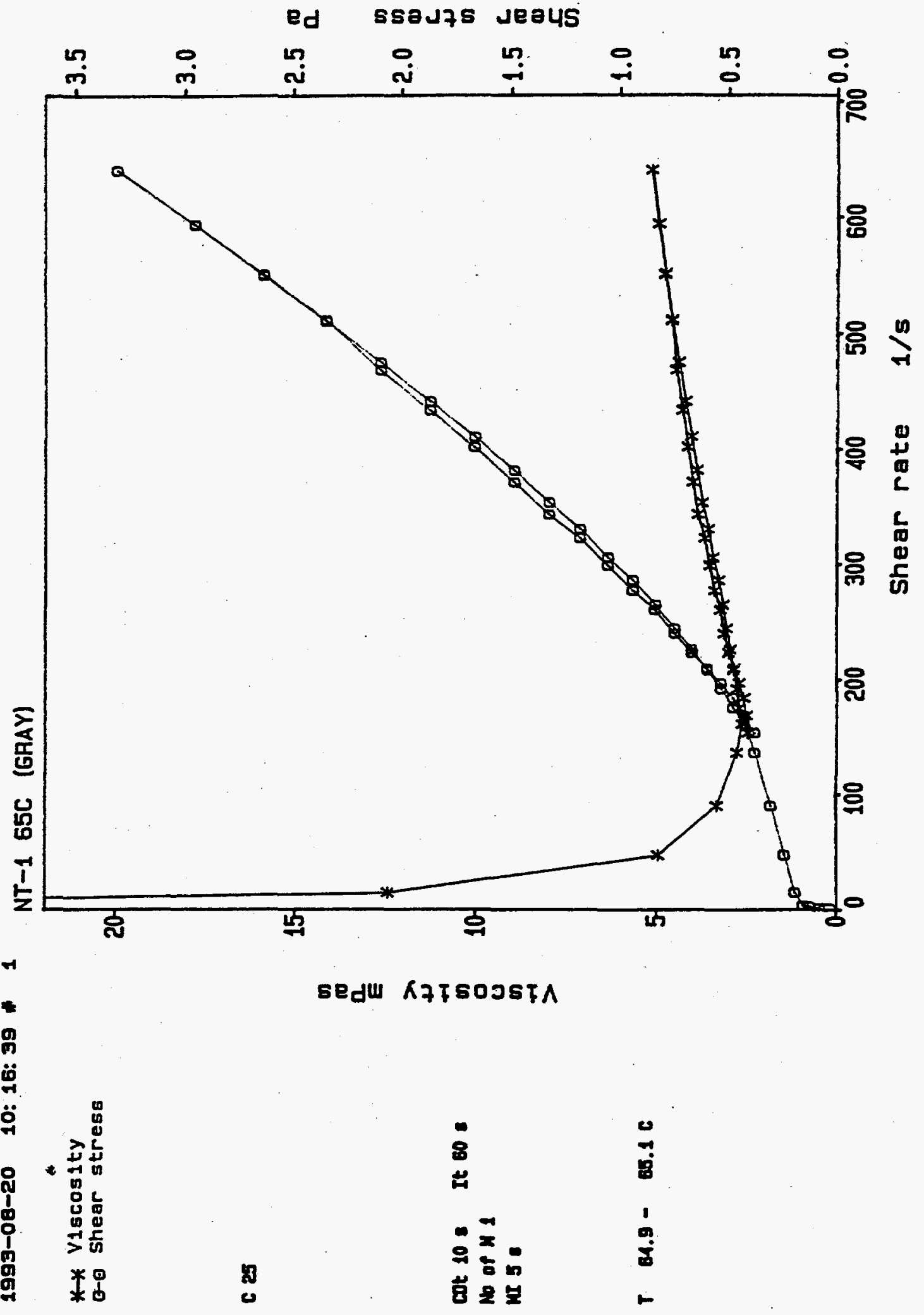




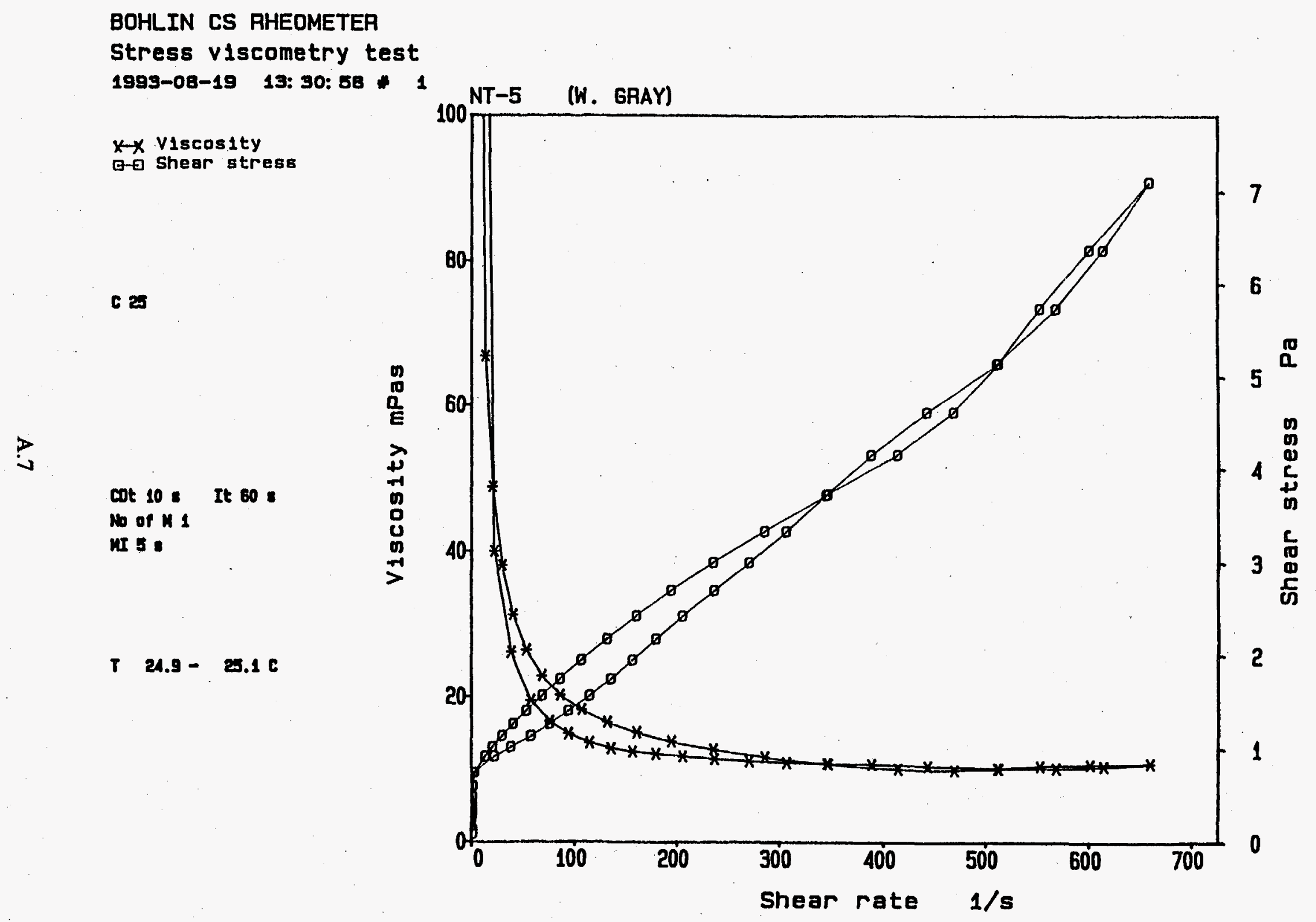


BOHLIN CS RHEOMETER

Stress viscometry test

1993-08-19 12: 20: 02 *1

$x-x$ viscosity

o- Shoar stress

C 25

$p_{\infty}$

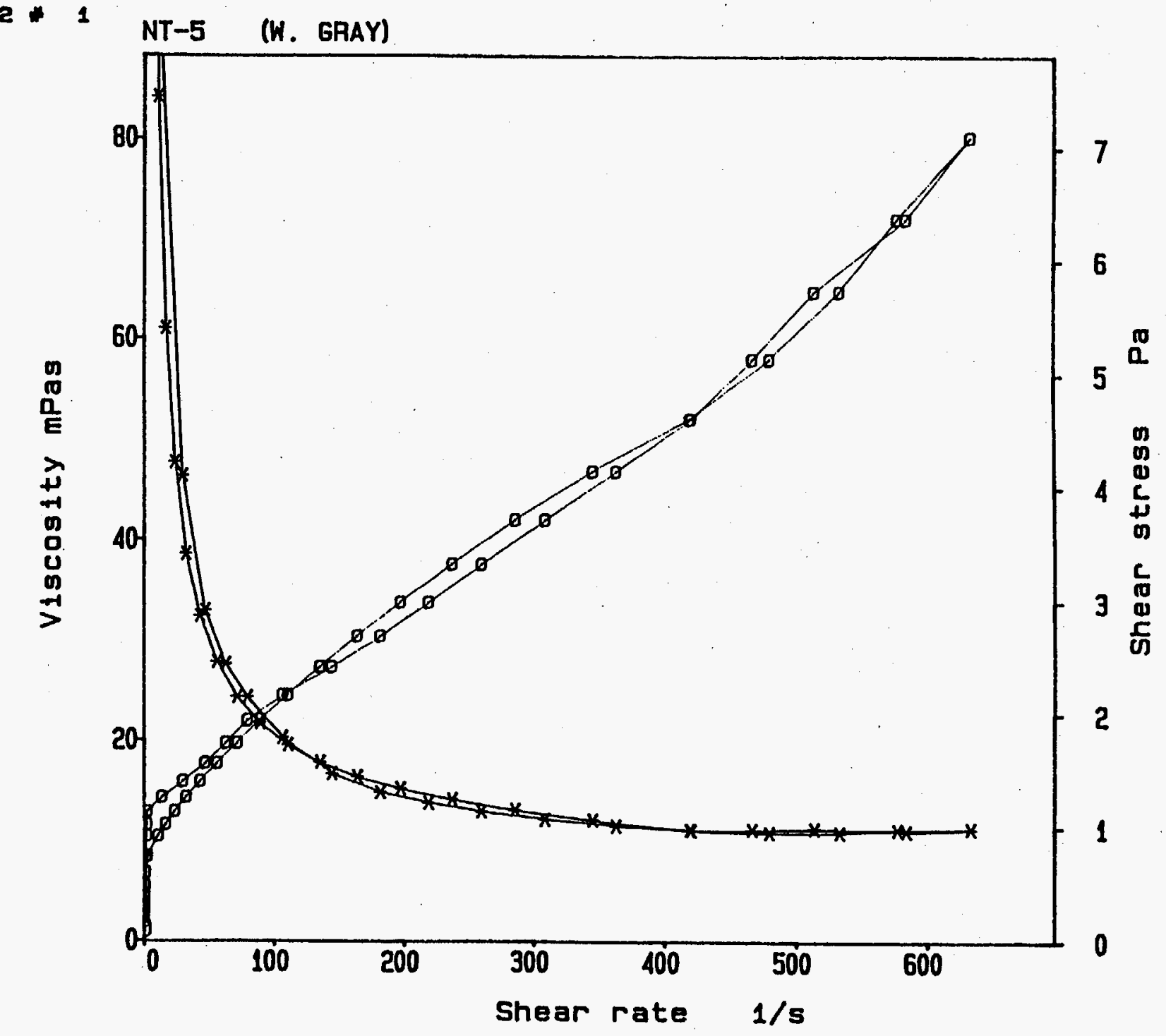

cot $10=$ It 60 =

No of $N 1$

MI 5 :

T $24.9-25.10$ 
BOHLIN CS RHEOMETER

Stress viscometry test

1999-08-20 12: 37: 53*1

$x-x$ Viscosity

Ge Shear stress

C 25

b

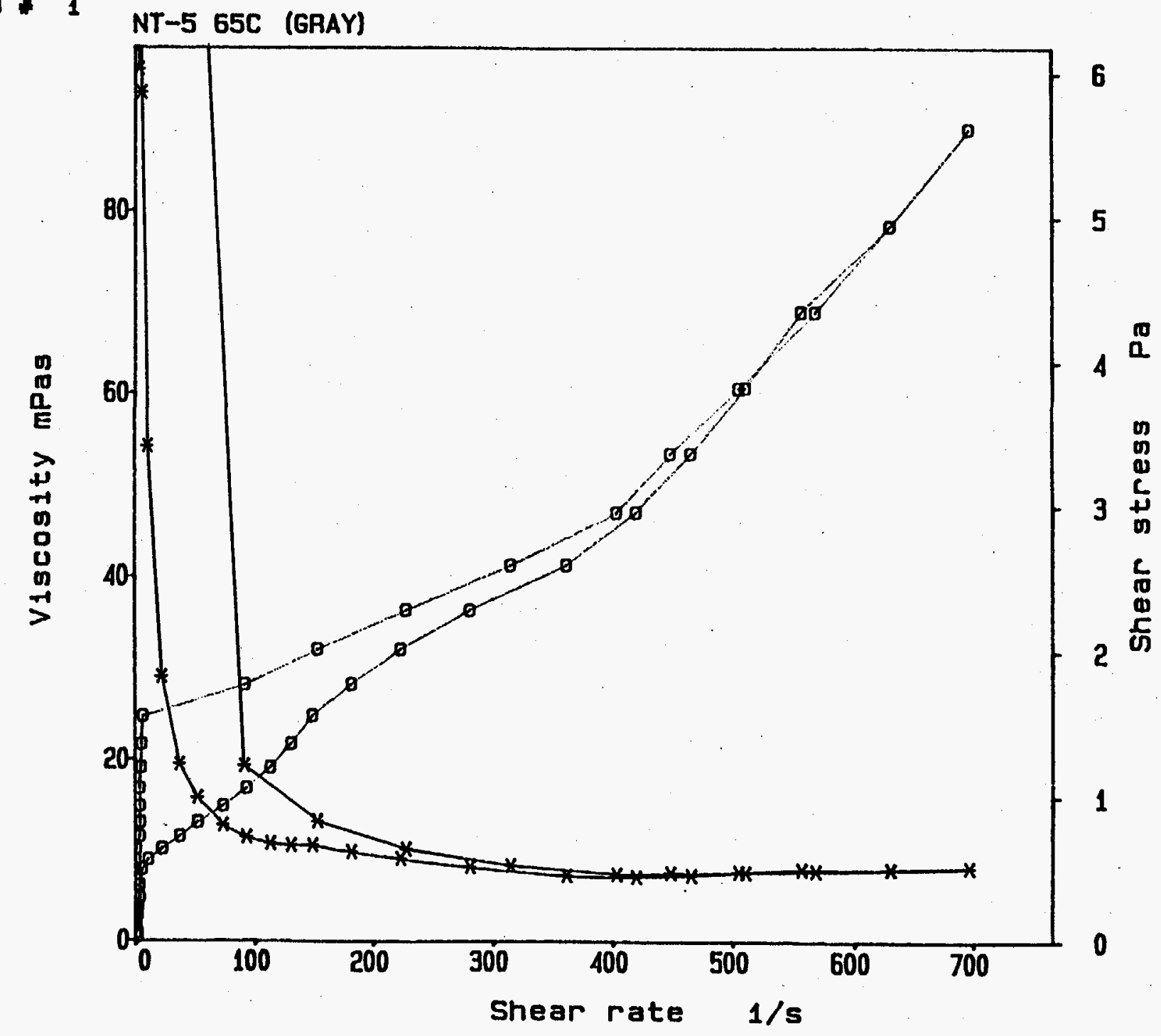

Cot 10 It 60 ino of $n 1$

MI 5 s

T $64.9-65.2 \mathrm{C}$

c Vatavisoscl 
BOHLIN CS RHEOMETER

Stress viscometry test

1993-08-20 13: 99: 44 * 1

*-* V18cosity

O-o Shear stress

c 25

$\frac{7}{0}$

cot 10 It 60 : No of $n 1$

MI $5:$

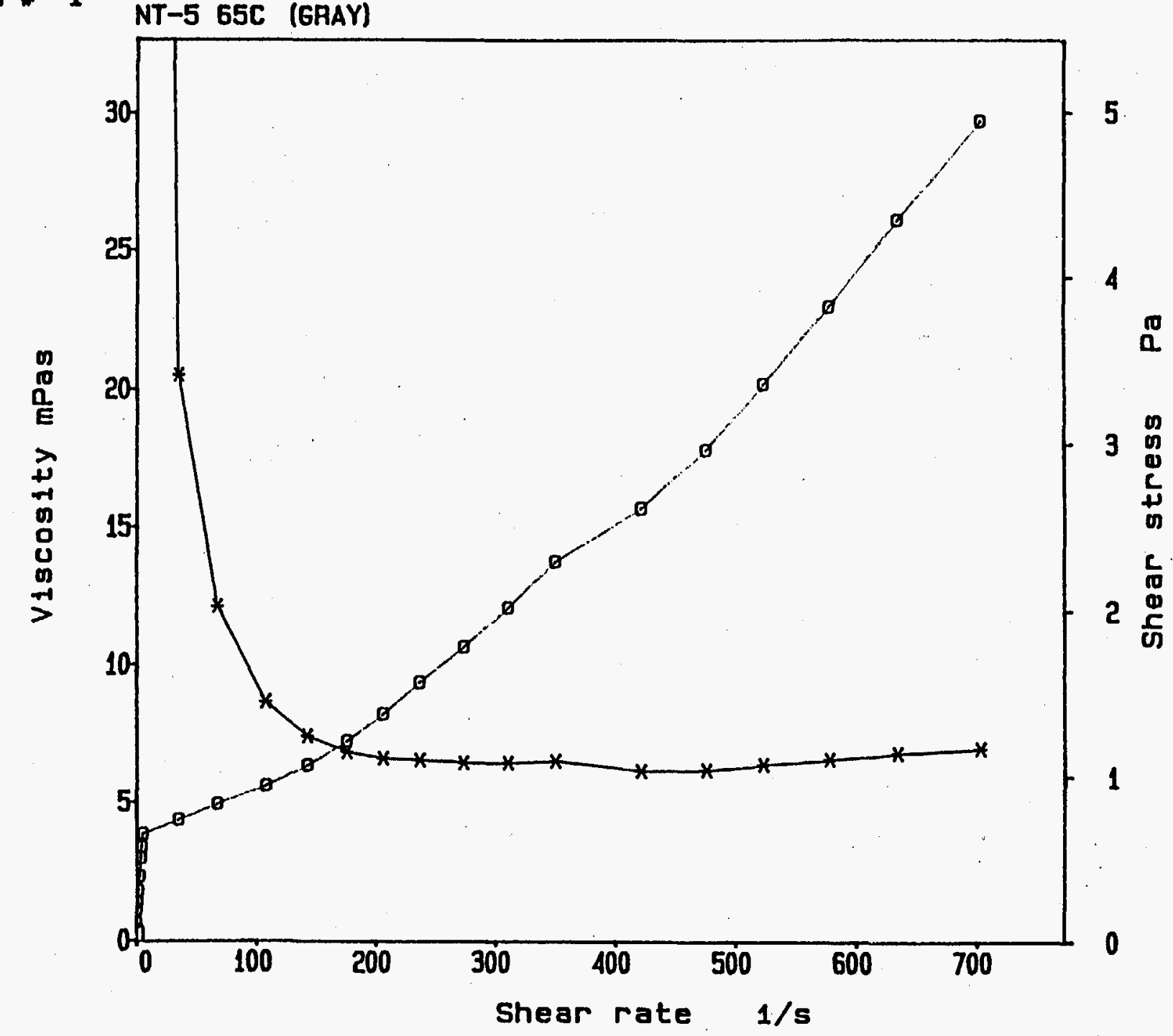

I $64.9-60.1 \mathrm{C}$

c. Datawissoser 


\begin{tabular}{|c|c|c|c|c|}
\hline \multicolumn{5}{|c|}{ YIELD POWER IAW MODEL } \\
\hline \multicolumn{3}{|c|}{$\begin{array}{l}\text { DIAMETER }=2.07 \text { in. } \\
\text { YIELD STRESS (TO) }=0.71 \mathrm{~Pa} \\
\text { CONSISTENCY (K) } 0.237 \mathrm{E}-01 \mathrm{~Pa}^{*}{ }^{*} \mathrm{~m} \\
\text { DENSITY }=1.28 \mathrm{~g} / \mathrm{Cm}{ }^{-3} \\
\text { FIOW BEHAVIOR INDEX }(\mathrm{M})=0.857\end{array}$} & $\begin{array}{l}\text { HEDSTROM } \\
\text { RECRIT = } \\
\text { VCRIT }=2 \\
\text { FIOW CRIT } \\
\text { B }=45.30\end{array}$ & $\begin{array}{l}\text { UMBER }=13869.6 \\
3791.7 \\
.33 \mathrm{ft} / \mathrm{s} \\
=24.33 \mathrm{GPM} \\
1128\end{array}$ \\
\hline POINT & $\begin{array}{l}\text { VEIOCITY } \\
\text { Vel ( fps) }\end{array}$ & $\begin{array}{l}\text { REYNOLDS } \\
\text { Re }\end{array}$ & $\underset{f}{\text { FRICTION FACTOR }}$ & $\begin{array}{l}\text { PRESSURE GRADIENT } \\
\mathrm{dP} / \mathrm{L}(\text { Psi } / 100 \mathrm{ft})\end{array}$ \\
\hline $\begin{array}{r}0 \\
1 \\
2 \\
3 \\
4 \\
5 \\
6 \\
7 \\
8 \\
9 \\
10 \\
11 \\
12 \\
13 \\
14 \\
15\end{array}$ & $\begin{array}{l}0.50 \\
1.00 \\
1.50 \\
2.00 \\
2.50 \\
3.00 \\
3.50 \\
4.00 \\
4.50 \\
5.00 \\
5.50 \\
6.00 \\
6.50 \\
7.00 \\
7.50 \\
8.00\end{array}$ & $\begin{array}{r}654.2 \\
1444.8 \\
2296.6 \\
3190.7 \\
4117.7 \\
5071.8 \\
6049.0 \\
7046.4 \\
8061.8 \\
9093.6 \\
10140.2 \\
11200.5 \\
12273.6 \\
13358.5 \\
14454.6 \\
15561.2\end{array}$ & $\begin{array}{l}0.08419 \\
0.02634 \\
0.01382 \\
0.00889 \\
0.00644 \\
0.00596 \\
0.00572 \\
0.00549 \\
0.00529 \\
0.00512 \\
0.00498 \\
0.00485 \\
0.00474 \\
0.00464 \\
0.00455 \\
0.00447\end{array}$ & $\begin{array}{l}0.420 \\
0.526 \\
0.621 \\
0.710 \\
0.804 \\
1.072 \\
1.398 \\
1.752 \\
2.138 \\
2.556 \\
3.006 \\
3.487 \\
3.999 \\
4.541 \\
5.113 \\
5.714\end{array}$ \\
\hline
\end{tabular}




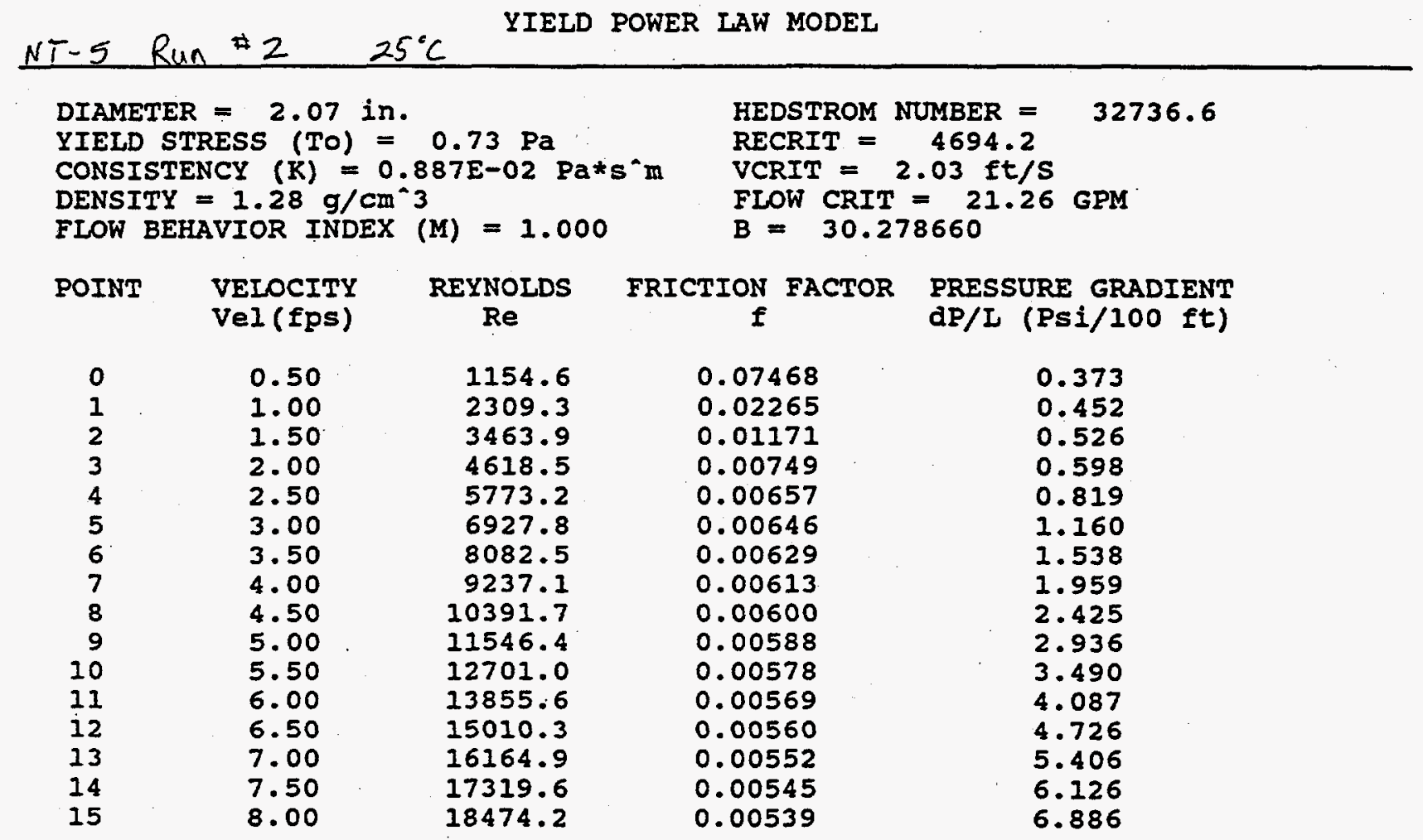




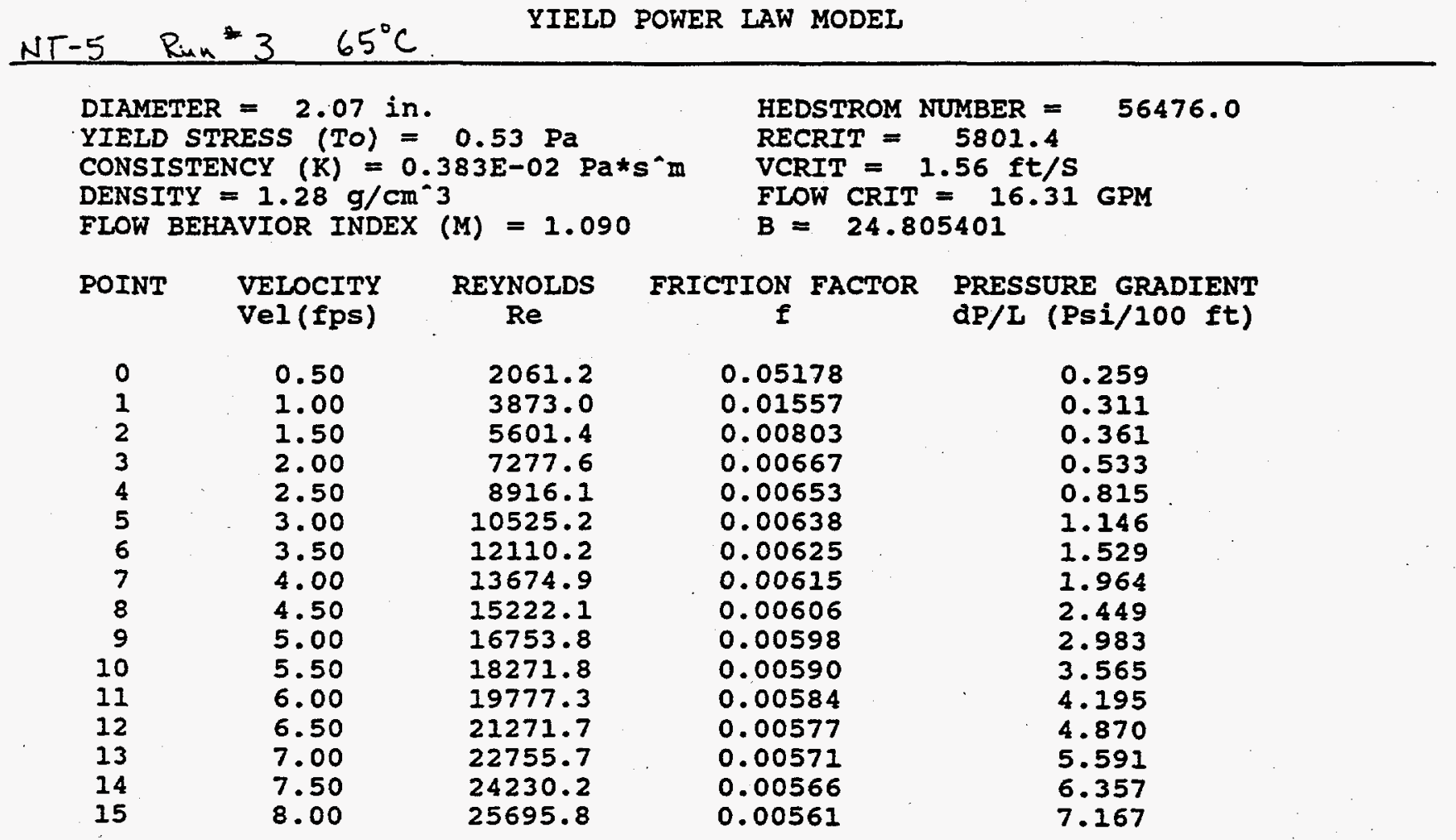




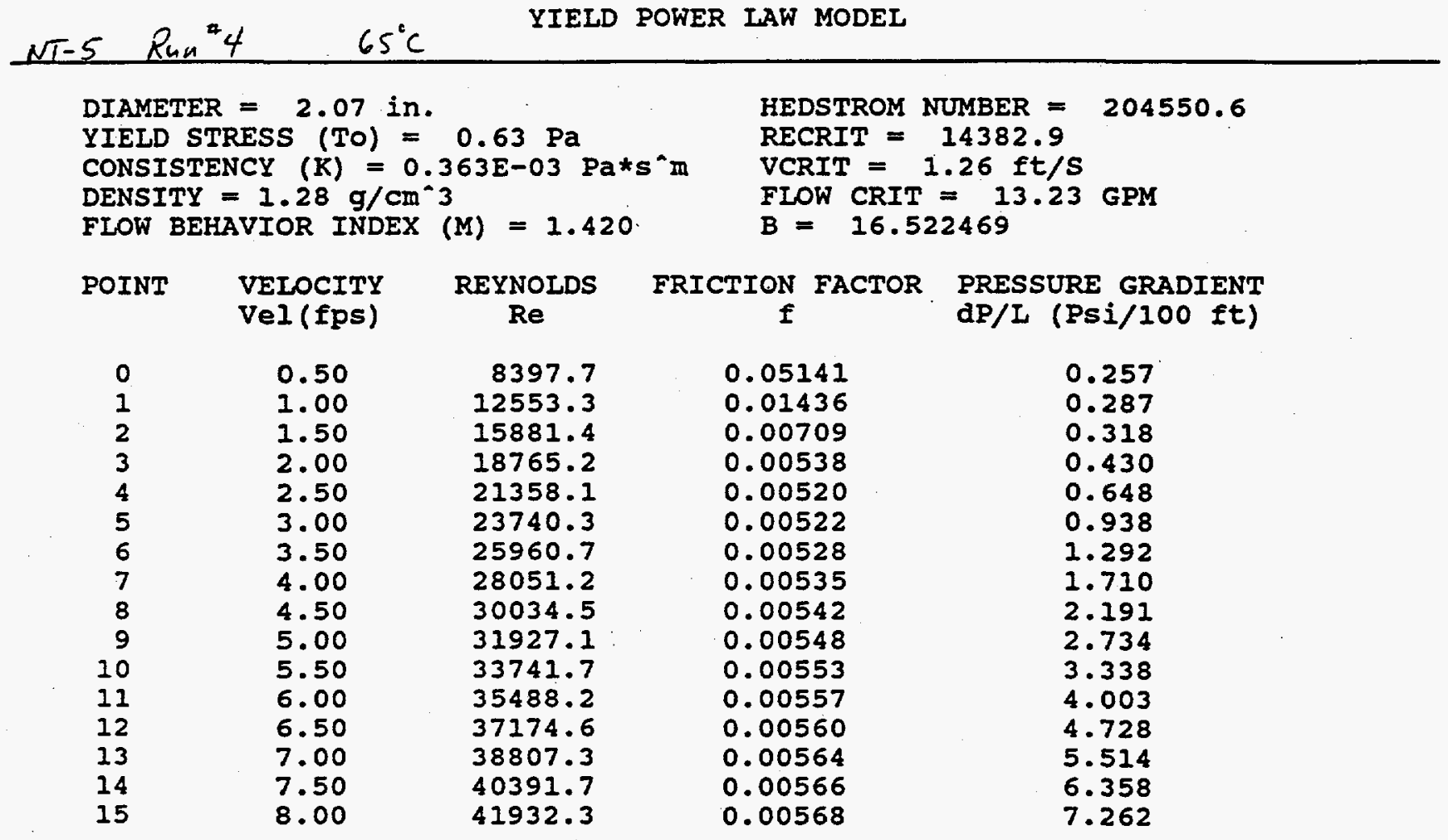


Appendix B

Particle-Size Distribution Results 


\section{Appendix B}

\section{Particle-Size Distribution Results}

This appendix shows the results of particle-size distribution measurements made by a Brinkman particle-size analyzer on two slurries produced by mixing dilute THOREX with $1 \mathrm{M} \mathrm{NaOH}$ (designated NT-1) and with $5 \underline{\mathrm{M} \mathrm{NaOH}}$ (designated NT-5). Results are also shown for a glass sphere reference standard, Duke 147, with a nominal mean particle diameter of $20 \mu \mathrm{m}$.

Results for the standard are shown on a volume density graph using a logarithmic scale. Results for the two slurries are shown in three ways: (1) a number density graph with a logarithmic scale; (2) a volume density graph with a logarithmic scale; and (3) a volume density graph using a linear scale.

The number density graphs list the mean particle diameter based on the total number of particles, which was calculated by Equation (B.1).

$$
\operatorname{Mean}(\mathbf{n l})=\Sigma \mathrm{d} / \mathrm{n}
$$

where $\Sigma d=$ summation over the measured individual particle diameters

$\mathrm{n}=$ total number of particles.

The volume density graphs list mean particle diameters based on the total volume of particles in two ways, Equations (B.2) and (B.3).

$$
\operatorname{Mean}(\mathbf{n v})=\Sigma \mathrm{V} / \mathrm{n}
$$

where $\Sigma \mathrm{V}=$ summation over the measured individual particle volumes

$\mathbf{n}^{\prime}=$ total number of particles

$$
\operatorname{Mean}(\mathrm{vm})=\Sigma \mathrm{Vd} / \Sigma \mathrm{V}
$$

where $\Sigma V d=$ summation over the measured individual particle volumes multiplied by their measured diameters

$\Sigma \mathrm{V}=$ total volume of particles

The last equation gives the mean particle diameter that is probably most useful. See Section 3.1.3 for additional discussion of the different ways of representing the particle-size results. 


$$
G A L A X-C I S-1
$$

Computeri

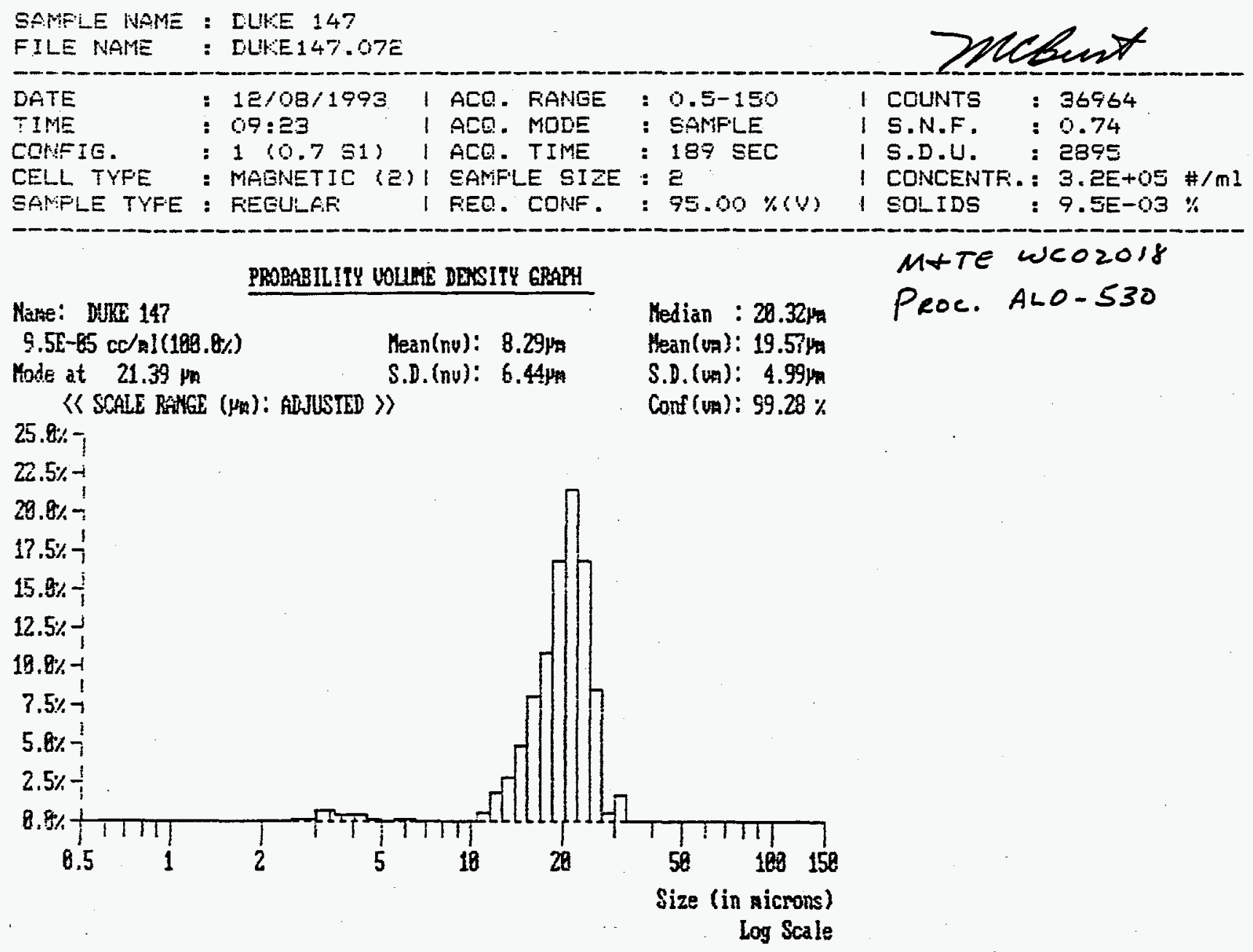




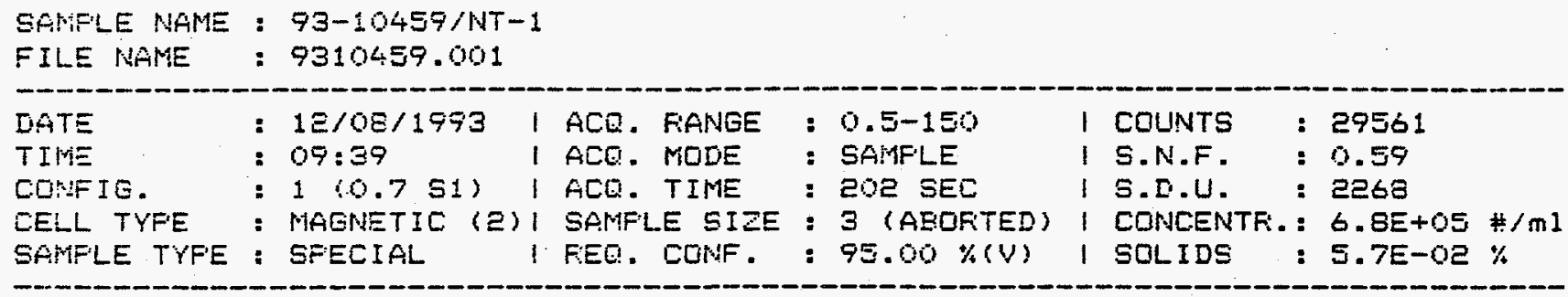

\section{PROPGBILITY HUREER DEASITY GRAPH}

hane: $93-18459$ NTI-1

Median : $1.25 \mathrm{H}_{\mathrm{R}}$

$6.8 \mathrm{E}+65 \mathrm{Vm} /(199.8 \%)$

rode at $1.25 \mathrm{fm}$

Hean(nl): 2.27 pm

S.D.(nl): $5.80 \mathrm{pm}$

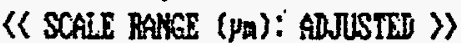

$\operatorname{Conf}(n): 93.48 \%$

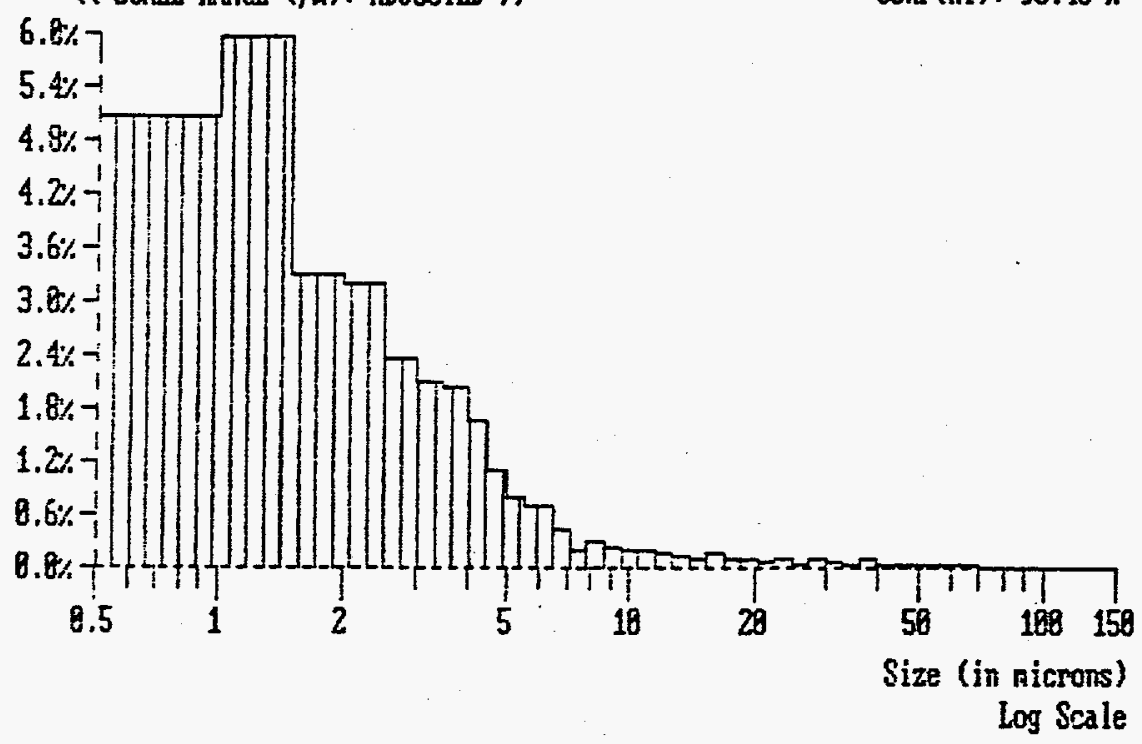




\section{GALA I I

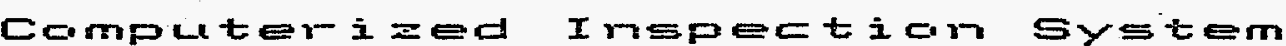

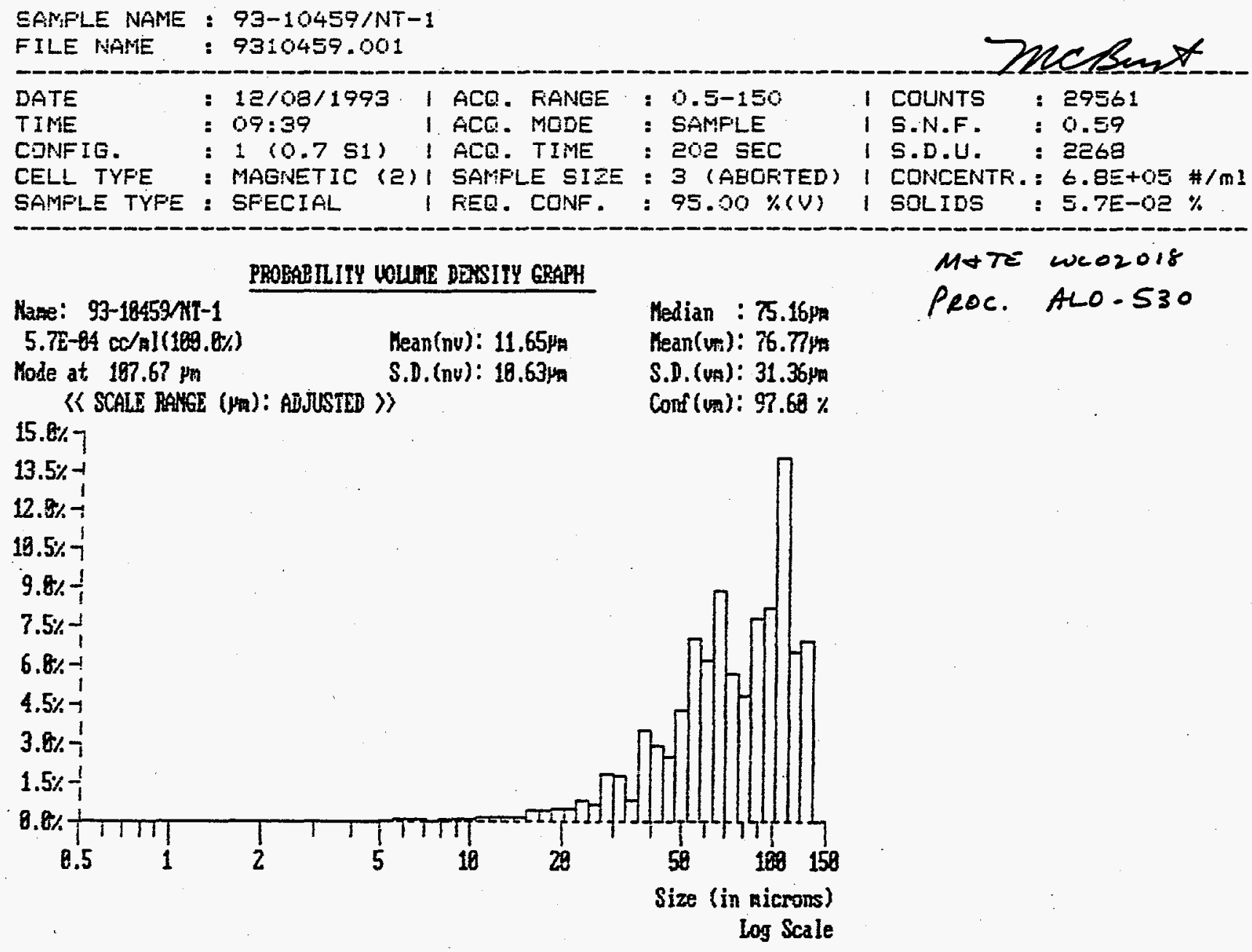




\begin{tabular}{|c|c|c|c|c|c|c|c|c|c|c|}
\hline $\begin{array}{l}\text { SAMFLE NAME } \\
\text { FILE NAME }\end{array}$ & : & $\begin{array}{l}93-10459 / N T- \\
9310459.001\end{array}$ & & & & & & & & \\
\hline & & & & & & & & & & \\
\hline DATE & $:$ & $12 / 08 / 1993$ & 1 & ACQ. FAANGE & : & $0.5-150$ & 1 & COUNTS & : 27561 & \\
\hline TIME & $:$ & $09: 39$ & 1 & ACQ. MODE & $:$ & SAMFLE & 1 & S.W.F. & $=0.59$ & \\
\hline EENFIG. & $:$ & $1(0.751)$ & 1 & ACQ. TIME & $:$ & 2OP SEC & 1 & S.D.U. & : Eᄅడ & \\
\hline CELL TYFE & $:$ & MAGHETIC (P) & & SAMFLE SIZE & $:$ & $\Xi$ (AECIFITED) & 1 & CONCENTE. : & $=6.8 E+05$ & 邦/ $\mathrm{ml}$ \\
\hline SAMFLE TYFE & : & SFEEIAL & 1 & FEEQ . COIJF. & $:$ & $95.00 \%(\mathrm{~V})$ & 1 & SOLIDS & $: 5.7 E-02$ & $\%$ \\
\hline
\end{tabular}

\section{PROBABILITY VOLUHE DEXSITY GRAPH}

Nane: 93-18459/4T-1

$5.72-84 \mathrm{cc} / \mathrm{al}(180.8 \%)$

Hode at $68.75 \mathrm{ma}$

《( SCALE RANGE ( $p m):$ ADJUSITI 》)

Hean(nv): $11.65 \mathrm{Hm}$

Median : $75.16 \mathrm{~m}$

$6.8 \% 7$

S.D.(nv): 18.63 pa

Kean $(\mathrm{m}): 76.77 \mathrm{pm}$

S.D. (vm): 31.36\%

Conf (U⿴囗十): $97.68 \%$

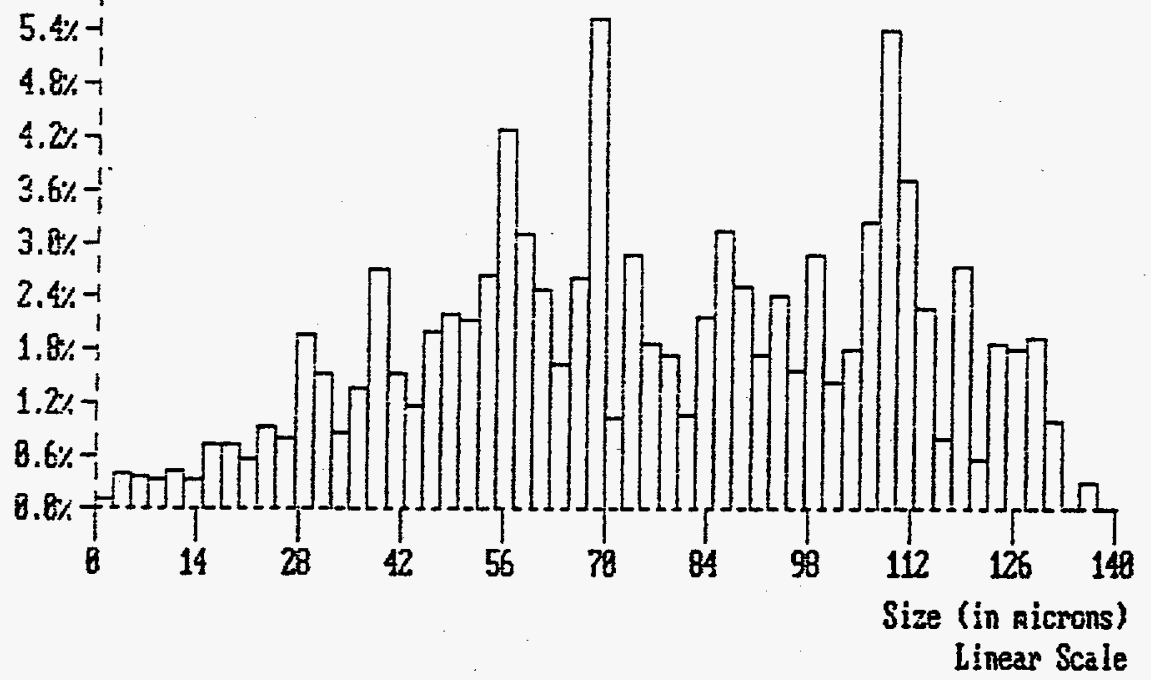




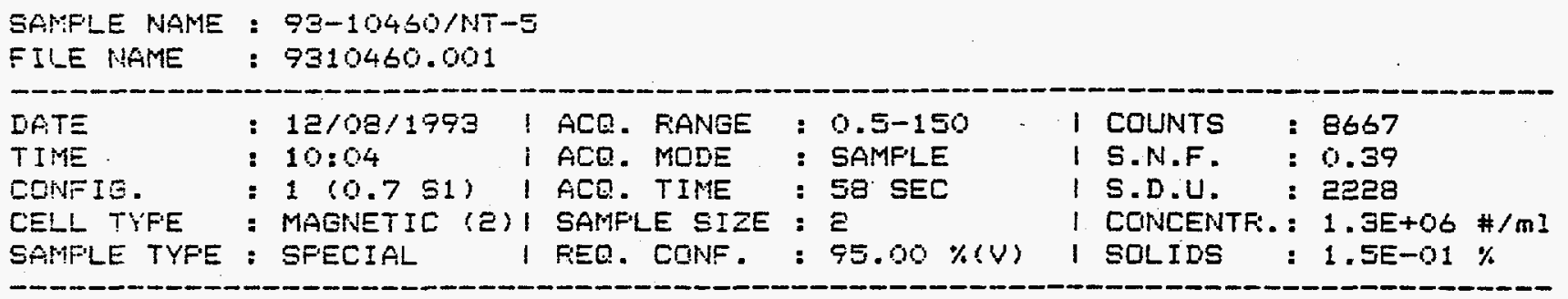

\section{FROBAEILIFY KMBRR IEASITY GRAPA}

Hane: $97-18468$ /it -5

$1.35+85 \% / n 1(188.8 \%)$

tode at $1.25 \mathrm{~m}$

《( SCALE RANGE $(\mu m):$ ADIUSTE 》

Median : $1.18 \mathrm{~mm}$

Kean(nl): 2.82\%

S.D.(nl): $5.13 \mathrm{man}$

7.8\% 7

$6.3 \%+$

Conf (nl): $81.81 \%$

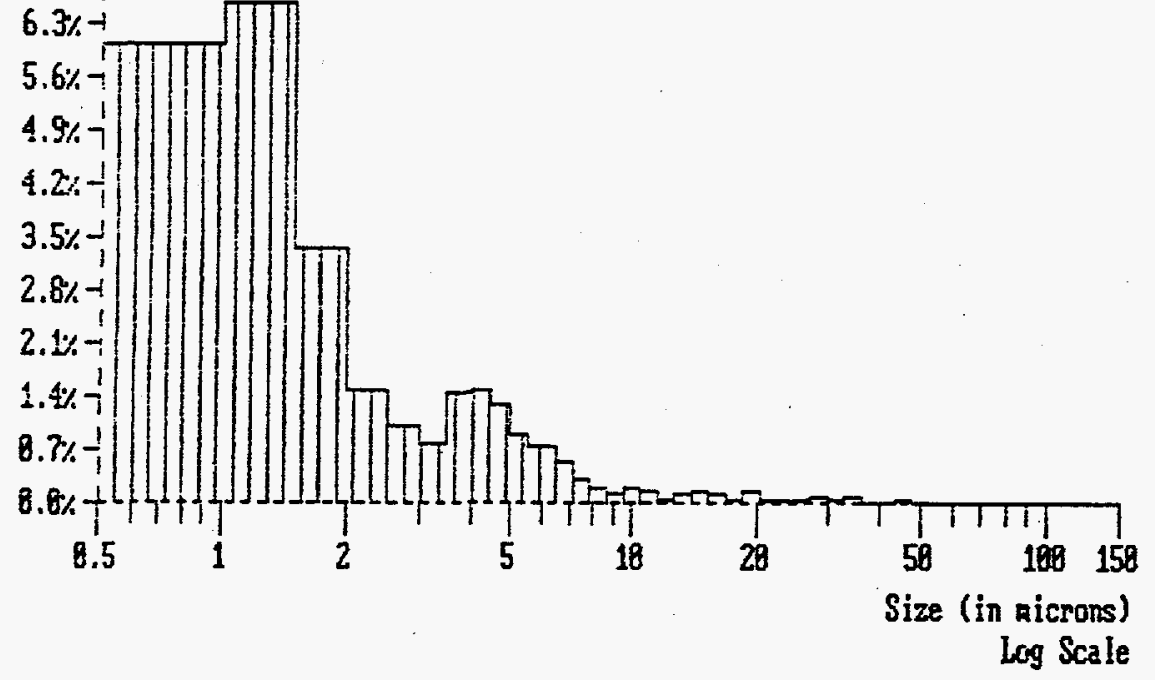

B.6 


\section{$G A L A$ G \\ CсMPLtEr}

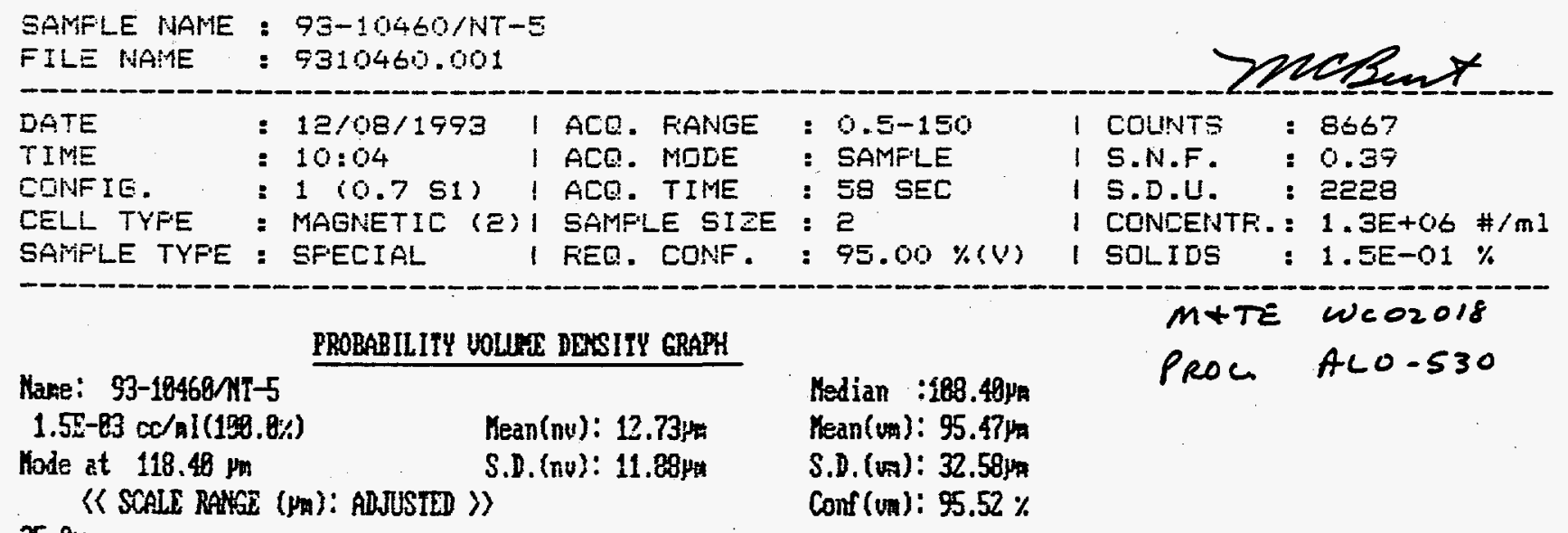

$25.8 \% 7$

$22.5 \%-1$

$17.5 \% ?$

$15.8 \% \frac{1}{1}$

$12.5 \%$ 光

$10.8 \%-1$

7.5\%-

$5.8 \% 7$

$2.5 \% \frac{1}{1}$

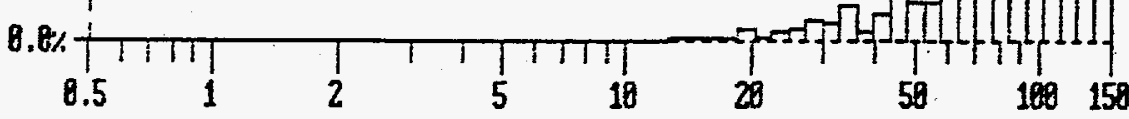

Size (in nicrons)

Log Scale 


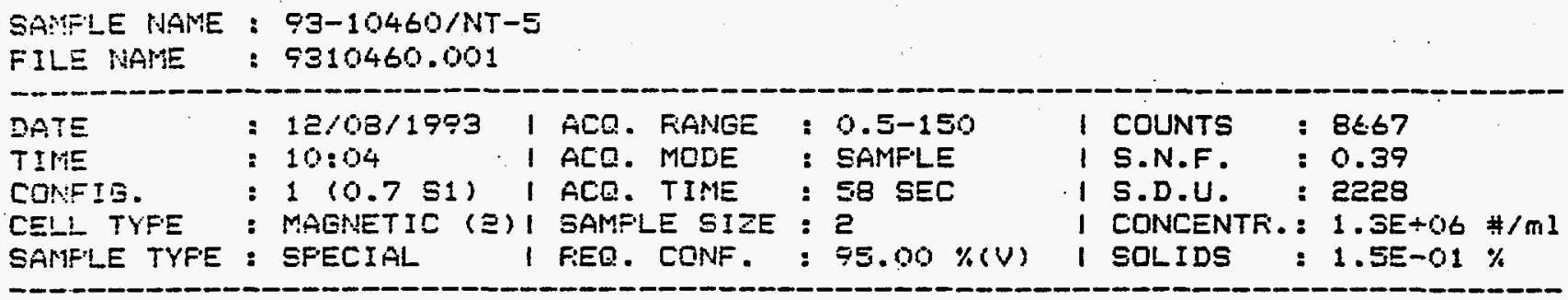

PROBABILITY VOLHE DESITY GPAPH

Nape: 93-18469/it-5

$1.5 \mathrm{E}-83 \mathrm{cc} / \mathrm{ml}(188.8 \%)$

Node at 118,75 $\mathrm{pm}$

《S SCALE PANGE ( $\left.\mu_{m}\right)$ : ADJUSTED 》

Mean(nu): 12.73/m

S.D. (nv): 11.88)

Median :188.40 $\mathrm{pm}$

heer. (va): 95.47\%

S.D. (vm): $32.58 \mathrm{pm}$

Conf (on): $95.52 \%$

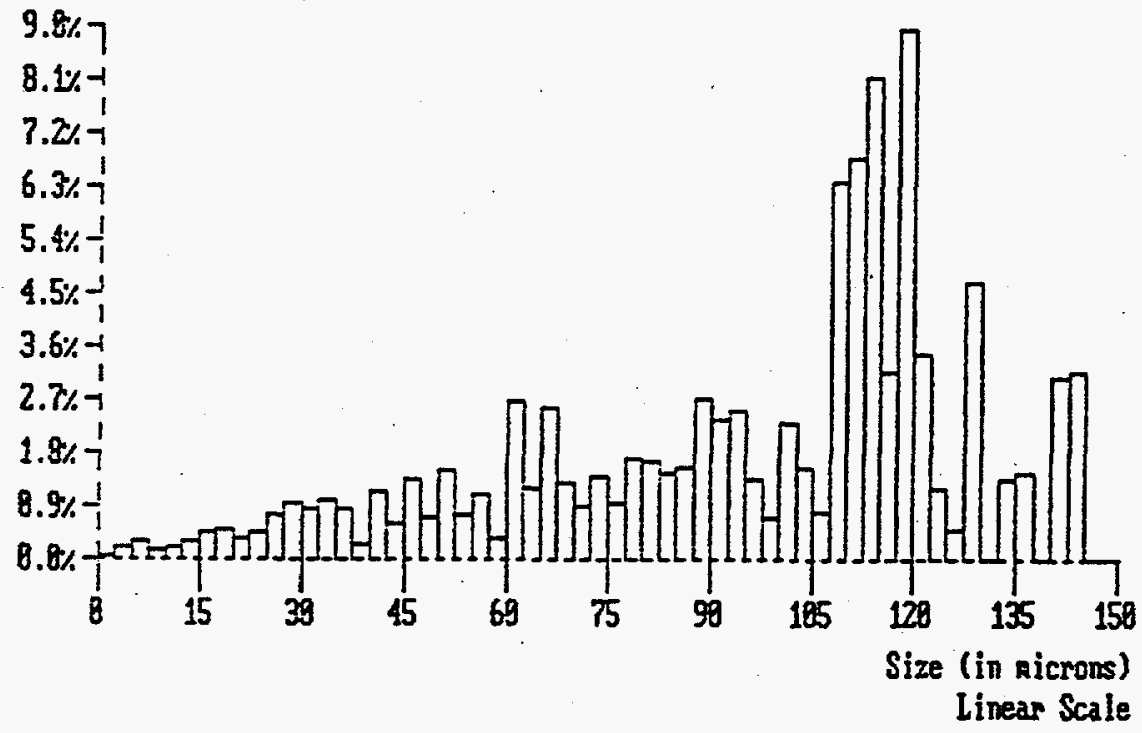


Appendix C

Figures 


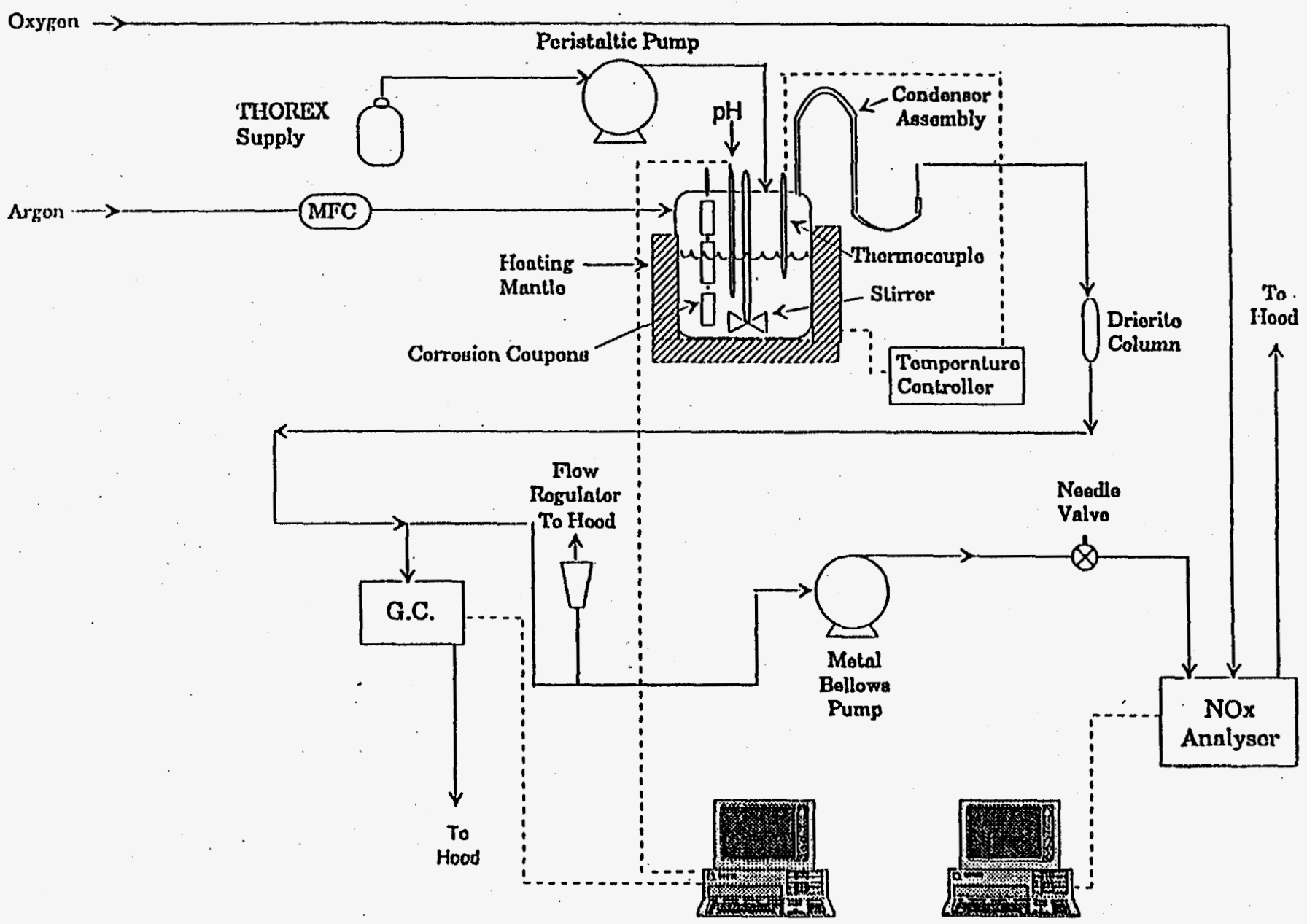

Figure C.1. Schematic Diagram of THOREX/PUREX Mixing Apparatus and Gas Analysis Equipment 


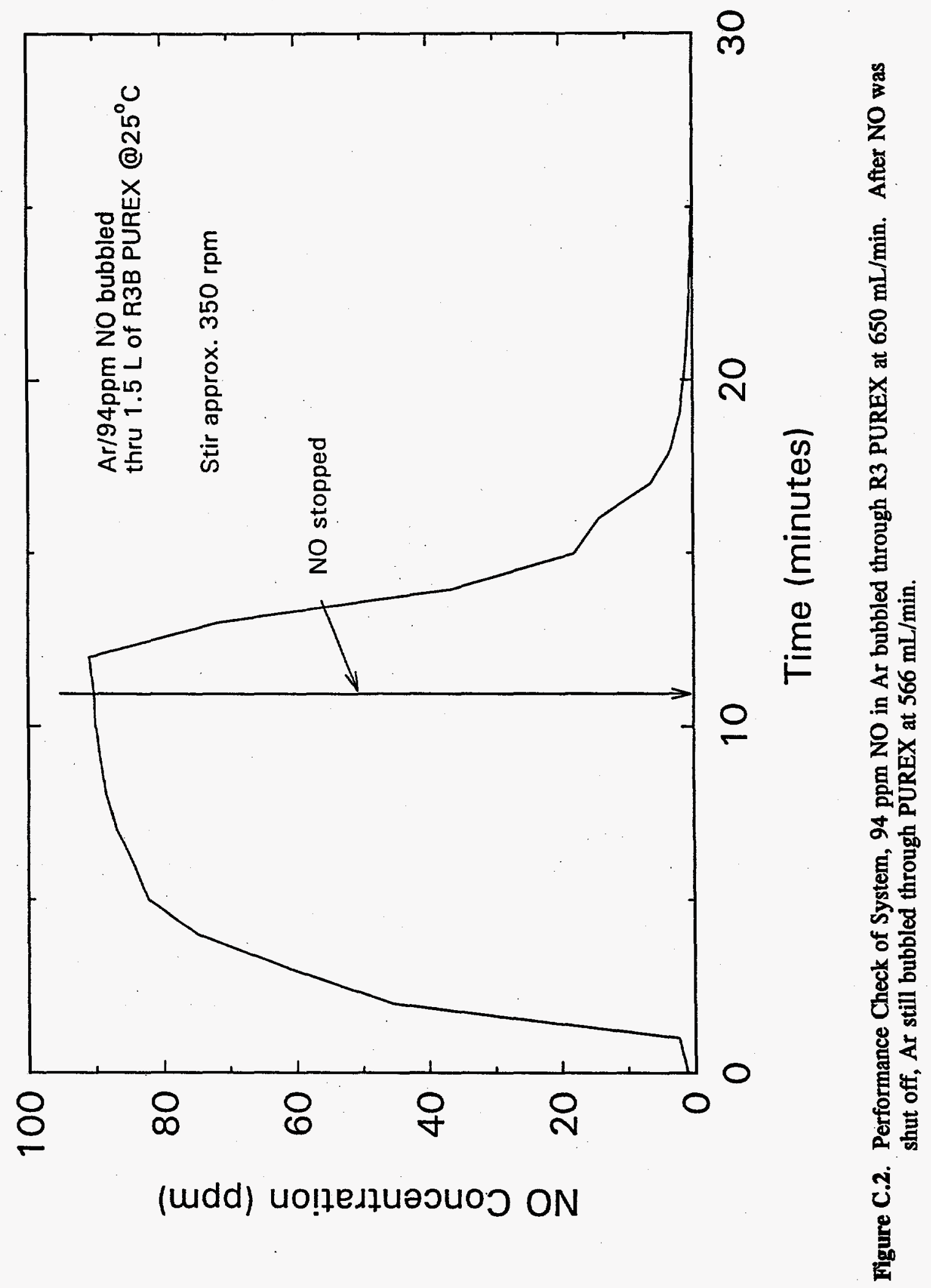




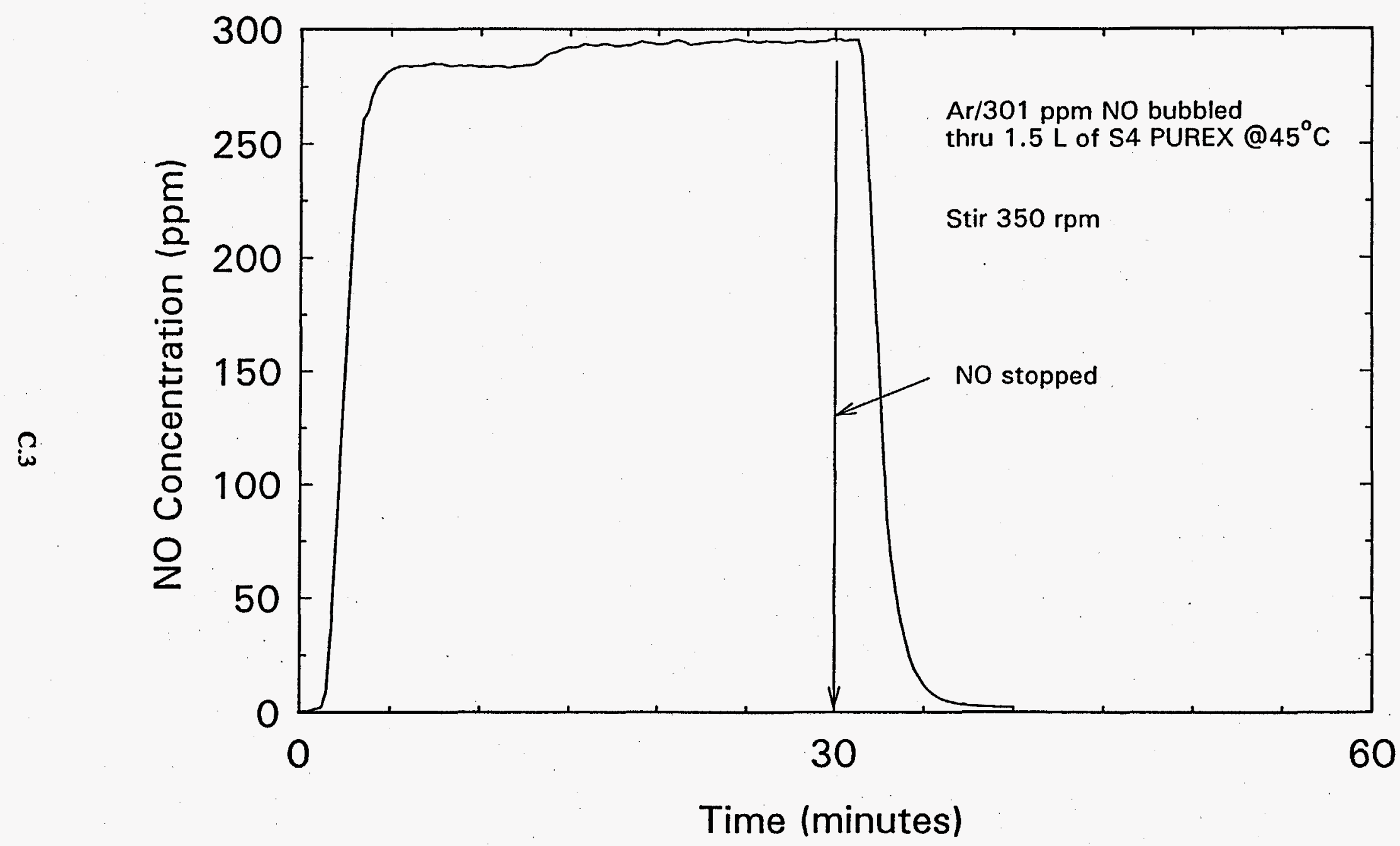

Figure C.3. Performance Check of System, $301 \mathrm{ppm}$ NO in Ar bubbled through S4 PUREX at $1500 \mathrm{~mL} / \mathrm{min}$. After NO was shut off, Ar still passed through vessel at $1090 \mathrm{~mL} / \mathrm{min}$. 


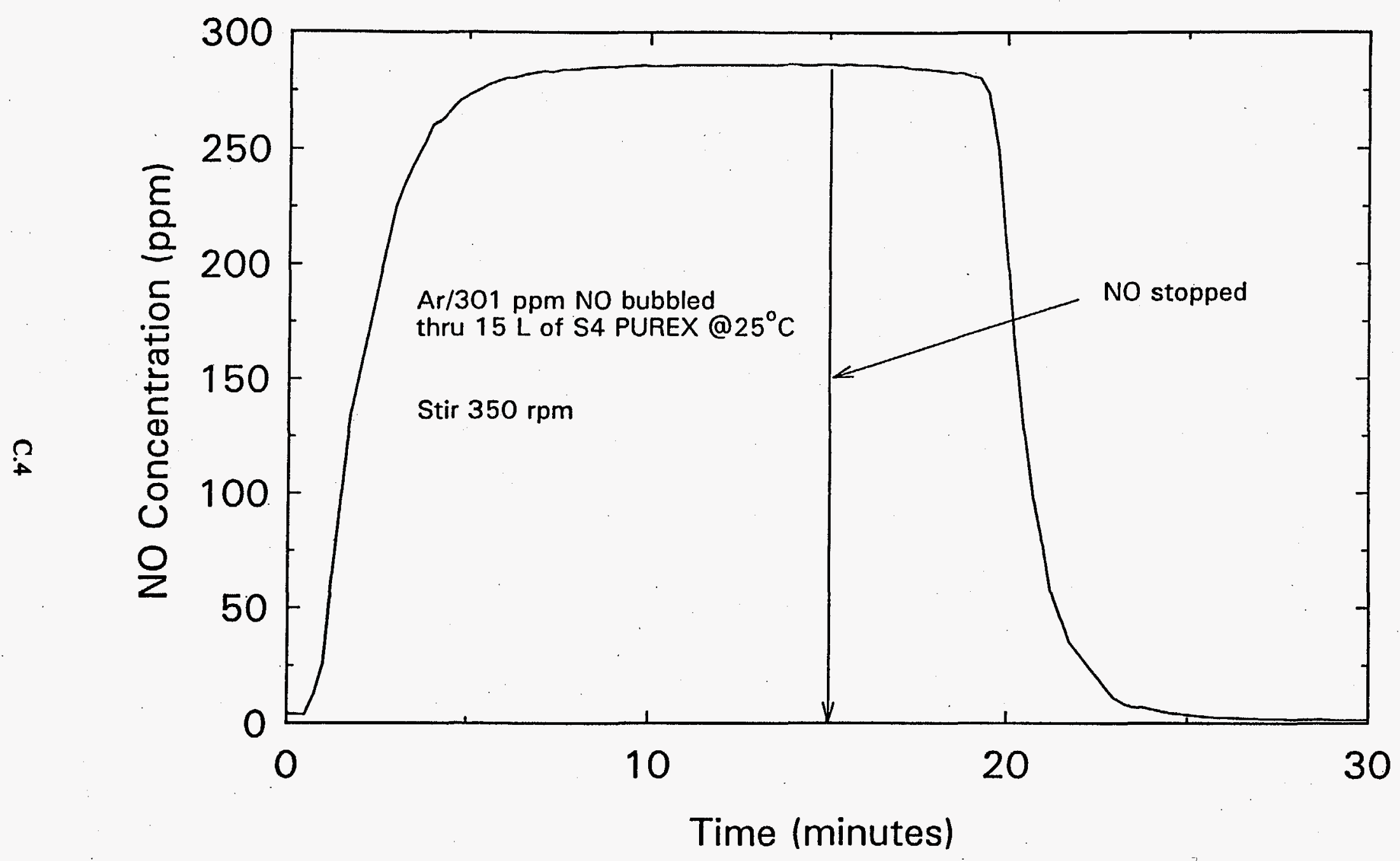

Figure C.4. Performance Check of Large-Scale System, $301 \mathrm{ppm}$ NO in Ar bubbled through S4 PUREX at $1510 \mathrm{~mL} / \mathrm{min}$. After NO was shut off, Ar still bubbled through PUREX at $1090 \mathrm{~mL} / \mathrm{min}$. 


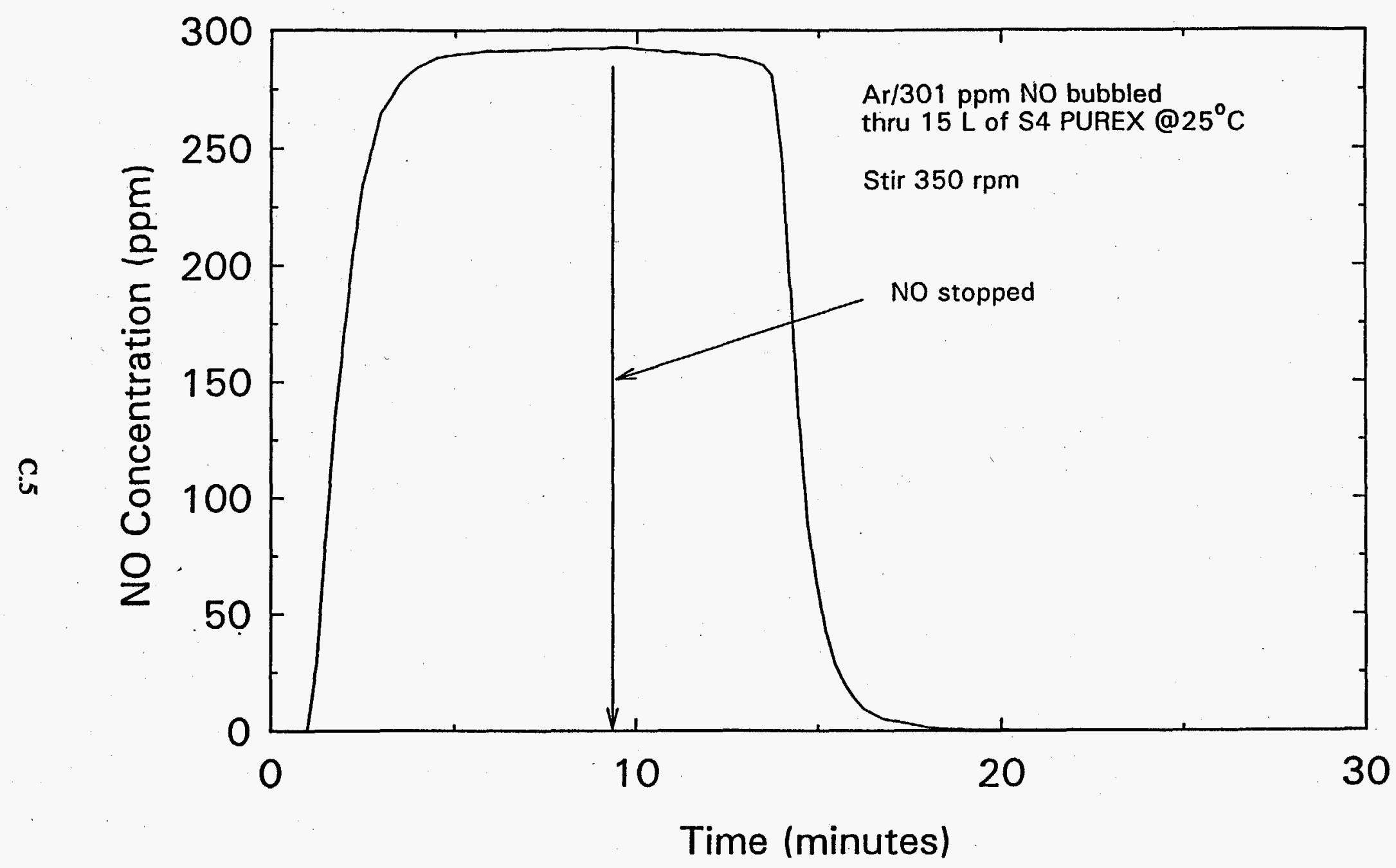

Figure C.5. Performance Check of Large-Scale System, $301 \mathrm{ppm}$ NO in Ar bubbled through S4 PUREX at $1510 \mathrm{~mL} / \mathrm{min}$ following Test 23B; thus, the vessel contained the solids that resulted from Test 23B. After NO was shut off, Ar still bubbled through PUREX at $1090 \mathrm{~mL} / \mathrm{min}$. 


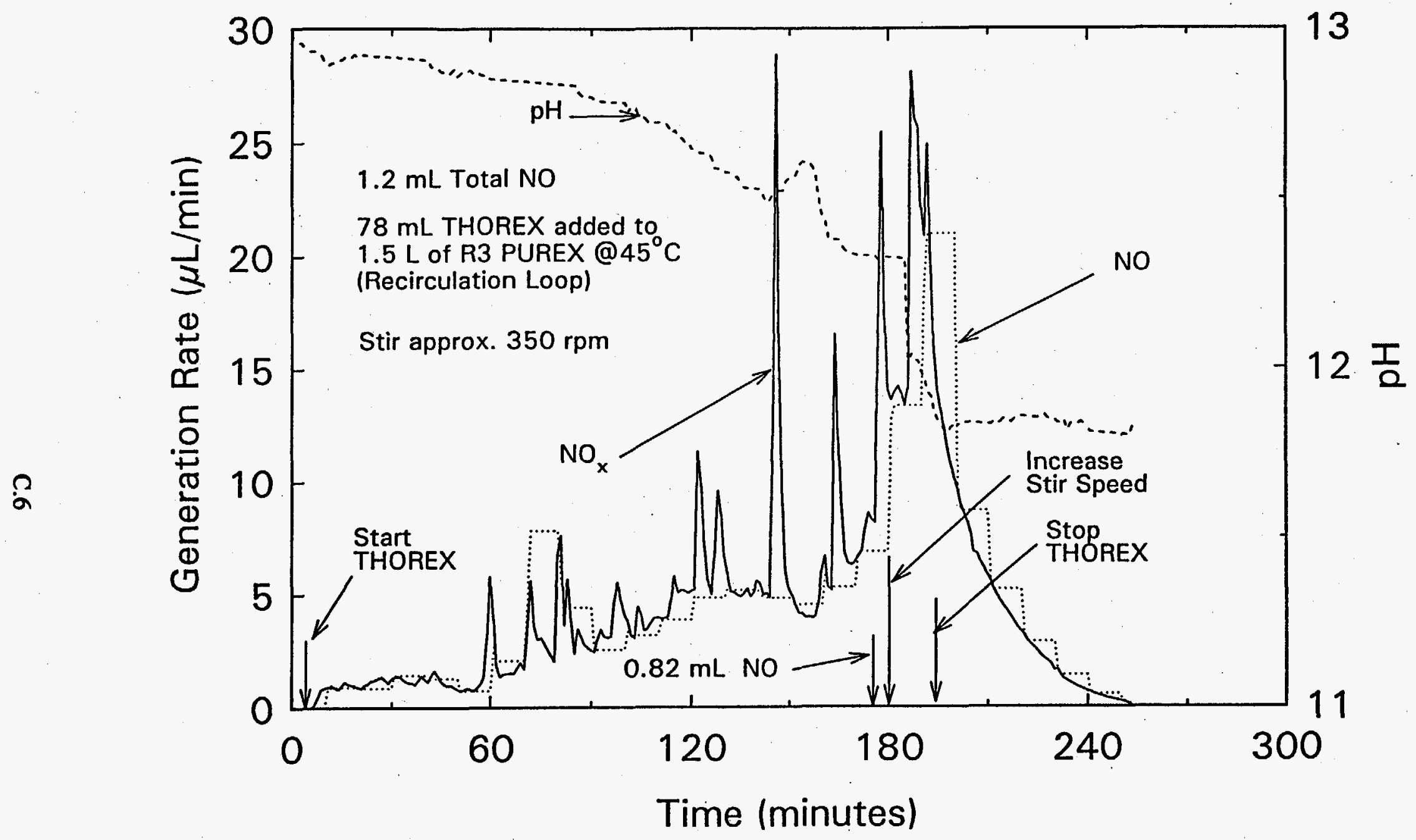

Figure C.6. Test 1. This Test, Along with Tests 2 and 3 (Figures C:7 and C.8), was Conducted to Determine Whether Pumping THOREX Into a PUREX Recirculation Loop would Generate less NO than Addition of THOREX Directly into the PUREX. 


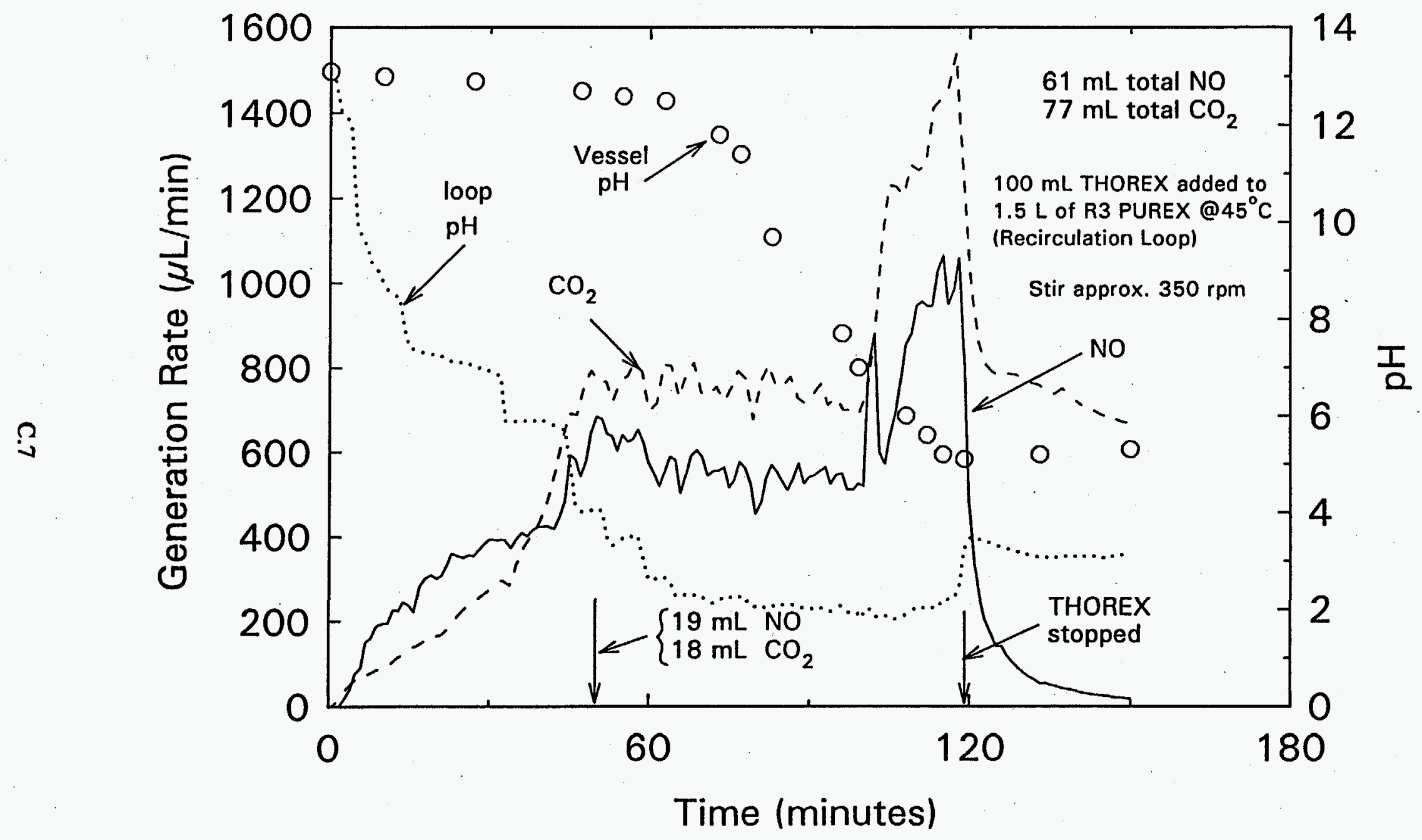

Figure C.7. Test 2. The Ratio of Loop-Flow-Rate to THOREX-Addition-Rate was much Lower than that Represented in Figure C.6 


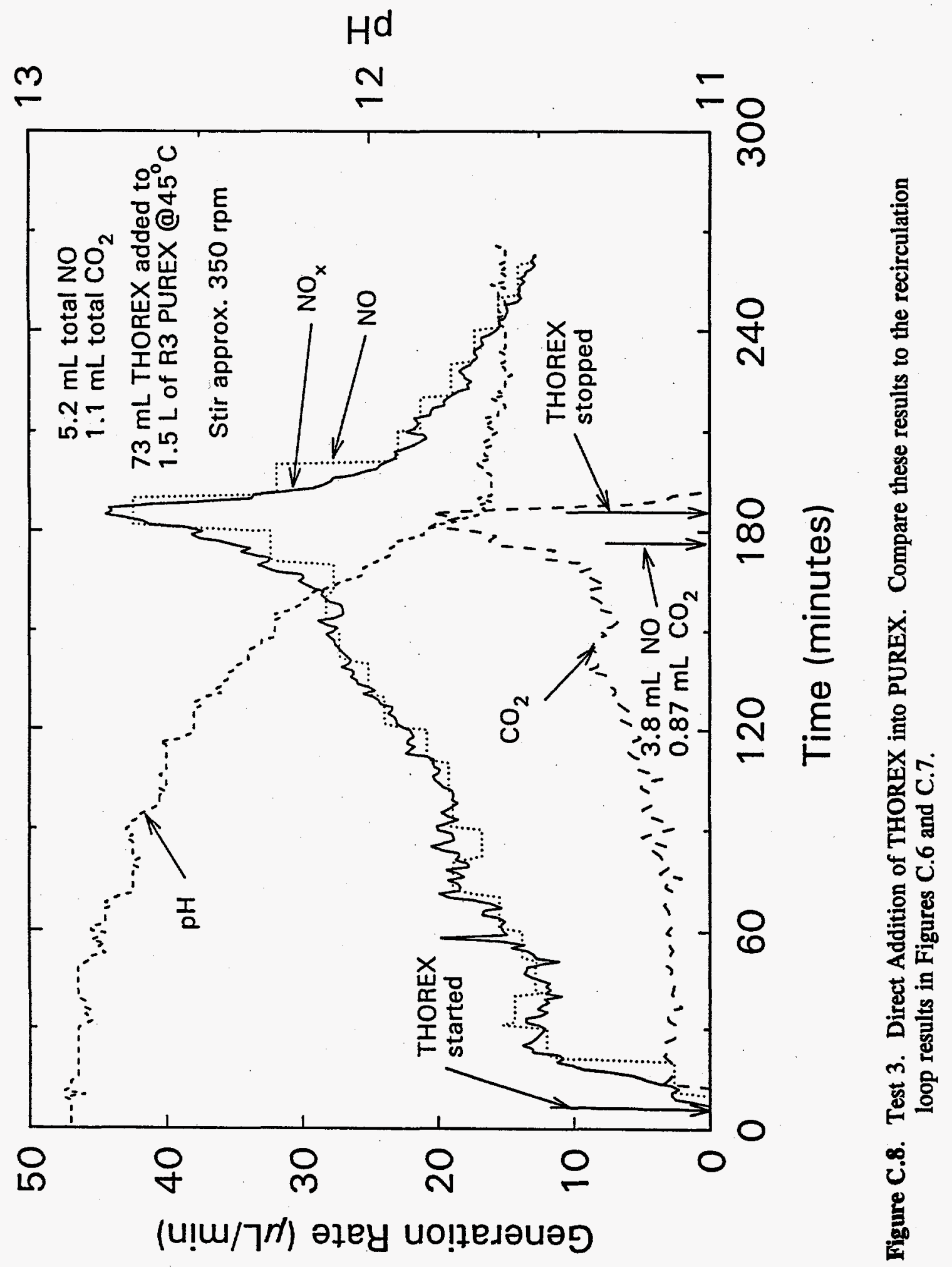




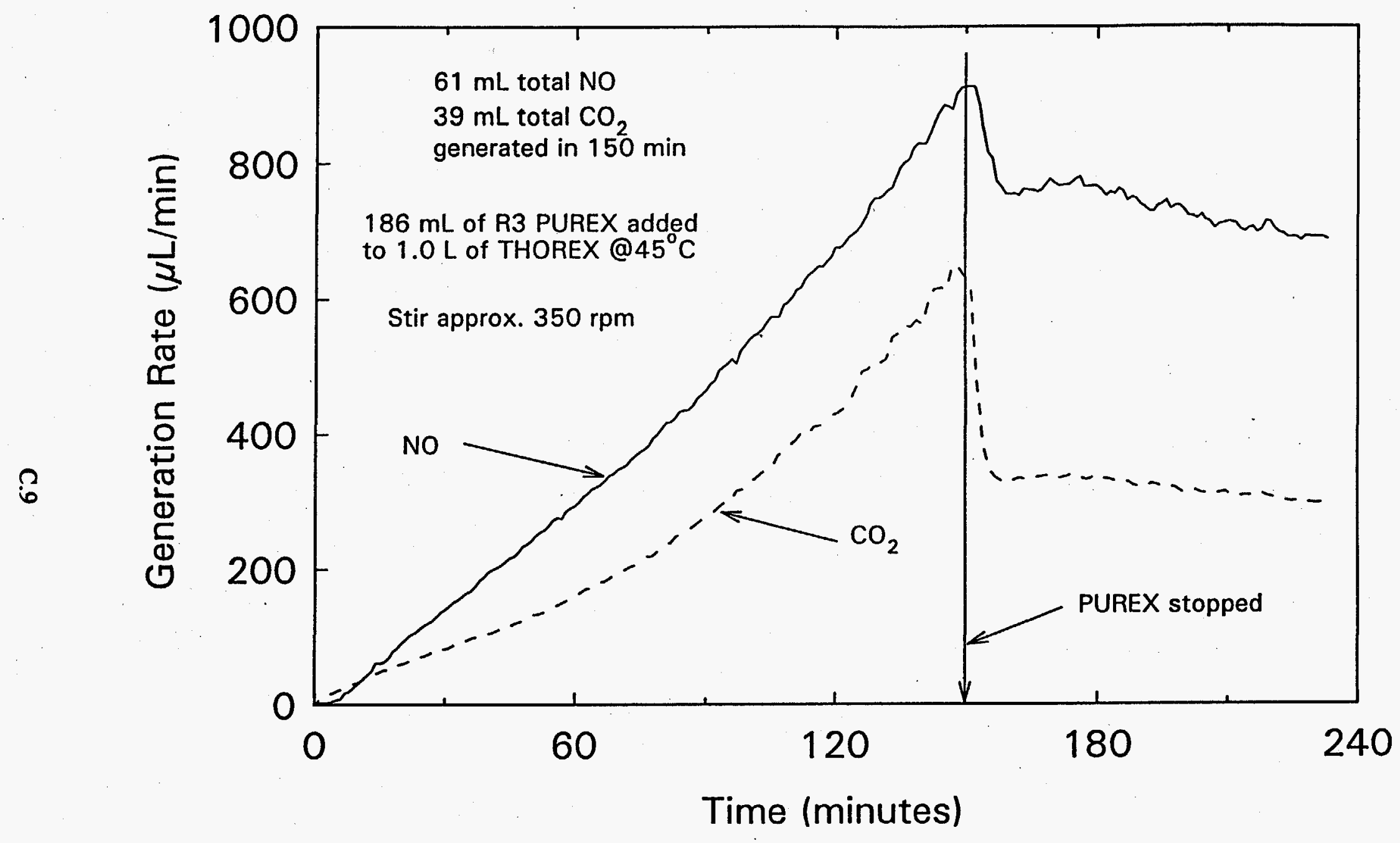

Figure C.9. Test 4. First Back-Flow Test. PUREX was pumped into reaction vessel containing THOREX. The object was to provide data on the consequence of an accidental reverse flow situation in which PUREX was injected into THOREX in Tank 8D-4. 


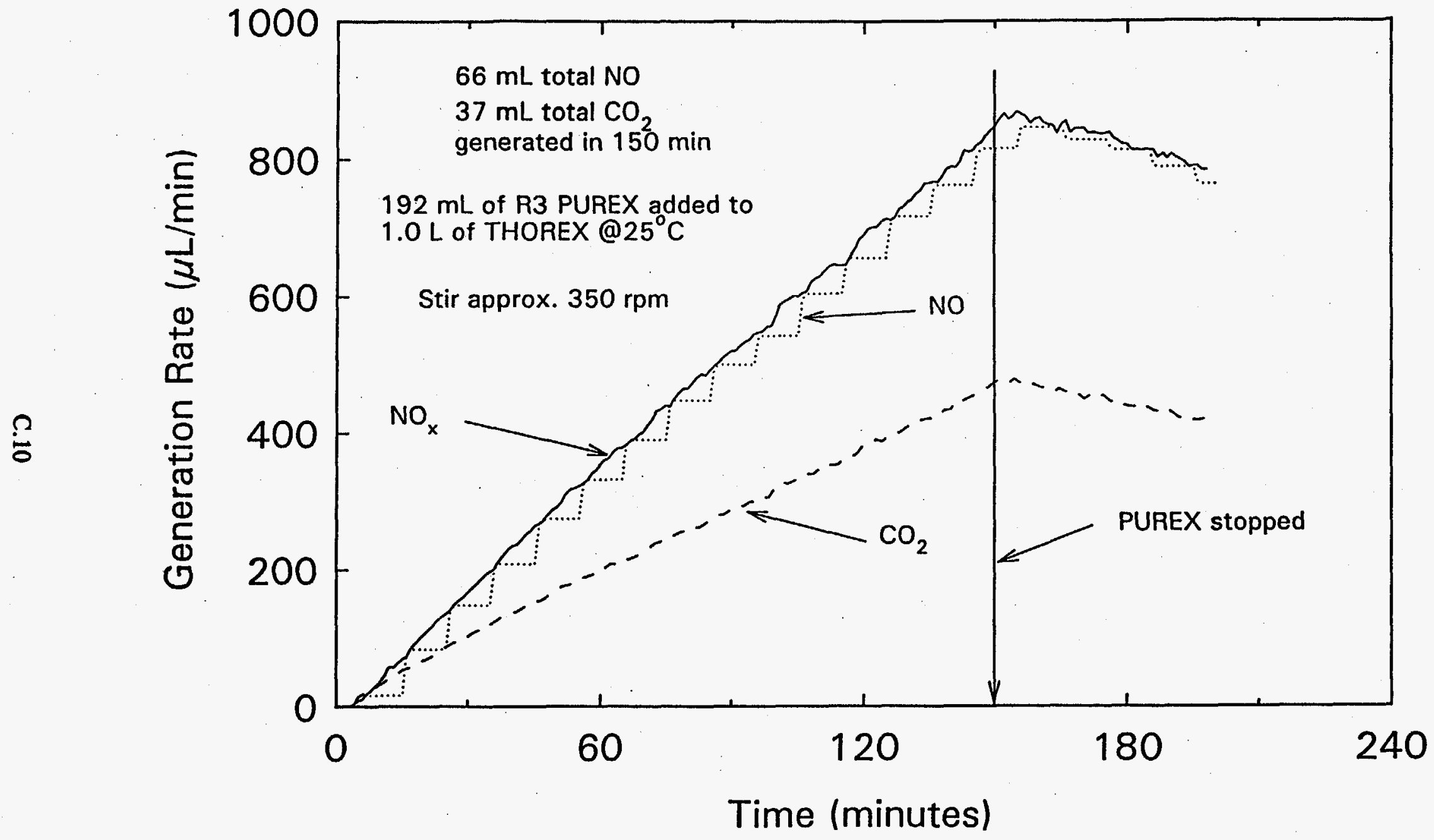

Figure C.10. Test 5. Second Back-Flow Test. Test conditions were the same as in Figure C.9 except the temperature was reduced from $45^{\circ} \mathrm{C}$ to $25^{\circ} \mathrm{C}$. 


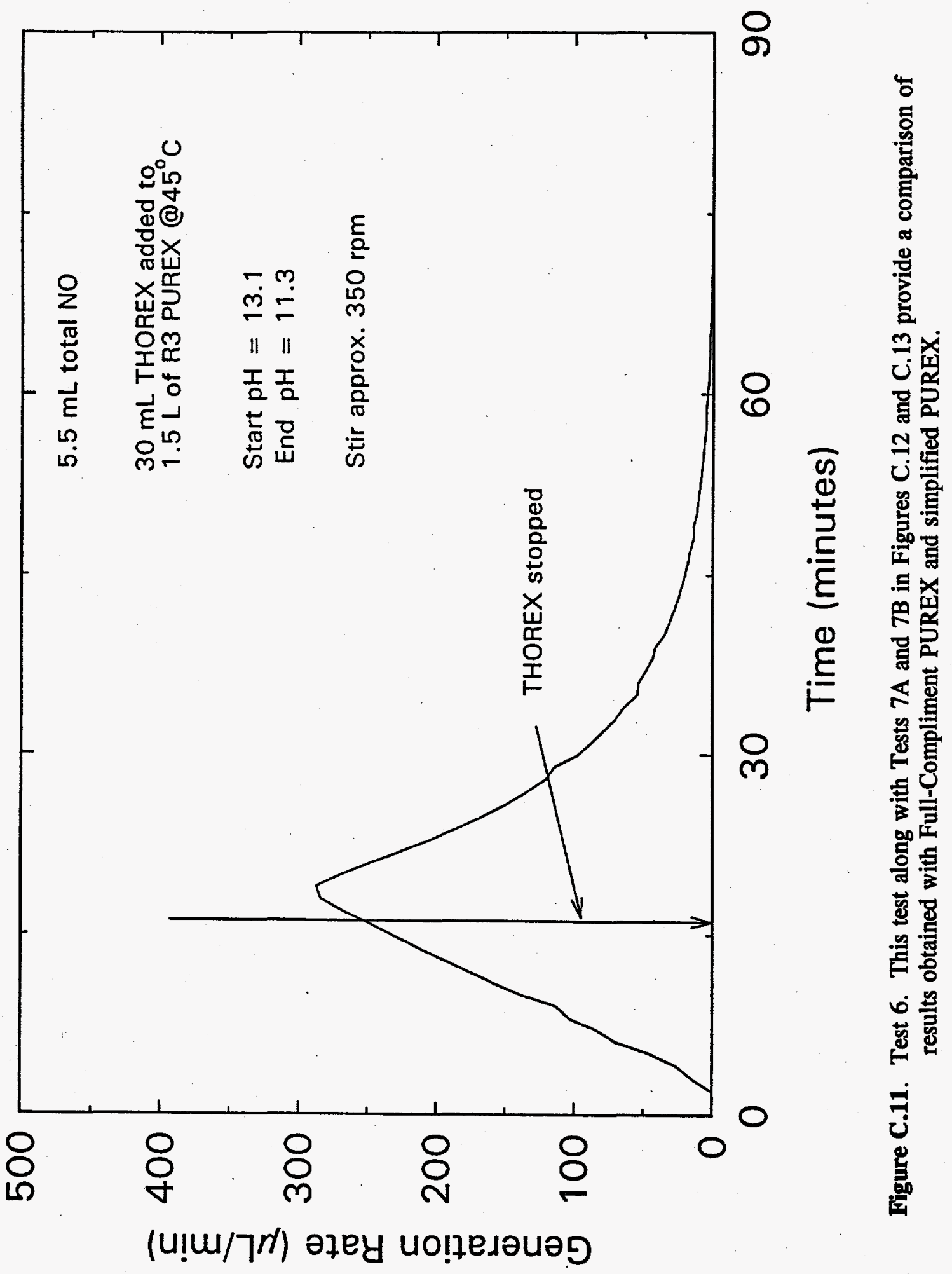

C.11 


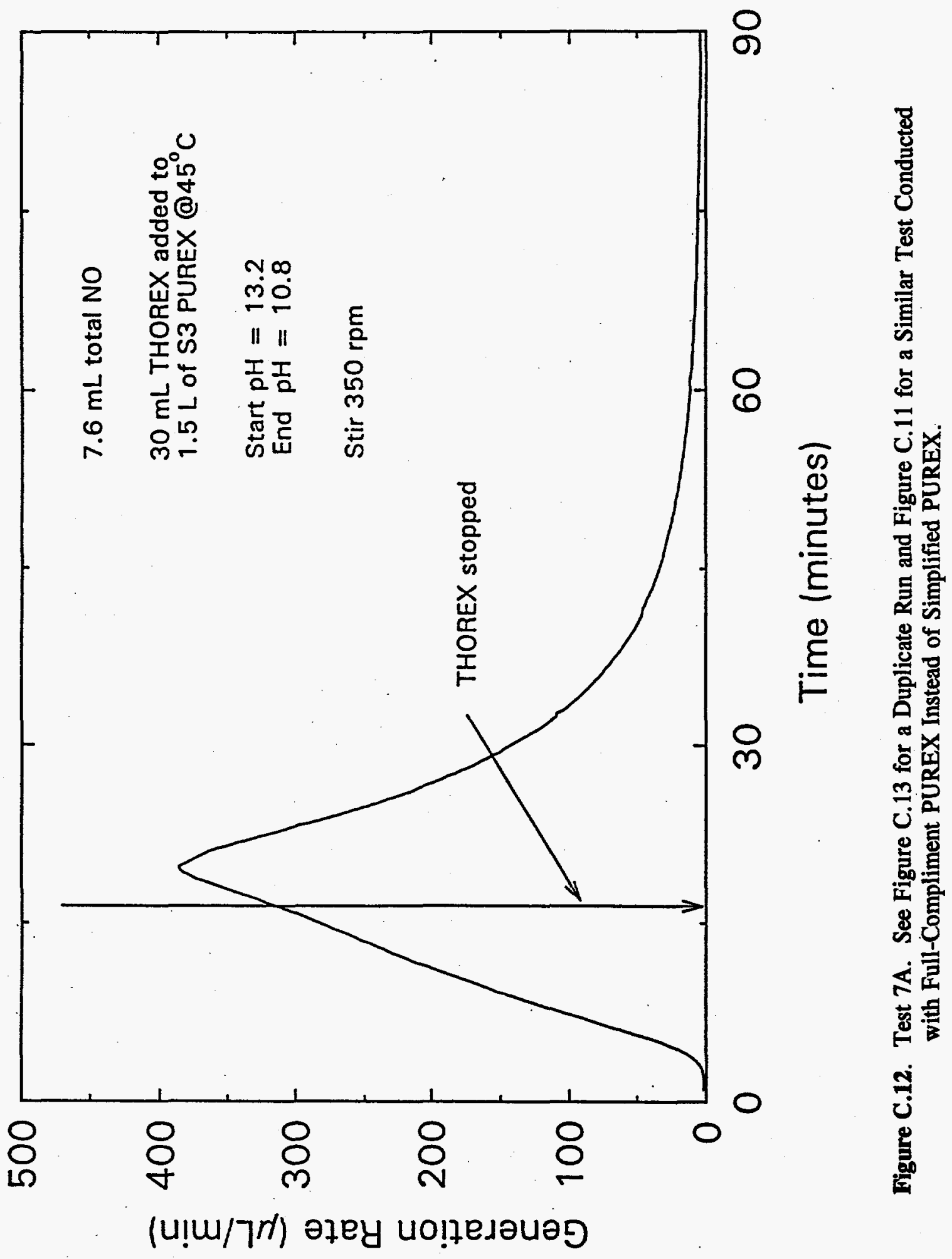

C. 12 


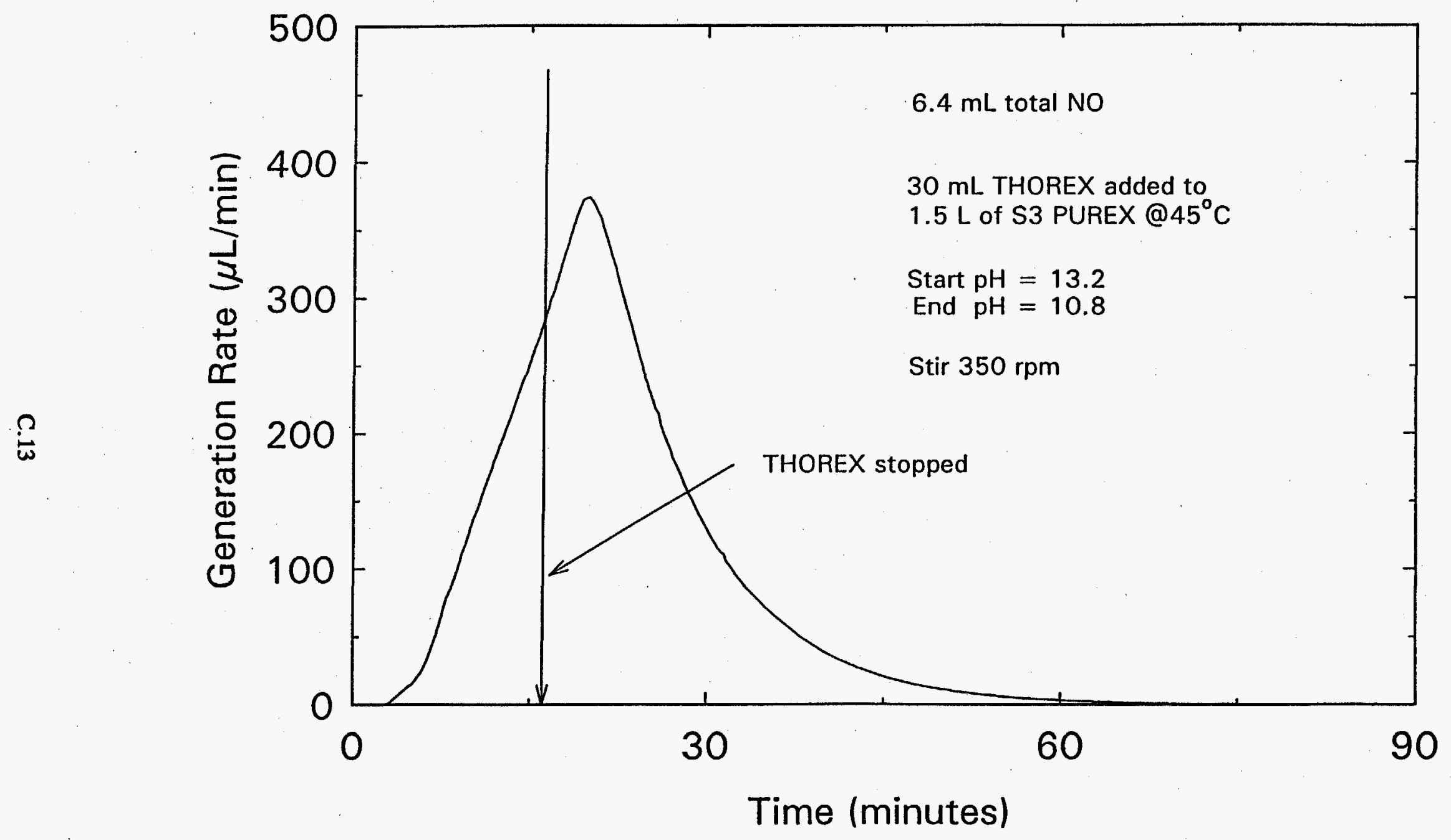

Figure C.13. Test 7B. See Figure C.12 for a Duplicate Run and Figure C.11 for a Similar Test Conducted with Full-Compliment PUREX Instead of Simplified PUREX. 


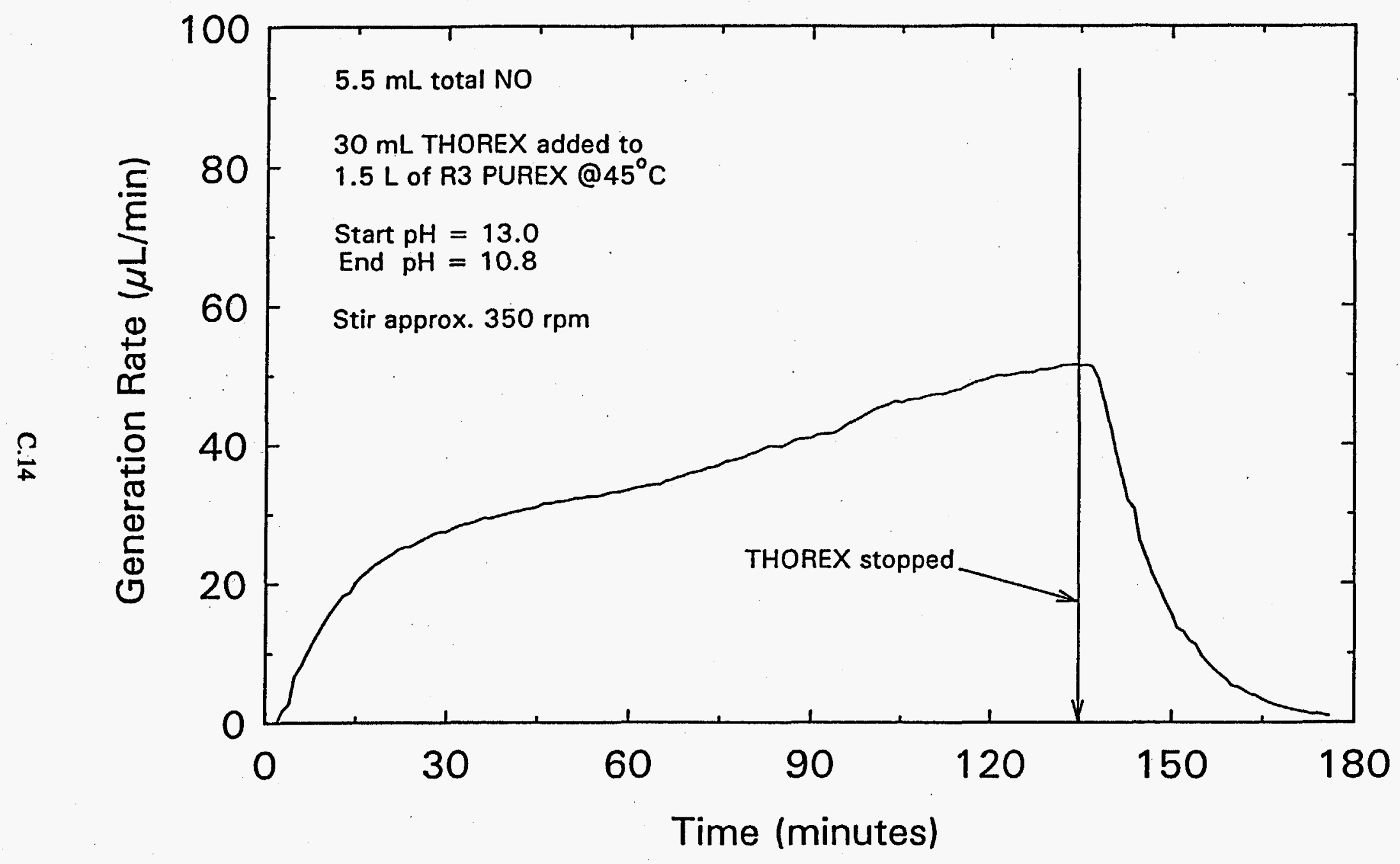

Figure C.14. Test 8 was Conducted to Determine the Effect of Slower THOREX Addition Rate 


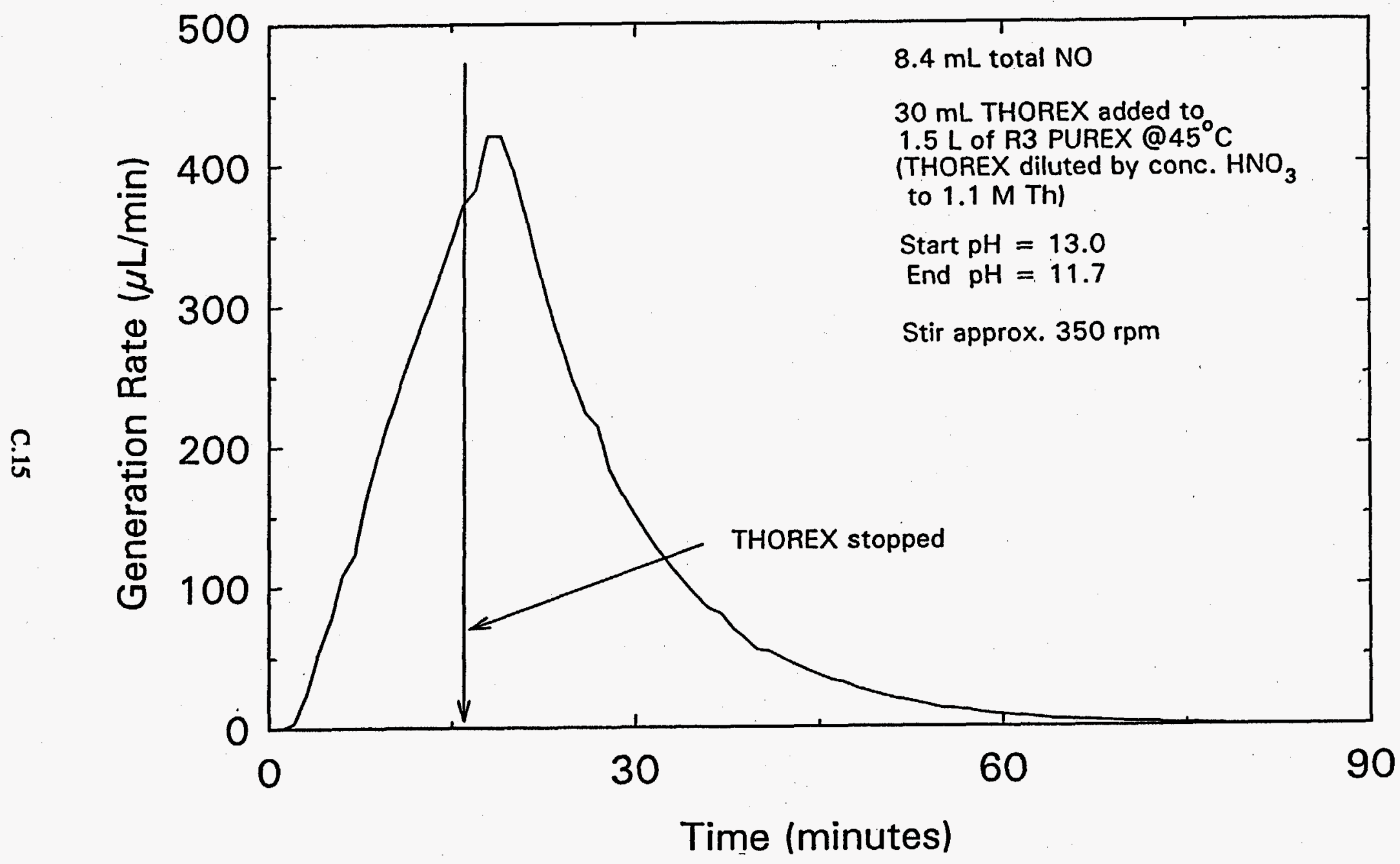

Figure C.15. Test 9 was Conducted with THOREX to Which Additional $\mathrm{HNO}_{3}$ had been Added to Test the Effect of Higher-Than-Anticipated Acidity in Tank 8D-4. 


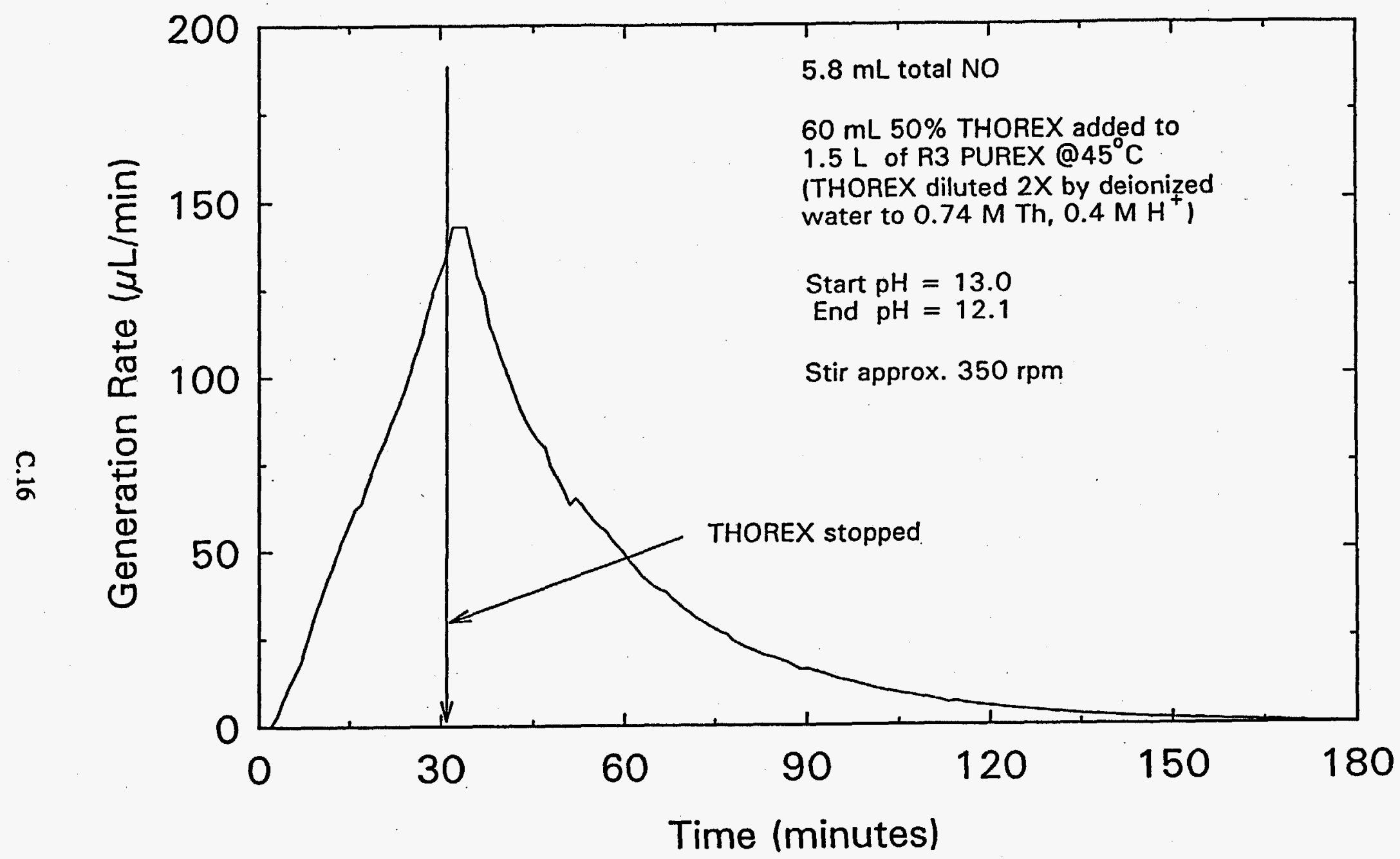

Figure C.16. Test 10 was Conducted to Determine the Effect of Simply Diluting the THOREX by a Factor of Two 


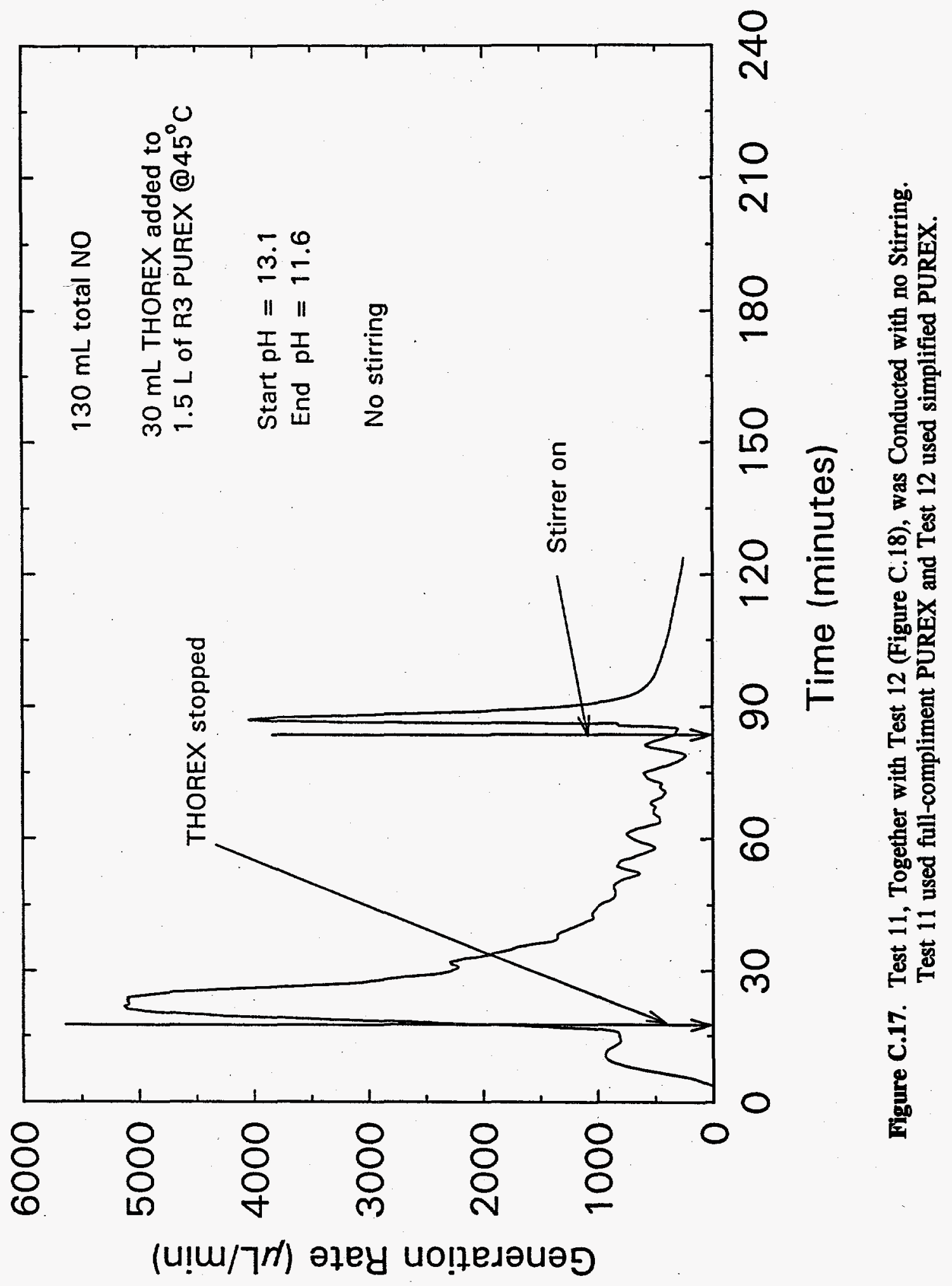




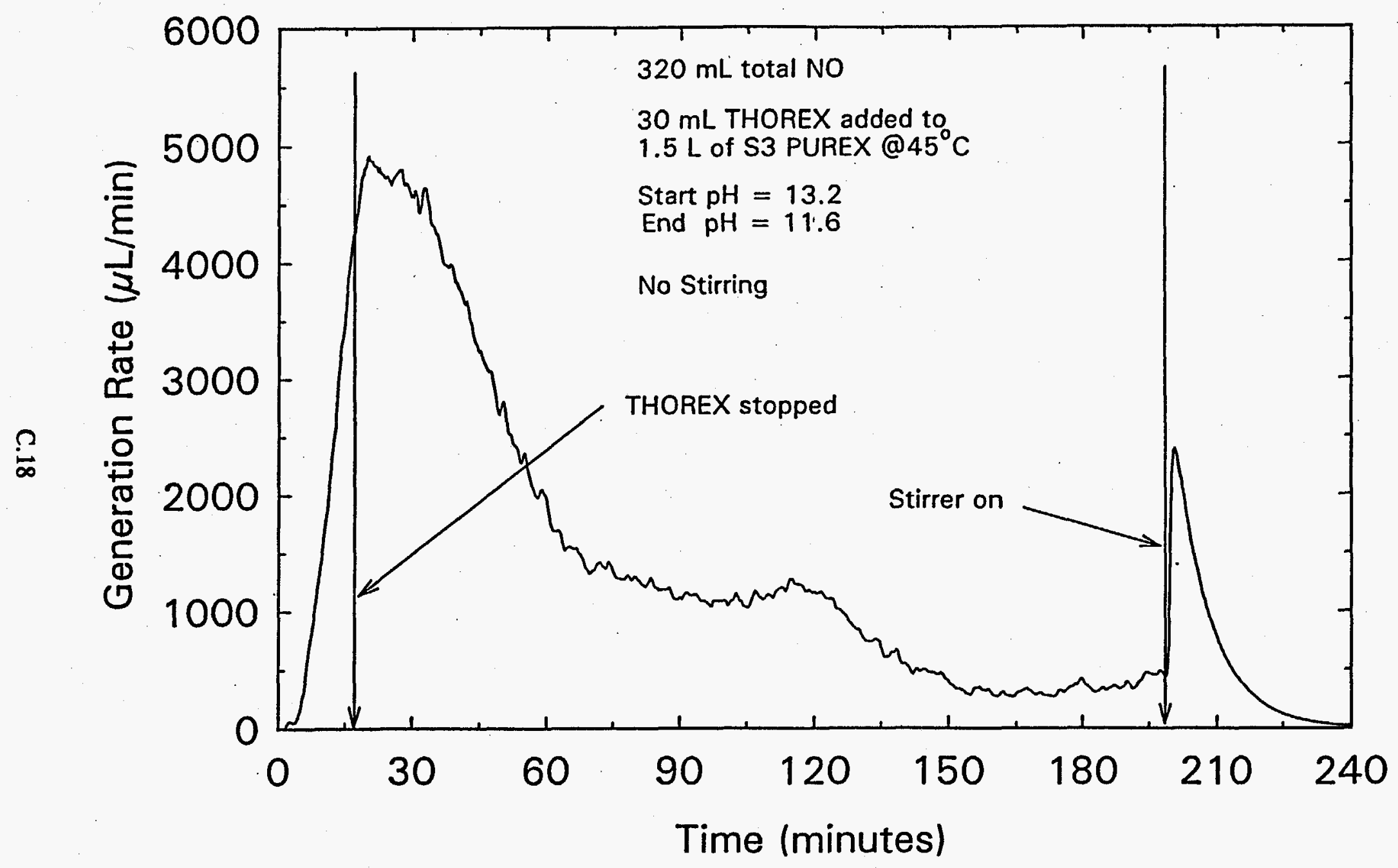

Figure C.18. Test 12, Together with Test 11 (Figure C.17), was Conducted with no Stirring. Test 11 used full-compliment PUREX and Test 12 used simplified PUREX. 


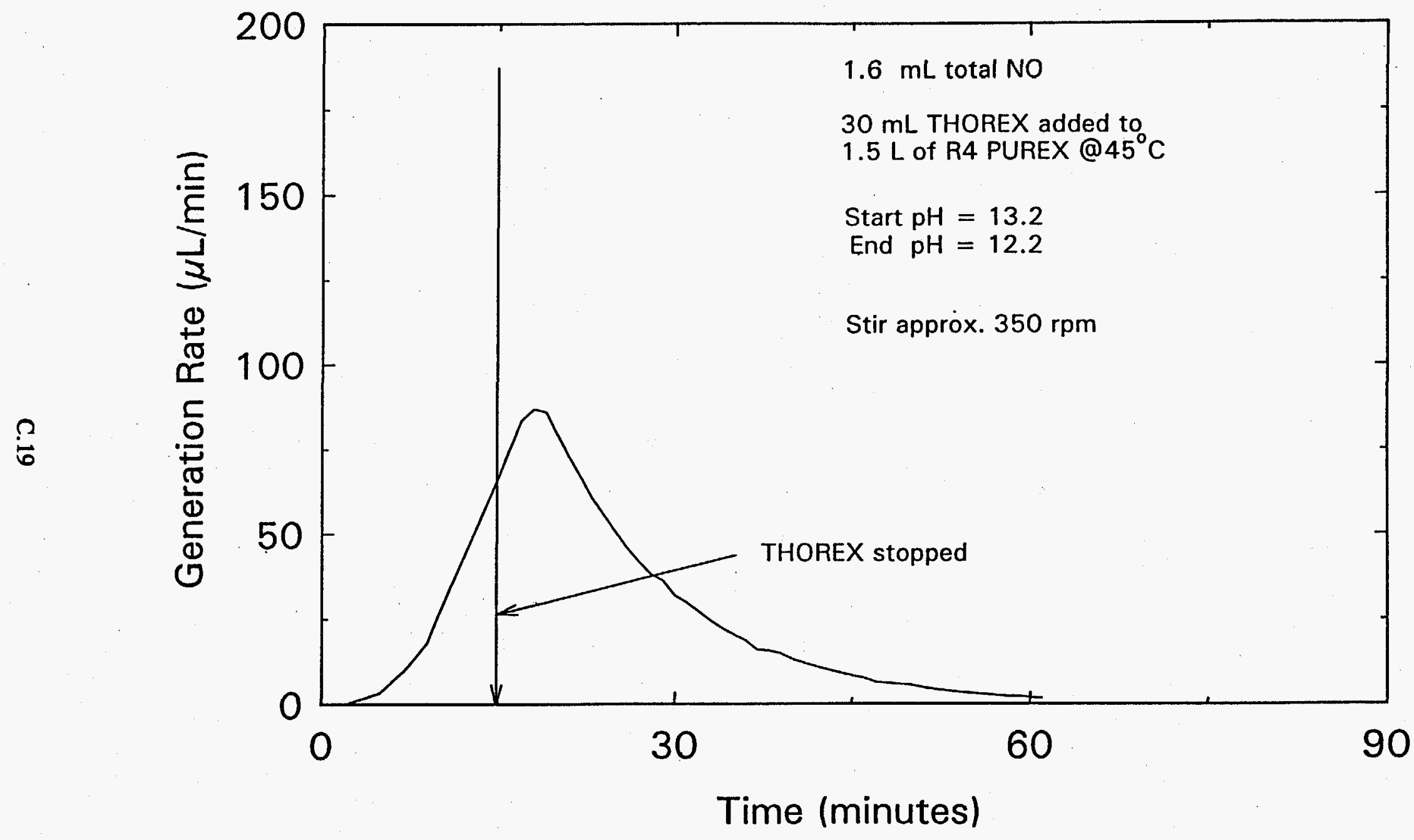

Figure C.19. Test 13 was the First Test Performed with Fourth-Wash PUREX. These results can be compared with Tests 14A to 14D (Figures C.20 to C.23), which were performed with simplified fourth-wash PUREX. 


$$
\text { 0Z: }
$$

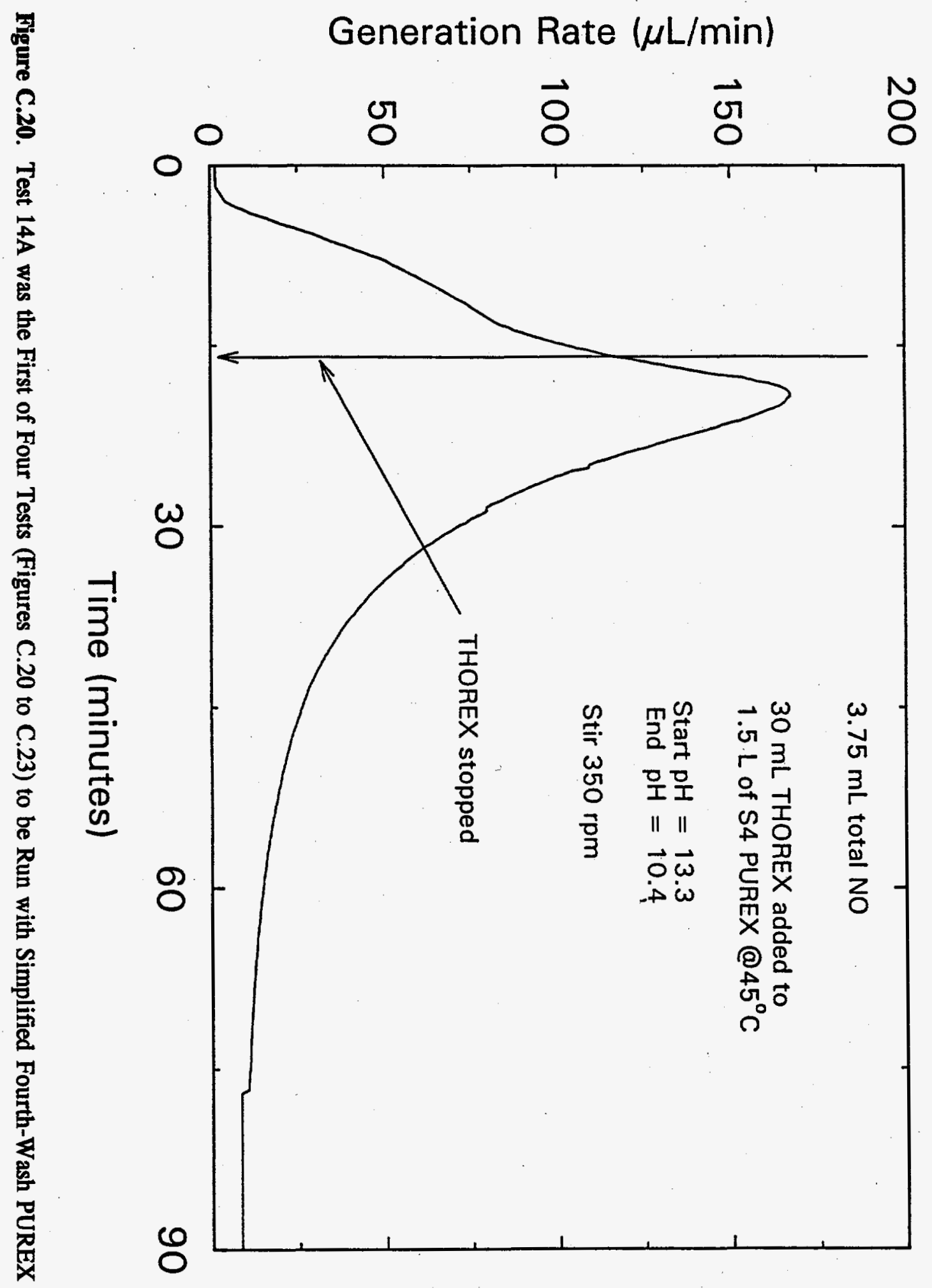


โว’ว

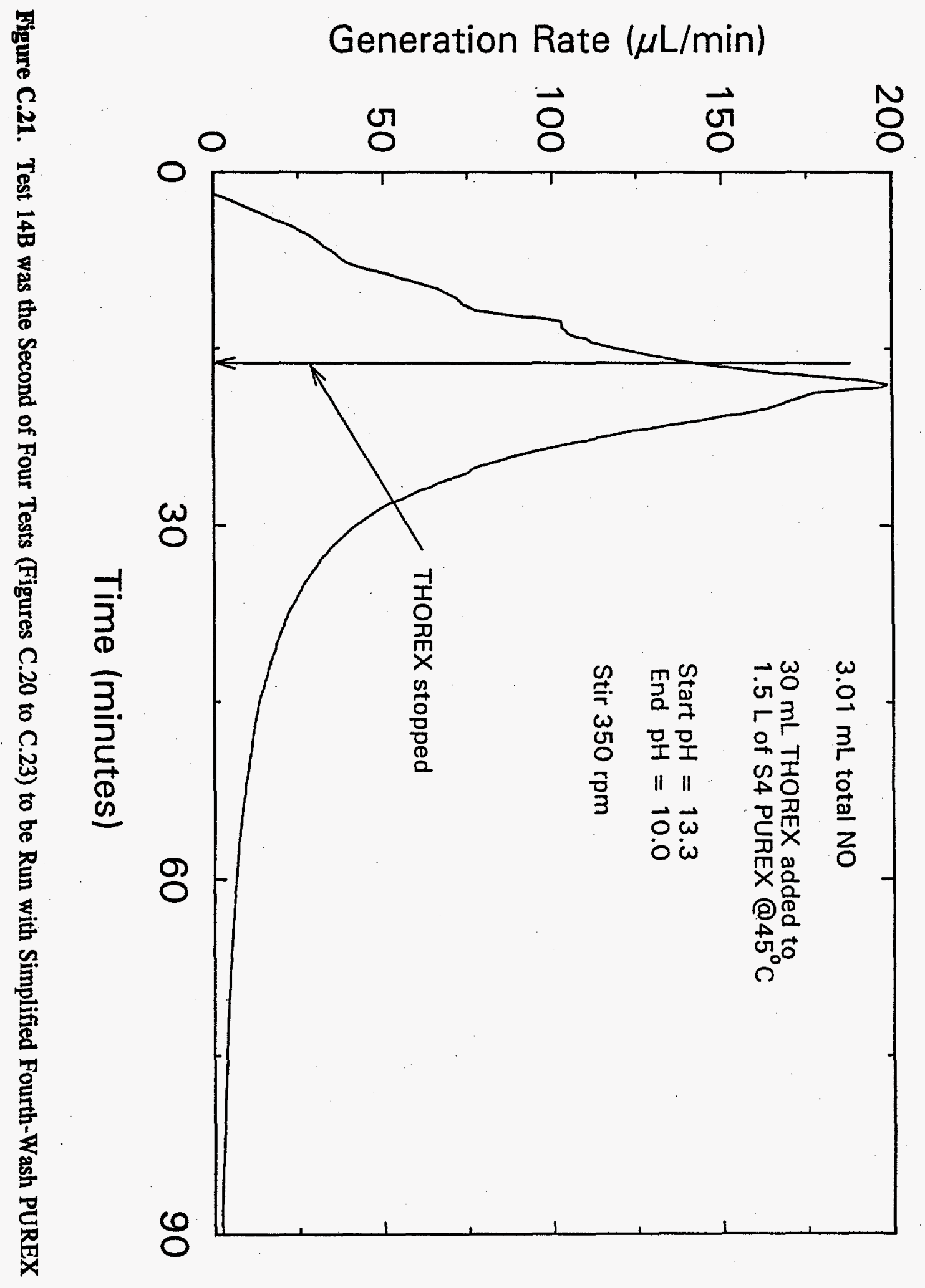




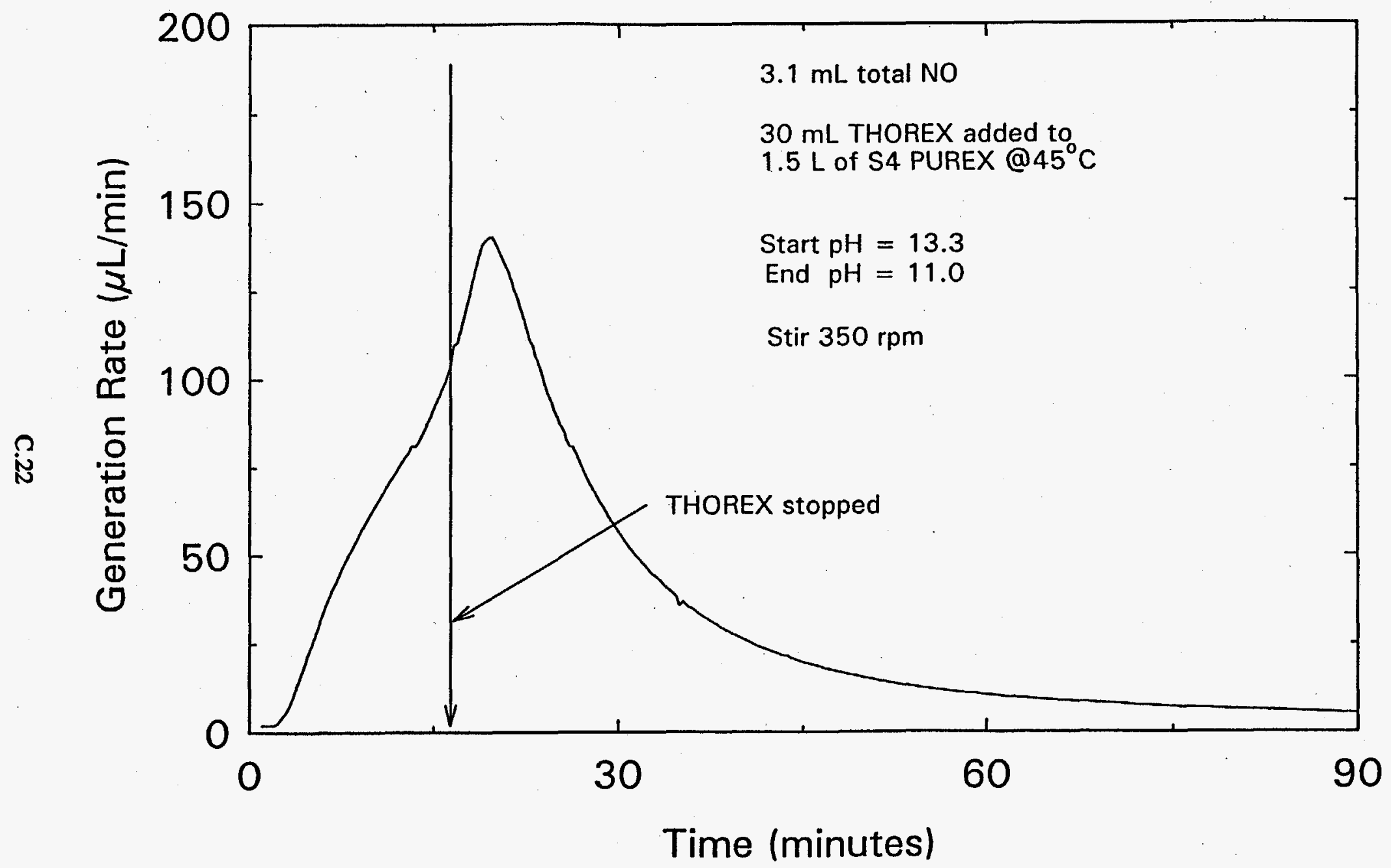

Figure C.22. Test 14C was the Third of Four Tests (Figures C.20 to C.23) to be Run with Simplified Fourth-Wash PUREX 


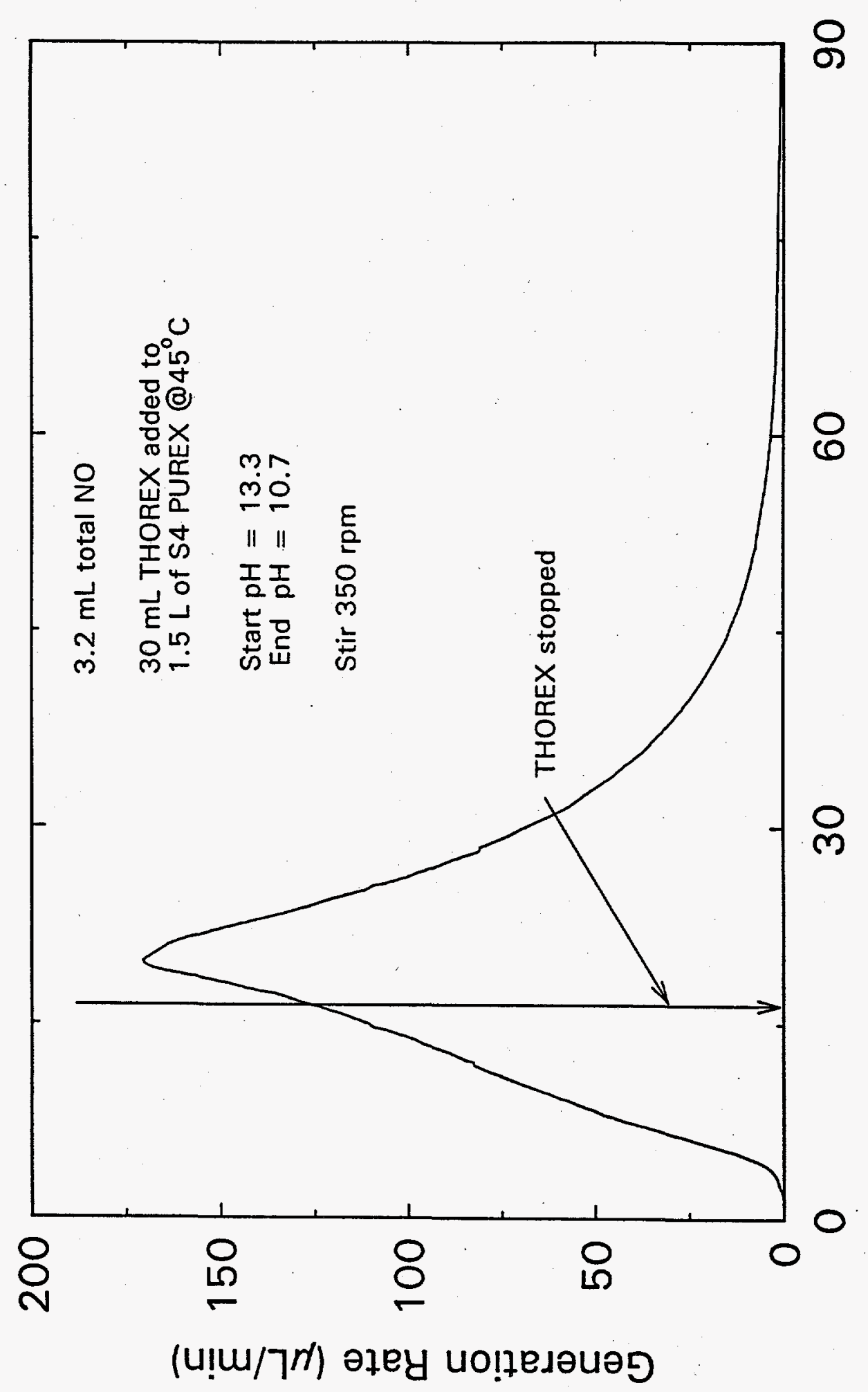

空 


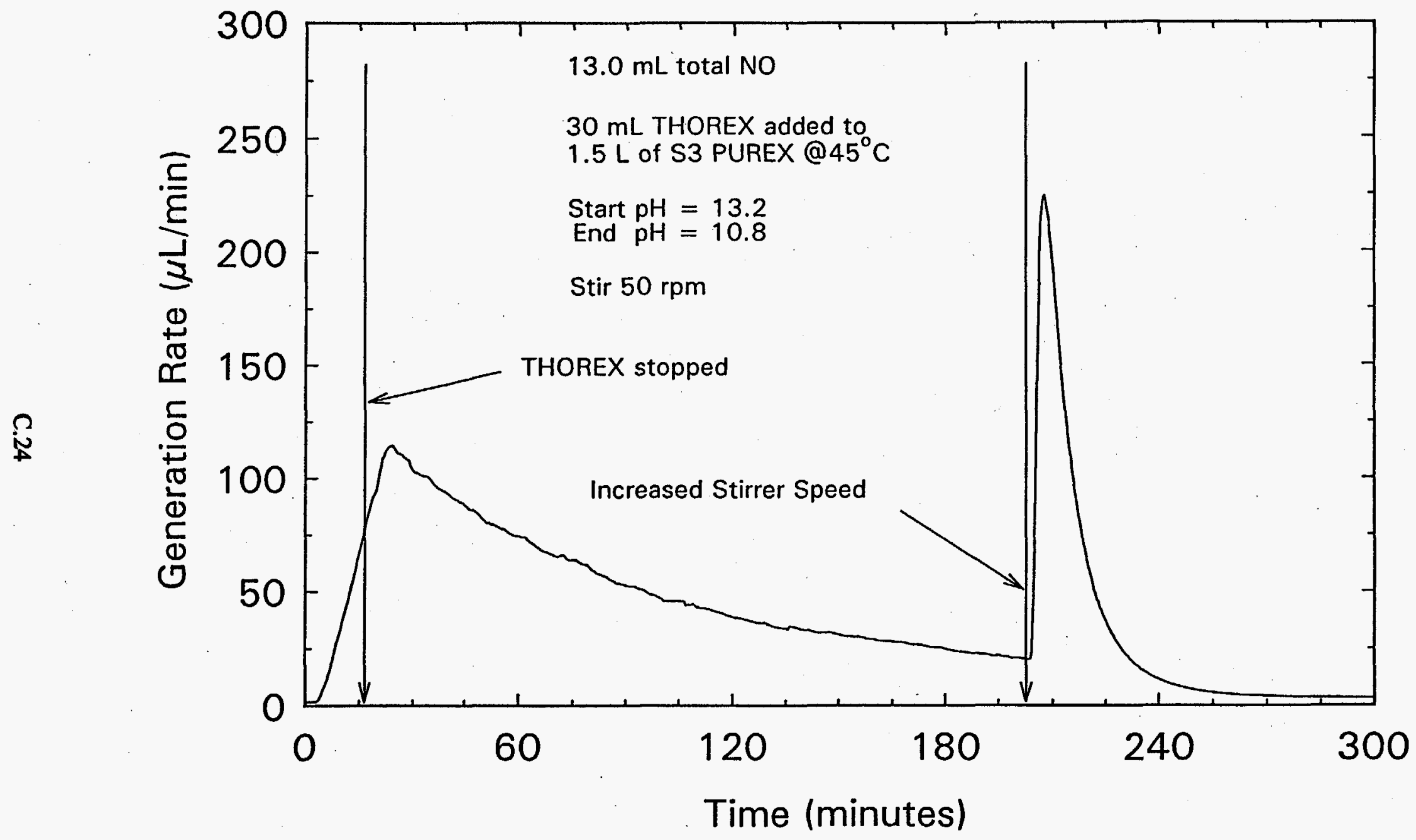

Figure C.24. Test 15 was Performed to Determine the Effect of a Slower Stirring Rate. See Figure C.25 for a test with a faster stirring rate. 


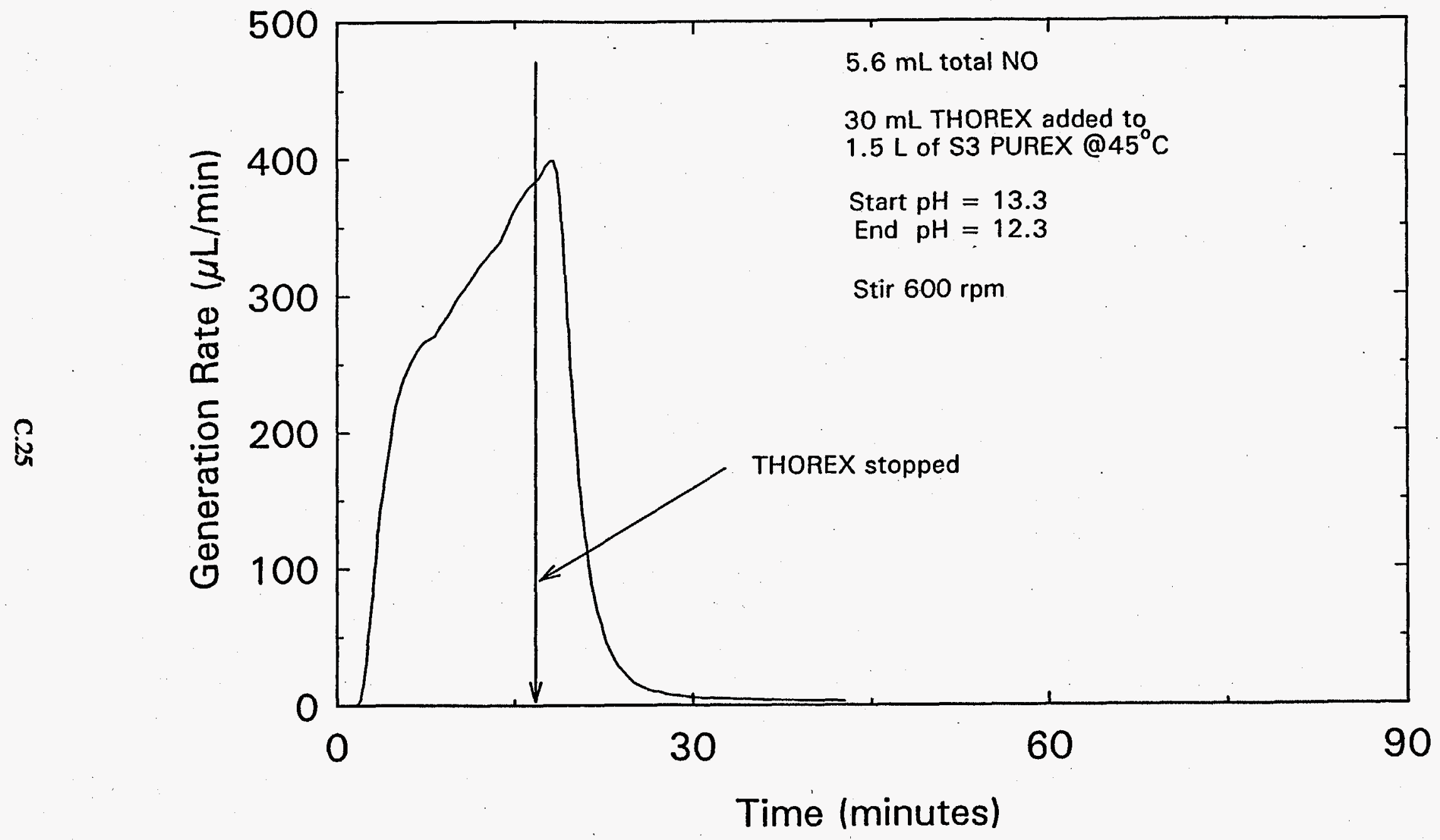

Figure C.25. Test 16 was Performed to Determine the Effect of a Faster Stirring Rate.

See Figure C.24 for a test with a slower stirring rate. 


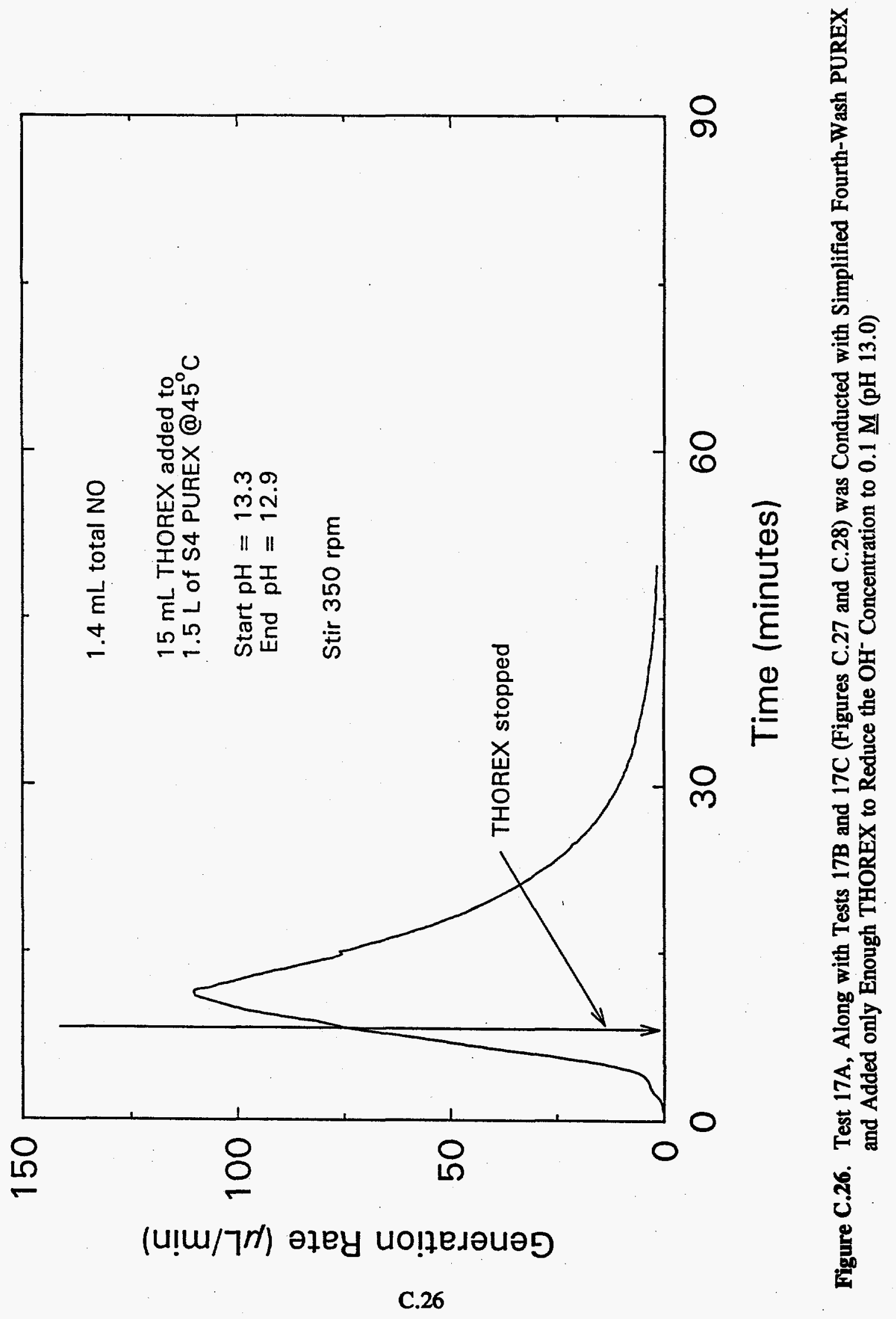




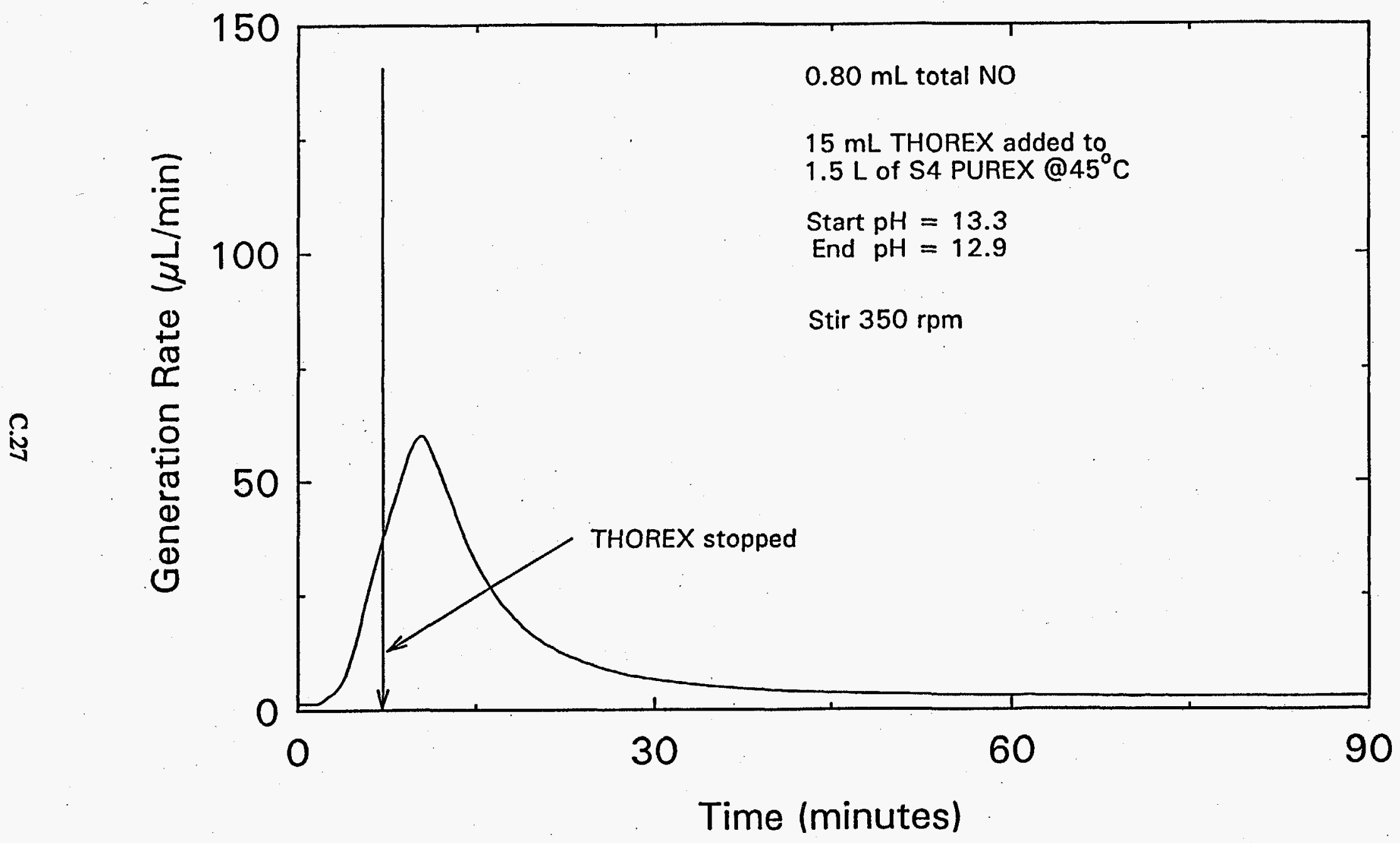

Figure C.27. Test 17B, Along with Tests 17A and 17C (Figures C.26 and C.28) was Conducted with Simplified Fourth-Wash PUREX and Added only Enough THOREX to Reduce the $\mathrm{OH}^{-}$Concentration to $0.1 \mathrm{M}$ (pH 13.0) 


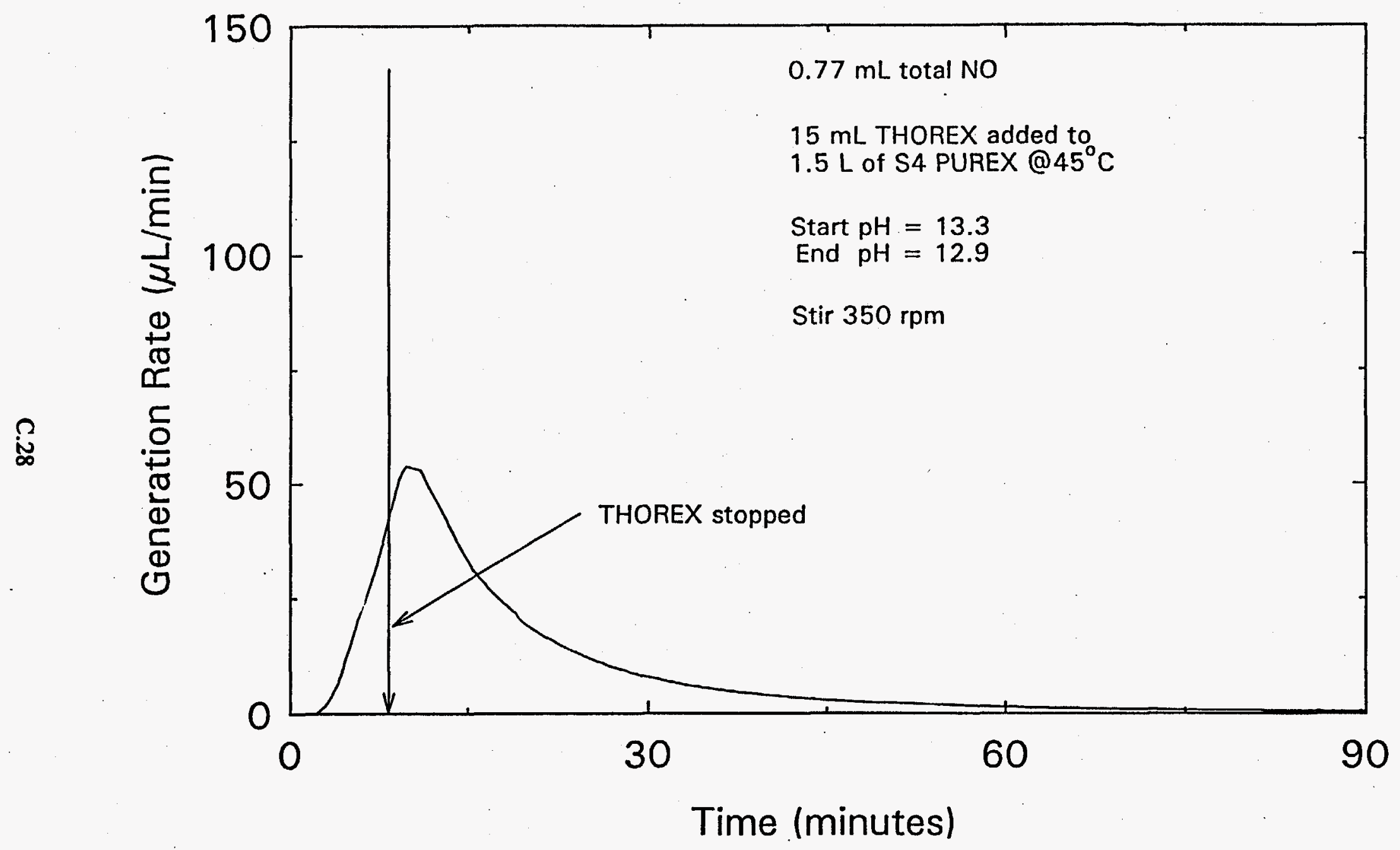

Figure C.28. Test 17C, Along with Tests 17B and 17C (Figures C.26 and C.27) was Conducted with Simplified Fourth-Wash PUREX and Added only Enough THOREX to Reduce the $\mathrm{OH}^{-}$Concentration to $0.1 \mathrm{M}(\mathrm{pH} 13.0)$ 


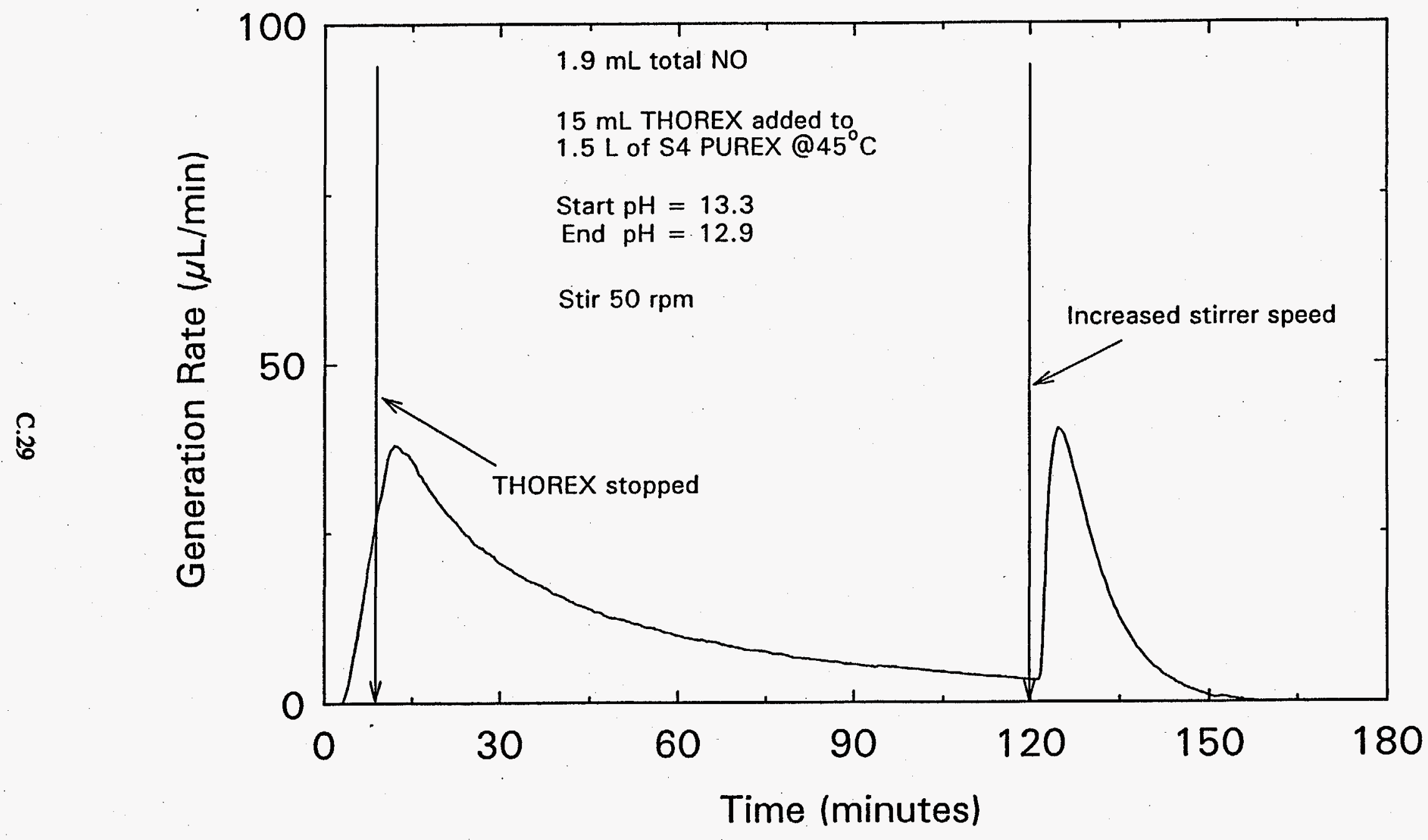

Figure C.29. Test 18 was Conducted Under the Same Conditions as Tests 17 A to $17 \mathrm{C}$ (Figures C.26 to C.28) Except that a Slower Stirring Rate was Used 


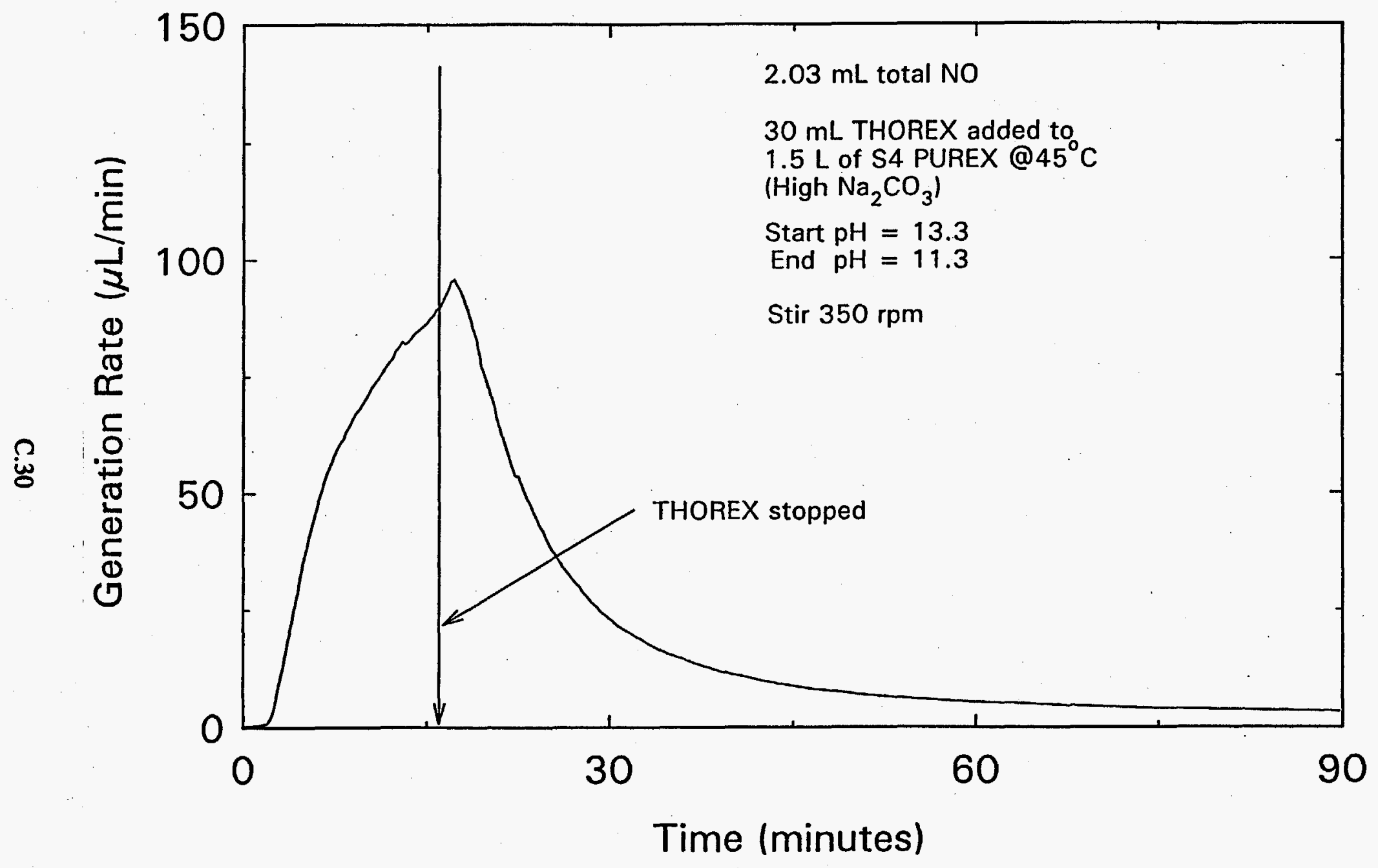

Figure C.30. Test 19 was Conducted with Conditions Similar to Those in Tests 14A to 14D (Figures C.20 to C.23) Except that the $\mathrm{Na}_{2} \mathrm{CO}_{3}$ Concentration Here was Increased Ten-Fold 


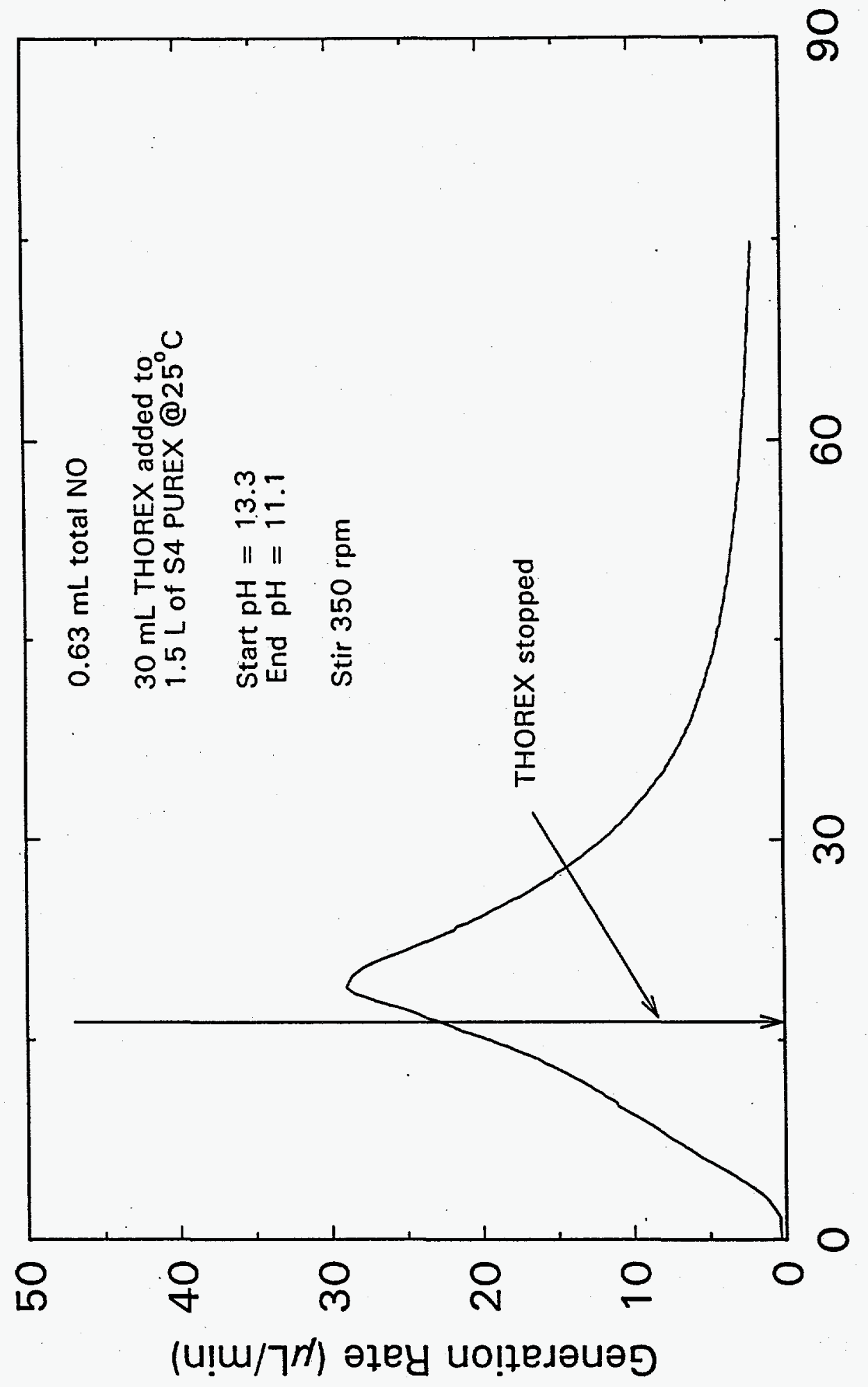

C. 31

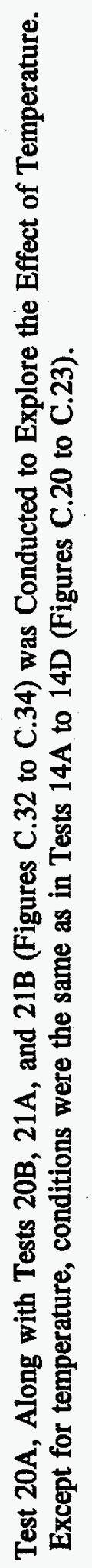




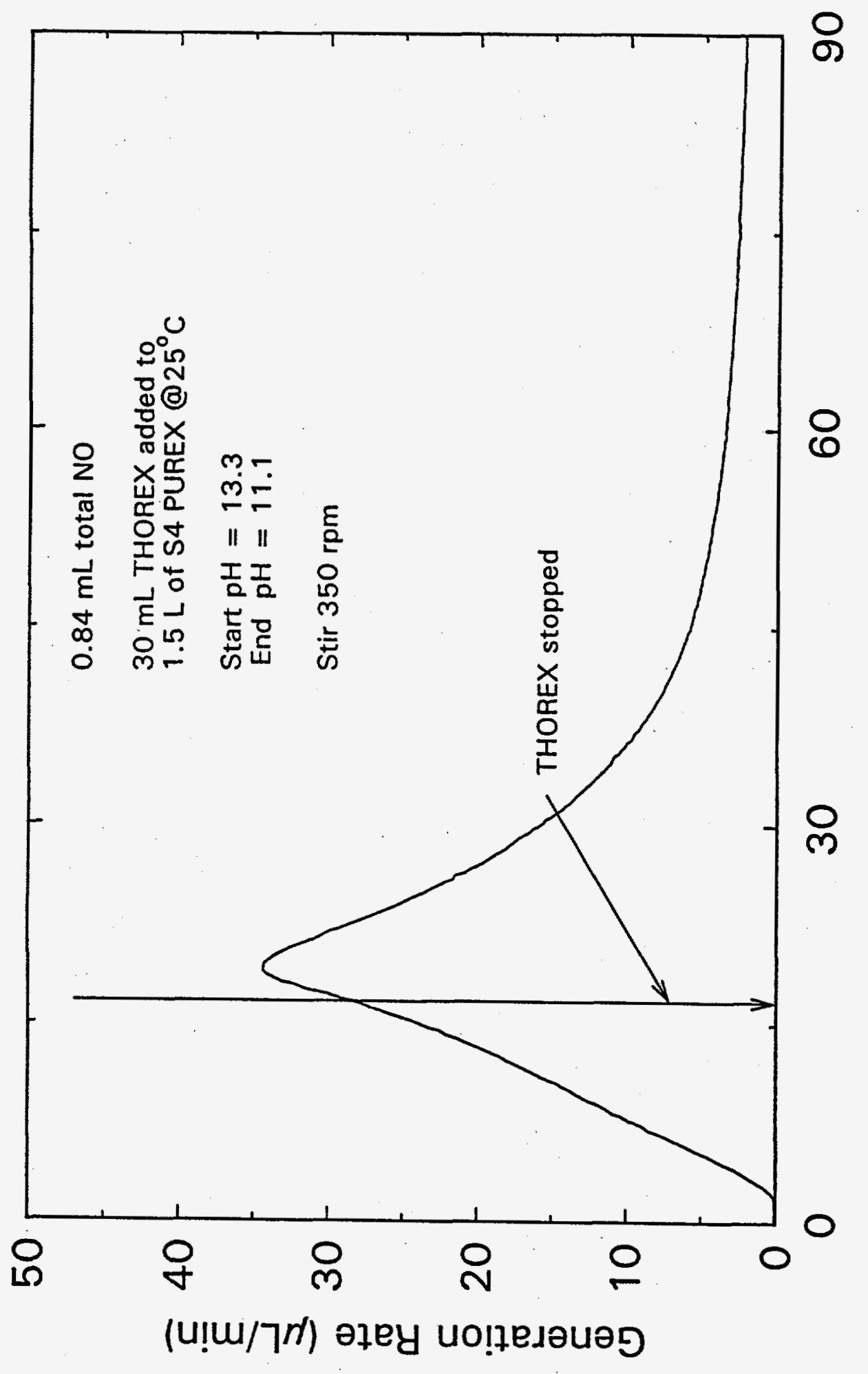

菦

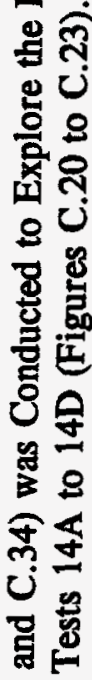

क ก.

$\frac{\text { E }}{\text { E }}$

i

记

㝵

娄

远

喝

宣

त

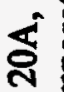

苟

总

造

ชู่ 


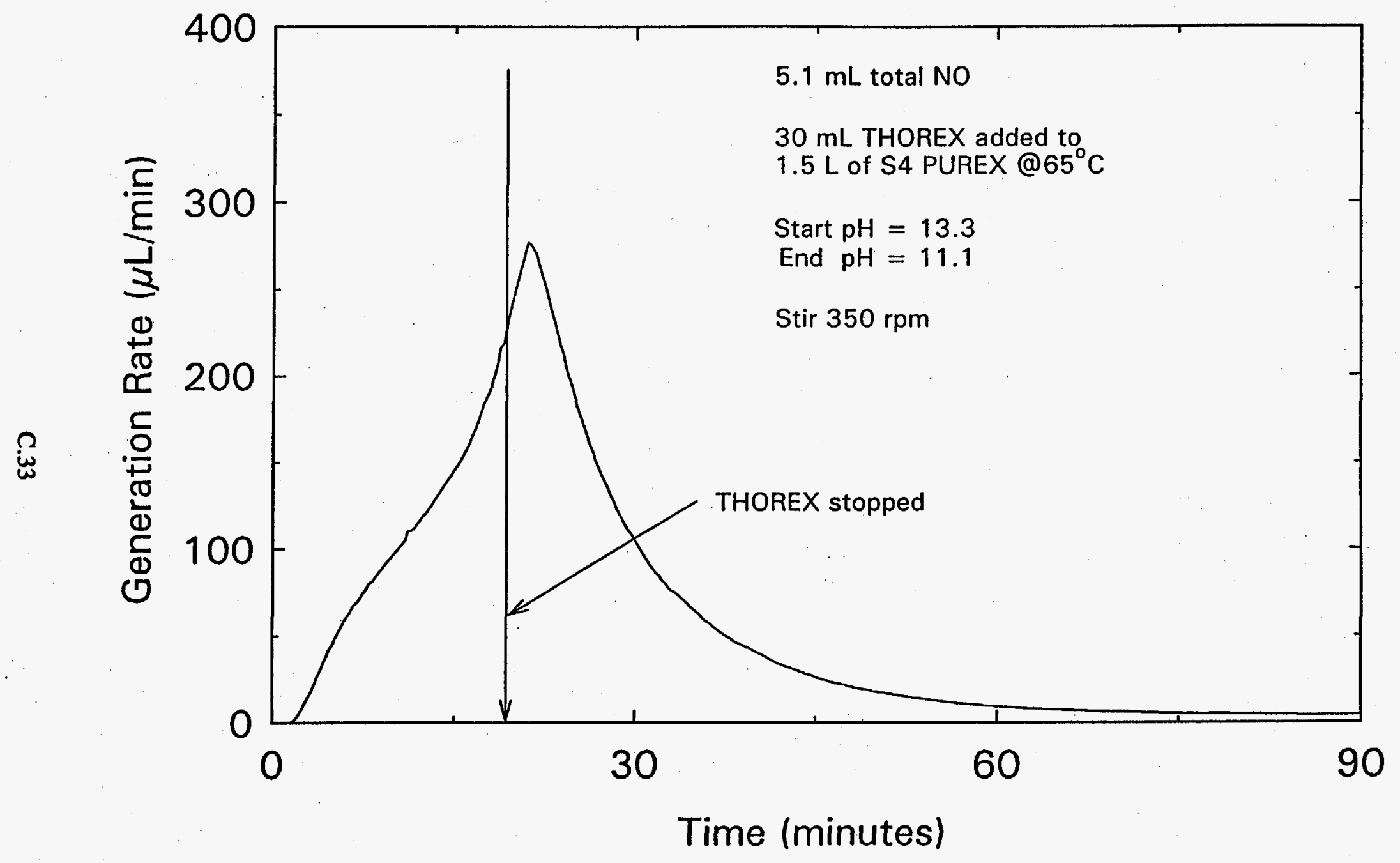

Figure C.33. Test 21A, Along with Tests 20A, 20B, and 21B (Figures C.31, C.32, and C.34) was Conducted to Explore the Effect of Temperature. Except for temperature, conditions were the same as in Tests 14A to 14D (Figures C.20 to C.23). 


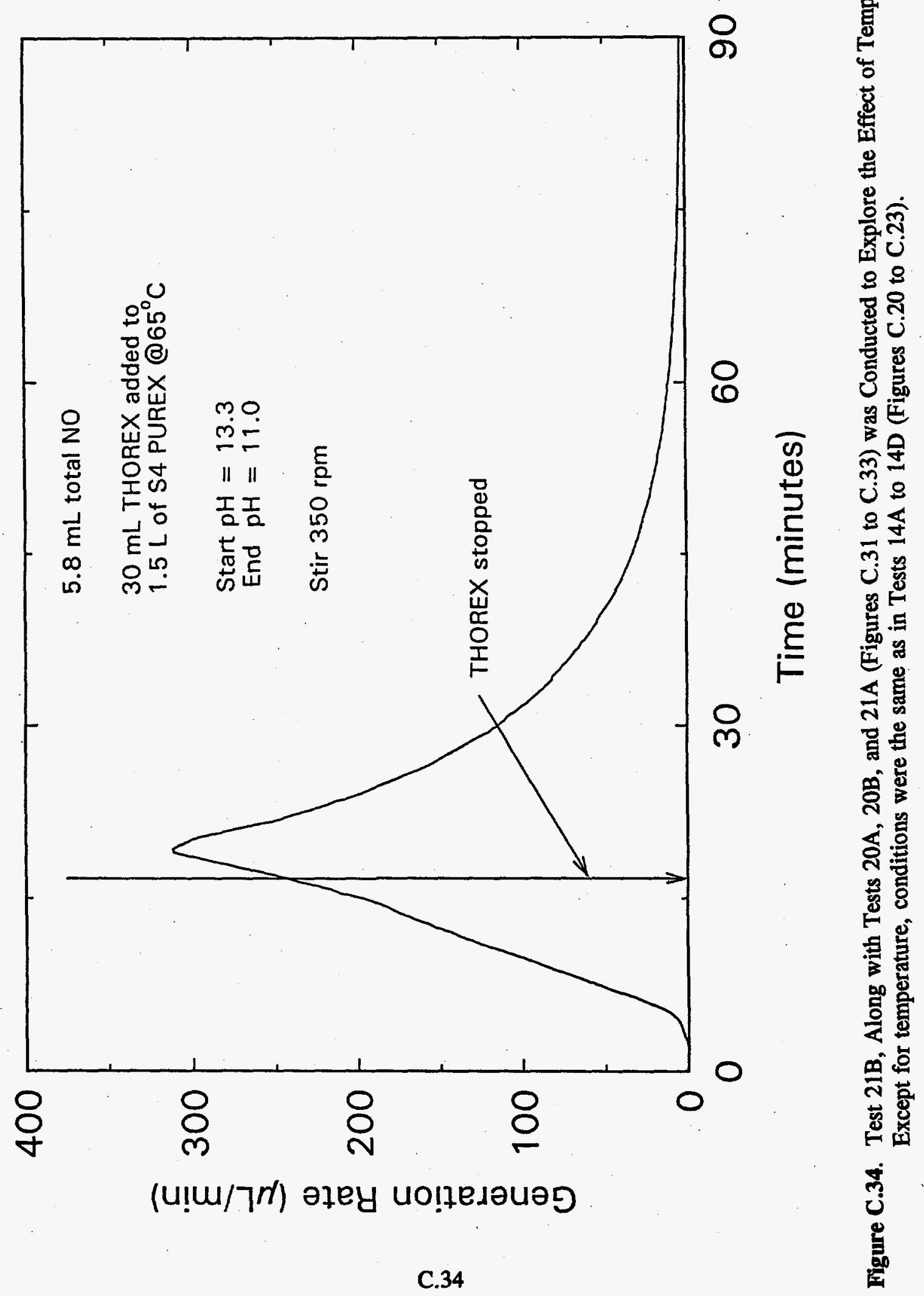




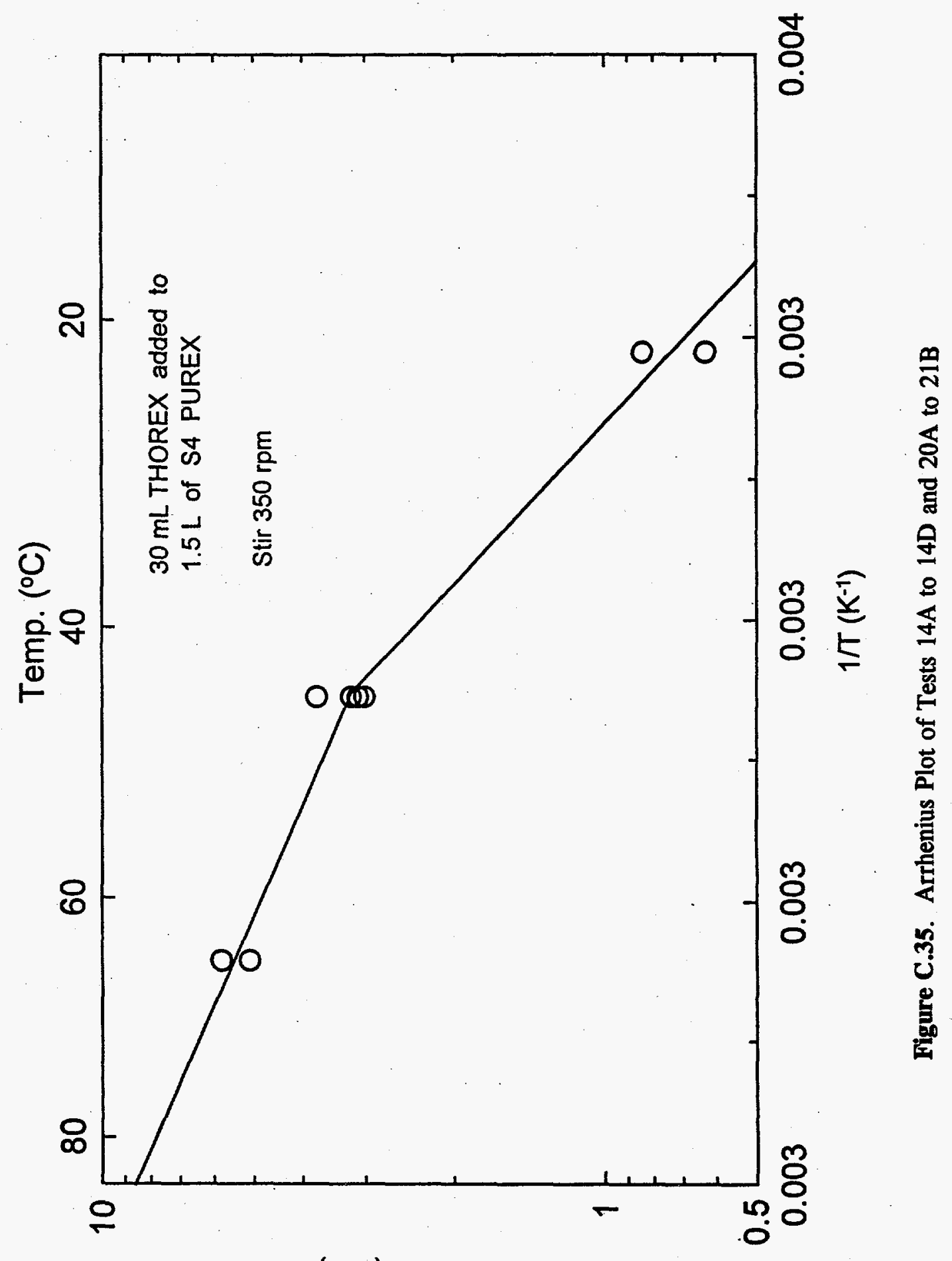

(ךw) ON IEłOL 


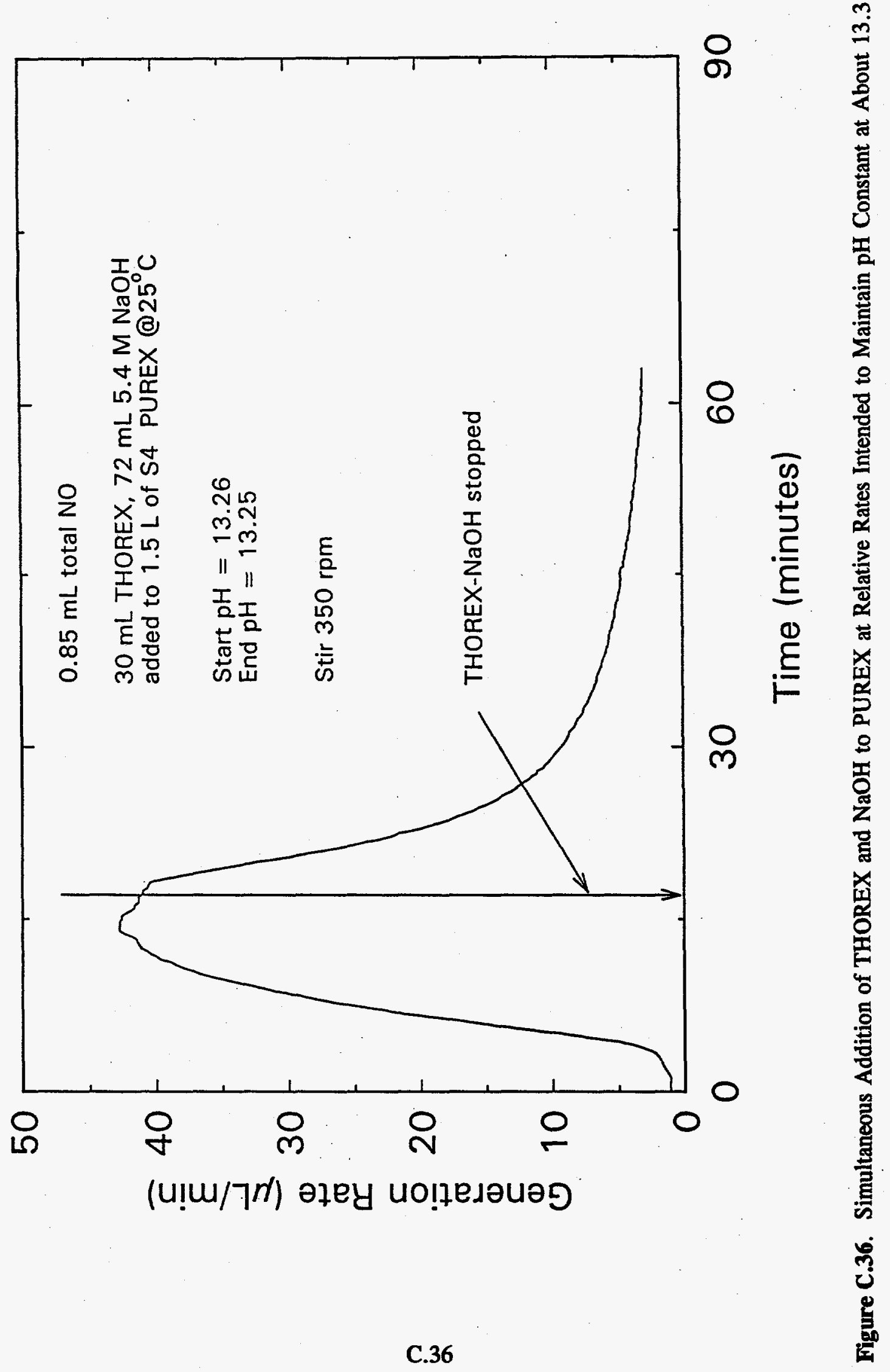




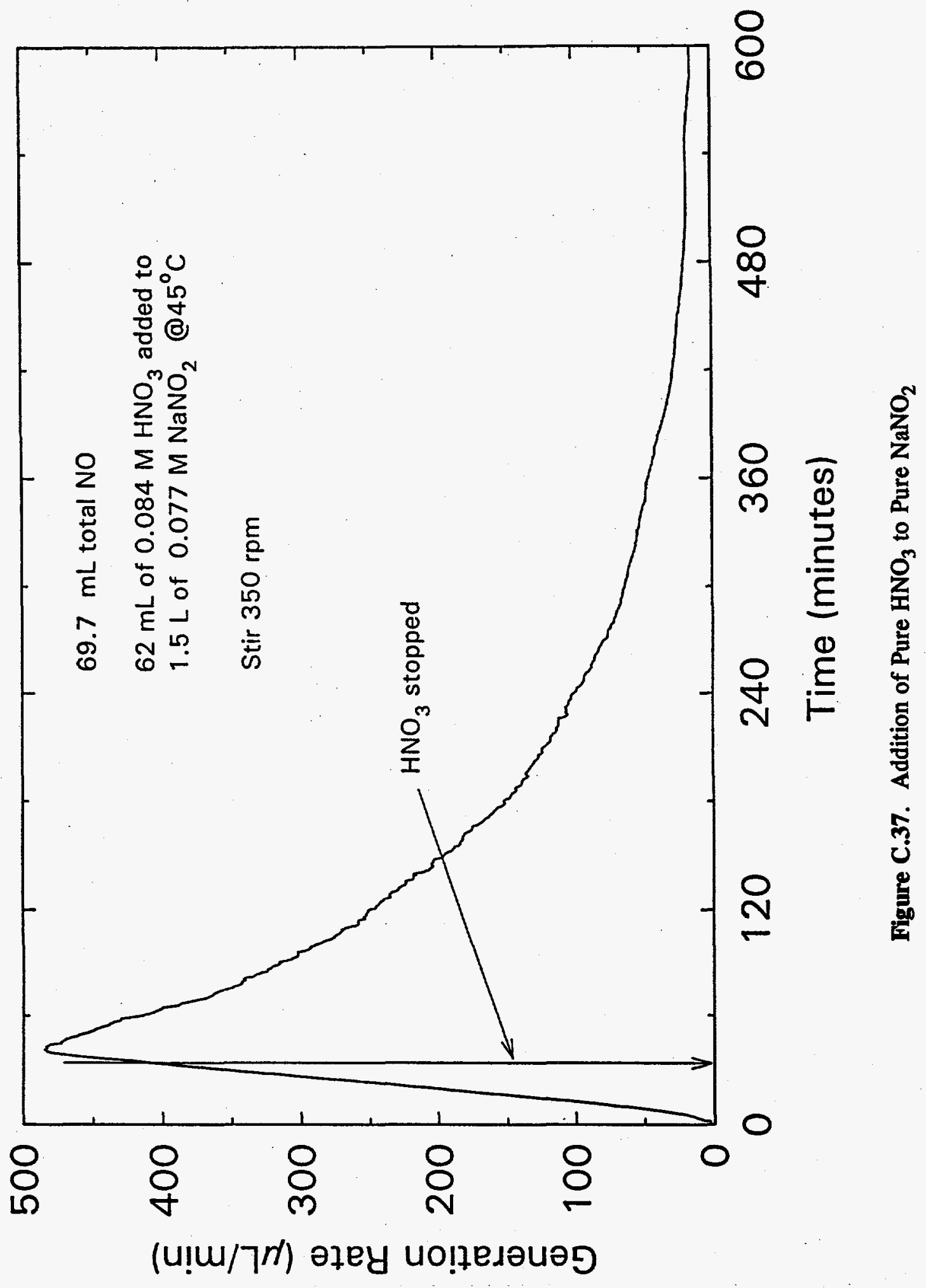




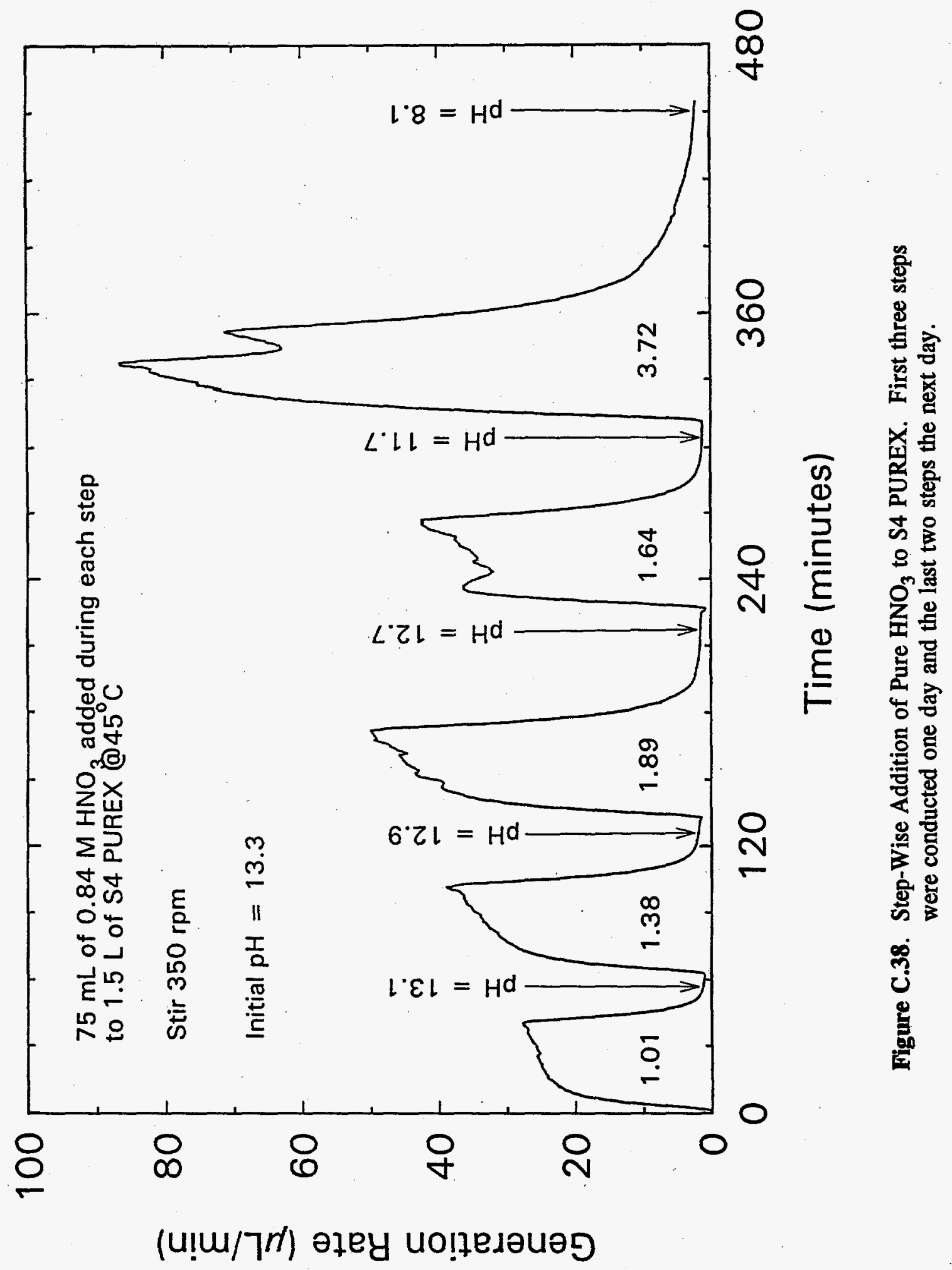

C.38 


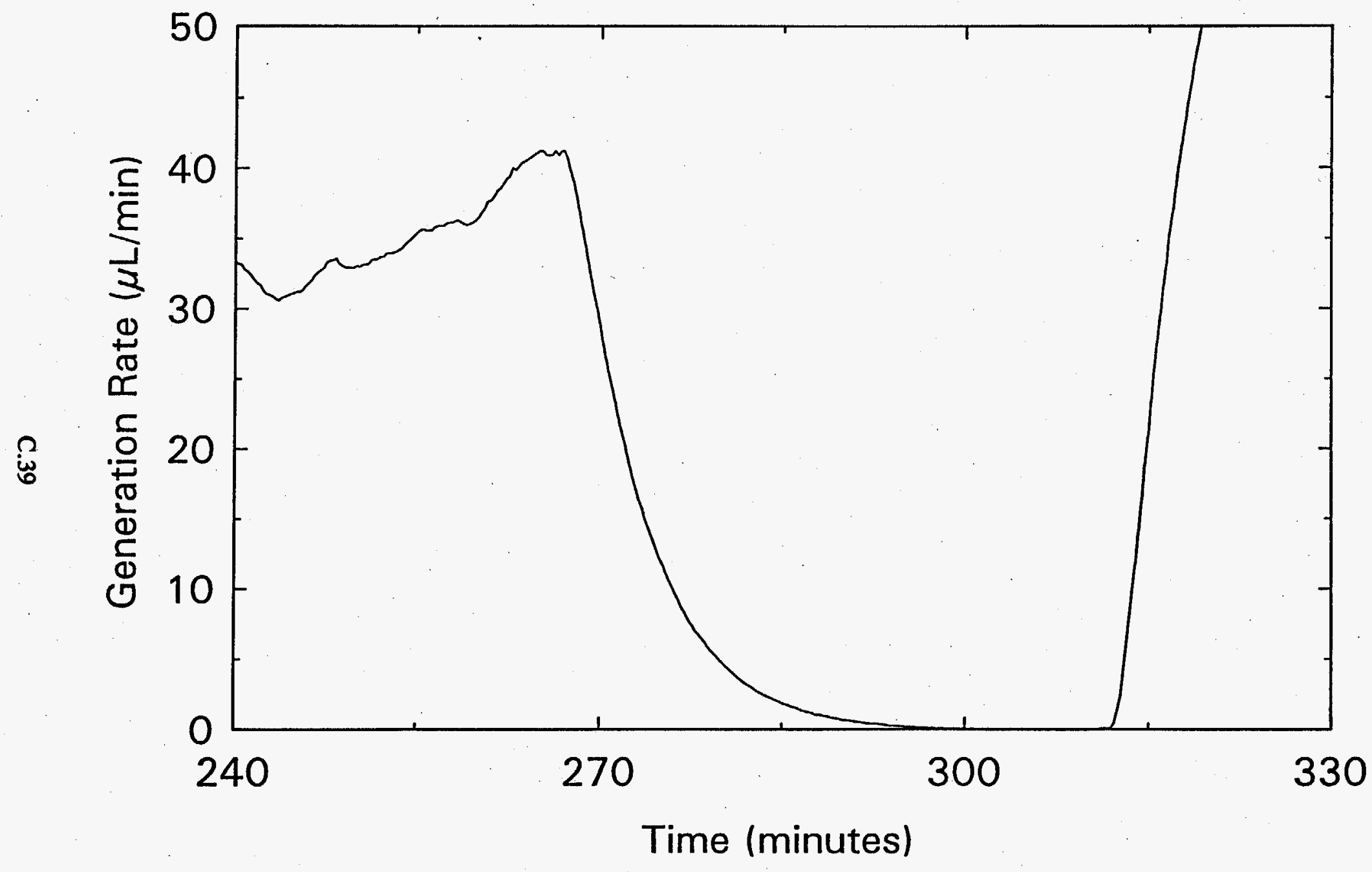

Figure C.39. Expansion of Figure C.38 Between 240 and 330 minutes. The baseline was normalized to zero near 300 minutes. 


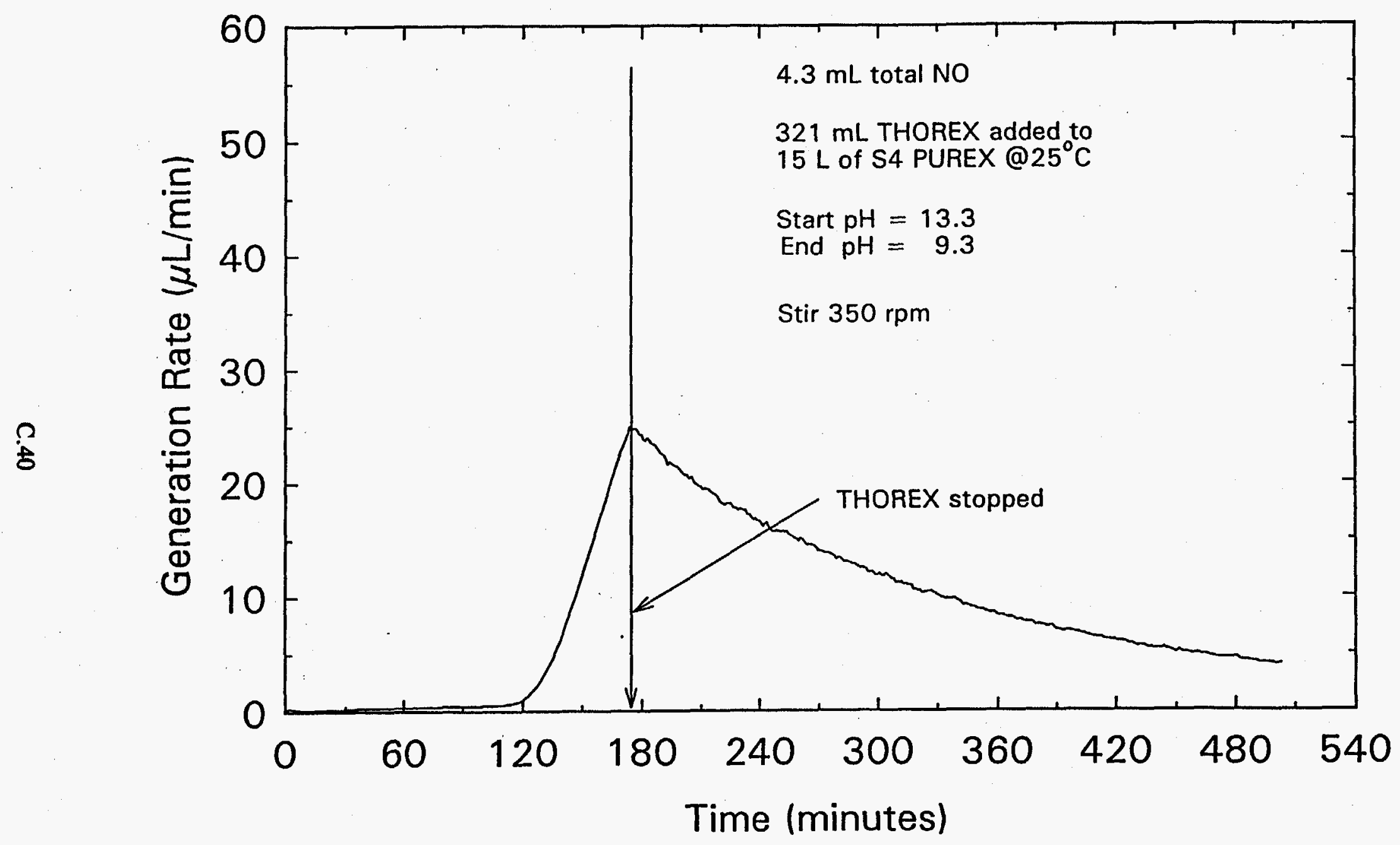

Figure C.40. Test 23A, First Large-Scale Test Using $17 \mathrm{~L}$ Reaction Vessel. Test was terminated before the NO generation rate returned to zero. 


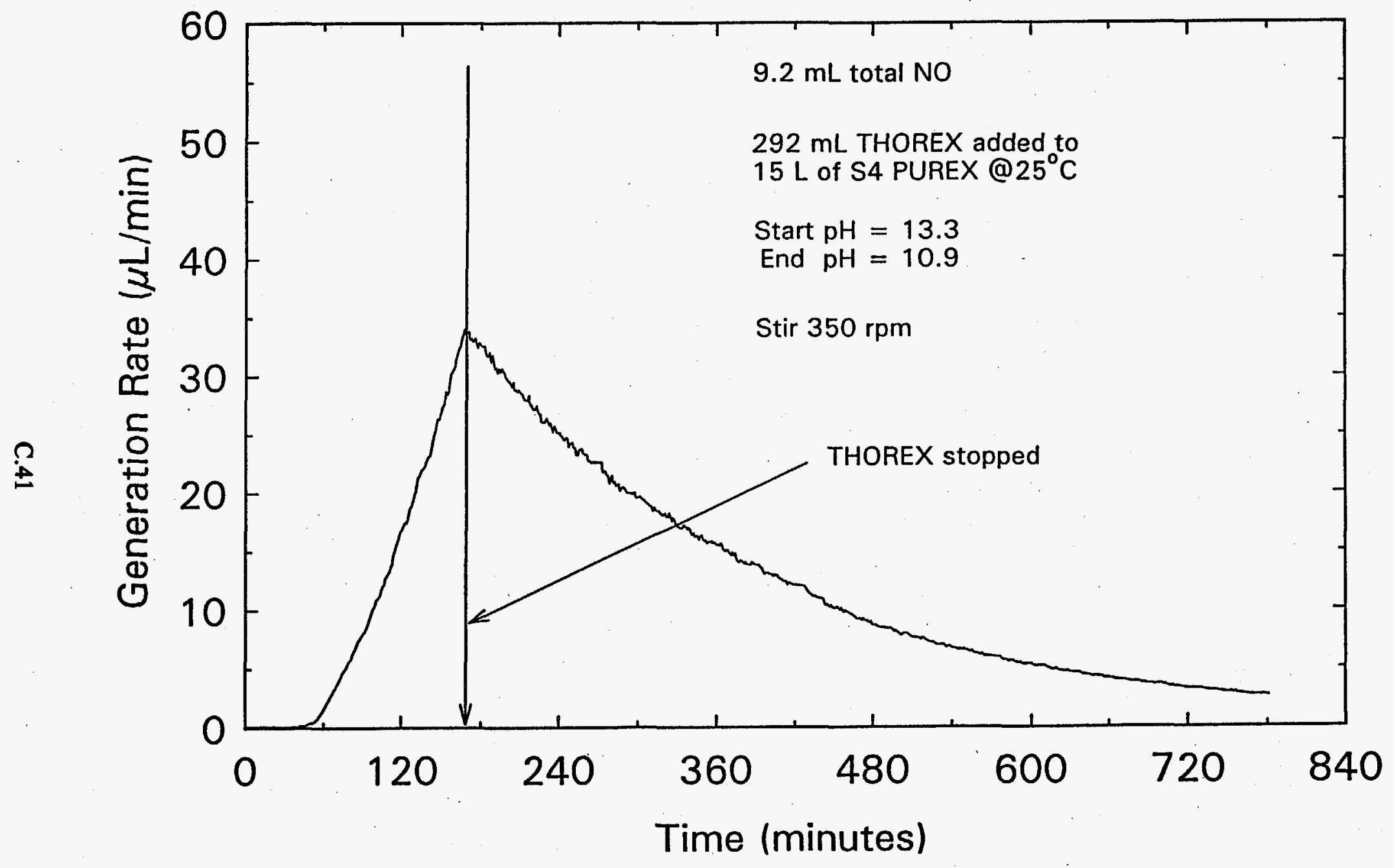

Figure C.41. Test 23B, Second Large-Scale Test Using $17 \mathrm{~L}$ Reaction Vessel. NO $\mathrm{X}$ analyzer zero was verified at end of test. This confirmed that a small amount of NO was still being generated when the test was terminated. 


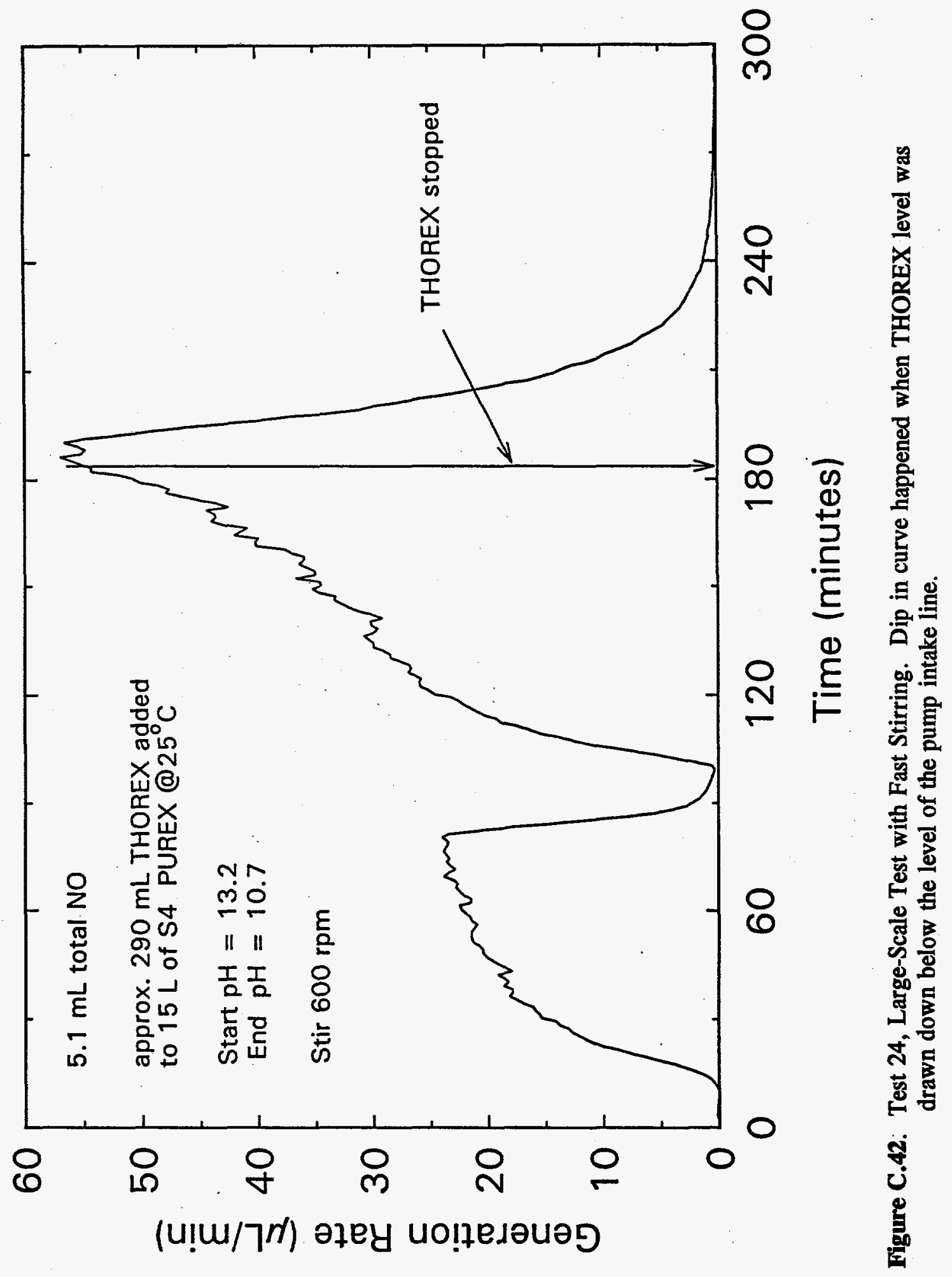




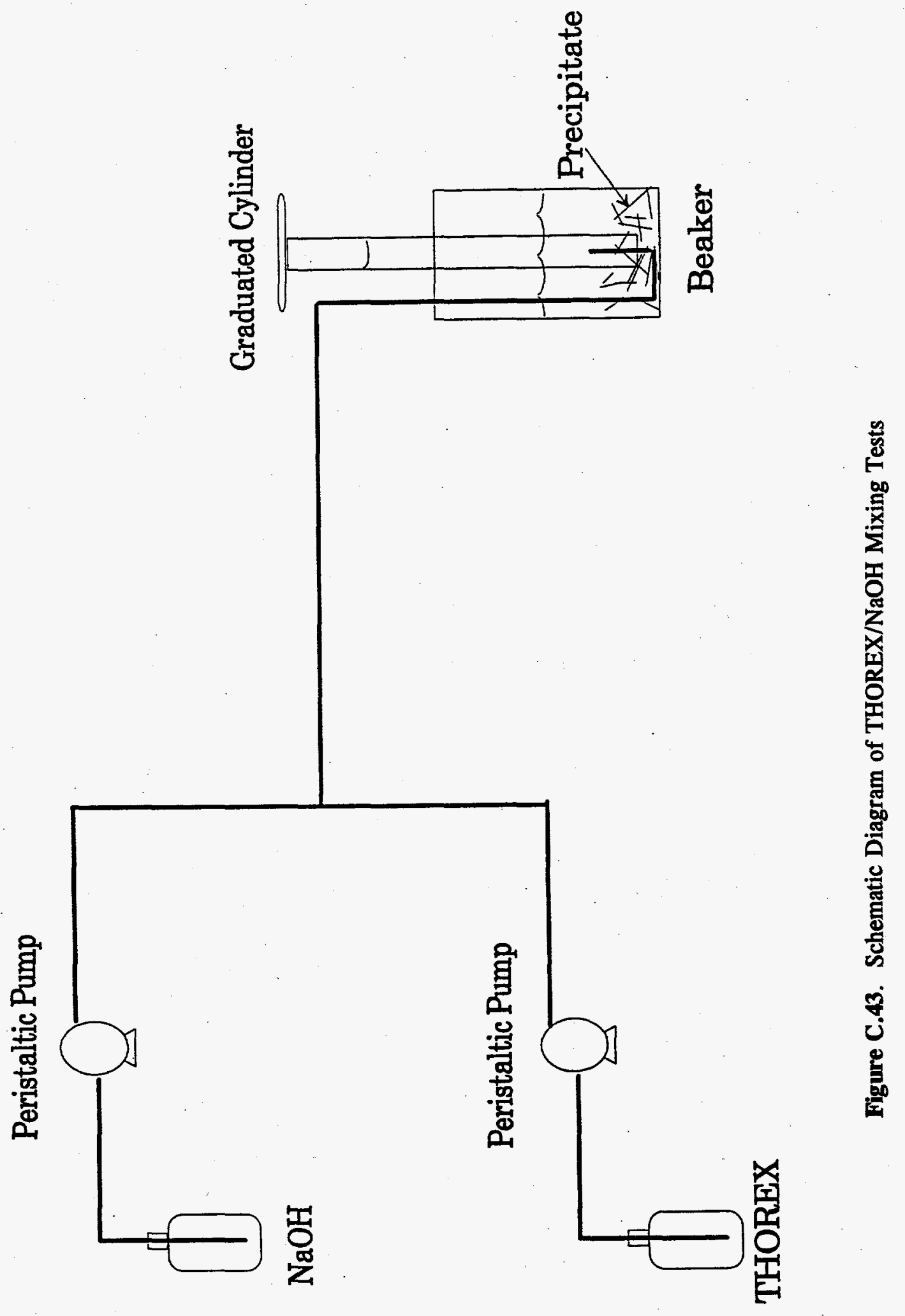




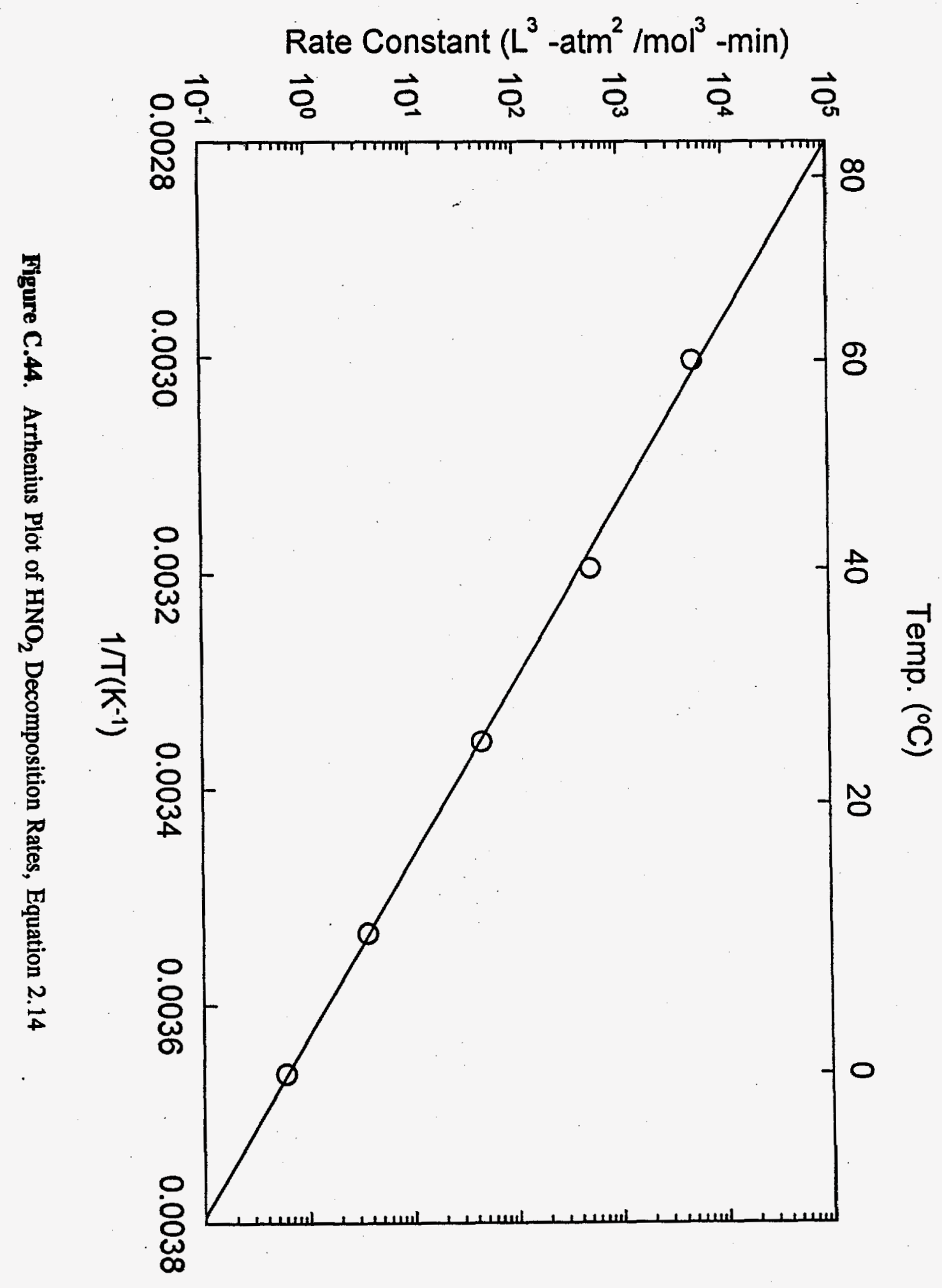


รtว

Equilibrium Constant (L-atm $2 / \mathrm{mol})$

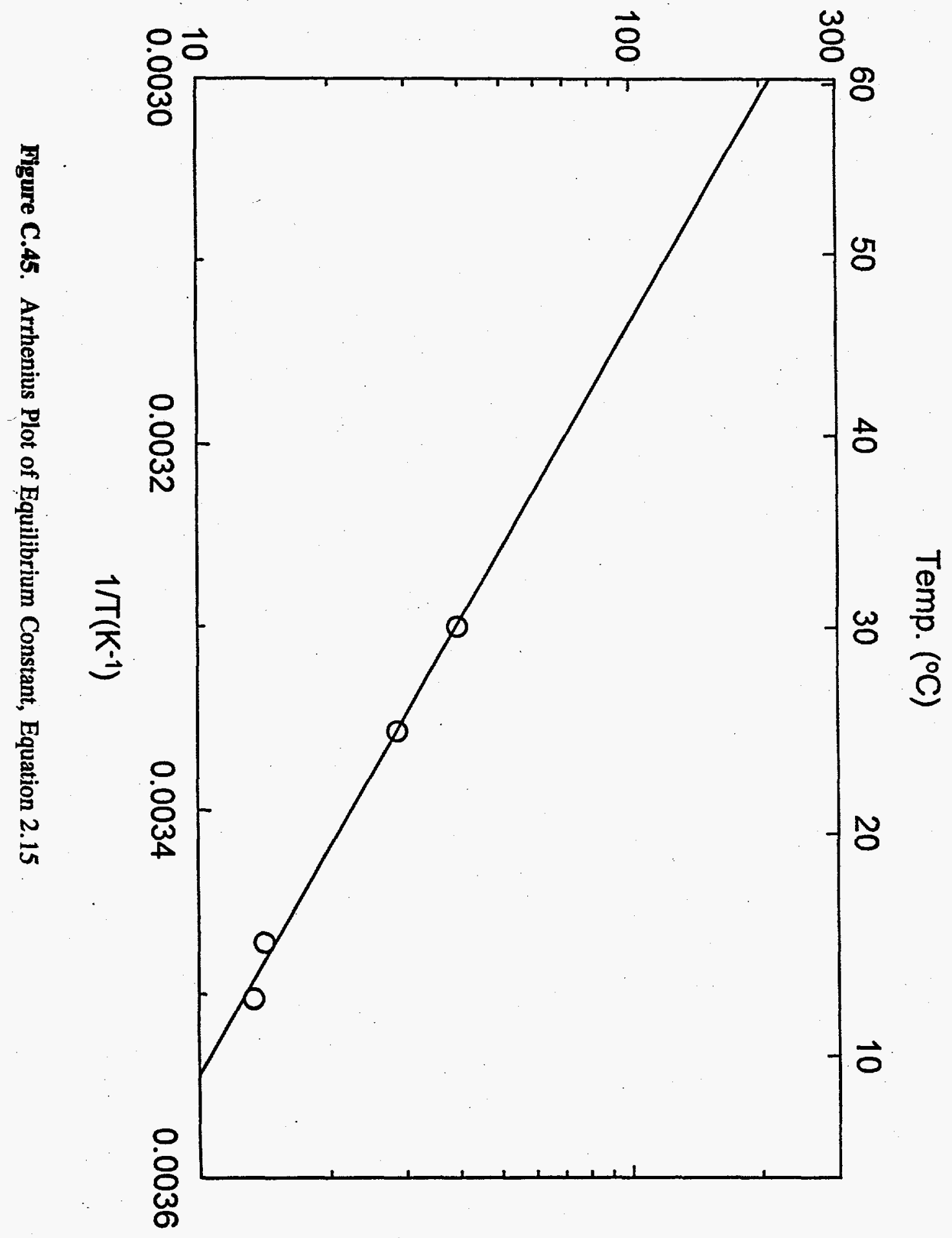




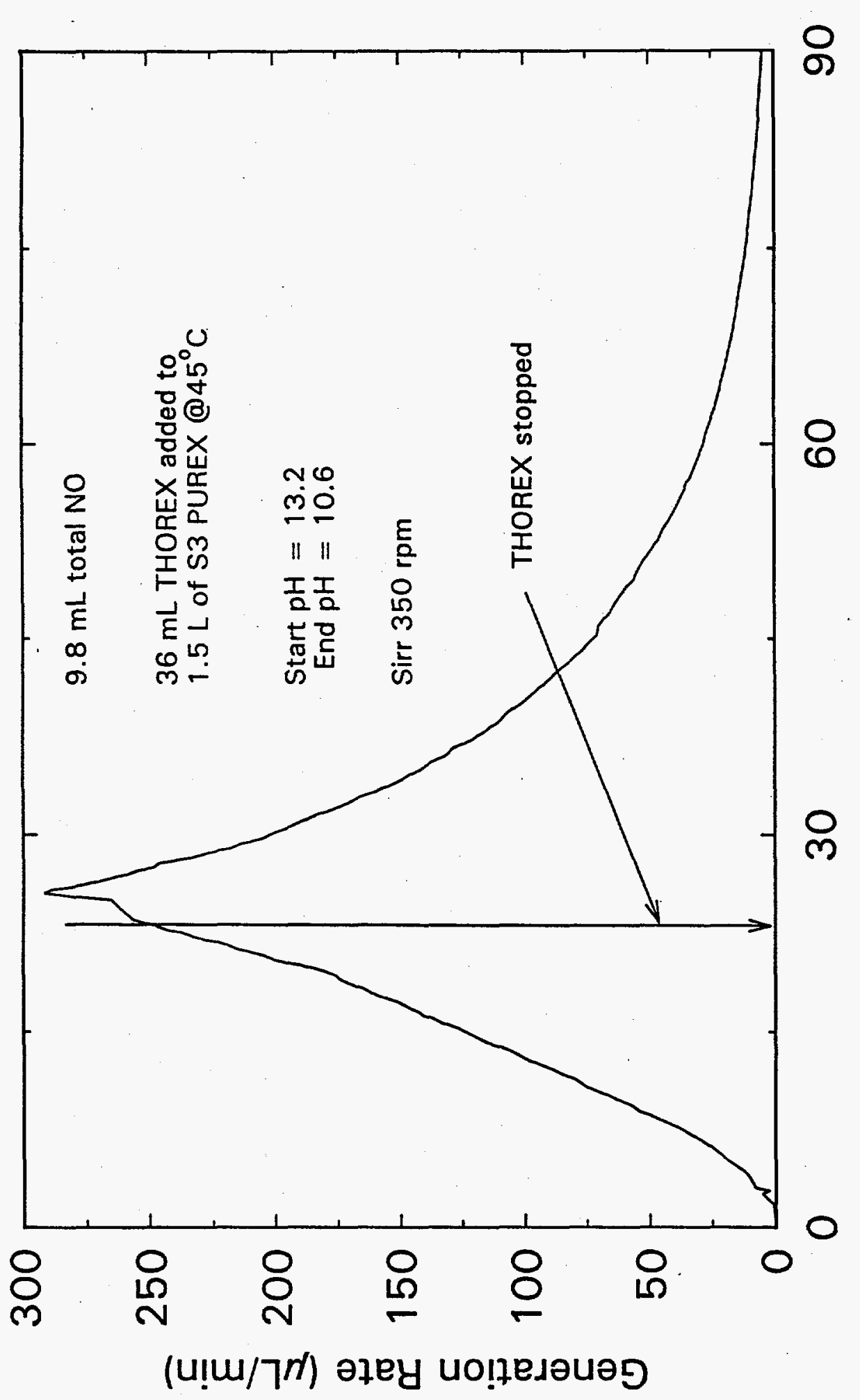

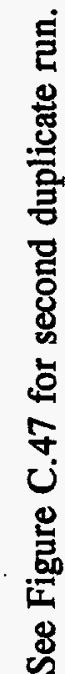

क

崩

.를

है

E

记

$\sum$

范

4

E

ปัँ

范

๙ู่

苟

퐁

C. 46 


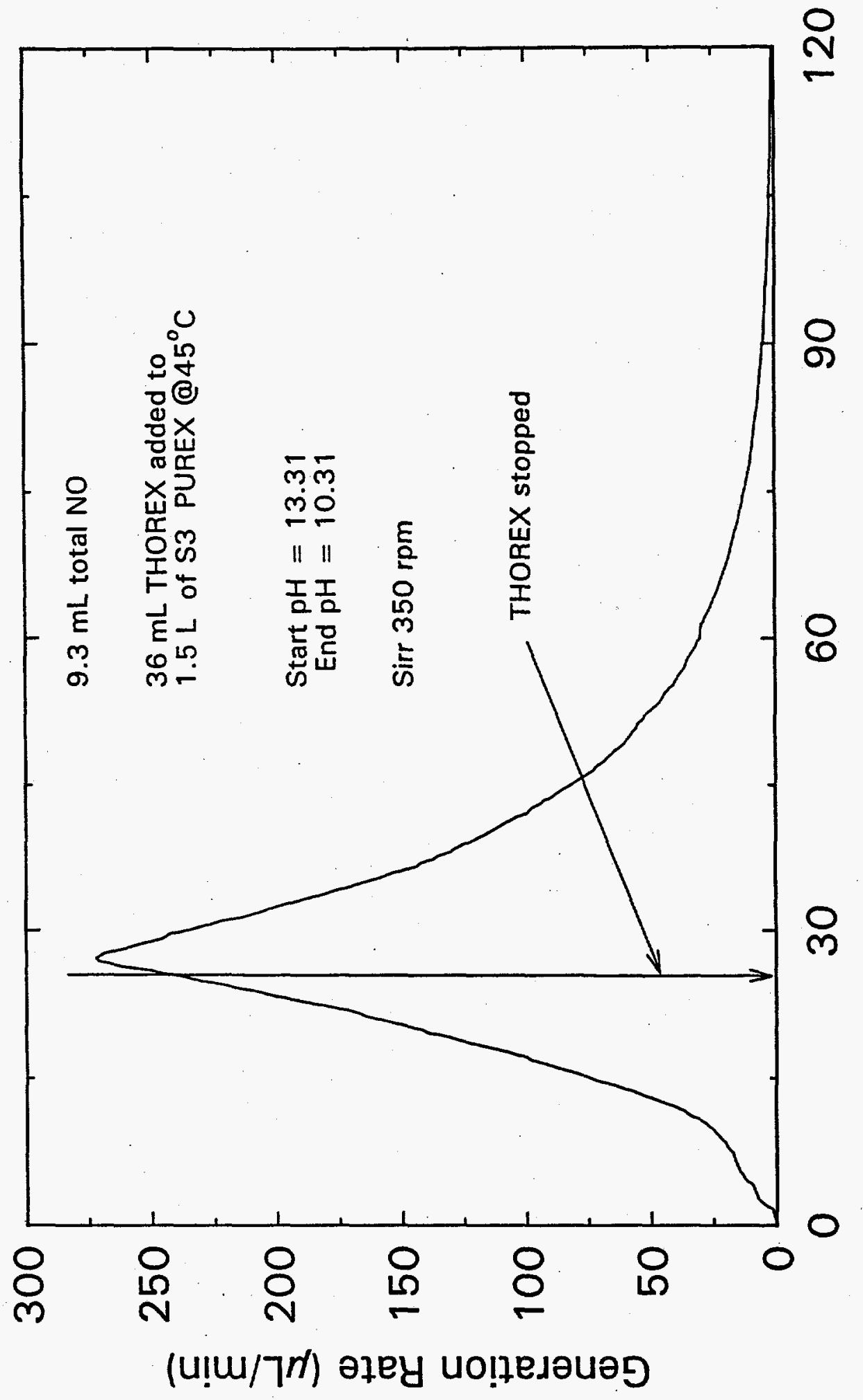

C. 47 


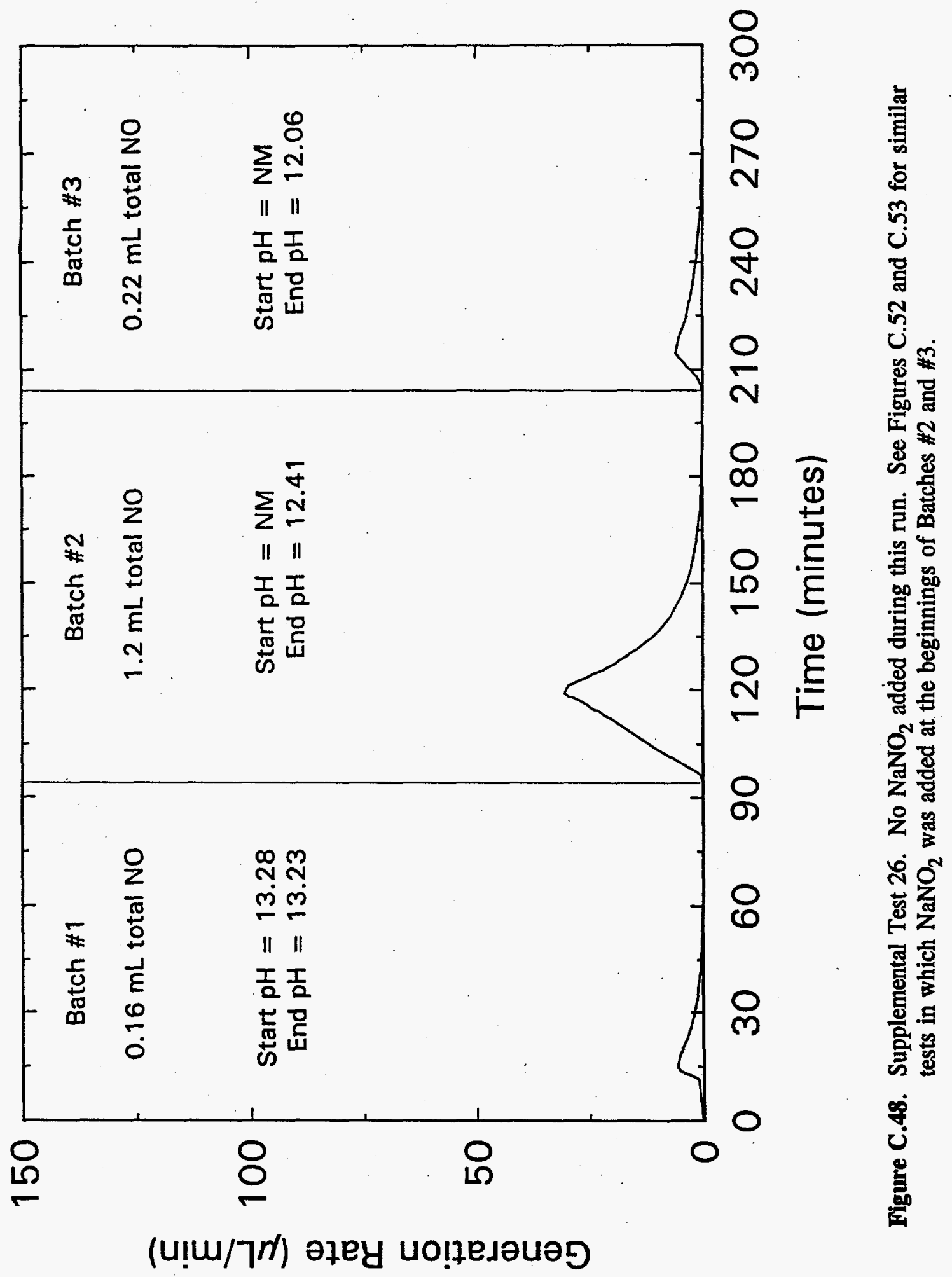




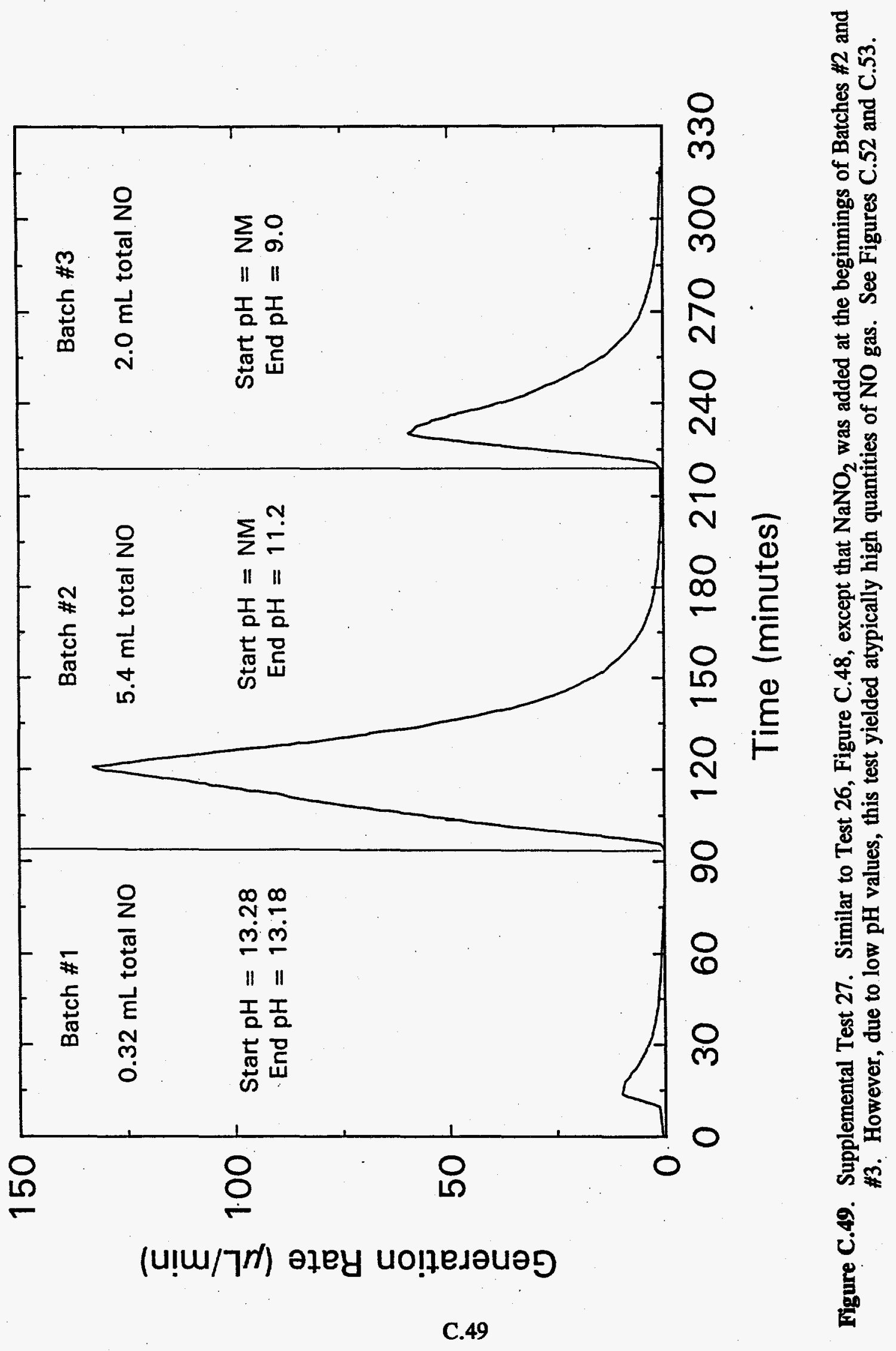




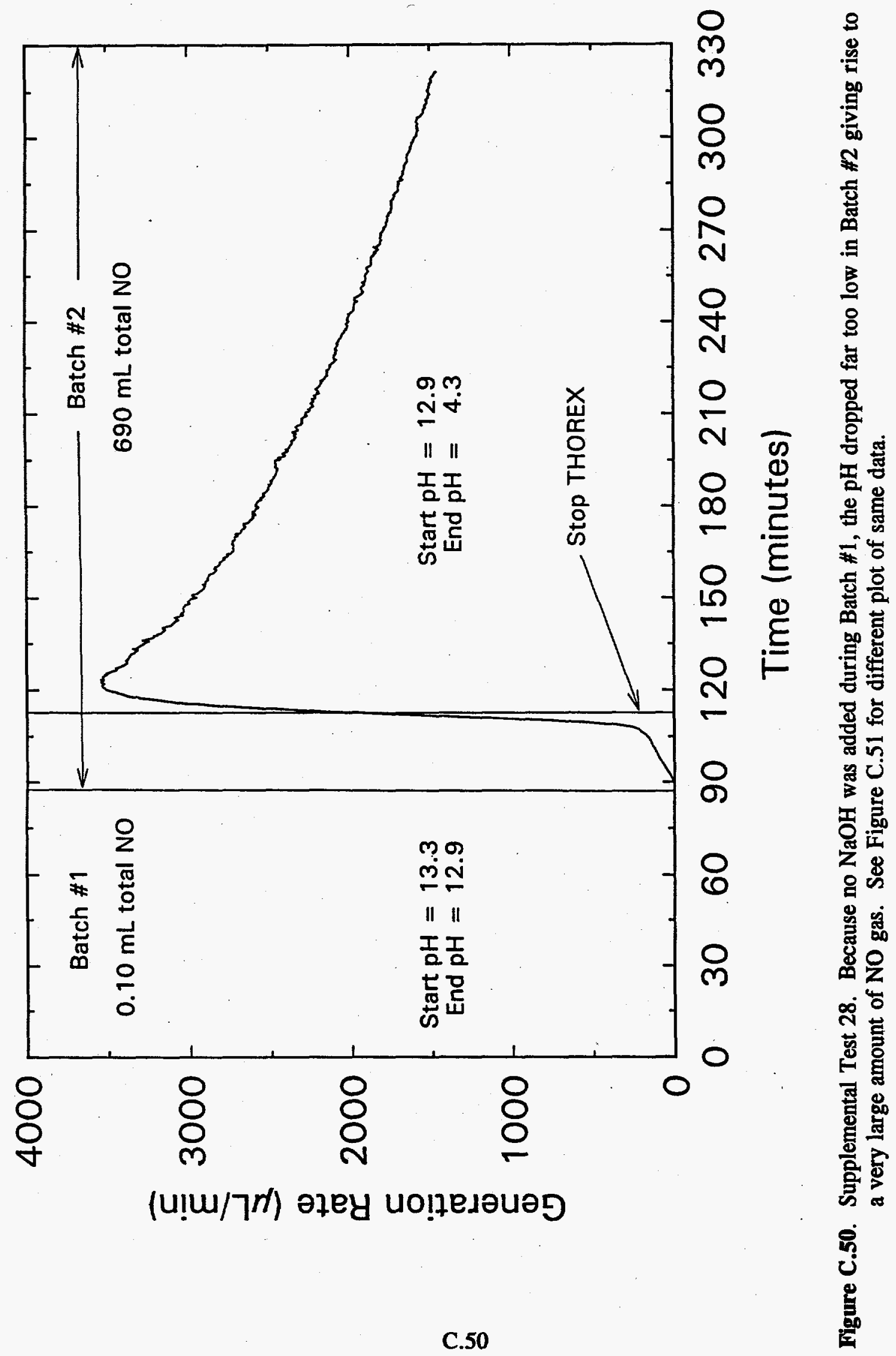




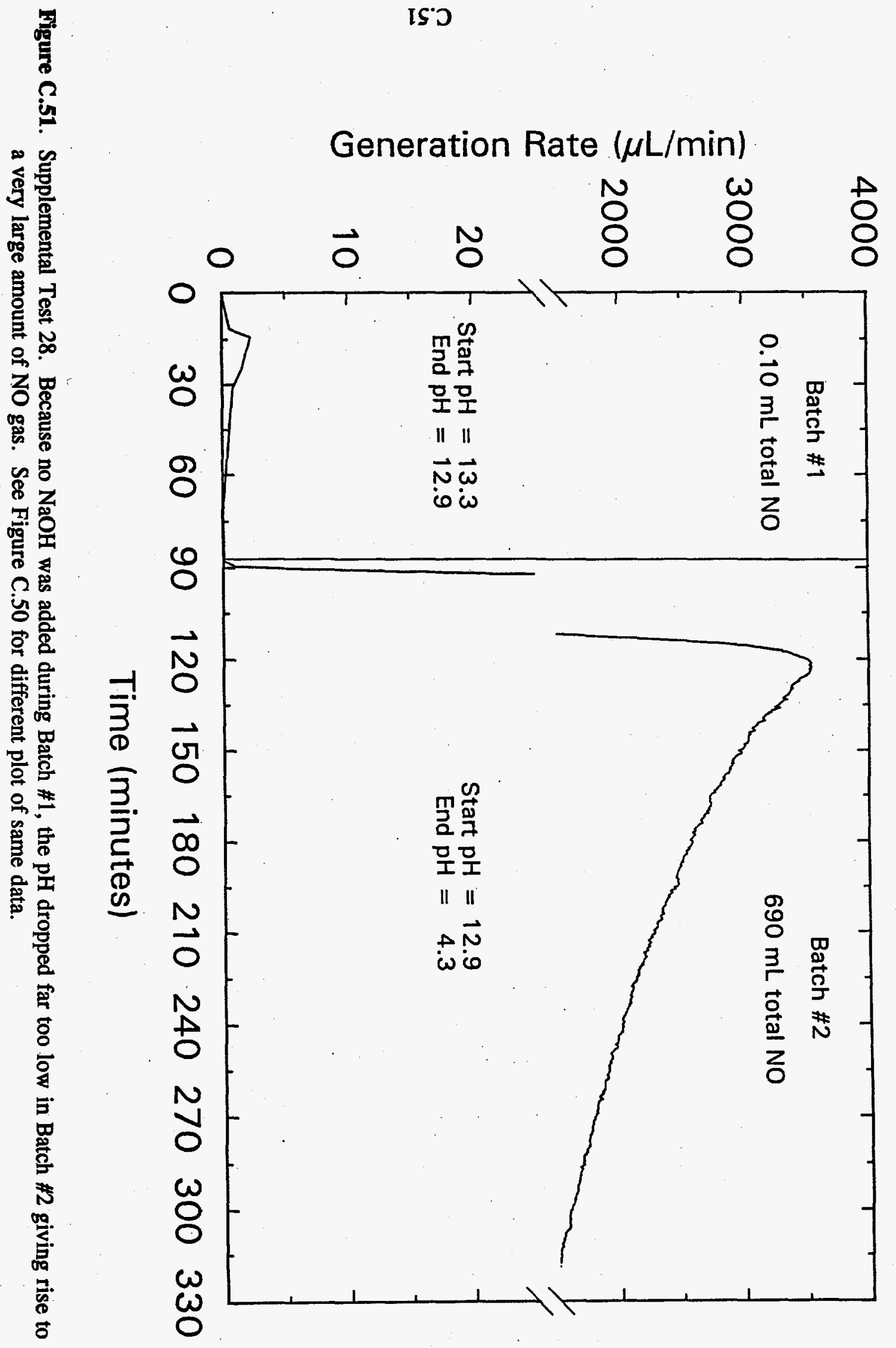



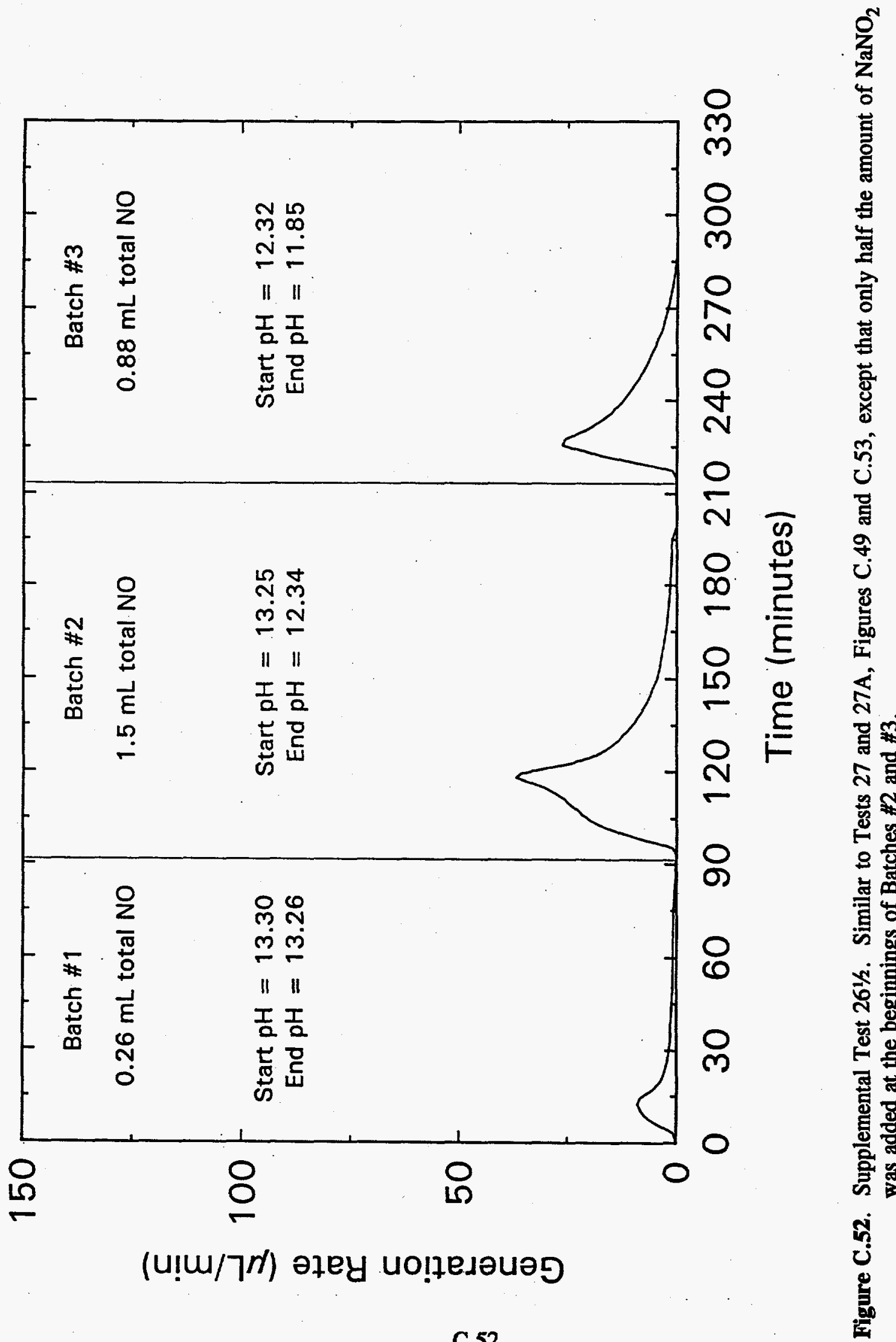


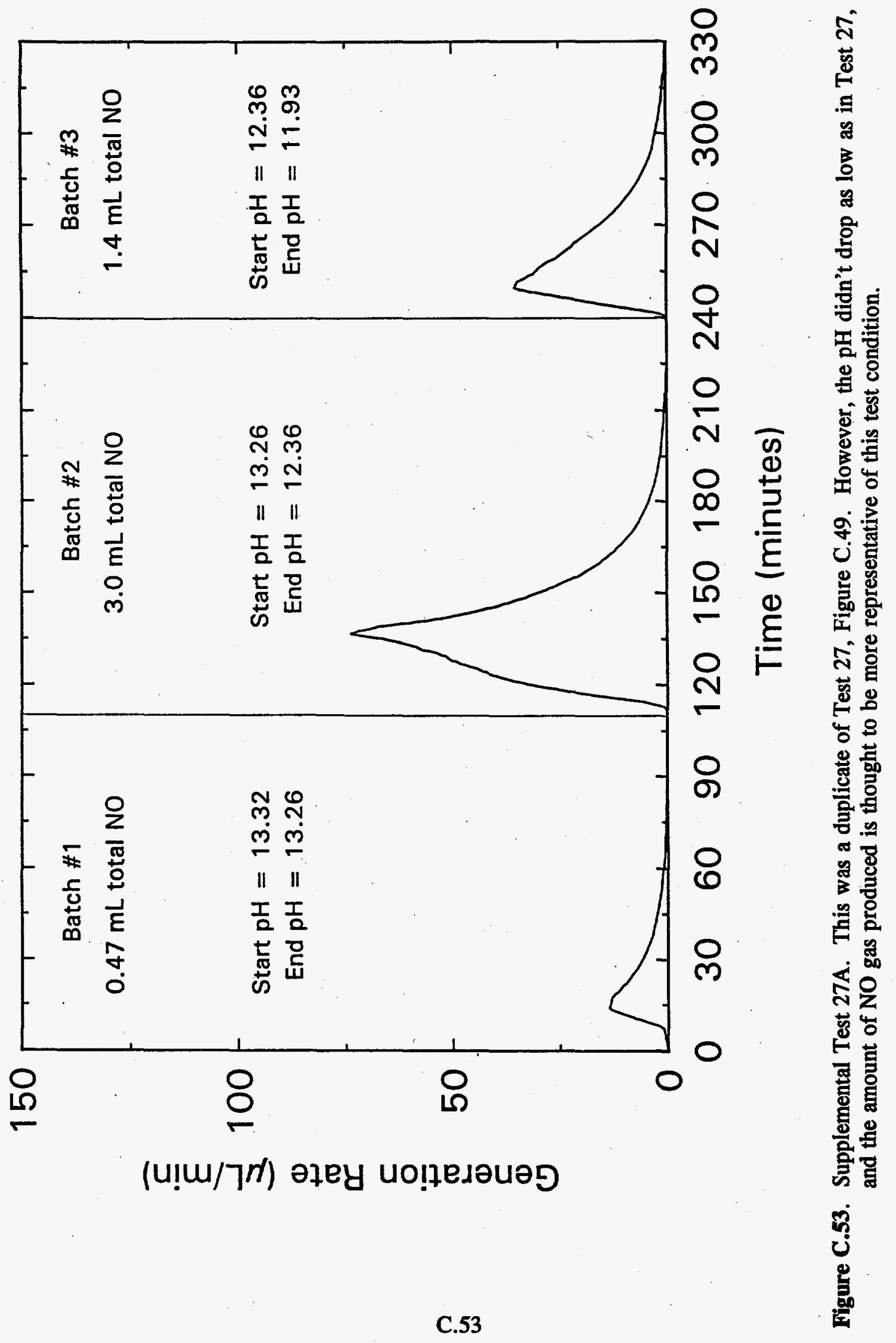


$t \boldsymbol{S} \supset$

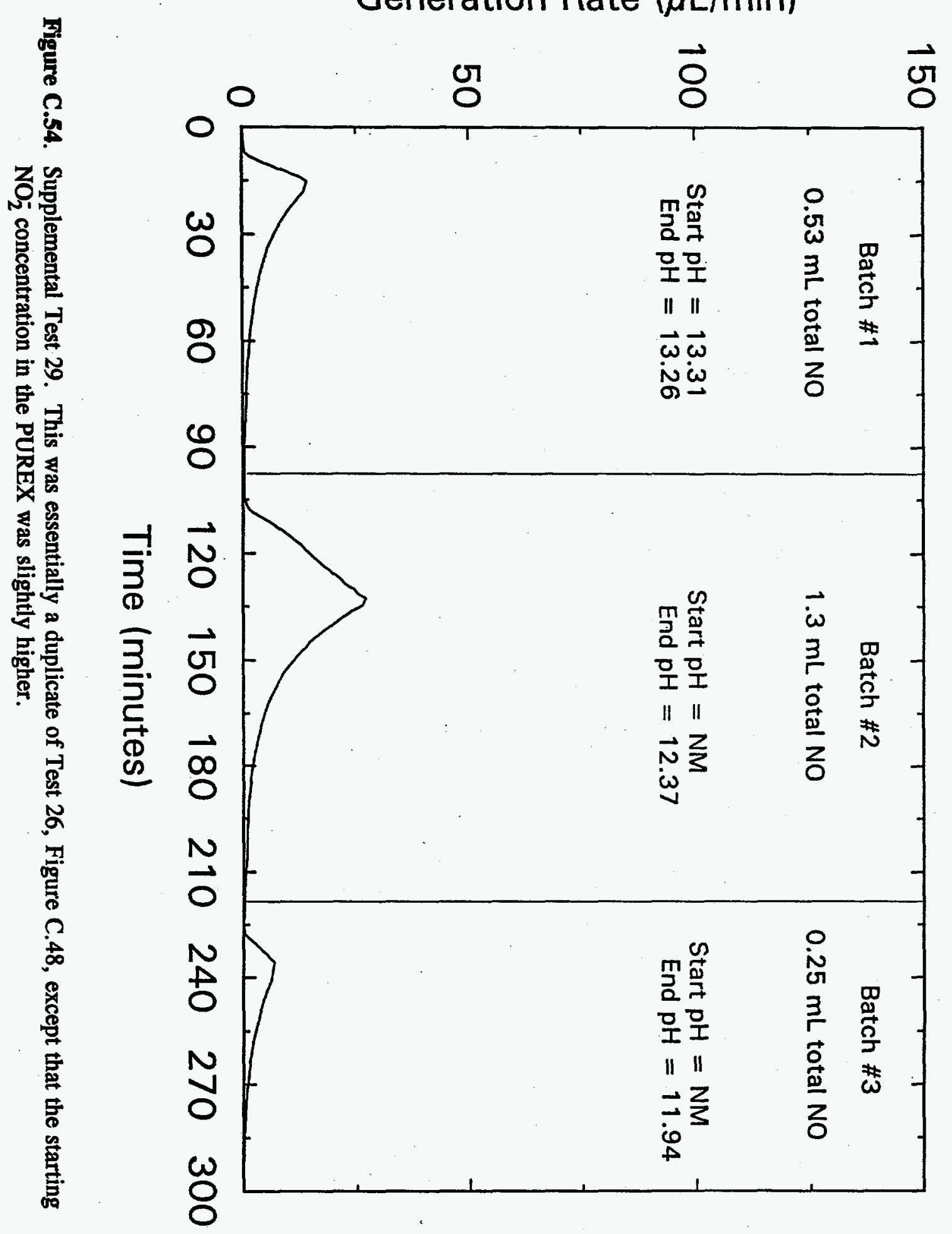

Generation Rate $(\mu \mathrm{L} / \mathrm{min})$ 


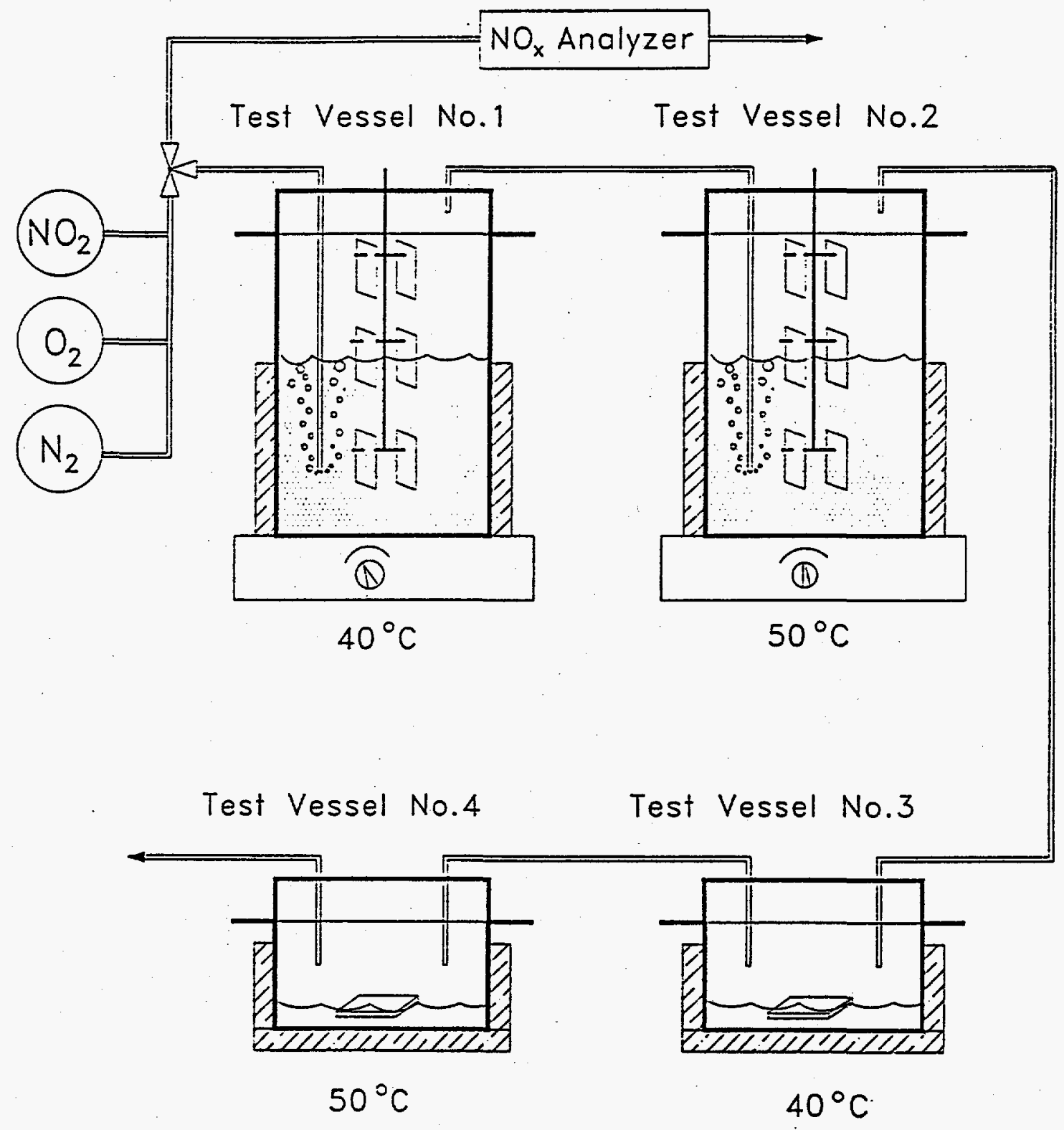

Figure C.55. Sketch of $\mathrm{NO}_{\mathrm{X}}$ Corrosion Test System Configuration 


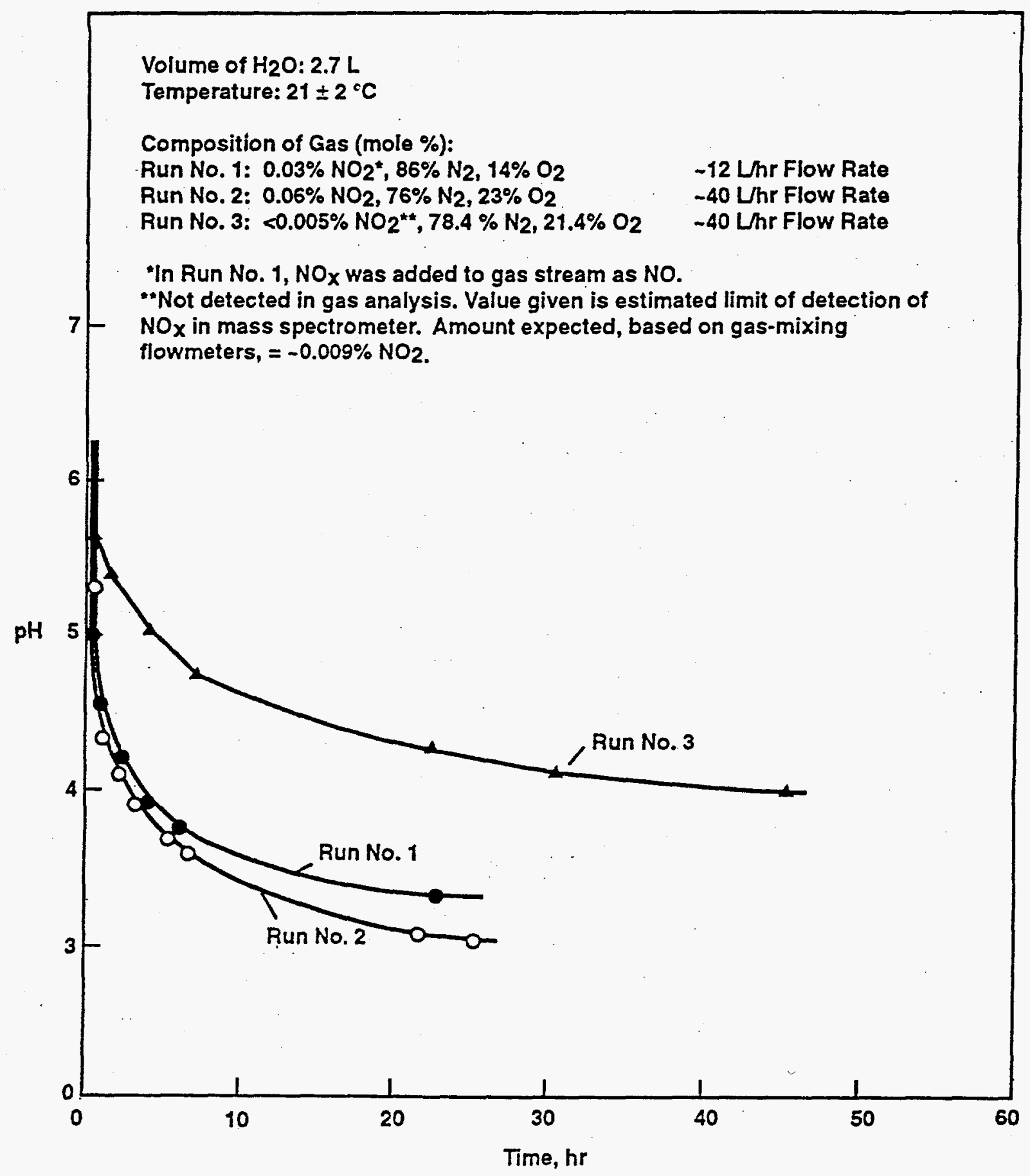

Figure 56. Solution $\mathrm{pH}$ as a function of $\mathrm{NO}_{2}$ Purge Conditions 


\section{Distribution}

No. of

Copies

Offisite

12 DOE/Office of Scientific and Technical Information

T. Evans

U.S. Department of Energy (HQ),

EM-55

12800 Middlebrook Rd., SU400

Germantown, MD 20874

10 West Valley Nuclear Services Co., Inc. P.O. Box 191

West Valley, NY 14171-0191

ATTN: S. M. Barnes (3)

R. E: Lawrence

J. L. Mahoney

D. C. Meess

M. A. Schiffhauer (3)

2 DOE/West Valley Area Office

P.O. Box 191

West Valley, NY 14171-0191

ATTN: J. J. May

W. F. Hamel
No. of

Copies

4 Westinghouse Hanford Company

R. L. Gibby, H5-27

R. L. Gilchrist, L5-63

W. O. Greenhalgh, L5-31

R. W. Powell, G3-21

34 Pacific Northwest Laboratory

G. H. Beeman, S7-71

N. G. Colton, K3-75

J. M. Creer, K9-80

R. E. Einziger, P7-14

M. L. Elliott (3), P7-41

W. J. Gray (10), P7-14

B. M. Johnson, K9-70

L. A. Mahoney, K7-15

E. V. Morrey, P7-19

J. M. Perez, P7-41

H. D. Smith, P7-14

R. E. Westerman (5), P8-44

K. D. Wiemers, P7-14

Publishing Coordination

Technical Report Files (5)

Onsite

3 DOE Richland Field Office

S. T. Burnum, S7-53

D. D. Button, S7-53

J. C: Peschong, S7-53 